Universidad de Lima

Facultad de Ingeniería Industrial

Carrera de Ingeniería Industrial

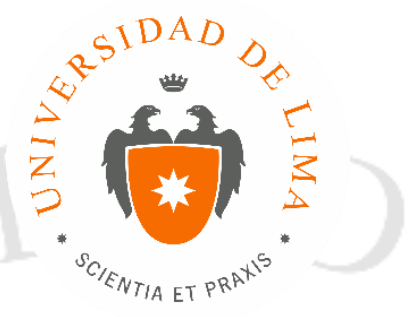

\title{
ESTUDIO DE PRE-FACTIBILIDAD PARA LA INSTALACIÓN DE UNA PLANTA PRODUCTORA DE MANGO (Mangifera indica) EN ALMÍBAR PARA EL MERCADO DE LIMA METROPOLITANA
}

Trabajo de investigación para optar el título profesional de Ingeniero Industrial

Gabby Alexandra Cárdenas Palomino

20100216

José Enrique Ortiz Caja 20090795

Asesor

Ezilda Cabrera Gil Grados

Lima - Perú

Octubre - 2016 


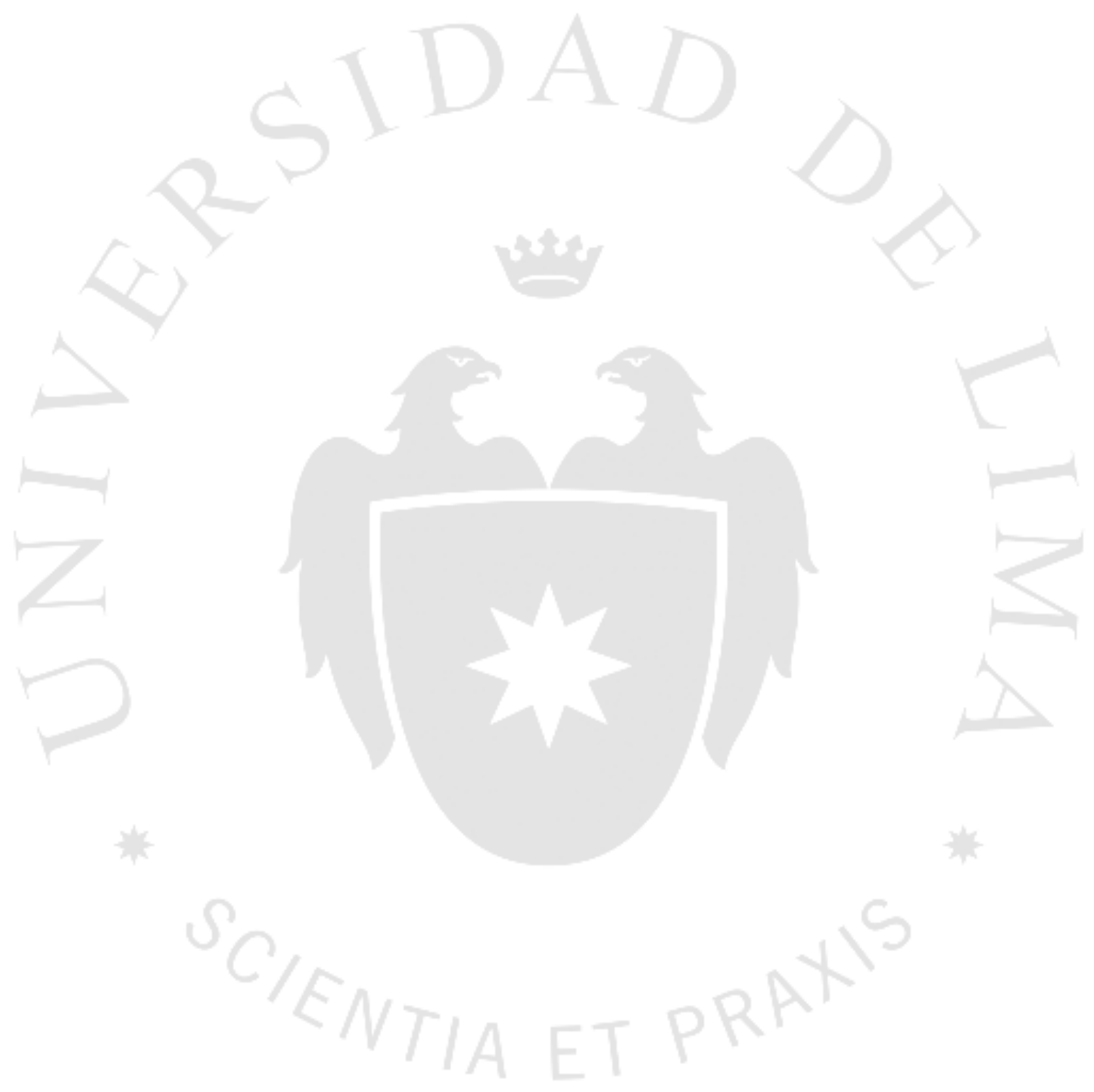




\section{ESTUDIO DE PRE-FACTIBILIDAD PARA LA}

INSTALACIÓN DE UNA PLANTA PRODUCTORA DE MANGO (Mangifera indica) EN ALMÍBAR PARA EL MERCADO DE LIMA METROPOLITANA 


\section{TABLA DE CONTENIDO}

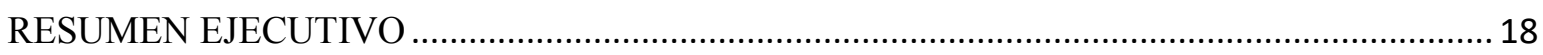

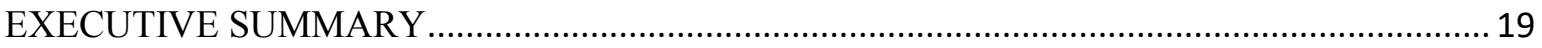

CAPITULO I. ASPECTOS GENERALES …........................................................................ 20

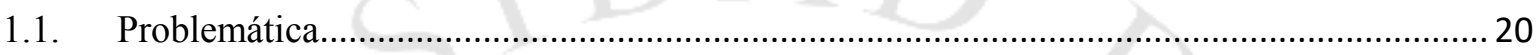

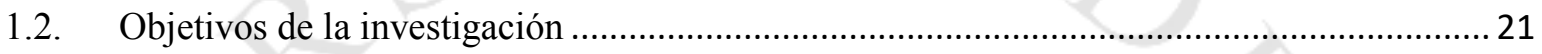

1.3. Alcance y limitaciones de la investigación ................................................................ 21

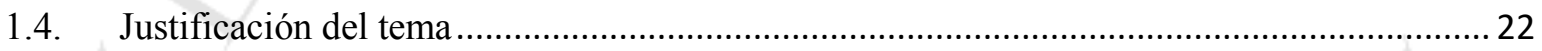

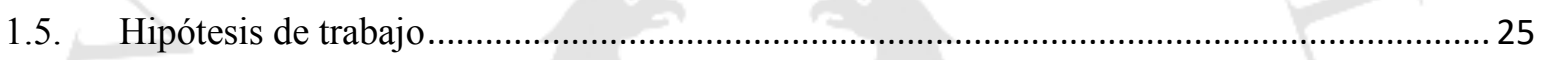

1.6. Marco referencial de la investigación ................................................................... 25

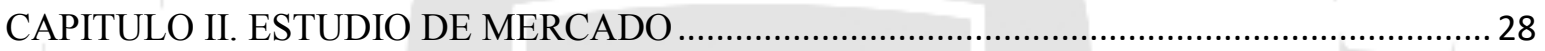

2.1. Aspectos generales del estudio de mercado ........................................................... 28

2.1.1. Definición comercial del producto ........................................................................ 28

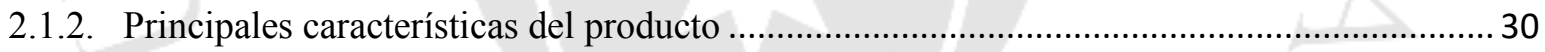

2.1.2.1. Usos y características del producto …....................................................................... 30

2.1.2.2. Bienes sustitutos y complementarios .................................................................... 31

2.1.3. Determinación del área geográfica que abarcará el estudio ............................................... 31

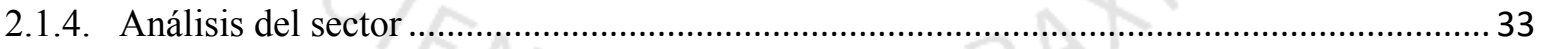

2.1.5. Determinación de la metodología que se empleará en la investigación de mercado ............ 35

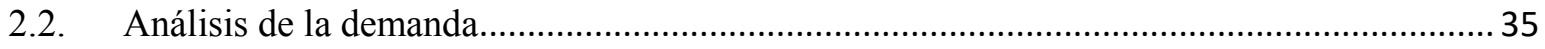

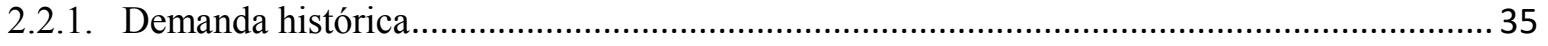

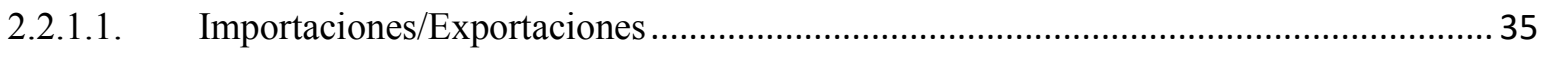

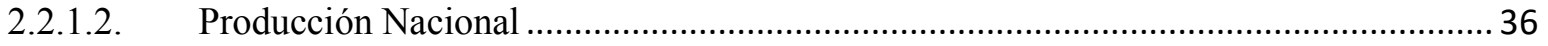

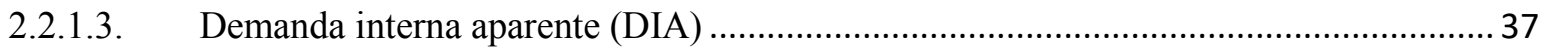


2.2.2.1. Patrones de consumo: incremento poblacional, consumo per cápita, estacionalidad ... 37

2.2.2.2. Determinación de la demanda potencial ............................................................. 38

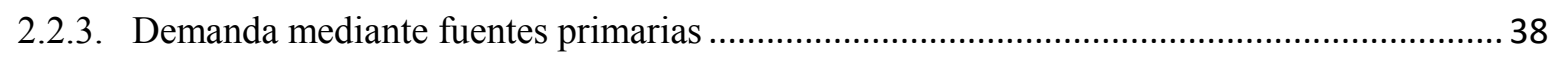

2.2.3.1. Diseño y aplicación de encuestas u otras técnicas ................................................... 38

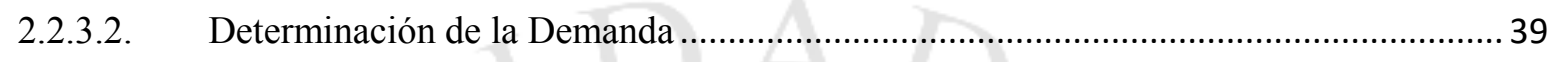

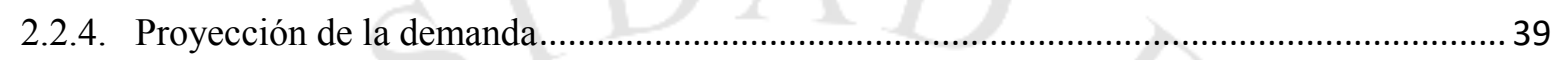

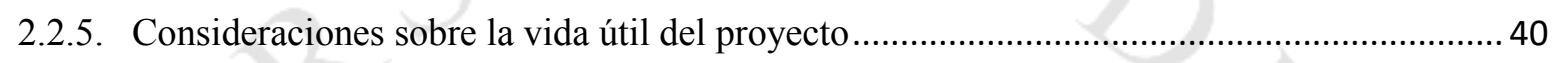

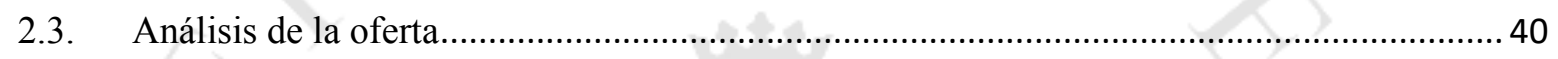

2.3.1. Empresas productoras, importadoras y comercializadoras ............................................ 40

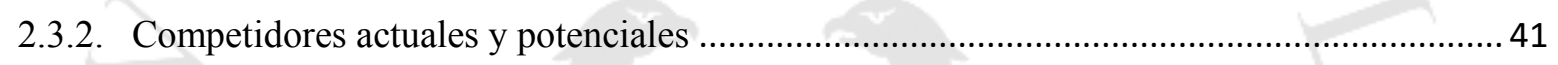

2.4. Determinación de la Demanda para el proyecto ….................................................. 42

2.4.1. Segmentación del mercado …...................................................................... 42

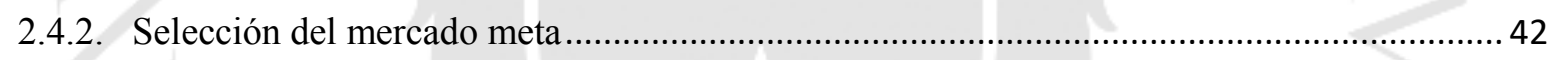

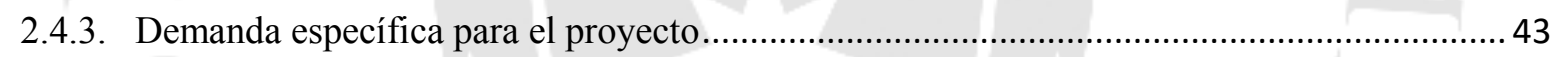

2.5. Definición de la Estrategia de Comercialización .......................................................... 43

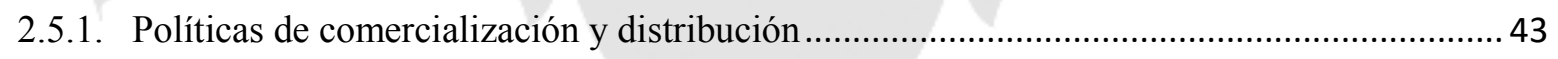

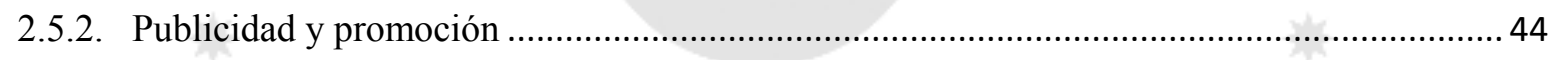

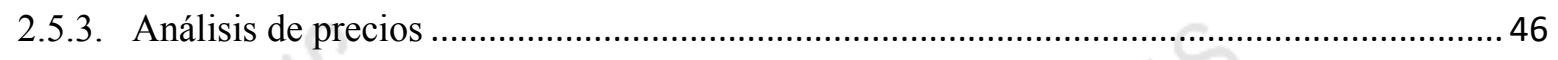

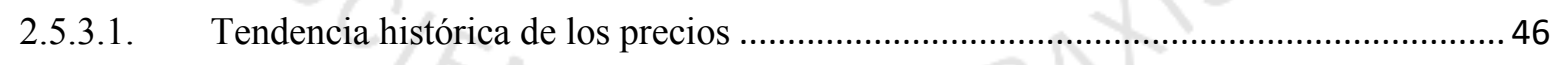

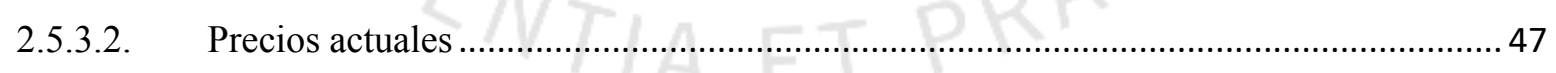

2.6. Análisis de Disponibilidad de los insumos principales ................................................ 48

2.6.1. Características principales de la materia prima ............................................................. 48

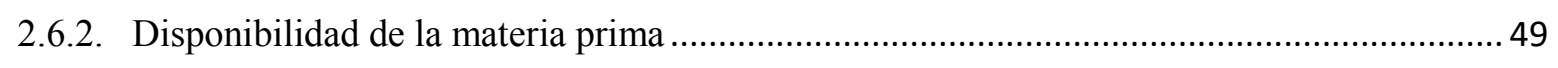

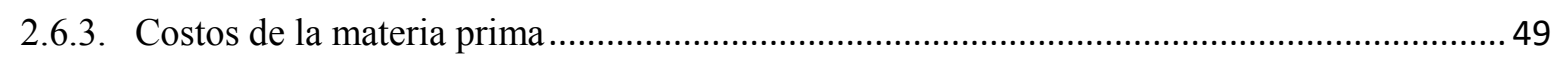

CAPITULO III. LOCALIZACIÓN DE PLANTA …........................................................... 51 
3.1. Identificación y análisis detallado de los factores de localización

3.2. Identificación y descripción de las alternativas de localización.

3.3. Evaluación y selección de localización

3.3.1. Evaluación y selección de la macro localización 62

3.3.2. Evaluación y selección de la micro localización. 64

CAPITULO IV. TAMAÑO DE PLANTA. 70

4.1. Relación tamaño-mercado. 70

4.2. Relación tamaño-recursos productivos 70

4.3. Relación tamaño-tecnología .71

4.4. Relación tamaño - inversión. .72

4.5. Relación tamaño-punto de equilibrio .73

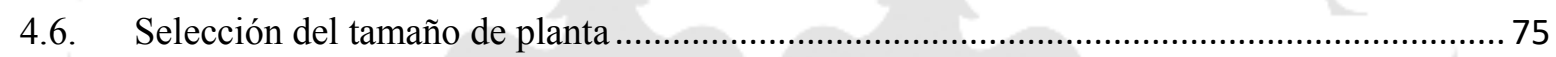

CAPITULO V. INGENIERÍA DEL PROYECTO …............................................................ 76

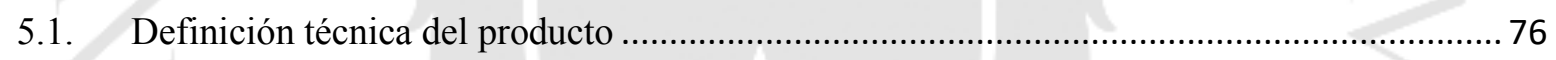

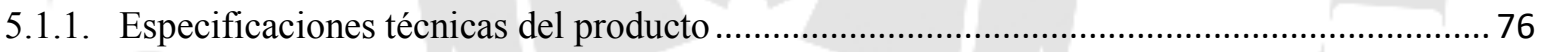

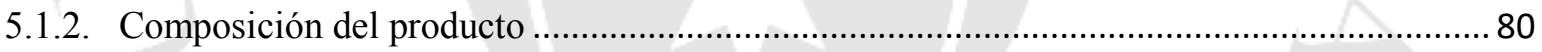

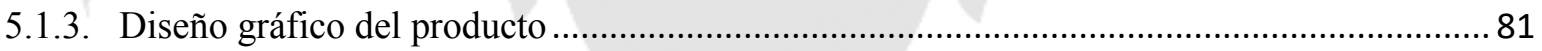

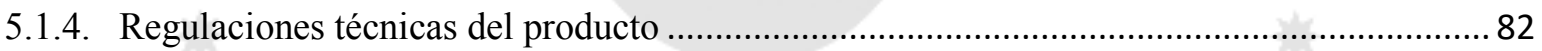

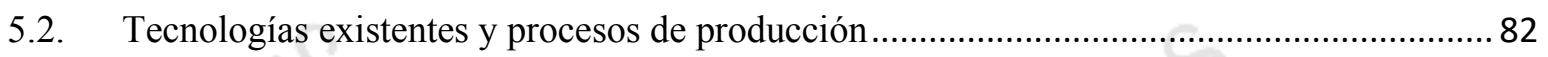

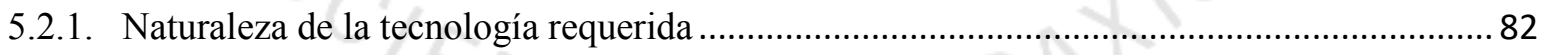

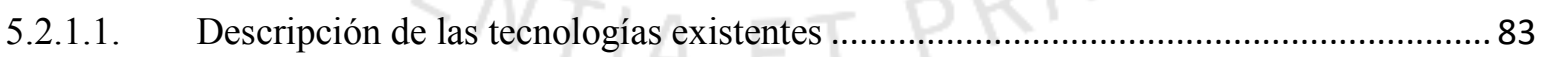

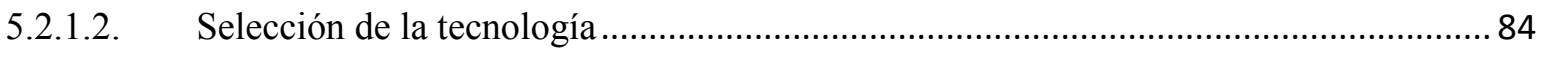

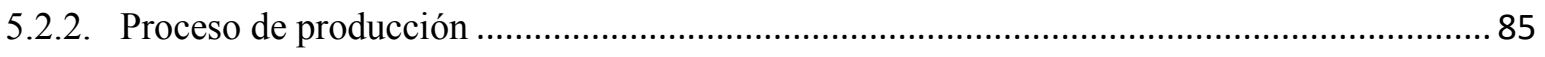

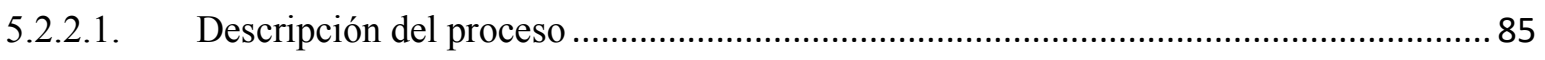

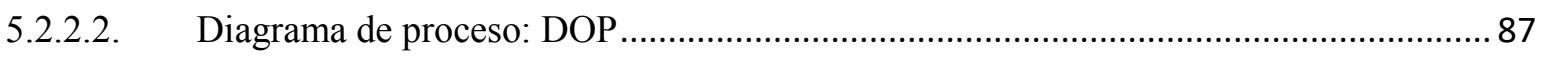

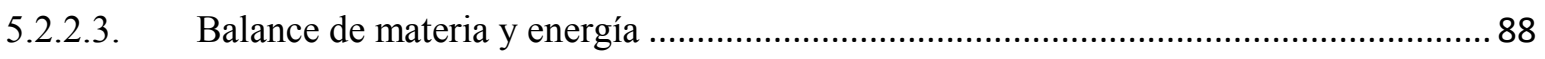




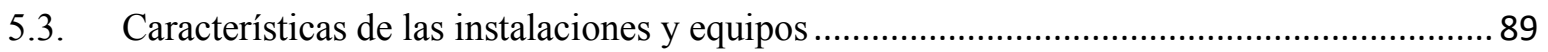

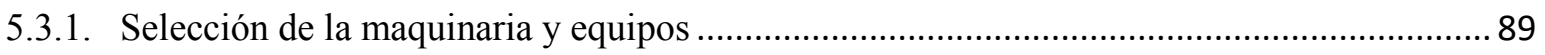

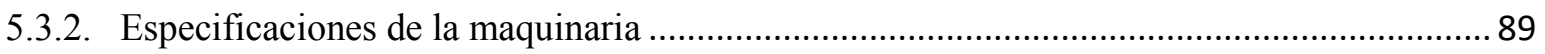

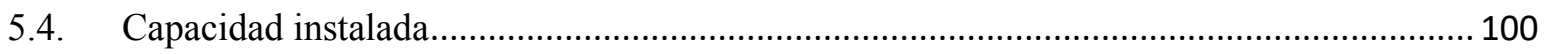

5.4.1. Cálculo detallado del número de máquinas requeridas ................................................. 100

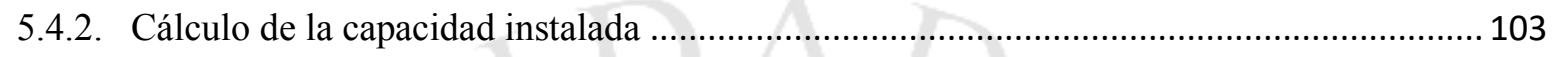

5.4.3. Calidad de la materia prima, de los insumos, del proceso y del producto ......................... 104

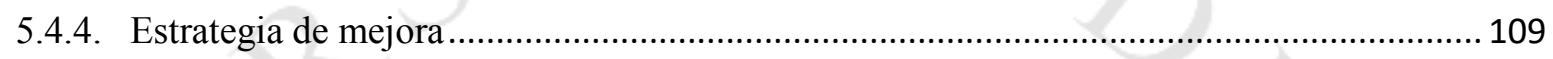

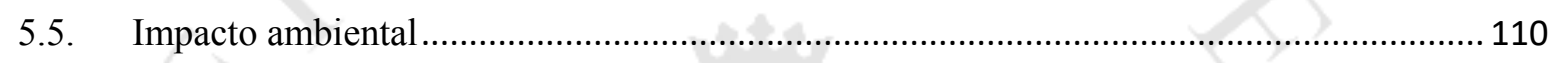

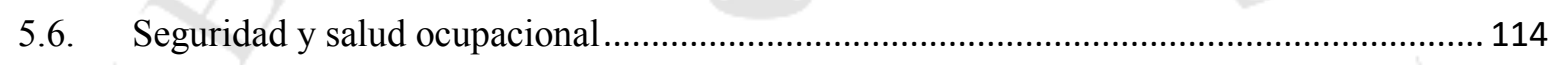

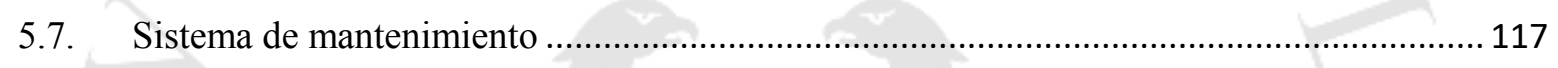

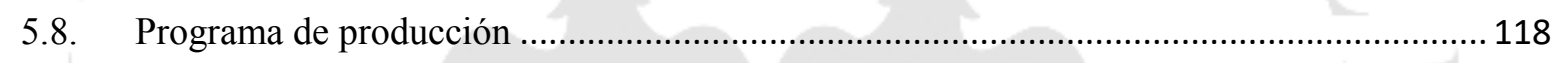

5.8.1. Factores para la programación de la producción.......................................................... 118

5.8.2. Programa de producción para la vida útil del proyecto .................................................. 119

5.9. Requerimiento de insumos, personal y servicios ..................................................... 119

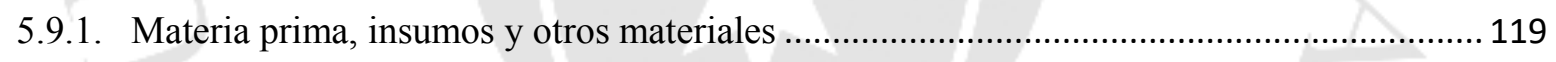

5.9.2. Servicios: energía eléctrica, agua, combustible, vapor, etc........................................... 120

5.9.3. Determinación del número de operarios y trabajadores indirectos ................................... 122

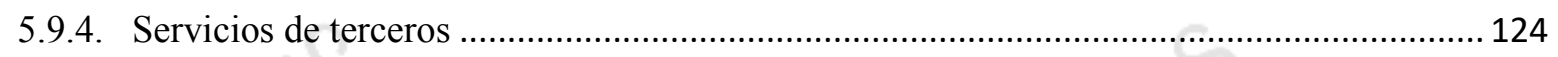

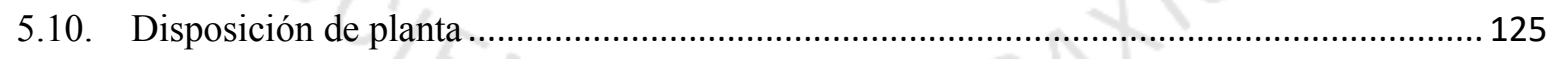

5.10.1. Características físicas del proyecto ……........................................................... 125

5.10.2. Determinación de las zonas físicas requeridas ..................................................... 128

5.10.3. Cálculo de áreas para cada zona.............................................................................. 129

5.10.4. Dispositivos de seguridad industrial y señalización.................................................... 132

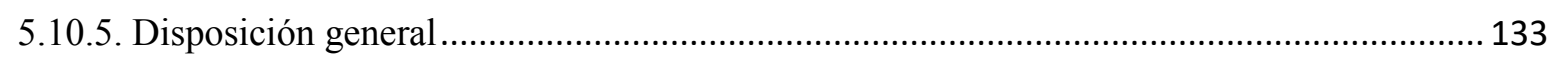

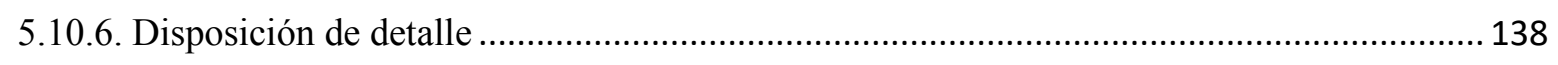


5.12. Cronograma de implementación del proyecto ............................................................. 140

CAPÍTULO VI. ORGANIZACIÓN ADMINISTRATIVA....................................................... 142

6.1. Formación de la Organización empresarial................................................................. 142

6.2. Requerimientos de personal directivo, administrativo y de servicios ............................. 145

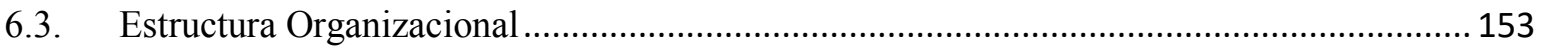

CAPITULO VII. ASPECTOS ECONÓMICOS Y FINANCIEROS ............................................ 155

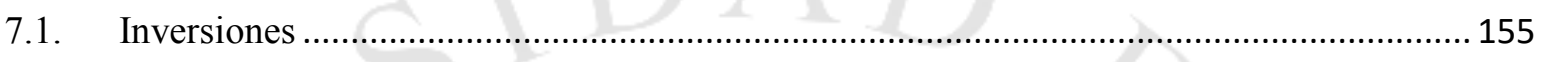

7.1.1. Estimación de las inversiones de largo plazo (tangibles e intangibles) ............................. 155

7.1.2. Estimación de las inversiones de corto plazo (Capital de trabajo)................................... 156

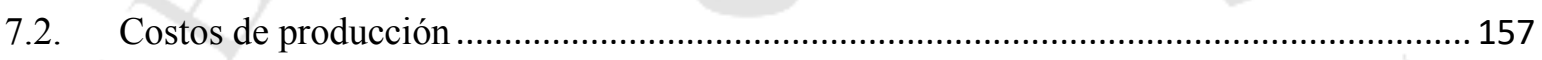

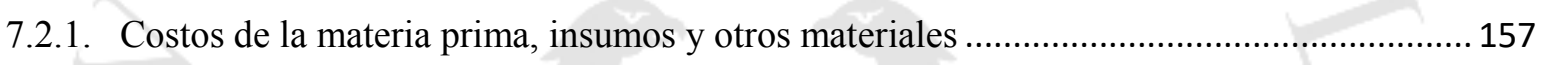

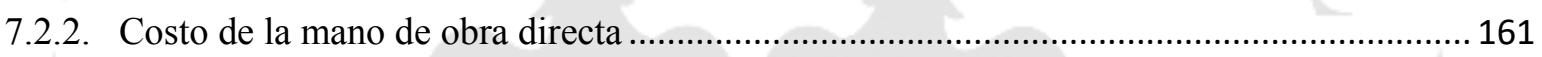

7.2.3. Costo Indirecto de Fabricación (materiales indirectos, mano de obra indirecta y costos

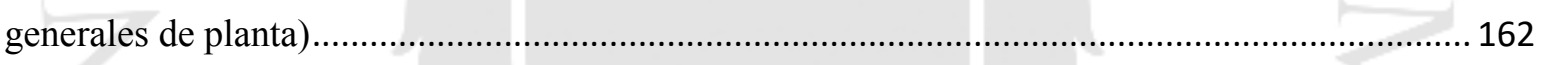

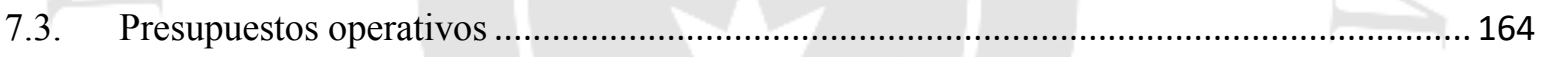

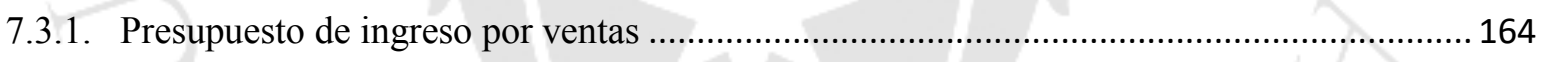

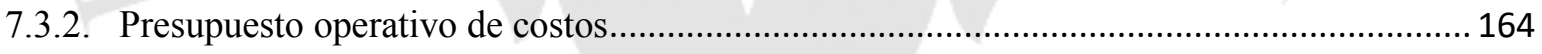

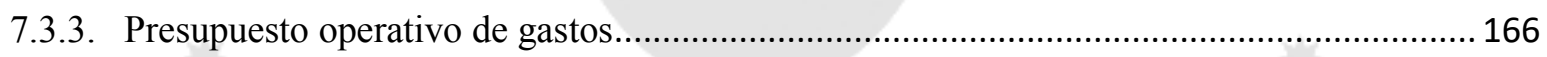

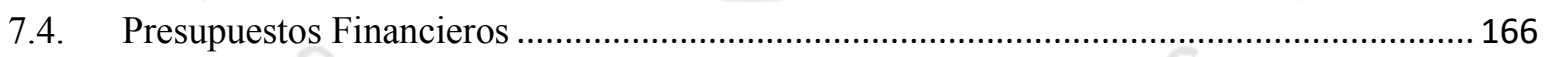

7.4.1. Presupuesto de Servicio de Deuda ............................................................................. 166

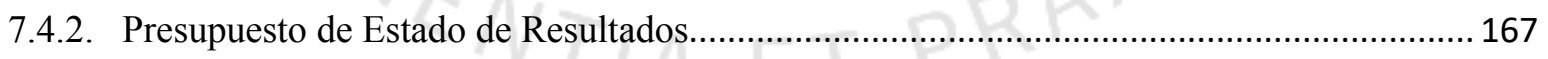

7.4.3. Presupuesto de Estado de Situación Financiera ............................................................. 168

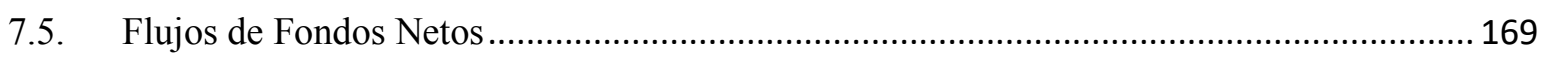

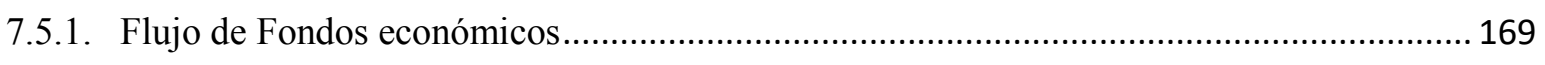

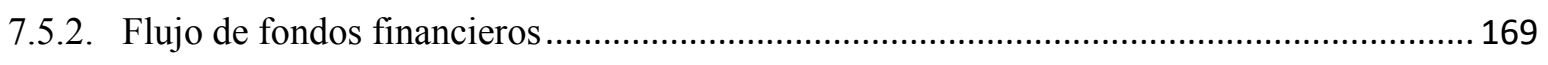

CAPITULO VIII. EVALUACIÓN ECONÓMICA Y FINANCIERA DEL PROYECTO .............171 


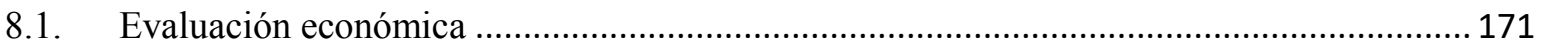

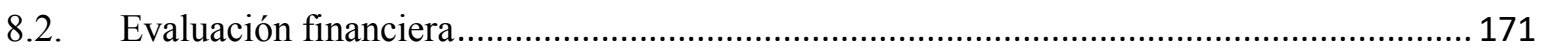

8.3. Análisis de ratios e indicadores económicos y financieros del proyecto .......................... 171

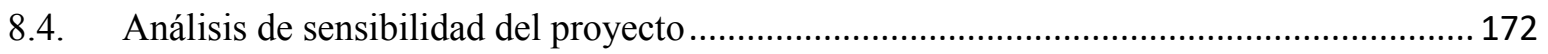

CAPITULO IX. EVALUACIÓN ECONÓMICA Y FINANCIERA DEL PROYECTO................176

9.1. Identificación de las zonas y comunidades de influencia del proyecto.............................. 176

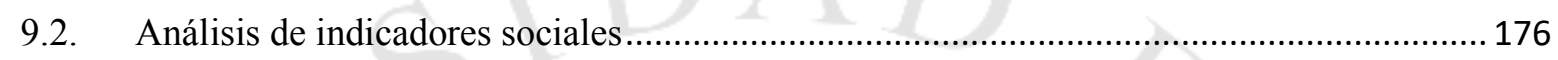

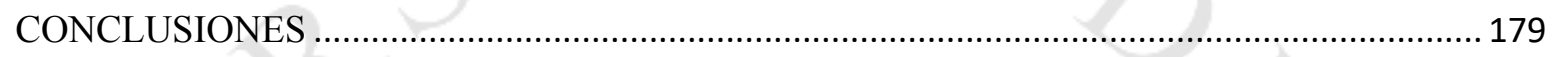

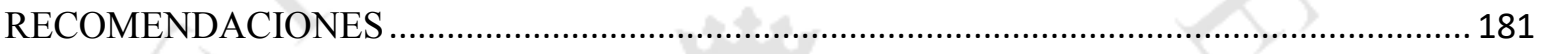

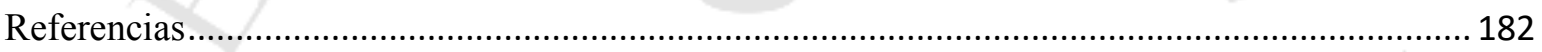

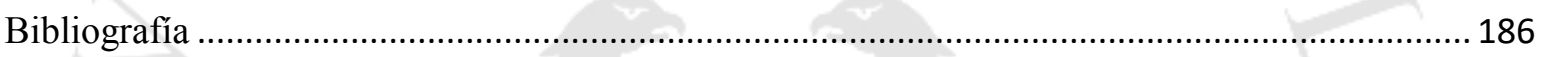

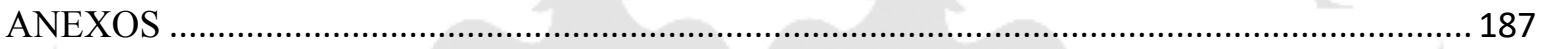

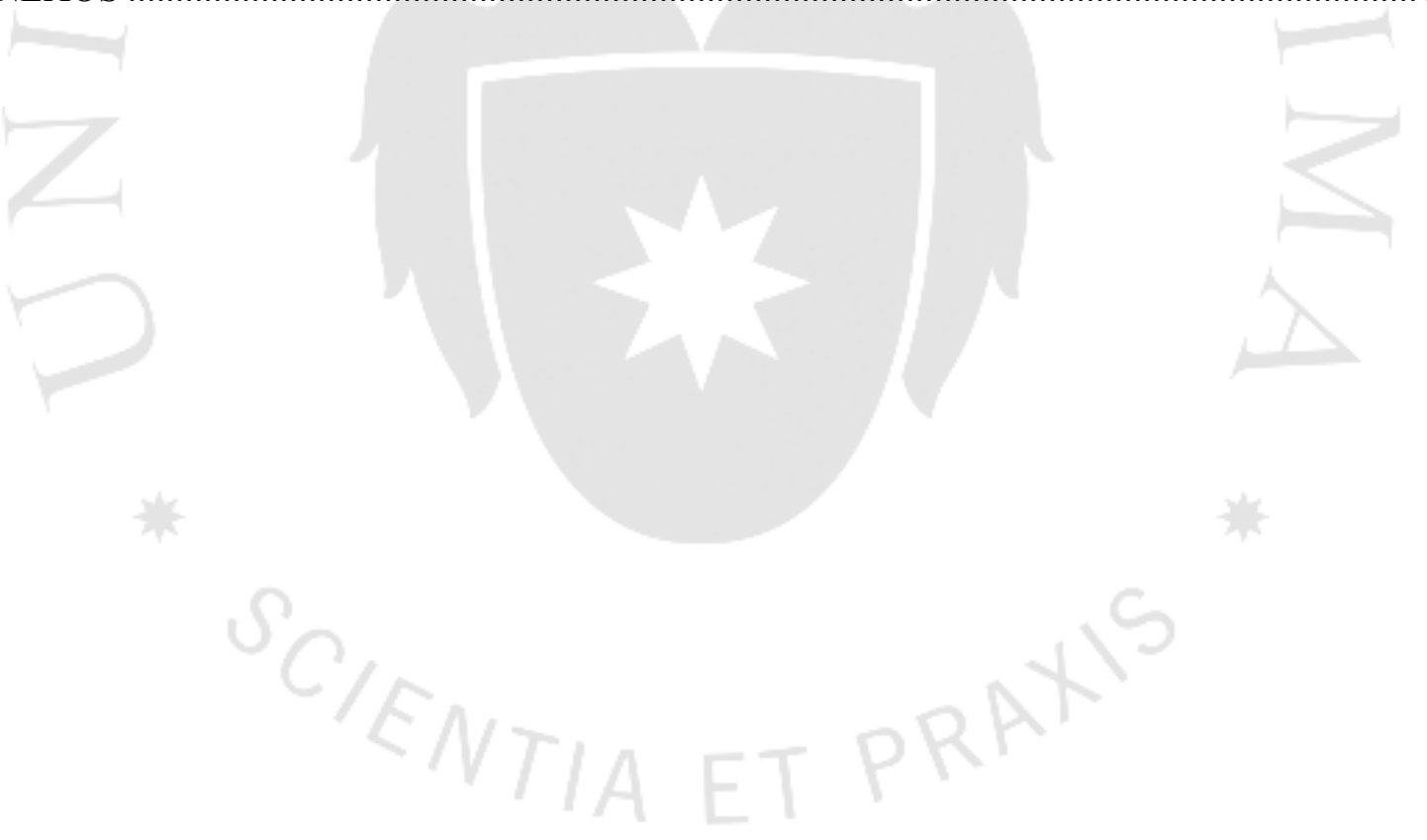




\section{ÍNDICE DE TABLAS}

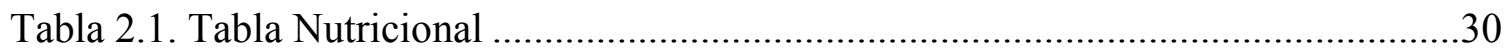

Tabla 2.2: Ingresos y gastos según NSE 2015 en Lima Metropolitana ............................33

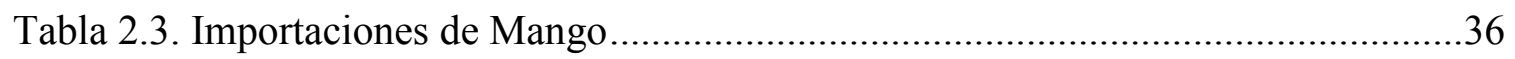

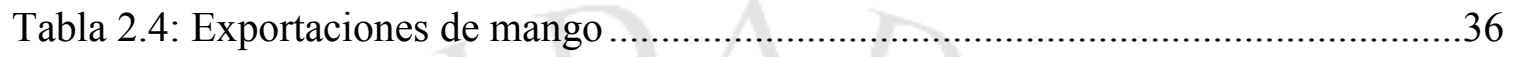

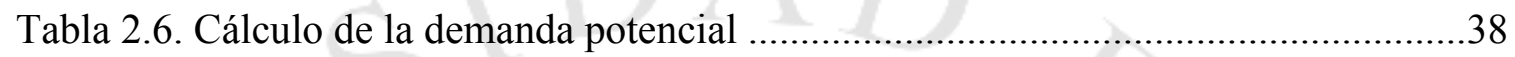

Tabla 2.7. Demanda de conservas de mango en almíbar ..........................................39

Tabla 2.8. Proyección de la demanda de conservas de mango en almíbar .......................40

Tabla 2.9. Proyección de la demanda de conservas de mango (incluye fruta y cobertura

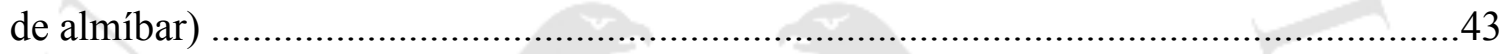

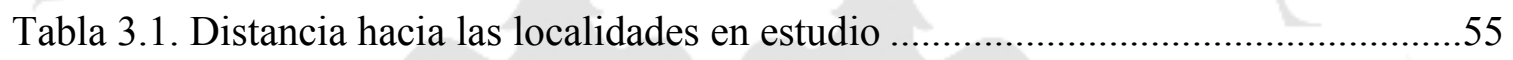

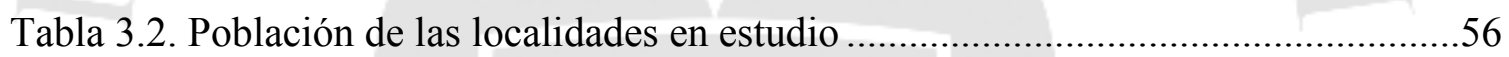

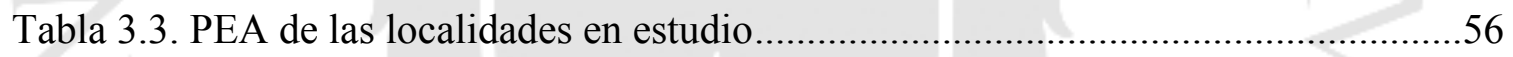

Tabla 3.4. PEA según grupo ocupacional de las localidades en estudio..........................56

Tabla 3.5. Tasa de Empleo de las localidades en estudio ..............................................56

Tabla 3.6. Nivel de Educación de las localidades en estudio........................................57

Tabla 3.7. Disponibilidad de terrenos de las localidades en estudio..............................58

Tabla 3.8. Empresas productoras y distribuidoras de agua potable por localidad ...........59

Tabla 3.9: Tarifa de la Categoría Industrial para agua potable y alcantarillado por

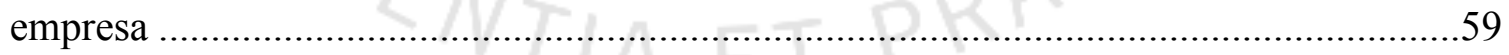

Tabla 3.10: Parámetros de calidad del agua por departamento .....................................59

Tabla 3.11. Energía Eléctrica en las localidades de estudio .......................................60

Tabla 3.12. Distancia a recorrer entre departamentos .............................................61

Tabla 3.13. Servicio de transportes de las localidades en estudio ...................................62

Tabla 3.14. Matriz de enfrentamiento ..................................................................63 
Tabla 3.15. Escala de Calificación

Tabla 3.16. Evaluación de Macro localización .....................................................................64

Tabla 3.17. Tarifas de agua potable y alcantarillado por provincia ....................................66

Tabla 3.18: Costos anuales de los factores objetivos ......................................................67

Tabla 3.19: Matriz de evaluación de factores subjetivos ..................................................67

Tabla 3.20. Escala de Calificación ...............................................................................67

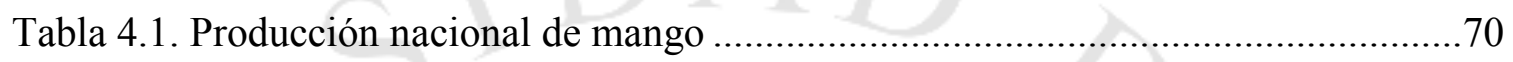

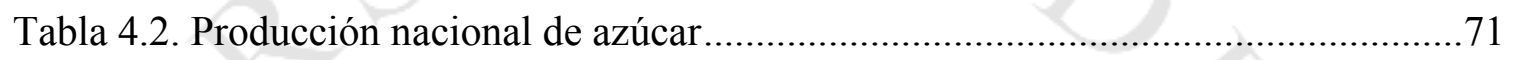

Tabla 4.3. Capacidad de las maquinas …………………............................................72

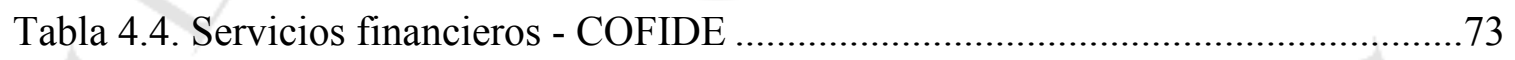

Tabla 4.5. Costos directos e indirectos al producto ........................................................

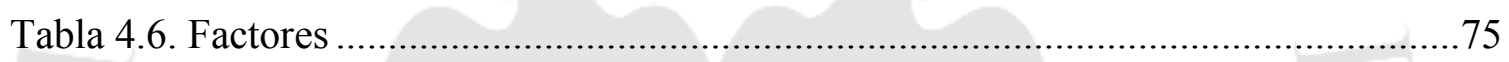

Tabla 5.1. Términos de las conservas de mango de acuerdo a la Norma Técnica.............76

Tabla 5.2:.Ficha técnica del producto final .................................................................79

Tabla 5.3. Tabla nutricional de conserva de mango..........................................................

Tabla 5.4. Porcentaje de ingredientes por porción ............................................................ 80

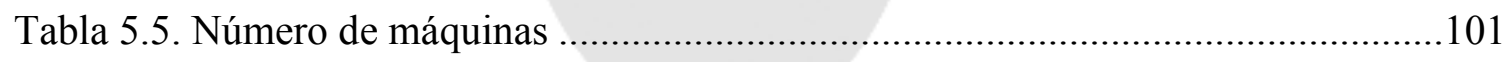

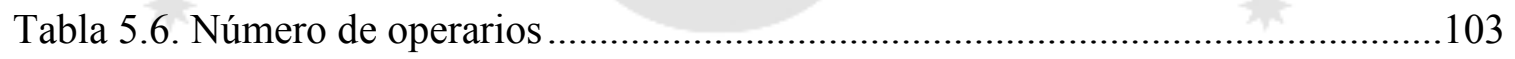

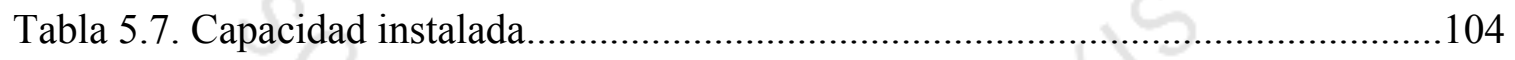

Tabla 5.8: Principales defectos del mango según origen …..........................................105

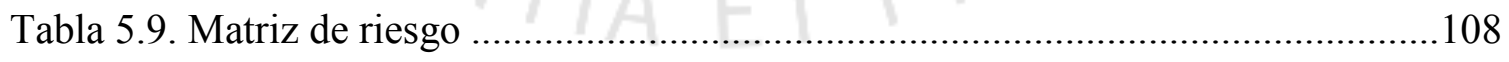

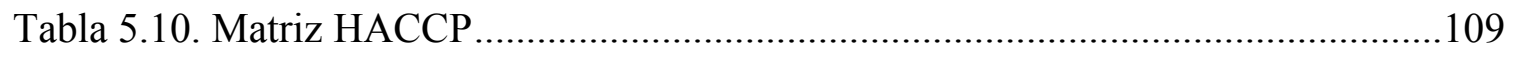

Tabla 5.11. Matriz de evaluación de Impactos ambientales ...........................................111

Tabla 5.12. Tabla de valoración de factores ..............................................................112

Tabla 5.13. Registro de la evaluación de aspectos ambientales.......................................113 
Tabla 5.14. Matriz IPER

Tabla 5.15. Tipos de mantenimiento según máquina.........................................................118

Tabla 5.16. Datos para el cálculo del stock de seguridad ...............................................118

Tabla 5.17. Cálculo del stock de seguridad................................................................119

Tabla 5.18. Programa de producción ...........................................................................119

Tabla 5.19. Requerimientos de materia prima e insumos .............................................120

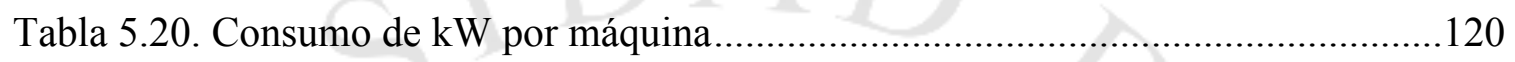

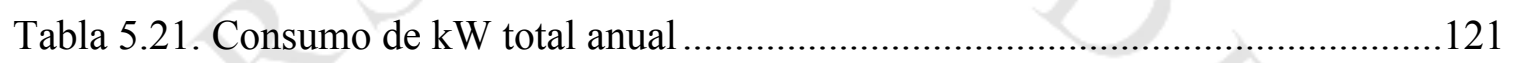

Tabla 5.22. Consumo de agua (m3) anual................................................................122

Tabla 5.23. Costo anual por consumo de telefonía …………………............................122

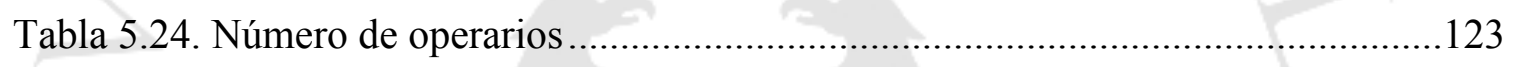

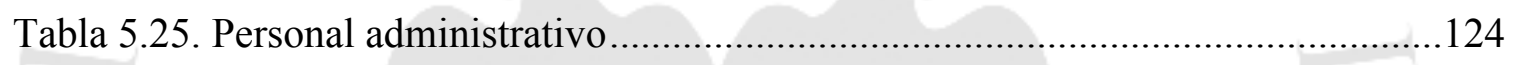

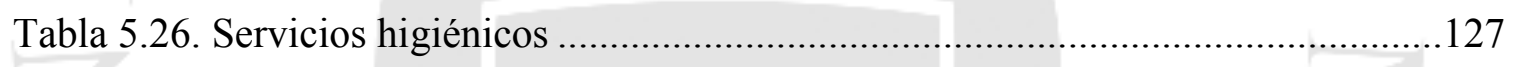

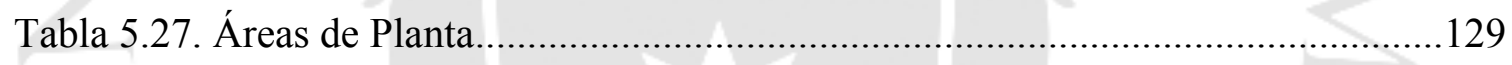

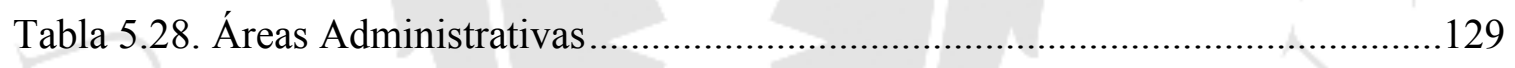

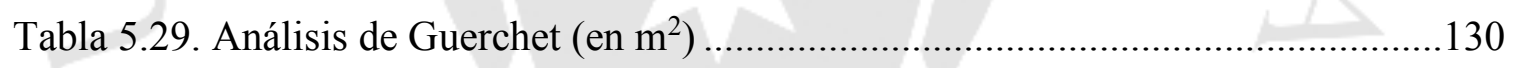

Tabla 5.30. Áreas adicionales de la empresa …………………………......................131

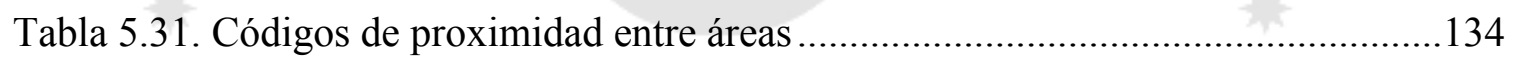

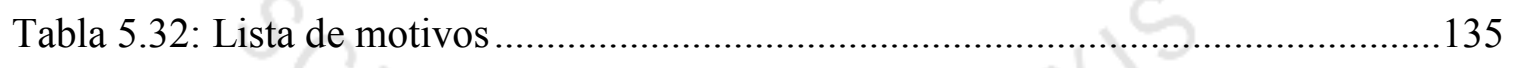

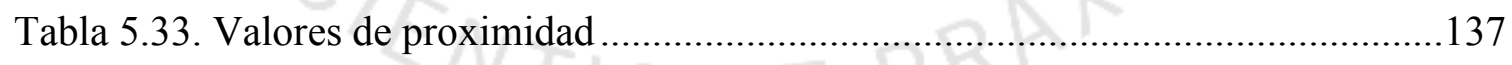

Tabla 5.34. Lista de tareas a realizar en el proyecto …………………...........................140

Tabla 6.1. Características del tipo de empresa a adoptar .................................................144

Tabla 6.2. Número de trabajadores operativos............................................................145

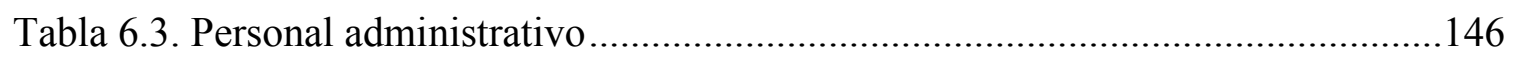

Tabla 7.1. Valor de la maquinaria ..............................................................................155 


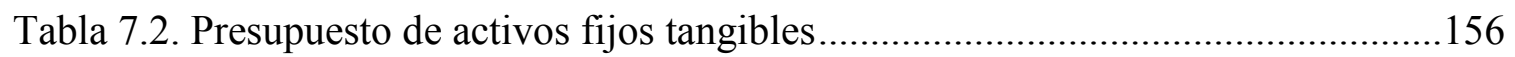

Tabla 7.3. Presupuesto de activos fijos intangibles.........................................................156

Tabla 7.4. Requerimientos para los primeros 4 meses de capital de trabajo ...................157

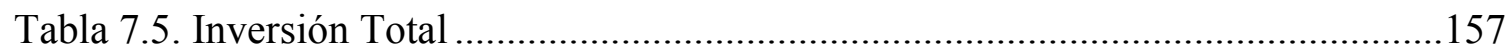

Tabla 7.6. Precio de mango en chacra en Piura ................................................................158

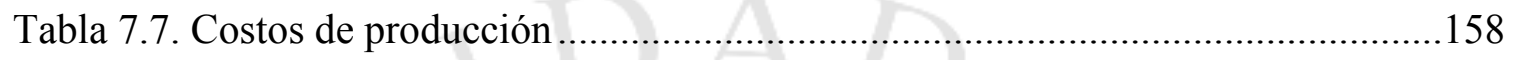

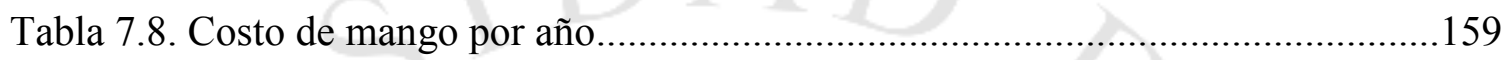

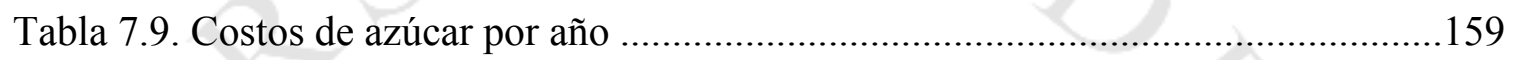

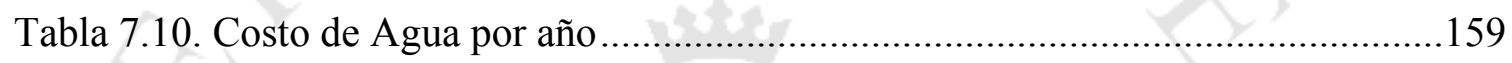

Tabla 7.11. Costo de Ácido Cítrico por año.................................................................159

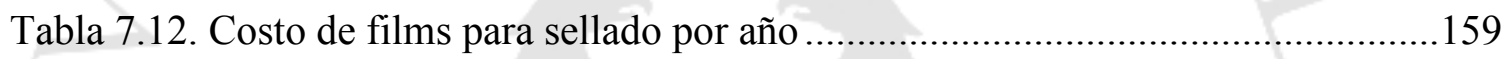

Tabla 7.13. Costo de cajas de cartón por año................................................................159

Tabla 7.14. Costo de envases de polipropileno por año...................................................160

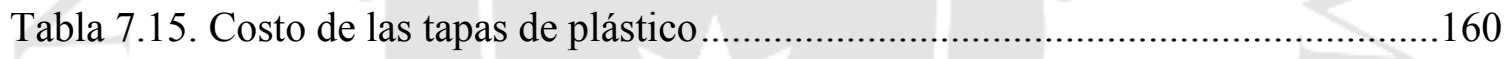

Tabla 7.16. Costo de los tenedores de plástico ................................................................160

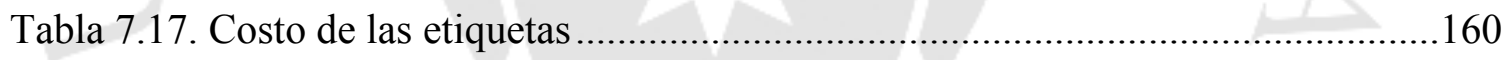

Tabla 7.18. Costos mensuales de insumos y materia prima.............................................160

Tabla 7.19. Costos anuales de mano de obra directa .......................................................161

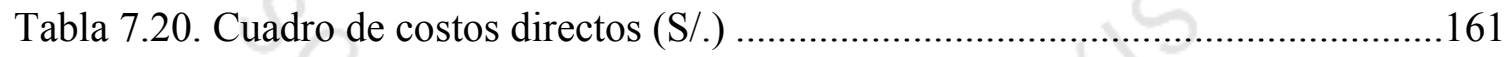

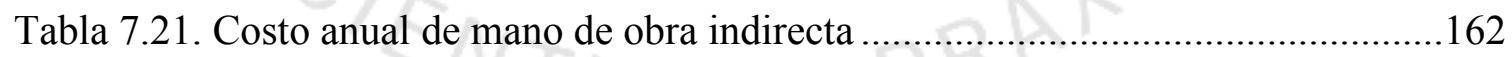

Tabla 7.22. Costos anuales de materiales indirectos .......................................................163

Tabla 7.23. Costos anuales indirectos ........................................................................163

Tabla 7.24: Costos mensuales y anuales de los principales servicios requeridos para el

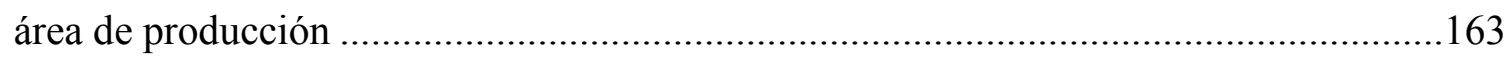

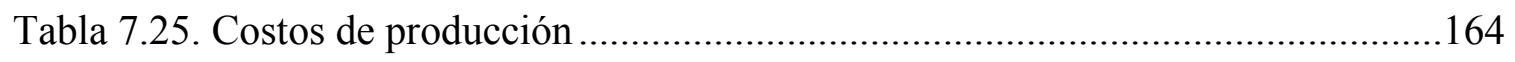


Tabla 7.26. Costos unitarios de producción .164

Tabla 7.27. Presupuesto de ingresos 164

Tabla 7.28. Presupuesto de depreciaciones de activos tangibles 165

Tabla 7.29. Presupuesto de depreciaciones de activos intangibles 165

Tabla 7.30. Presupuesto de costos de producción 166

Tabla 7.31. Presupuesto de gastos generales 166

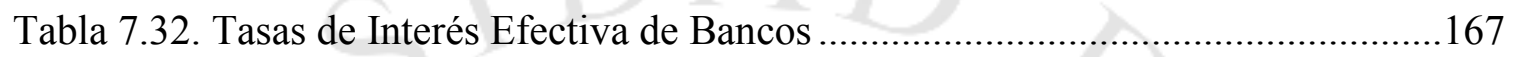

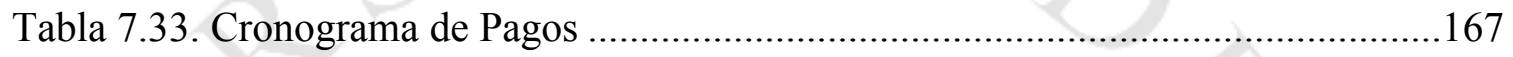

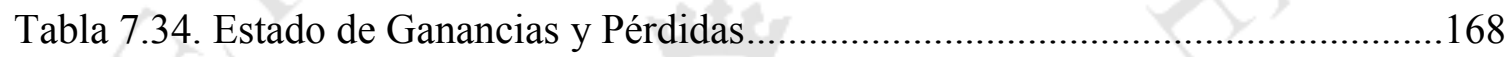

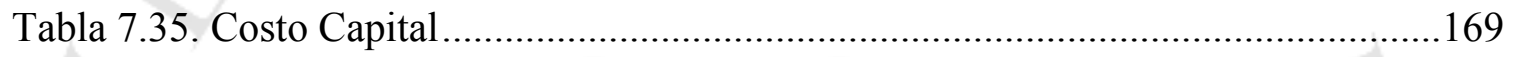

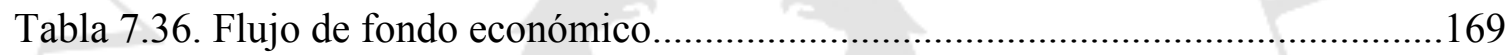

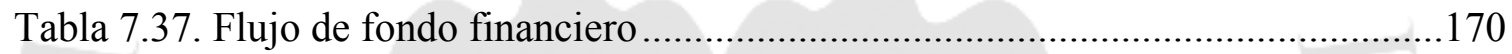

Tabla 8.1. Análisis del flujo de fondo económico .................................................171

Tabla 8.2. Análisis del flujo de fondo financiero ............................................... 171

Tabla 8.3. Análisis de sensibilidad en el precio sin financiación...................................173

Tabla 8.4. Análisis de sensibilidad en el precio con financiación ................................174 


\section{ÍNDICE DE FIGURAS}

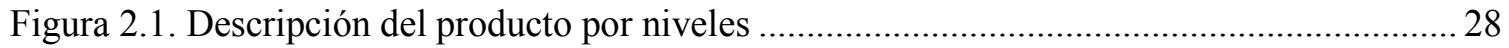

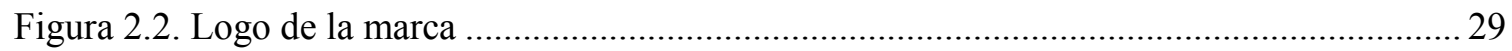

Figura 2.3: Distribución de personas según NSE 2015 en Lima Metropolitana ........................... 32

Figura 2.4. Marcas de conservas de Fruta de mayor consumo 2012 ......................................... 41

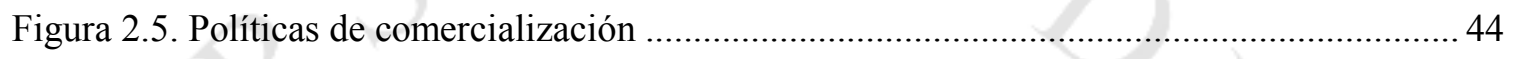

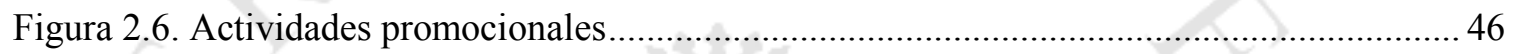

Figura 2.7. Línea de tendencia histórica de precios de conservas de durazno .............................. 47

Figura 3.1. Principales zonas de cultivo de mangos en el Perú................................................... 54

Figura 3.3. Tarifario Eléctrico del departamento de Piura ......................................................... 60

Figura 3.4. Tarifario Eléctrico del departamento de Lambayeque............................................ 60

Figura 3.5. Tarifario Eléctrico del departamento de Áncash .................................................. 61

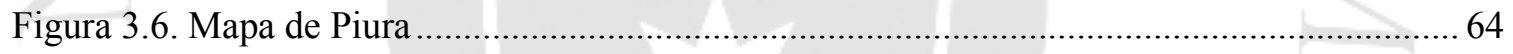

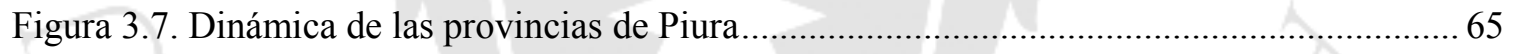

Figura 3.8. Tarifario Eléctrico de las provincias de Piura y Sullana............................................. 66

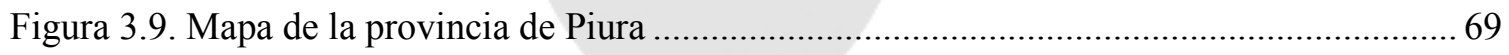

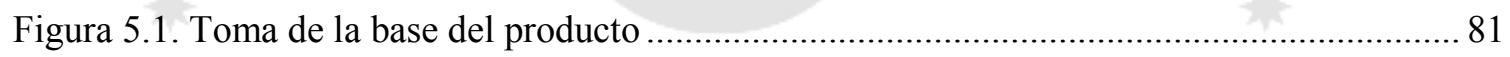

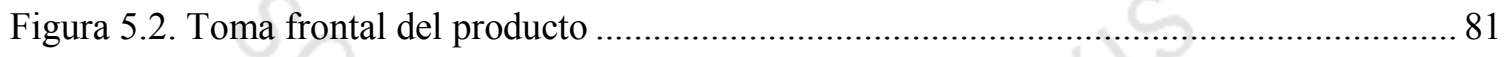

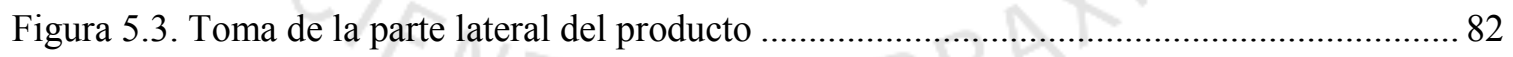

Figura 5.4. Diagrama de Operaciones del Proceso para la elaboración de conservas de mango en

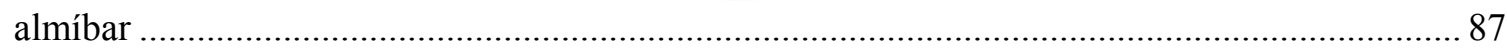

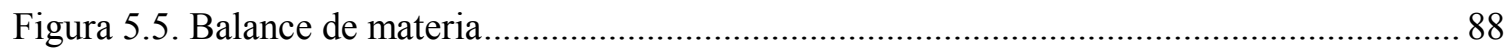

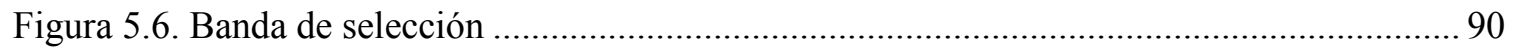

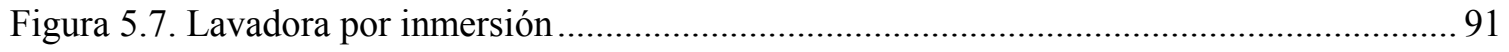

Figura 5.8. Máquina de envasado, llenado y sellado ............................................................... 92 


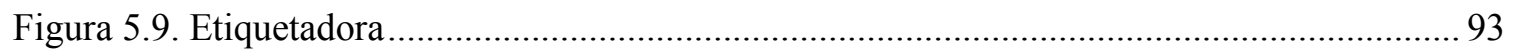

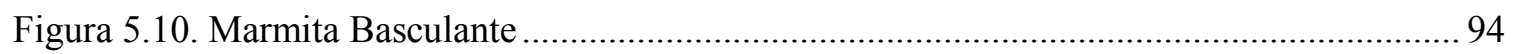

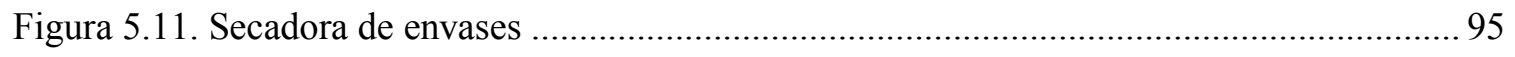

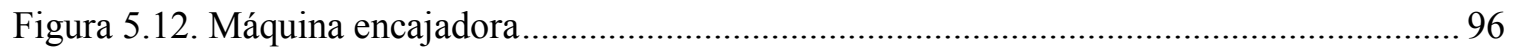

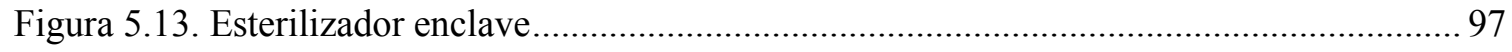

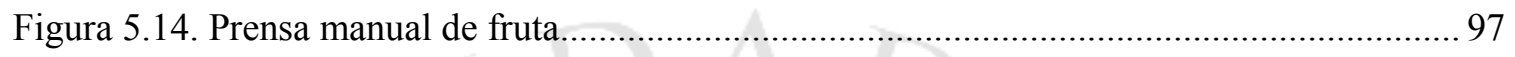

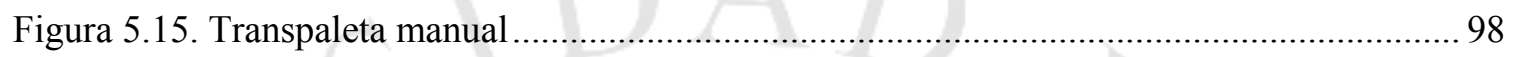

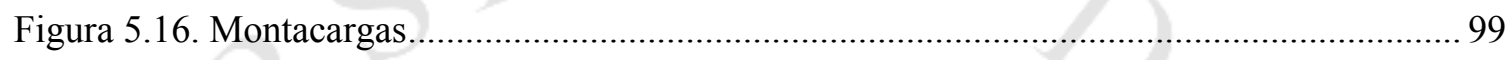

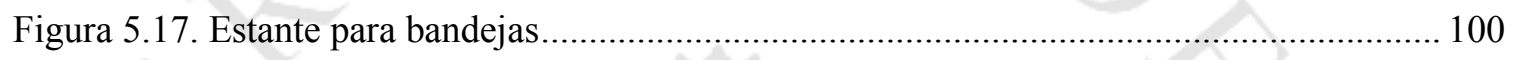

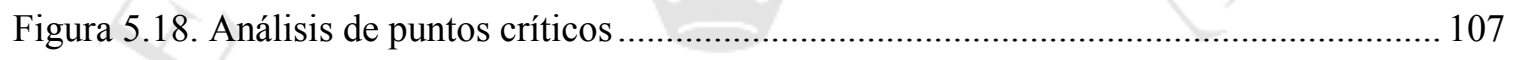

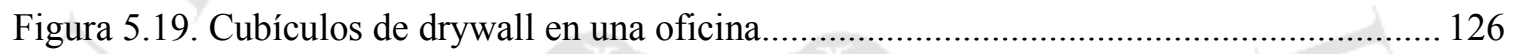

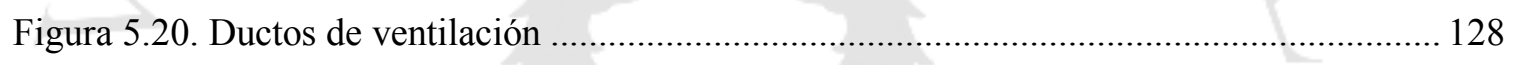

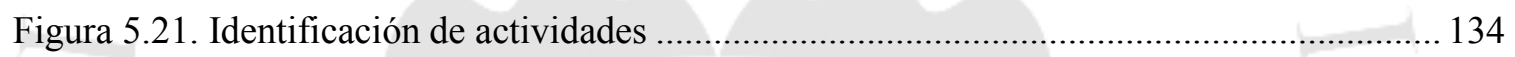

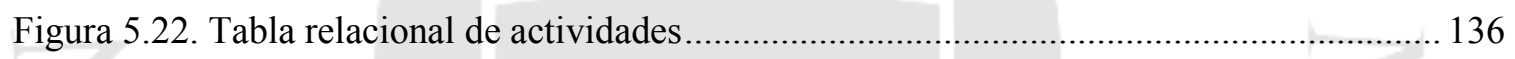

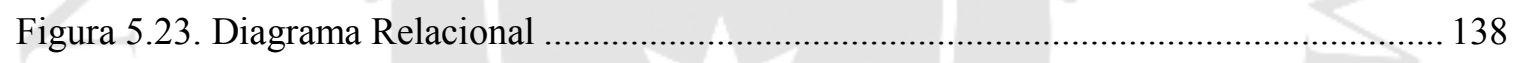

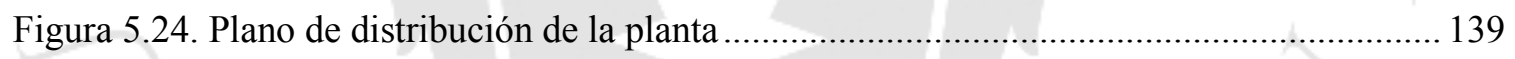

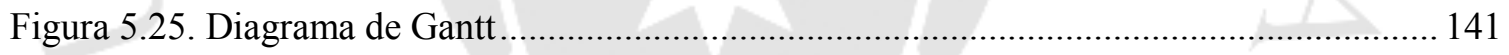

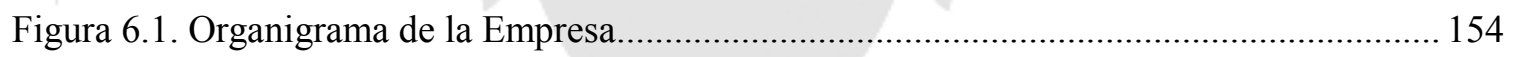




\section{ÍNDICE DE ANEXOS}

Anexo 1: Encuestas

188

Anexo 2: Cálculo del costo de capital ...

191

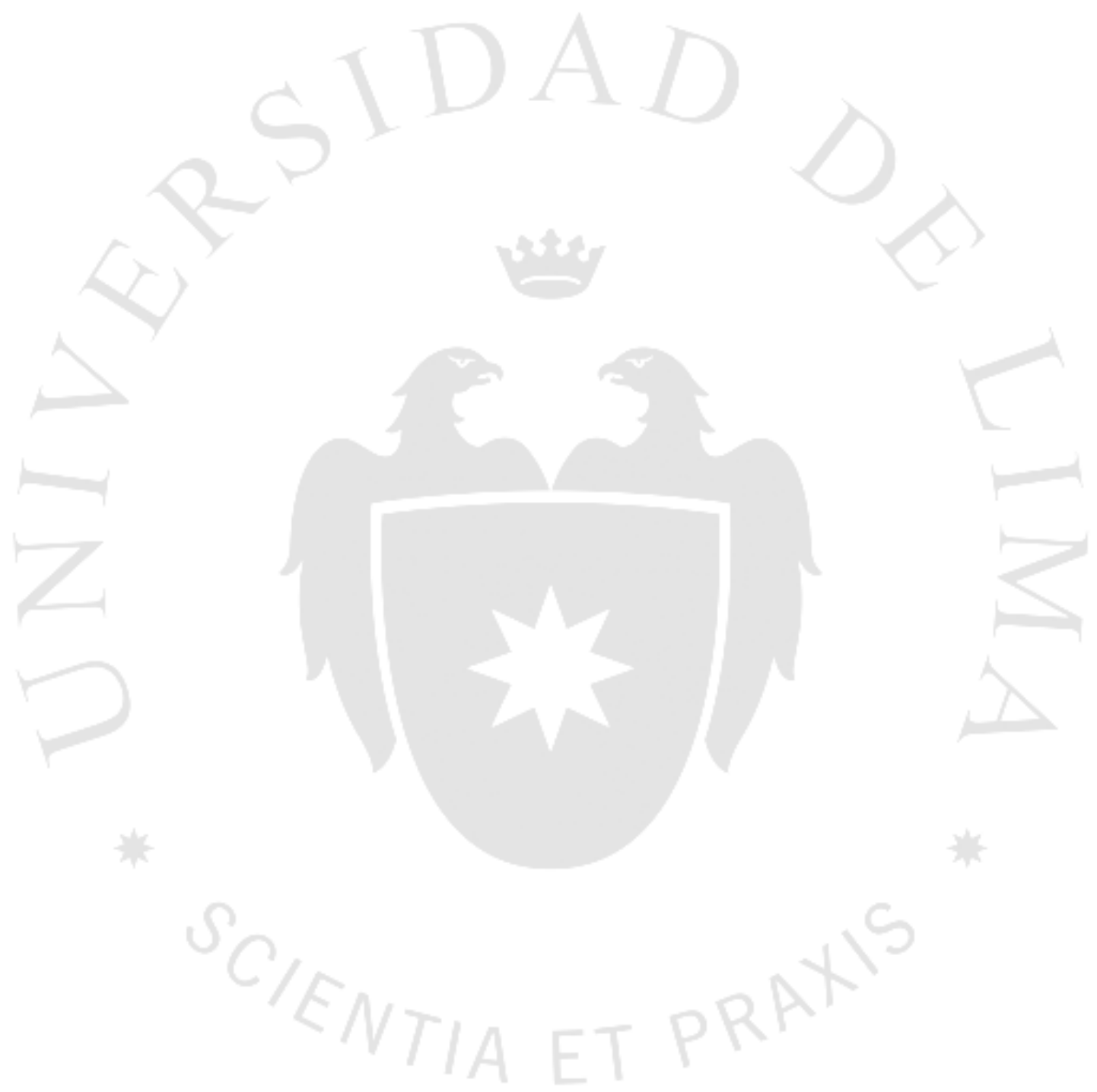




\section{RESUMEN EJECUTIVO}

Con el presente estudio de pre-factibilidad se ha obtenido un VAN Financiero de 4, 092,787 nuevos soles, un TIR Financiero de $60.20 \%$ con un COK de $13.27 \%$, por lo que se demuestra que el proyecto es rentable.

Además, el presente estudio tiene como objetivo determinar la pre-factibilidad de la instalación de una planta procesadora de conservas de mango en almíbar a partir de la evaluación de la viabilidad de mercado, tecnológica, económica y financiera. Para la elaboración de conservas se utilizará como materia prima principal el mango nacional de gran calidad y reconocimiento. Esta investigación resulta relevante debido a que en los últimos años el precio de las conservas se ha ido incrementando debido a la creciente demanda existente por estos productos. Otro aspecto importante para la relevancia de esta investigación es que se le dará valor agregado al mango peruano.

"Perú es el séptimo país con mayor rendimiento por hectárea en la producción de mangos del mundo, según información de la Organización de las Naciones Unidas para la Agricultura y la Alimentación"1, gracias a esto la materia prima no representara una restricción para la elaboración del proyecto. "La producción peruana de mango alcanzó los 119.190 toneladas en febrero del año 2013, lo que representa un incremento de $196,5 \%$ en comparación con el mismo mes del año pasado". 2

En los primeros capítulos se apreciarán reportes de investigación acerca de la demanda y la oferta, en donde se podrá observar cómo es que se ha venido manejando la venta de este tipo de producto. Luego, se evalúa los puntos estratégicos de ubicación y se define la capacidad de planta junto con los procesos para la elaboración del producto. A continuación, se tiene la ficha técnica del producto y los procesos que se requieren para su fabricación así como el detalle de las áreas de la empresa. Finalmente, se culmina con el análisis económico y financiero de los costos y presupuestos del producto final.

\footnotetext{
${ }^{1}$ FAO, (2015)

${ }^{2}$ Fuente: INEI, (2015)
} 


\section{EXECUTIVE SUMMARY}

The present study has obtained a financial NPV of 4,992,787 soles, a financial TIR of $60.20 \%$ with a $\mathrm{COK}$ of $13.27 \%$, which demonstrates that the project is profitable.

In addition, the present study aims to determine the pre-feasibility of installing a mango canning processing plant in syrup based on the evaluation of market, technological, economic and financial feasibility. The main raw material is national mango, which has high quality and recognition in the country. This research is relevant because in the last years the price of canned food has been increasing due to the growing demand for these products. Another important aspect is that it will give value added to the Peruvian mango.

"Peru is the seventh country with the highest yield per hectare in mango production in the world, according to information from the Food and Agriculture Organization of the United Nations", as a result the raw material does not represent a restriction on the production of this study. "Peruvian mango production reached 119,190 tons in February 2013, which represents an increase of $196.5 \%$ compared to the same month last year." 3

In the first chapters, you will see research reports on demand and supply, where you can see how it has been managing the sale of this type of product. Next, the strategic location points are evaluated and the plant capacity is defined along with the processes for the production of the product. Then, the technical file of the product and the processes that are required for its production as well as the detail of the areas of the company. Finally, the study finishes with the economic and financial analysis of the costs and budgets of the final product.

${ }^{3}$ Fuente: INEI, (2015) 


\section{CAPITULO I. ASPECTOS GENERALES}

\subsection{Problemática}

La presente investigación busca generar un proyecto de pre factibilidad para la implementación de una planta productora de conservas de mango en almíbar, el producto contará con un envase novedoso en el mercado ya que será de polipropileno y las presentaciones serán para consumo personal 226 gramos a diferencia de las conservas tradicionales cuyos envases son latas de metal y de gran tamaño destinadas para consumo familiar. Con esto se busca beneficiar a los consumidores nacionales ya que se les brinda un producto de agradable sabor, nutritivo y que podrá ser consumido en cualquier momento gracias a su practicidad.

Es importante mencionar que el potencial de consumo de las conservas de fruta en nuestro país está en aumento, tal es el caso que en el 2014 se logró un aumento más rápido de ventas con una tasa de crecimiento del valor de $15 \%$, explicado principalmente por un aumento del $8 \%$ en el precio unitario debido a una caída de las importaciones ${ }^{4}$, con ello se puede ver que a pesar que el precio se eleve la demanda de conservas se mantiene. Vale la pena mencionar que las conservas de fruta consumidas en Perú principalmente son importadas de Chile.

Además el precio unitario promedio se incrementó en un 5\% en 2014, debido principalmente al hecho de que las dos categorías más grandes de conservas (pescado y frutas) registraron importantes alzas de precios promedio por unidad por las ofertas restringidas que existen actualmente ${ }^{5}$.

\footnotetext{
${ }^{4}$ Euromonitor Internacional http://www.portal.euromonitor.com/portal/analysis/relatedtab [Consulta:25 de mayo de 2015]

${ }^{5}$ Euromonitor Internacional http://www.portal.euromonitor.com/portal/analysis/relatedtab [Consulta:25 de mayo de 2015]
} 


\subsection{Objetivos de la investigación}

\subsubsection{Objetivo general}

El objetivo general de la investigación es determinar la viabilidad de mercado, técnica, económica y financiera para la instalación de una planta procesadora de conservas de mango en almíbar.

\subsubsection{Objetivos específicos}

- Realizar un estudio de mercado para determinar la demanda de conservas de mango en almíbar.

- Evaluar la viabilidad tecnológica del proyecto mediante el análisis de la maquinaria requerida para el proceso de producción.

- Determinar la mejor ubicación de la planta procesadora.

- Determinar si el proyecto es viable económica y financieramente, además de evaluar si resulta rentable.

- $\quad$ El proyecto generará puestos de trabajo y otorgará un producto con valor que permitirá el ahorro de tiempo en el consumo.

Como objetivo medio ambiental se determinaran los principales impactos generados por los residuos de las operaciones, pero estos no son de gran magnitud para el medio ambiente ya que son orgánicos.

\subsection{Alcance y limitaciones de la investigación}

El presente trabajo de investigación tiene como objetivo la obtención de información necesaria y la aplicación de distintos métodos y técnicas para poder evaluar la pre factibilidad de la implementación de una planta procesadora de conservas de mango en almíbar.

El estudio está enfocado en estudiar la viabilidad de mercado, técnica, económica y financiera de la instalación de una planta procesadora de conservas. Además, se realizará un estudio de precios de las principales marcas de conservas que están en el mercado, así como también se presentaran los costos necesarios para producir conservas.

En este estudio no se considera la opción de exportar los productos a otros países ya que se tiene como mercado objetivo a la población de lima metropolitana y tampoco se utilizará mango de otros países debido a que afectaría el sabor del producto. También se 
pretende solo producir un producto destinado al consumo personal dado el tamaño de las raciones, a diferencia de las conservas tradicionales que tienen presentaciones más grandes destinas al consumo familiar.

El estudio también se limita a realizar una selección de la macro y micro localización, sin considerar como opciones otros países.

\subsection{Justificación del tema}

Se consideró justificar esta investigación desde tres puntos de vista los cuales son: técnico, económico y social.

\subsubsection{Justificación técnica}

El proyecto es factible técnicamente ya que existe la maquinaria y tecnología necesaria para realizar el proceso productivo, este proceso es utilizado en muchas industrias del sector alimenticio dedicado a las conservas de frutas.

Entre las máquinas más importantes para la elaboración de este producto se encuentra la autoclave, la marmita basculante y el termo formador-llenador, a continuación se detallan las principales características de estos equipos.

\section{Autoclave cilíndrica horizontal Modelo L}

- Material: Acero inoxidable

- $\quad$ Capacidad $300 \mathrm{~kg} / \mathrm{h}$

- $\quad$ Presión de trabajo $3.5 \mathrm{~kg} / \mathrm{cm} 2$

- Controlador y registro de temperatura automático

La autoclave tiene la función de pasteurizar las conservas sometiéndolas a alta temperatura y vapor de agua con el fin de aumentar su tiempo de vida.

\section{Marmita Basculante}

- Material: Acero inoxidable

- Capacidad 50 a 400 litros

- Temperatura: $152{ }^{\circ} \mathrm{C}$ 
La marmita se utilizará para la elaboración del almíbar que cubrirá la fruta en cubos.

\section{Termo formador llenador (Form fill seal-MD 4)}

- $\quad$ Capacidad 4000 envases/hora

- $\quad$ Material: Acero inoxidable

- $\quad$ Potencia: $5 \mathrm{kw}$

La función del termo formador llenador es la de llenar los envases de polipropileno con la fruta en cubos y el almíbar para luego sellar el producto con el film protector.

Además de que existe la tecnología necesaria para la elaboración de las conservas la materia prima no representara una restricción ya que como se mencionó, en nuestro país existen terrenos para cultivar y en los últimos años se están llegando a obtener buenas tasas de rendimiento por hectárea en comparación con otros países que producen mayor cantidad de mango, en el 2010 el país produjo en una tasa de 18 toneladas por hectárea, ubicándose en la séptima posición del ranking mundial por rendimiento en mango, mientras que países como India, China y Tailandia apenas alcanzaron las 6.3, 9.4 y 8.2 toneladas por hectárea respectivamente ${ }^{6}$

A continuación, se presenta la figura que muestra la producción y rendimiento del mango nacional.

\footnotetext{
${ }^{6} \mathrm{FAO},(2015)$
} 
Figura 1.1

Evolución de producción y rendimiento de mango nacional

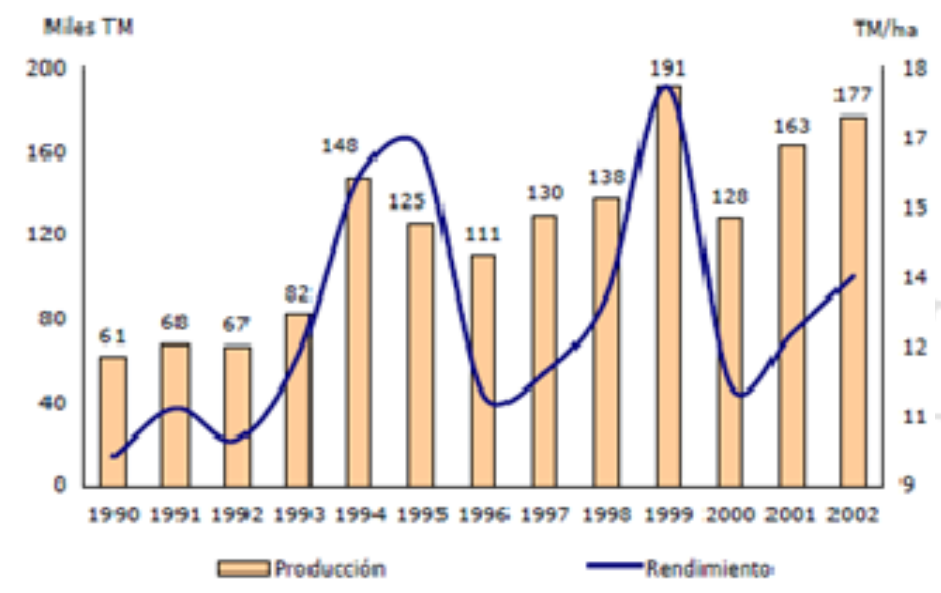

Fuente: MINAG, (2014)

Elaboración Maximixe

\subsubsection{Justificación económica}

Se espera que el proyecto sea rentable. Basado en proyectos relacionados sobre conservas de frutas se obtuvo resultados positivos en todos los indicadores. En la siguiente tabla se muestran los resultados económicos de estudios similares.

\section{Tabla 1.1}

Resultados económicos y financieros de proyectos similares

\begin{tabular}{|c|c|c|c|c|c|c|}
\hline & \multicolumn{2}{|c|}{$\begin{array}{l}\text { 1) Planta productora de } \\
\text { conservas de tomates } \\
\text { cherry en almíbar }\end{array}$} & \multicolumn{2}{|c|}{$\begin{array}{l}\text { 2) Planta productora de } \\
\text { Longan en conservas }\end{array}$} & \multicolumn{2}{|c|}{$\begin{array}{l}\text { 3) Planta productora de } \\
\text { cocktail de frutas con } \\
\text { yogurt }\end{array}$} \\
\hline & $\begin{array}{l}\text { Evaluación } \\
\text { económica }\end{array}$ & $\begin{array}{l}\text { Evaluación } \\
\text { financiera }\end{array}$ & $\begin{array}{l}\text { Evaluación } \\
\text { económica }\end{array}$ & $\begin{array}{l}\text { Evaluación } \\
\text { financiera }\end{array}$ & $\begin{array}{l}\text { Evaluación } \\
\text { económica }\end{array}$ & $\begin{array}{l}\text { Evaluación } \\
\text { financiera }\end{array}$ \\
\hline VAN & 169,932 & 702,017 & 247,040 & 275,420 & 487,280 & 551,990 \\
\hline TIR & $31.11 \%$ & $93.40 \%$ & $24.73 \%$ & $27.83 \%$ & $33.60 \%$ & $41.21 \%$ \\
\hline $\mathrm{B} / \mathrm{C}$ & 1.41 & 1.55 & 1.46 & 1.06 & 1.48 & 1.77 \\
\hline R (años) & 3.12 & 1.36 & 6.74 & 6.37 & 3.97 & 3.57 \\
\hline
\end{tabular}

Fuente: Romero, O (2013); Sbarbaro, A (2002); Fonseca, C (2014). 


\subsubsection{Justificación social}

Este proyecto tendrá importancia social debido a varios aspectos. Primero, es un proyecto que generará desarrollo en la zona donde se ubique la planta y en el lugar donde se cultivan las materias primas debido a que se generarán puestos de trabajo y se capacitará a los empleados con esto ellos podrán tener más conocimiento sobre las frutas que crecen en sus zonas y sabrán el verdadero valor que tiene tanto monetario como nutritivo.

También este proyecto permitirá beneficiar al medio ambiente ya que se desarrollarán las plantaciones de mango aumentando los sembríos, con esto se ayudará a la captura de $\mathrm{CO} 2$ y así a disminuir el efecto invernadero.

Finalmente ayudará a satisfacer la necesidad de los consumidores que actualmente buscan productos de consumo rápido ya que no tienen mucho tiempo para preparar sus alimentos o pelar y lavar frutas que son difíciles de consumir, este producto permitirá que el consumidor ahorre tiempo y pueda consumir una fruta saludable.

\subsection{Hipótesis de trabajo}

La instalación de una planta procesadora de conservas de mango en almíbar es factible, pues existe un mercado que va a aceptar el producto y además será viable tecnológica, económica y financieramente.

\subsection{Marco referencial de la investigación}

A continuación, se presentan investigaciones utilizadas como referencia para la elaboración de este proyecto:

- Prepalec Campos, Tomisla. (1989). Estudio tecnológico del proceso de obtención de mango en conserva. Lima: Universidad de Lima. La similitud principal que presenta esta investigación con el proyecto es el proceso productivo, esto será de gran utilidad para obtener las técnicas empleadas para la producción, así como la maquinaria necesaria, también presenta los requisitos microbiológicos y requisitos físico químicos para la elaboración del producto. Sin embargo, las diferencias están en que esta investigación fue realizada hace 25 años y no es un estudio de pre factibilidad por lo que el cálculo de precios de las materias primas está desactualizado y solo plantea el proceso de la conserva mas no 
los indicadores financieros o económicos, tampoco presenta un estudio de determinación de la localización de planta.

- Janampa Mercado, Celestino. (1988). Estudio tecnológico para el desarrollo de una planta procesadora de hojuelas de mango. Lima: Universidad de Lima. Presenta similitudes y diferencias con la investigación anterior, una de las principales diferencias es que en esta investigación el producto final serán hojuelas de mango y el proceso productivo será diferente al igual que la maquinaria requerida. Otra diferencia es que es un estudio tecnológico y por lo tanto no presenta indicadores financieros ni económicos, pero sí de localización de planta. Un punto que será de gran utilidad de esta investigación es que presenta los rendimientos de la materia prima además de requisitos físicos químicos necesarios.

Becerra Gamero, María Soledad. (1988). Industrialización del mango de la variedad Haden. Lima: Universidad de Lima. Esta investigación presenta muchas similitudes a la investigación planteada ya que se enfoca a producir conservas con el mango de la variedad Haden que crece en el Perú. Será de gran utilidad pues presenta información sobre el rendimiento de la fruta, así como de sus características y disponibilidad de esta materia prima. La principal desventaja es que es una tesis antigua y presenta datos desactualizados además de no presentar evaluaciones económicas y financieras.

- Espinoza Rivera, Marco Aurelio. (1986). Estudio preliminar para la implementación de una planta procesadora de conservas, néctares, mermeladas y jugos de frutas. Lima: Universidad de Lima. El presente estudio permitió conocer temas relacionados a la calidad de las conservas, requisitos para la conservación de frutas, requisitos para el etiquetado y factores para la localización de planta como las necesidades en energía eléctrica, agua y cercanía a materias primas. La principal diferencia es que esta tesis está destinada a varios productos en los que incluye néctares, jugos y mermeladas centrándose en la exportación a países andinos. 
- $\quad$ Fonseca, C y Mestanza, M. (2014). Estudio de pre factibilidad para la elaboración de cocktail de frutas en almíbar acompañado con yogurt Lima: Universidad de Lima. Esta investigación presenta similitudes importantes ya que utilizará frutas para procesarlas y elaborará conservas en almíbar, además contiene información actual ya que es del año 2014 y será de utilidad pues presenta maquinaria moderna y nuevos procesos para la fabricación de conservas. Otro punto importante es que contiene información económica y financiera, también tiene estudios de localización de planta y de rendimiento de las frutas. La principal diferencia es que esta investigación propone acompañar la conserva de frutas con yogurt el cual al ser un producto extra hará variar los costos ya que no solo está ofreciendo la conserva.

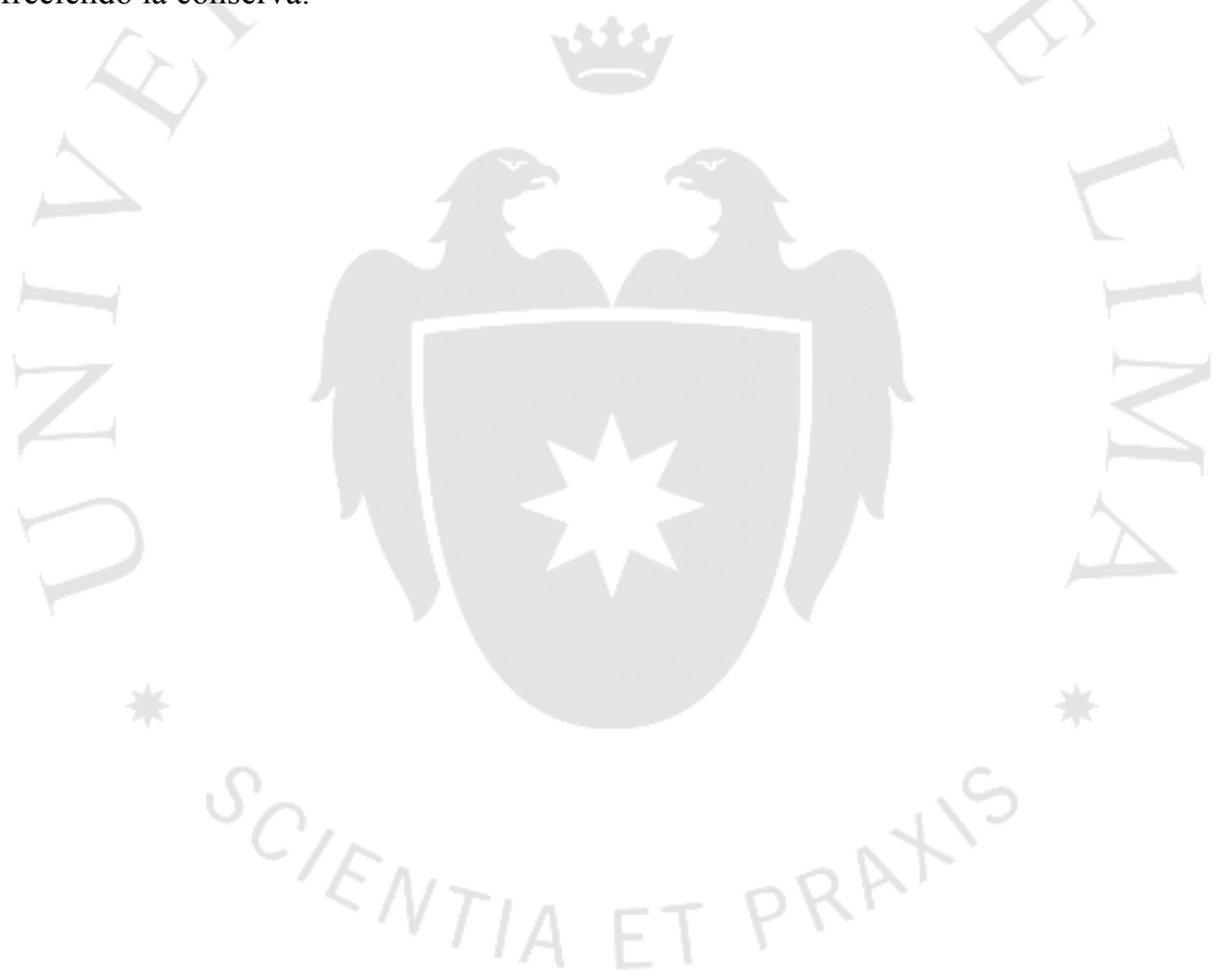




\section{CAPITULO II. ESTUDIO DE MERCADO}

\subsection{Aspectos generales del estudio de mercado}

\subsubsection{Definición comercial del producto}

El producto consiste en una conserva de mango en almíbar cuyo envase es de polipropileno y está cubierto por un film rígido en la parte superior. Posee un agradable sabor además de constituir una opción saludable de consumo de fruta entre las conservas que actualmente existen en el mercado.

La descripción del producto se ha realizado tomando en cuenta tres niveles fundamentales. A continuación, se presenta la descripción del producto de acuerdo a los tres niveles de marketing:

Figura 2.1

Descripción del producto por niveles

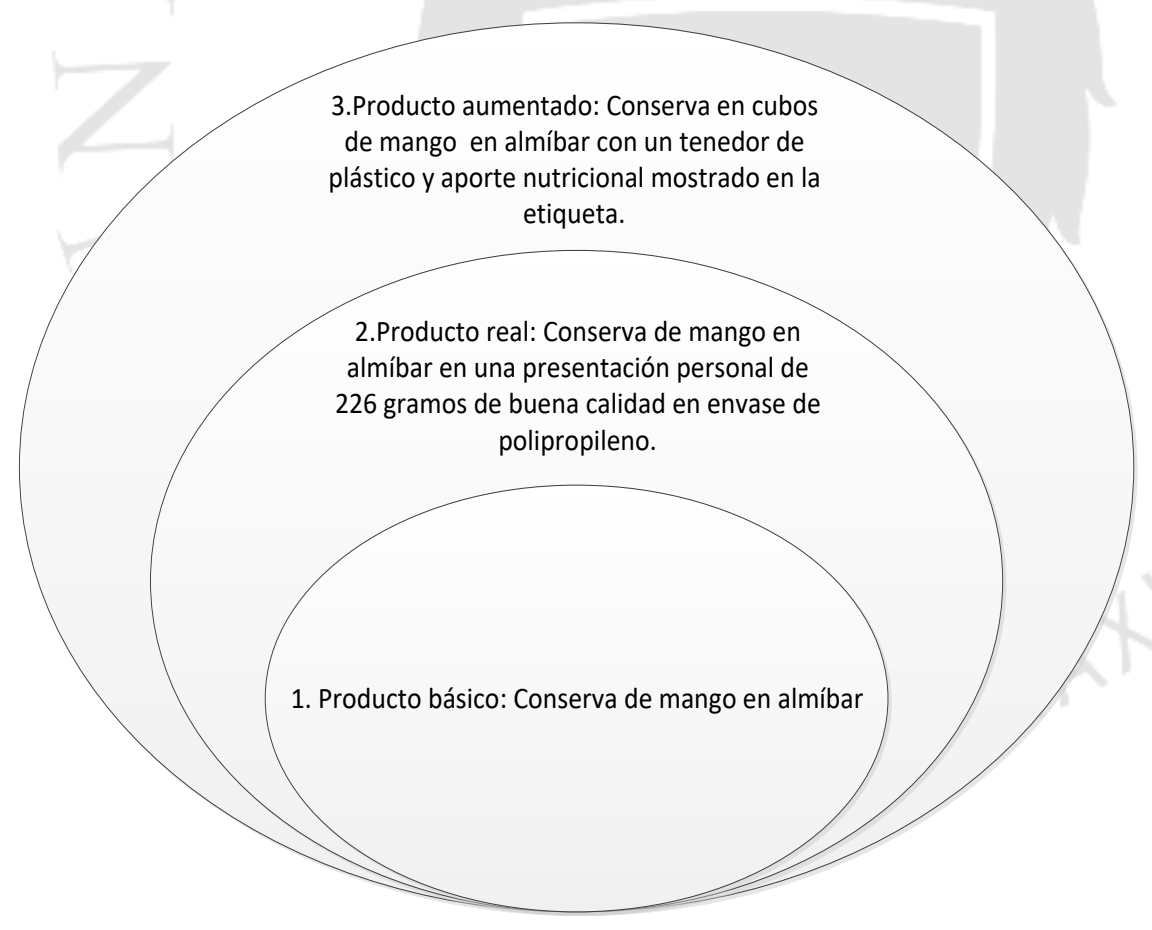

Elaboración Propia 
Producto básico: El producto básico es una conserva de mango en almíbar cuya función es alimenticia.

Producto real: El producto real corresponde a una conserva de mango en almíbar en envase de polipropileno con un tenedor para que se pueda comer fácilmente el producto lleva como marca Practi-fruit que se consolidará en el mercado, además el producto es de buena calidad y posee una presentación novedosa y de impacto que captará la atención de los consumidores. También tiene un precio justo y acorde con el mercado. En la etiqueta a parte del nombre irá una imagen del producto y un mango para que los consumidores lo relacionen con una fruta peruana, natural y saludable.

En la etiqueta se mostrará el logo de la marca y la información nutricional del producto.

Figura 2.2

Logo de la marca

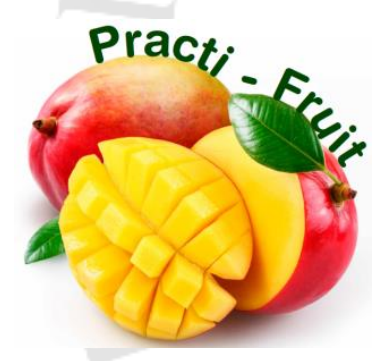

Elaboración Propia 
Tabla 2.1

Tabla Nutricional

\begin{tabular}{|c|c|}
\hline \multicolumn{2}{|c|}{ INFORMACIÓN NUTRICIONAL } \\
\hline Tamaño de porción & $1 / 2$ Cucharada $(226 \mathrm{~g})$ \\
\hline Porciones por envase & 2 \\
\hline \multicolumn{2}{|c|}{ Amount per serving/Cantidades por porción } \\
\hline \multicolumn{2}{|l|}{ Calorías : $30 \mathrm{kcal}$} \\
\hline \multicolumn{2}{|l|}{ Calorias de la grasa: 0} \\
\hline \multicolumn{2}{|c|}{ Valor nutricional por porción de $50 \mathrm{~g}$} \\
\hline Grasa total & $0 \mathrm{~g}$ \\
\hline Grasa saturada & $0 \mathrm{~g}$ \\
\hline Grasas trans & $0 \mathrm{mg}$ \\
\hline Colesterol & $0 \mathrm{~g}$ \\
\hline Sodio & $0 \mathrm{~g}$ \\
\hline Carbohid. Totales & $8.5 \mathrm{~g}$ \\
\hline Fibra dietaria & $0.3 \mathrm{mg}$ \\
\hline Azúcares & $7.7 \mathrm{~g}$ \\
\hline Proteinas & $0.1 \mathrm{~g}$ \\
\hline Peso Neto $(g)$ & 226 \\
\hline Peso Drenado $(g)$ & 130 \\
\hline
\end{tabular}

Fuente: Valle Fértil, (2015)

Producto aumentado: El producto aumentado es una conserva de mango en almíbar que brinda información de nutrición y sugerencias de uso además presenta recomendaciones de la cantidad que se debe consumir para tener una dieta balanceada, también presenta teléfonos de ayuda y/o consulta (0-800) y tiene un envase de polipropileno con una presentación novedosa en la etiqueta y posee garantía de que el producto se encuentra en buen estado, en caso contrario se podrá presentar un reclamo.

\section{Clasificación CIIU}

En cuanto a la clasificación Industrial Internacional Uniforme, las conservas se encuentran en la clase 15131 - Preparación de conservas de frutas, hortalizas y legumbres.

\subsubsection{Principales características del producto}

\subsubsection{Usos y características del producto}

Las conservas de mango en almíbar buscan satisfacer la necesidad de las personas de ingerir un producto dulce y saludable en cualquier época del año ya que esta fruta solo puede ser consumida en los meses de cosecha, para el mango es en los meses de diciembre a abril. Este producto puede consumirse preferentemente en la tarde como postre después del almuerzo, 
también como acompañante en el lonche, puede ser utilizado para acompañar tortas o puede consumirse de forma directa. Además, es ideal para transportarse debido a que está en presentaciones de 226 gramos.

El producto tendrá un envase de polipropileno transparente que permitirá ver el producto, además contará con un tenedor de plástico para que sea consumido fácilmente. La conserva consiste en cubos de mango cubiertos con almíbar. En la presentación se incluirá un tenedor de plástico para que el consumidor pueda comer el producto de forma más cómoda.

\subsubsection{Bienes sustitutos y complementarios}

Como bienes sustitutos están consideradas las conservas de otras frutas ya sean conservadas en almíbar o deshidratadas como el durazno, pera, uva, cocktail de frutas etc. También se incluye a las frutas frescas pero que solo serán un sustituto por algunos meses ya que el resto del tiempo no se pueden conseguir en estado fresco, debido a la estacionalidad que presentan y también porque no se importa mango fresco.

Como bienes complementarios tenemos los yogures bebibles, ensaladas de fruta, pasteles. También los yogures batidos y griegos sin frutas en los cuales el producto puede ser mezclado fácilmente.

\subsubsection{Determinación del área geográfica que abarcará el estudio}

El estudio propone localizar la planta de producción en el norte del país, ya que es allí donde se concentra la mayor producción de mango que será utilizada para la producción de las conservas. Además de ello es en esa zona en donde los precios de mango son más bajos ya que están cerca a los lugares de cosecha.

Con respecto al sector de venta se tomará el área de Lima metropolitana como base para realizar el estudio de mercado, ya que el gasto promedio en alimentos que presentan las personas es superior a las demás ciudades del Perú ${ }^{7}$, debido a este factor es mucho más fácil

\footnotetext{
${ }^{7}$ Fuente: INEI, 2015
} 
que las personas compren las conservas. Además es aquí en donde se encuentra la mayor población urbana ${ }^{8}$.

Las conservas están enfocadas a los sectores socioeconómicos que poseen mayores recursos económicos y que también estén dispuesto a consumir este producto. Se conoce que en Lima Metropolitana el $66.4 \%$ de la población pertenece a los NSE A, B y C. El producto está dirigido a las personas de estos NSE ya que son quienes presentan un mayor gasto promedio en alimentación y tienen una mayor tendencia de consumo de productos que sean saludables y nutritivos. La figura 2.2 y la tabla 2.1 muestran la distribución de personas, los ingresos y gastos promedios por NSE en Lima Metropolitana.

Figura 2.3

Distribución de personas según NSE 2015 en Lima Metropolitana

\begin{tabular}{|c|c|c|c|c|c|c|}
\hline \multirow[b]{3}{*}{ NSE A } & \multicolumn{2}{|c|}{ No PERSONAS $10 ' 269,613^{*}$} & \multirow{3}{*}{$\begin{array}{c}\text { NSE } \\
\text { A }\end{array}$} & \multirow{2}{*}{$\begin{array}{c}\text { Estrato } \\
\text { A1 }\end{array}$} & \multicolumn{2}{|c|}{ Porcentaje } \\
\hline & \multirow[b]{2}{*}{4.7} & & & & 0.7 & \multirow{2}{*}{4.7} \\
\hline & & & & A2 & 4.0 & \\
\hline \multirow{2}{*}{ NSE B } & \multirow{2}{*}{19.7} & & \multirow{2}{*}{ B } & B1 & 6.9 & \multirow{2}{*}{19.7} \\
\hline & & $66.4 \%$ & & B2 & 12.8 & \\
\hline \multirow{2}{*}{ NSE C } & \multirow{2}{*}{42.0} & & \multirow{2}{*}{ c } & C1 & 26.2 & \multirow{2}{*}{42.} \\
\hline & & & & C2 & 15.8 & \\
\hline NSE D & 25.5 & & D & D & 25.5 & 25.5 \\
\hline NSE E & 8.1 & & $\mathbf{E}$ & E & 8.1 & 8.1 \\
\hline
\end{tabular}

Fuente: INEI, (2015)

Elaboración APEIM

\footnotetext{
${ }^{8}$ Fuente: Estadística poblacional 2011 IPSOS APOYO
} 
Tabla 2.2

Ingresos y gastos según NSE 2015 en Lima Metropolitana

\begin{tabular}{|c|c|c|c|c|c|c|c|c|c|c|c|c|c|c|}
\hline & \multicolumn{14}{|c|}{ Lima Metropolitana } \\
\hline & \multicolumn{2}{|r|}{ NSE A } & \multicolumn{2}{|c|}{ NSE B } & \multicolumn{2}{|r|}{ NSE C } & \multicolumn{2}{|c|}{ NSE C1 } & \multicolumn{2}{|c|}{ NSE C2 } & \multicolumn{2}{|c|}{ NSE D } & \multicolumn{2}{|c|}{ NSE E } \\
\hline Grupo 1 : Alimentos - gasto promedio & s/. & 975.00 & s/. & 803.00 & s/. & 689.00 & S/. & 718.00 & s/. & 643.00 & s/. & 548.00 & s/. & 468.00 \\
\hline Grupo 2 : Vestido y Calzado - gasto promedio & $\mathrm{S} / \mathrm{s}$ & 233.00 & $\mathrm{~S} /$. & 132.00 & $\mathrm{~S} /$. & 89.00 & $\mathrm{~S} /$. & 97.00 & $\mathrm{~S} /$. & 76.00 & $\mathrm{~S} /$. & 60.00 & S/. & 59.00 \\
\hline $\begin{array}{l}\text { Grupo } 3 \text { : Alquiler de vivienda, Combustible, } \\
\text { Electricidad y Conservación de la Vivienda - gasto } \\
\text { promedio }\end{array}$ & $\mathrm{S} / \mathrm{s}$ & 566.00 & S/. & 356.00 & S/. & 223.00 & S/. & 236.00 & S/. & 202.00 & S/. & 147.00 & S/. & 94.00 \\
\hline $\begin{array}{l}\text { Grupo } 4 \text { : Muebles, Enseres y Mantenimiento de la } \\
\text { vivienda - gasto promedio }\end{array}$ & S/. & 578.00 & S/. & 159.00 & S/. & 68.00 & S/. & 73.00 & S/. & 59.00 & S/. & 45.00 & S/. & 36.00 \\
\hline $\begin{array}{l}\text { Grupo } 5 \text { : Cuidado, Conservación de la Salud y } \\
\text { Servicios Médicos - gasto promedio }\end{array}$ & S/. & 360.00 & S/. & 172.00 & S/. & 122.00 & S/. & 122.00 & S/. & 122.00 & S/. & 73.00 & S/. & 48.00 \\
\hline $\begin{array}{l}\text { Grupo } 6 \text { : Transportes y Comunicaciones - gasto } \\
\text { promedio }\end{array}$ & S/. & 876.00 & $\mathrm{~S} /$. & 396.00 & S/. & 155.00 & S/. & 175.00 & S/. & 123.00 & & 73.00 & S/. & 49.00 \\
\hline $\begin{array}{l}\text { Grupo } 7 \text { : Esparcimiento, Diversión, Servicios } \\
\text { Culturales y de Enseñanza - gasto promedio }\end{array}$ & & $1,056.00$ & S/. & 459.00 & S/. & 211.00 & S/. & 242.00 & S/. & 160.00 & S/. & 106.00 & S/. & 61.00 \\
\hline Grupo 8 : Otros bienes y servicios - gasto promedio & S/. & 265.00 & S/. & 155.00 & S/. & 102.00 & S/. & 107.00 & S/. & 94.00 & S/. & 67.00 & S/. & 56.00 \\
\hline Promedio General de Gasto Familiar Mensual & s/. & $7,394.00$ & s/. & $4,414.00$ & s/. & $2,880.00$ & s/. & $3,077.00$ & s/. & $2,563.00$ & s/. & $1,952.00$ & s/. & $1,535.00$ \\
\hline Promedio de Ingreso Familiar Mensual & & $11,596.00$ & s/. & $5,869.00$ & s/. & $3,585.00$ & s/. & $3,834.00$ & s/. & $3,185.00$ & s/. & $2,227.00$ & s/. & $1,650.00$ \\
\hline
\end{tabular}

Fuente: INEI, (2015)

Elaboración APEIM

\subsubsection{Análisis del sector}

$\underline{\text { Riesgo de ingreso de competidores potenciales }}$

El producto actualmente no se encuentra disponible en el mercado en la presentación propuesta, pero si existe en envases de vidrio y metal en presentaciones de mayor cantidad. Debido a que el sistema de producción es conocido, el acceso a las materias primas es de bajo costo, la maquinaria necesaria no es de alta tecnología y se puede adquirir importándola existe un riesgo alto de que nuevos competidores puedan entrar al mercado ya que el producto podría ser copiado con facilidad.

\section{$\underline{\text { Poder de negociación de clientes }}$}

Los principales clientes son los mayoristas y supermercados de Lima metropolitana, a través de ellos se comercializará el producto para que lleguen al consumidor final. 
El poder de negociación de clientes es alto debido a que ellos tienen el control de las ventas y podrían optar por no comercializar este producto nuevo y mantener sus ventas con las conservas tradicionales.

\section{Poder de negociación de los proveedores}

Los principales proveedores son acopiadores ubicados en Piura. La materia prima principal es el mango que será adquirido de dichos acopiadores. La producción es muy grande y no hay una gran diferenciación en la materia prima que se compra en la zona norte del país. Por estas razones consideramos que el poder de negociación de los proveedores es bajo ya que existe una gran competencia entre ellos.

\section{Amenaza de productos sustitutos}

Entre los principales productos sustitutos se encuentran las conservas de otras frutas (durazno, piña, pera) y las frutas en estado fresco. La principal diferencia respecto a las otras conservas es la cantidad que se ofrece ya que como se mencionó no existe en el mercado una conserva en esa cantidad, pero los consumidores podrían elegir las conservas tradicionales como sustituto. En base a esto se puede concluir que la amenaza de productos sustitutos es alta.

\section{Intensidad de rivalidad entre los competidores}

El producto ofrecido es novedoso por su envase de polipropileno y presentación de 226 gramos mientras que lo que ofrece la competencia son productos tradicionales en presentaciones de más de 400 gramos. Las principales conservas de frutas son importadas y existen marcas consolidadas en nuestro país como Dos Caballos, Aconcagua, Valle fértil, Del monte, Fanny, Florida y marcas de supermercados como Bell's de Plaza Vea o Aro de Makro. Para el caso de las conservas de mango existe una gran producción de estas, pero está destinada a la exportación debido a los altos precios que se obtienen, por ello el mercado nacional está desabastecido de conservas de mango y la principal conserva es la de durazno. La rivalidad entre los competidores es alta. 


\subsubsection{Determinación de la metodología que se empleará en la investigación de mercado}

Para la investigación de mercado se utilizaron encuestas físicas y a través de internet. Estas encuestas contenían listas de preguntas que permitieron conocer los gustos y preferencias del consumidor, así como el nivel de aceptación que muestran para consumir el producto. También permitió saber el rango de precios que estarían dispuestos a pagar por adquirir las conservas y la intención de compra.

Para realizar las encuestas primero se calculó el tamaño de muestra, para ello se utilizó la siguiente fórmula: $n=\left(p \times q \times Z^{2}\right) / e^{2}$

Donde $Z$ es el nivel de confianza. Para la investigación se utilizó un nivel de confianza de $95 \%$ que equivale a 1.96 según la tabla de distribución normal. $P$ representa la probabilidad de aceptación de un evento que para nuestro escenario es la aceptación del producto. Se utilizó un valor de 50\%. El valor de $q$ es calculado en base a la diferencia de 1$p$ y finalmente $e$ representa el error. En nuestro caso utilizamos un 5\%. Aplicando estos valores en la formula se obtiene un tamaño de muestra de 385 encuestas.

\subsection{Análisis de la demanda}

\subsubsection{Demanda histórica}

\subsubsection{Importaciones/Exportaciones}

\section{Importaciones}

Durante la investigación se obtuvo información sobre las importaciones de conservas de mango de SUNAT, observándose solo importación de conservas de mango en algunos años. El producto tiene la siguiente partida arancelaria: 2008993000 Mangos preparados o conservados.

Las cifras de importaciones de mango en conservas totalizadas por año y en unidades de producto terminado para la presentación de 226 g, según su partida se muestra en la siguiente tabla. 
Tabla 2.3

Importaciones de Mango

\begin{tabular}{|c|c|c|c|c|c|}
\hline Año & $\begin{array}{c}\text { Subpartida } \\
\text { Nacional }\end{array}$ & Descripción & $\begin{array}{c}\text { Peso Neto } \\
(\mathbf{k g})\end{array}$ & $\begin{array}{c}\text { Peso Bruto } \\
\text { (kg) }\end{array}$ & $\begin{array}{c}\text { Unidades de } \\
\mathbf{2 2 6} \text { gramos }\end{array}$ \\
\hline 2015 & 2008993000 & $\begin{array}{c}\text { MANGOS PREPARADOS O } \\
\text { CONSERVADOS }\end{array}$ & - & - \\
\hline 2014 & 2008993000 & $\begin{array}{c}\text { MANGOS PREPARADOS O } \\
\text { CONSERVADOS }\end{array}$ & 50 & - & - \\
\hline 2013 & 2008993000 & $\begin{array}{c}\text { MANGOS PREPARADOS O } \\
\text { CONSERVADOS }\end{array}$ & - & - \\
\hline 2012 & 2008993000 & $\begin{array}{c}\text { MANGOS PREPARADOS O } \\
\text { CONSERVADOS }\end{array}$ & - & - \\
\hline 2011 & 2008993000 & $\begin{array}{c}\text { MANGOS PREPARADOS O } \\
\text { CONSERVADOS }\end{array}$ & - & - \\
\hline
\end{tabular}

Fuente SUNAT, (2015)

Elaboración Propia

\section{Exportaciones}

Para las exportaciones de conservas de Mango se obtuvo información de SUNAT.

Tabla 2.4

Exportaciones de mango

\begin{tabular}{|c|c|c|c|c|c|}
\hline Año & $\begin{array}{c}\text { Sub partida } \\
\text { Nacional }\end{array}$ & Descripción & Peso Neto $(\mathrm{kg})$ & $\begin{array}{c}\text { Peso Bruto } \\
(\mathrm{kg})\end{array}$ & $\begin{array}{c}\text { Unidades de } \\
226 \text { gramos }\end{array}$ \\
\hline 2015 & 2008993000 & $\begin{array}{c}\text { MANGOS PREPARADOS O } \\
\text { CONSERVADOS }\end{array}$ & $4,666,822$ & $5,177,387$ & $20,649,655$ \\
\hline 2014 & 2008993000 & $\begin{array}{c}\text { MANGOS PREPARADOS O } \\
\text { CONSERVADOS }\end{array}$ & $6,669,570$ & $7,369,760$ & $29,511,372$ \\
\hline 2013 & 2008993000 & $\begin{array}{c}\text { MANGOS PREPARADOS O } \\
\text { CONSERVADOS }\end{array}$ & $5,490,630$ & $6,115,160$ & $24,294,823$ \\
\hline 2012 & 2008993000 & $\begin{array}{c}\text { MANGOS PREPARADOS O } \\
\text { CONSERVADOS }\end{array}$ & $5,153,580$ & $5,662,950$ & $22,803,451$ \\
\hline 2011 & 2008993000 & $\begin{array}{c}\text { MANGOS PREPARADOS O } \\
\text { CONSERVADOS }\end{array}$ & $8,373,470$ & $9,130,850$ & $37,050,752$ \\
\hline
\end{tabular}

Fuente SUNAT, (2015)

Elaboración Propia

\subsubsection{Producción Nacional}

Actualmente el mercado nacional de conservas de frutas en almíbar está dominado por productos importados. La producción de conservas de mango destinada para la venta en lima metropolitana es pequeña en comparación con los duraznos en lata que son importados principalmente de Chile. Se puede decir que no representan un porcentaje significativo que 
deba ser incluido en este análisis. Además, las conservas de mango que se venden en pocos supermercados tienen una presentación diferente a la propuesta en este estudio, presentan envases de vidrio y en porciones de 450 gramos con la denominación de mango gourmet. Como es el caso de los productos que vende la empresa Valle Fértil.

\subsubsection{Demanda interna aparente (DIA)}

La demanda interna aparente se calculará con la siguiente fórmula utilizando información de mango fresco debido a la falta de información sobre la producción nacional de mango en conserva:

$$
\text { Demanda }=\text { Importaciones }+ \text { Producción }- \text { Exportaciones }
$$

Es así como obtenemos la siguiente tabla con la demanda de mango.

Tabla 2.5

Demanda de mango

\begin{tabular}{|c|c|c|c|c|c|}
\hline Año & Producción (kg) & $\begin{array}{c}\text { Importaciones } \\
(\mathbf{k g})\end{array}$ & $\begin{array}{c}\text { Exportaciones } \\
\mathbf{( k g )}\end{array}$ & DIA (kg) & $\begin{array}{c}\text { Unidades de } \\
\mathbf{2 2 6} \mathbf{g}\end{array}$ \\
\hline 2015 & $193,600,000$ & 721 & $133,801,908$ & $59,798,813$ & $264,596,518$ \\
\hline 2014 & $377,300,000$ & 500 & $119,954,860$ & $257,345,640$ & $1,138,697,522$ \\
\hline 2013 & $458,800,000$ & 860 & $124,822,030$ & $333,978,830$ & $1,477,782,434$ \\
\hline 2012 & $185,200,000$ & - & $99,582,670$ & $85,617,330$ & $378,837,743$ \\
\hline 2011 & $351,900,000$ & - & $123,862,590$ & $228,037,410$ & $1,009,015,088$ \\
\hline
\end{tabular}

Fuente MINAG, (2015)

Elaboración Propia

\subsubsection{Demanda potencial}

2.2.2.1. Patrones de consumo: incremento poblacional, consumo per cápita, estacionalidad

Incremento poblacional

El incremento poblacional en lima metropolitana se viene dando a una tasa promedio de $1.1 \%$ anual según el INEI además el ingreso promedio de las familias también va en aumento y según la encuesta ENAHO en Lima metropolitana los gastos en alimentos y bebidas representan el $48 \%$ de la canasta familiar. Esto beneficiará el consumo del producto ya que en los próximos años habrá más personas con mejor capacidad adquisitiva para poder consumir el producto. 


\section{$\underline{\text { Consumo per cápita }}$}

El consumo per cápita de conservas de fruta en nuestro país es de $0.2 \mathrm{~kg} / \mathrm{hab}^{9}$, en base a esto se calculará la demanda para el proyecto.

\section{Estacionalidad}

La conserva no presenta una estacionalidad de consumo ya que es un producto que se puede consumir en cualquier temporada del año además estará a la venta durante todo el año ya que cuenta con un tiempo de vida de 18 .

\subsubsection{Determinación de la demanda potencial}

El producto en la presentación propuesta no existe en el mercado nacional; sin embargo, si existen conservas de fruta en envases de metal o vidrio. La demanda potencial será calculada en base al consumo per cápita de conservas de Chile y el número de habitantes en Lima metropolitana.

Tabla 2.6

Cálculo de la demanda potencial

\begin{tabular}{|c|c|c|c|c|c|}
\hline Año & $\begin{array}{c}\text { Cpc } \\
\text { (kg/hab) }\end{array}$ & $\begin{array}{c}\text { Número de } \\
\text { habitantes Perú }\end{array}$ & $\begin{array}{c}\text { Demanda potencial } \\
\text { Perú (Kg.) }\end{array}$ & $\begin{array}{c}\text { Demanda Potencial Segmento } \\
\text { Lima Metropolitana (Kg.) }\end{array}$ & $\begin{array}{c}\text { Unidades de } \\
\text { 226 gramos }\end{array}$ \\
\hline 2015 & 3.8 & $31,153,131$ & $118,381,898$ & $35,514,569$ & $157,144,112$ \\
\hline
\end{tabular}

Fuente: INEI, (2015)

Elaboración Propia

\subsubsection{Demanda mediante fuentes primarias}

Para calcular la demanda se utilizaron diversas fuentes, el procedimiento se mostrará en los siguientes puntos.

\subsubsection{Diseño y aplicación de encuestas u otras técnicas}

Para el presente estudio se realizaron encuestas en distintos puntos de Lima Metropolitana en donde concurre el público objetivo de los niveles socio económico A, B y C. entre los principales puntos están los supermercados Wong, Plaza Vea y Metro. También se realizaron

\footnotetext{
${ }^{9}$ Euro monitor
} 
encuestas por internet. Con los datos recopilados se pudo determinar el nivel de aceptación del producto además permitió conocer la intención de compra de los encuestados, el precio que estarían dispuestos a pagar por el producto y la cantidad por porción que prefieren del producto.

\subsubsection{Determinación de la Demanda}

Para determinar la demanda se utilizó el consumo per cápita de conservas en Perú que es de $0.2 \mathrm{~kg} / \mathrm{hab}^{10}$, el número de habitantes en el país por año. La demanda de Lima metropolitana se calculó en base a la población de este sector que representa el 30\% de la población nacional. ${ }^{11}$ Se realizó una segmentación por niveles socioeconómicos en donde se incluyen solo los NSE A, B y C que representan el $66.4 \%$ de la población de Lima metropolitana ${ }^{12}$.

Como resultado de la encuesta se obtuvo que el $66 \%$ de los encuestados consume conservas de frutas y entre ellos el $45 \%$ respondió que definitivamente compraría conservas de mango en almíbar.

Con esta información se determinó la demanda que se muestra en la siguiente tabla:

Tabla 2.7

Demanda de conservas de mango en almíbar

\begin{tabular}{|c|c|c|c|c|c|c|c|c|c|}
\hline \multirow[t]{2}{*}{ Año } & \multirow[t]{2}{*}{$\begin{array}{c}\text { Cpc } \\
\text { (kg/hab) }\end{array}$} & \multirow{2}{*}{$\begin{array}{l}\text { Número de } \\
\text { habitantes } \\
\text { Perú }\end{array}$} & \multirow[t]{2}{*}{$\begin{array}{l}\text { Demanda } \\
\text { Perú (Kg.) }\end{array}$} & \multirow{2}{*}{\begin{tabular}{|c|}
$\begin{array}{c}\text { Demanda Lima } \\
\text { Metropolitana (Kg.) }\end{array}$ \\
$30 \%$ \\
\end{tabular}} & \multirow{2}{*}{\begin{tabular}{|c} 
Segmentación por \\
NSE A/B/C (Kg.)
\end{tabular}} & \multirow{2}{*}{$\begin{array}{c}\text { Intención de } \\
\text { compra }\end{array}$} & \multirow{2}{*}{$\begin{array}{c}\begin{array}{c}\text { Intensidad de } \\
\text { compra (Kg.) }\end{array} \\
45 \%\end{array}$} & \multirow[t]{2}{*}{$\begin{array}{c}\text { Demanda } \\
\text { (Ton) }\end{array}$} & \multirow[t]{2}{*}{$\begin{array}{c}\text { Unidades de } \\
\text { producto }\end{array}$} \\
\hline & & & & & & & & & \\
\hline 2011 & 0.2 & $29,797,694$ & $5,959,539$ & $1,787,862$ & $1,187,140$ & 783,512 & 352,581 & 352.58 & $1,560,091$ \\
\hline 2012 & 0.2 & $30,135,875$ & $6,027,175$ & $1,808,153$ & $1,200,613$ & 792,405 & 356,582 & 356.58 & $1,577,797$ \\
\hline 2013 & 0.2 & $30,475,144$ & $6,095,029$ & $1,828,509$ & $1,214,130$ & 801,326 & 360,597 & 360.60 & $1,595,560$ \\
\hline 2014 & 0.2 & $30,814,175$ & $6,162,835$ & $1,848,851$ & $1,227,637$ & 810,240 & 364,608 & 364.61 & $1,613,310$ \\
\hline 2015 & 0.2 & $31,153,131$ & $6,230,626$ & $1,869,188$ & $1,241,141$ & 819,153 & 368,619 & 368.62 & $1,631,057$ \\
\hline
\end{tabular}

Elaboración Propia

\subsubsection{Proyección de la demanda}

Para determinar la proyección se utilizarán los datos sobre el comportamiento de la demanda en los últimos años. El nivel de consumo está relacionado con el nivel de ingresos y el gasto en alimentos de las personas, es así que para determinar la demanda se considera que el

\footnotetext{
${ }^{10}$ Fuente: Euro monitor

${ }^{11}$ Fuente: INEI. Instituto Nacional de Estadística e Informática

${ }^{12}$ Fuente: INEI. Instituto Nacional de Estadística e Informática
} 
consumo per cápita permanecerá constante en los próximos años. En el análisis se obtuvo que el comportamiento de la demanda presenta una tendencia lineal ya que presenta un coeficiente de correlación de 0.998 que está muy cerca de 1 . Al realizar las regresiones se obtuvieron las siguientes formulas y coeficientes de correlación $\left(R^{2}\right)$ :
Lineal:
$y=3.8243 x+324.08$
$R^{2}=0.998$
Logarítmica: $y=12.739 * \ln (x)+324.41$
$R^{2}=0.9149$
Potencial: $\quad y=324.66 x^{0.0375}$
$R^{2}=0.9207$
Exponencial: $y=324.4 e^{0.0112 x}$
$R^{2}=0.9303$

\section{Tabla 2.8}

Proyección de la demanda de conservas de mango en almíbar

\begin{tabular}{|c|c|c|c|c|c|c|c|c|c|}
\hline Año & $\begin{array}{c}\text { Cpc } \\
\text { (kg/hab) }\end{array}$ & $\begin{array}{c}\text { Número de } \\
\text { habitantes } \\
\text { Perú }\end{array}$ & $\begin{array}{l}\text { Demanda } \\
\text { Perú (Kg.) }\end{array}$ & $\begin{array}{c}\text { Demanda Lima } \\
\text { Metropolitana } \\
(\mathrm{Kg} .)\end{array}$ & $\begin{array}{c}\text { Segmentación } \\
\text { porNSE A/B/C } \\
(\mathrm{Kg})\end{array}$ & $\begin{array}{l}\text { Intención de } \\
\text { compra (Kg.) }\end{array}$ & $\begin{array}{l}\text { Intensidad de } \\
\text { compra (Kg.) }\end{array}$ & $\begin{array}{l}\text { Demanda } \\
\text { (Ton) }\end{array}$ & $\begin{array}{l}\text { Unidades de } \\
\text { producto }\end{array}$ \\
\hline 2016 & 0.2 & $31,495,815$ & $\langle 99,105$ & $1,889,749$ & $1,254,793$ & & & 372.67 & $1,648,998$ \\
\hline 2017 & 0.2 & $31,842,269$ & 68,454 & $1,910,536$ & $1,268,596$ & & & 376.77 & $1,667,137$ \\
\hline 2018 & 0.2 & $32,192,534$ & & $1,931,552$ & & & & 380.92 & $1,685,476$ \\
\hline 2019 & 0.2 & $32,546,652$ & $6,509,330$ & $1,952,799$ & $1,296,659$ & 855,795 & 385,108 & 385.11 & $1,704,016$ \\
\hline 2020 & 0.2 & $32,904,665$ & $6,580,933$ & $1,974,280$ & $1,310,922$ & 865,208 & 389,344 & 389.34 & $1,722,760$ \\
\hline 2021 & 0.2 & $33,253,012$ & $6,650,602$ & $1,995,181$ & $1,324,800$ & 874,368 & 393,466 & 393.47 & $1,740,998$ \\
\hline
\end{tabular}

Elaboración Propia

\subsubsection{Consideraciones sobre la vida útil del proyecto}

El proyecto tendrá una vida útil de 6 años. Iniciará en el año 2016 y concluirá en el año 2021. En base a estos años se calcularán los indicadores económicos y financieros. También se realizarán los análisis de sensibilidad para este periodo de tiempo.

\subsection{Análisis de la oferta}

\subsubsection{Empresas productoras, importadoras y comercializadoras}

Las principales empresas productoras de conservas de mango en nuestro país se encuentran ubicadas en el norte ya que generalmente están ubicadas cerca de las materias primas entre las más grandes se encuentran Danper, Valle Fertil, Del monte. Estas empresas se dedican principalmente a la exportación de sus productos por los buenos precios que se obtienen en 
el extranjero, pero por otro lado descuidan el mercado interno que está abastecido por empresas extranjeras ya que la conserva más consumida es la de durazno importado de Chile en su mayoría. Las principales marcas importadas son Aconcagua y dos caballos.

Figura 2.4

Marcas de conservas de Fruta de mayor consumo 2012

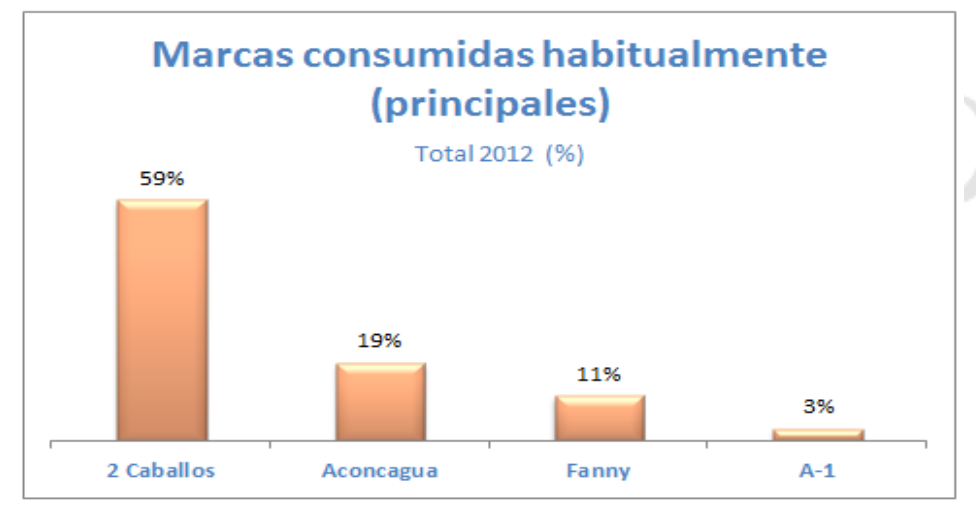

Fuente: Ipsos APOYO, (2014)

La marca Dos caballos pertenece al grupo Pentzke. Este grupo fue fundado en 1906, en la actualidad el grupo factura alrededor de USD 85 millones. Presenta crecimientos alrededor de un $12 \%$ anual en ventas. Esta marca está muy bien posicionada en el mercado nacional, además de las conservas de durazno elaboran conservas de uvas, ciruelas, cerezas, peras y cocktail de frutas.

Por otra parte, la marca Aconcagua de origen chileno también tiene buena aceptación en el mercado nacional debido a la buena calidad de sus productos.

Entre los principales productos que elabora están las conservas de durazno, pera, manzana y cerezas.

\subsubsection{Competidores actuales y potenciales}

En Lima metropolitana se ofrecen los duraznos en almíbar que son los mayores competidores y provienen de empresas extranjeras en su mayoría de Chile y Argentina que son los principales exportadores de frutas en conservas para nuestro país como se mencionó en el punto 2.3.1. Estas empresas comercializan sus productos con sus propias marcas. Cabe resaltar que en el mercado nacional también se cuenta con frutas en conserva de otras marcas 
de supermercados y los comercializan con sus propias marcas. Tales como Wong, Plaza Vea (Bell's), etc. Todos ellos importan sus productos y los comercializan con sus propias marcas.

\subsection{Determinación de la Demanda para el proyecto}

\subsubsection{Segmentación del mercado}

El proyecto presenta la siguiente segmentación de mercado:

Segmentación demográfica: Lima Metropolitana

Segmentación por nivel socio económico: A, B y C

Es importante mencionar que no se realiza una segmentación por edad debido a que el producto está dirigido al público en general y no hay ninguna restricción o ley que impida venderlo a menores de edad.

\subsubsection{Selección del mercado meta}

Para elegir el mercado meta primero se estudió el consumo per cápita anual de frutas según el ámbito geográfico, se encontró que el mango tiene un consumo per cápita de $1.9 \mathrm{~kg} / \mathrm{hab}$ en la costa a diferencia de la sierra y la selva en donde es de $1.4 \mathrm{~kg} / \mathrm{hab}$ y $0.6 \mathrm{~kg} / \mathrm{hab}$ respectivamente. En las ciudades de la costa se encontró que Lima Metropolitana tiene un consumo per cápita de $2.1 \mathrm{~kg} /$ hab que es superior a las demás ciudades de la costa e inclusive al promedio. En base a esto elegimos a Lima metropolitana como el mercado meta para el producto.

En Lima metropolitana se encontró que los principales consumidores de conservas de frutas son las personas de los NSE A, B y C que a la vez representan el 66.4\% de la población ubicada en este lugar ${ }^{13}$. Además se pretende vender los productos en los principales supermercados debido a que es allí donde el público objetivo realiza sus compras de alimentos ${ }^{14}$.

En base a estos factores se decidió elegir a la población ubicada en los NSE A, B y C de Lima Metropolitana como el mercado meta.

\footnotetext{
13 Fuente INEI

${ }^{14}$ Fuente Ipsos APOYO, Encuesta de lugar de compra por NSE 2012 (Lima metropolitana)
} 


\subsubsection{Demanda específica para el proyecto}

En la siguiente tabla se muestra la proyección de la demanda de conservas de mango hasta el año 2021.

Tabla 2.9

Proyección de la demanda de conservas de mango (incluye fruta y cobertura de almíbar)

\begin{tabular}{|c|c|c|}
\hline Año & Peso (Ton) & $\begin{array}{c}\text { Envases de } \\
\mathbf{2 2 6} \mathbf{g}\end{array}$ \\
\hline 2016 & 372.67 & $1,648,998$ \\
\hline 2017 & 376.77 & $1,667,137$ \\
\hline 2018 & 380.92 & $1,685,476$ \\
\hline 2019 & 385.11 & $1,704,016$ \\
\hline 2020 & 389.34 & $1,722,760$ \\
\hline 2021 & 393.47 & $1,740,998$ \\
\hline
\end{tabular}

Elaboración Propia

\subsection{Definición de la Estrategia de Comercialización}

\subsubsection{Políticas de comercialización y distribución}

Inicialmente se plantea 2 canales de distribución, canal moderno y canal tradicional. Para el canal moderno, solo se venderá a supermercados (HIPERMERCADOS TOTTUS, CENCOSUD, MAKRO, SUPERMERCADOS PERUANOS), lugares donde los niveles de compra de conservas son elevados. Sin embargo para el canal tradicional se venderá a las distintas distribuidoras que cubren Lima Metropolitana, tomando en cuenta los NSE seleccionados. Se ha escogido un distribuidor ya que tiene mayor experiencia en la especialización de venta de nuevos productos, cobertura y eficiencia, asimismo ellos se encargarán de distribuir el producto al consumidor final. Cabe resaltar que los cobros se realizarán luego de 3 meses de realizada la venta con todos nuestros clientes.

El esquema a usar para el producto es el que usualmente se aplica en el mercado para todo tipo de conservas y se puede apreciar en la figura 2.5 , la misma que presenta también los precios y márgenes a los que se venderá en cada eslabón de la cadena. Así, el precio sugerido al consumidor final es 4.50 nuevos soles. 
Figura 2.5

Políticas de comercialización

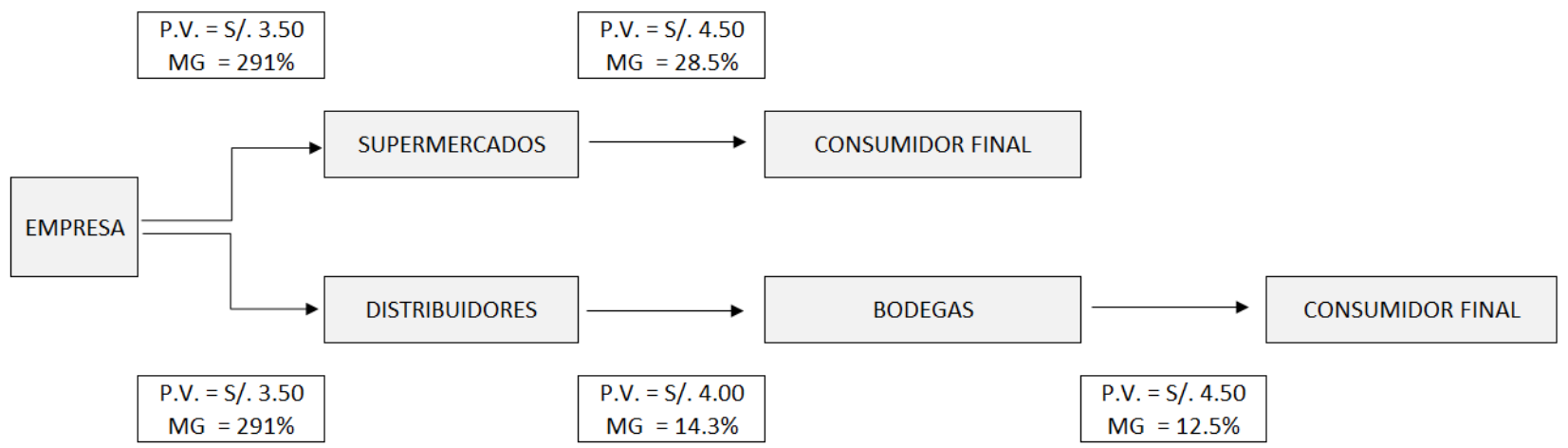

Elaboración Propia

Los canales por los cuales se llegará a los clientes son los supermercados, bodegas y tiendas por conveniencia, según el informe de Ipsos "Liderazgo en productos comestibles 2015" las personas pertenecientes a los NSE A/B prefieren comprar productos de consumo frecuente y bajo valor en supermercados, el 56.1\% del NSE A y el 45.3\% del NSE B muestran esta preferencia. Según el mismo informe las bodegas y tiendas por conveniencia representan el $41.5 \%$ de preferencia para el NSE A y el $47.1 \%$ para el NSE B.

El NSE C presenta una mayor preferencia por comprar en bodegas (41.1\%) seguido de supermercados $(39.7 \%)$

La distribución del producto terminado desde la planta hacia el mercado será mediante un espacio alquilado a una empresa tercera, el área de alquiler para el almacenaje es de $118 \mathrm{~m} 2$, cuya capacidad es de 99 paletas mensuales.

\subsubsection{Publicidad y promoción}

Dado que la publicidad en este sector es agresiva, se propone realizar actividades BTL; es decir, en el punto de venta por ser un producto que está en la etapa de inicio.

Algunas de las exhibiciones que se implementarán en el punto de venta en los supermercados son: jalavistas, muros, laterales, encartes, revestimientos de cabeceras y material publicitario. Además, se contará con una impulsadora que repartirá el material 
promocional y se realizaran degustaciones del producto en estudio para publicitarlo, finalmente se trabajará con merchandising para que el cliente conozca la marca en base a raspa y gana.

Para el canal tradicional, se tendrán afiches en donde se describirá el producto con imágenes y frases y se encontrará la página web y redes sociales para Practi-fruit (estrategia e-commerce), además, se realizará descuentos al canal y se darán bonificaciones tanto por sell in como por sell out. En ambos canales se trabajarán marcadores de precio llamativos.

Cabe resaltar, que lo que se quiere es posicionar un lugar en la mente del consumidor por ello como parte de la promoción del producto se harán convenios con otros productos complementarios para que puedan venderse juntos como oferta.
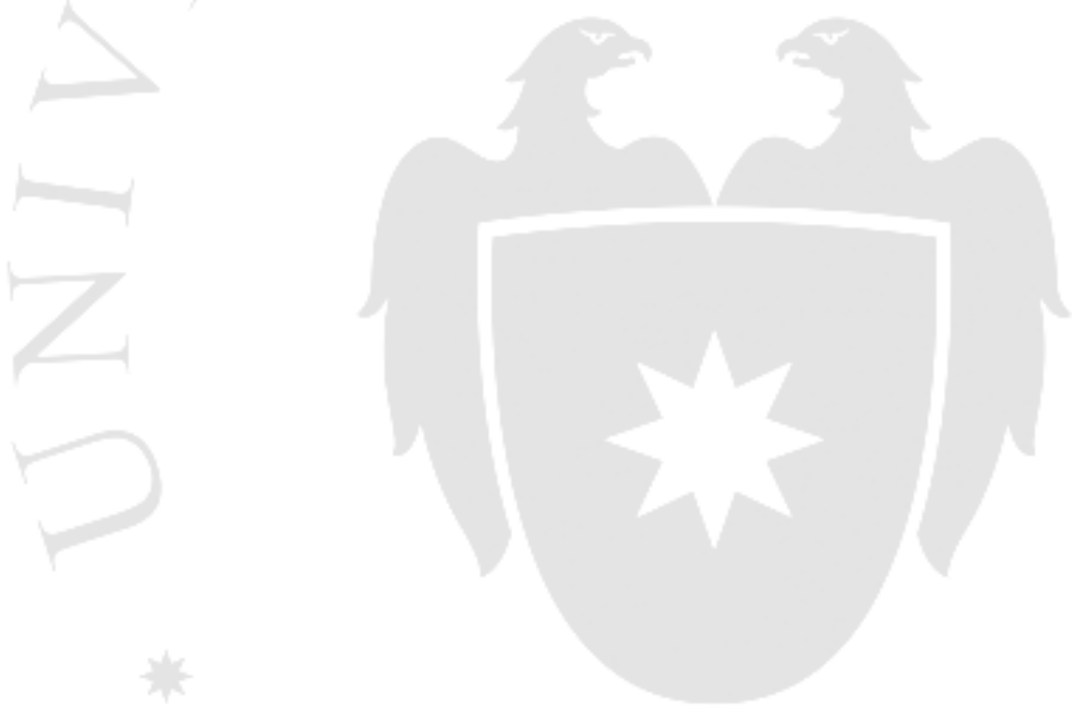
Figura 2.6

Actividades promocionales

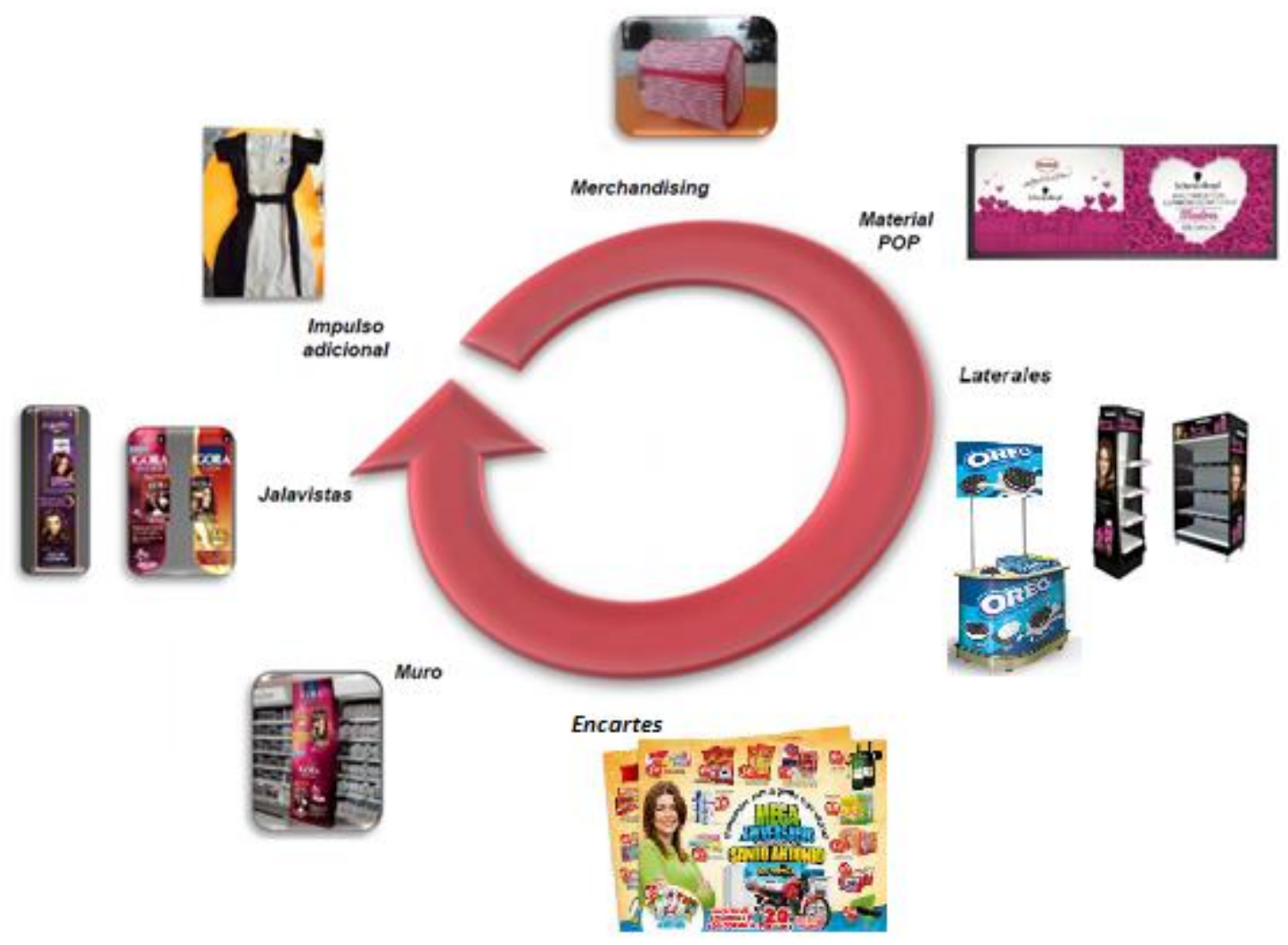

Elaboración propia

\subsubsection{Análisis de precios}

\subsubsection{Tendencia histórica de los precios}

Para analizar la tendencia histórica de precios utilizamos los precios de las conservas de duraznos que son las de mayor consumo en nuestro país. Sin embargo, estas conservas son vendidas en envases de metal en presentaciones de 822 gramos. 
A continuación, se presenta la tendencia historia de los precios.

Figura 2.7

Línea de tendencia histórica de precios de conservas de durazno

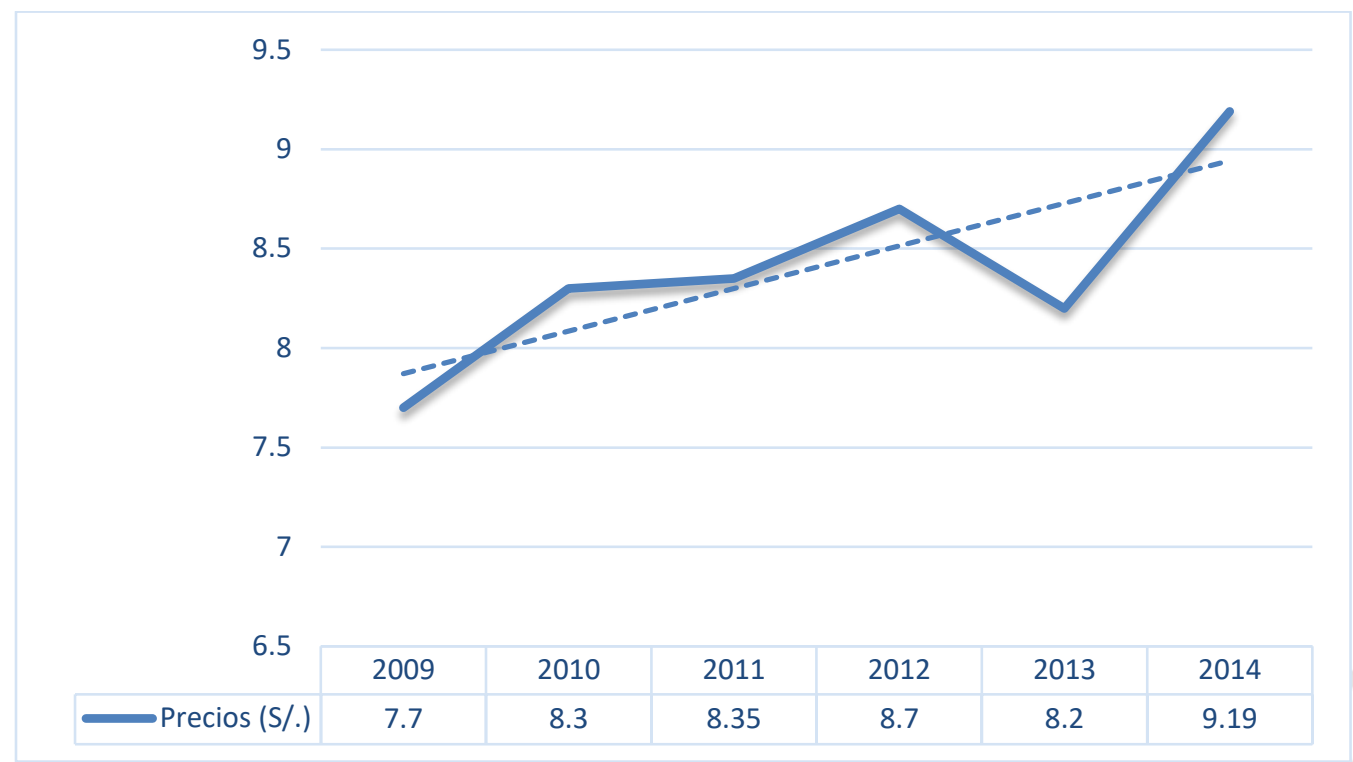

Fuente: Principales supermercados de Lima metropolitana (Metro, Plaza Vea, Wong), (2015)

Como se puede ver en el gráfico los precios de las conservas han ido en aumento a lo largo de los años y presentan una tendencia a seguir aumentando de precio.

\subsubsection{Precios actuales}

Se recopilaron los siguientes precios de conservas de fruta en base a visitas a supermercados de Lima Metropolitana. 
Tabla 2.10

Precios de conservas de fruta en supermercados 2015

\begin{tabular}{|l|c|c|c|}
\hline \multicolumn{1}{|c|}{ Tipo de conserva } & Marca & $\begin{array}{c}\text { Contenido } \\
\text { (gramos) }\end{array}$ & $\begin{array}{c}\text { Precio } \\
\text { (S/.) }\end{array}$ \\
\hline Mangos en tajadas & Valle Fértil & 450 & 8.99 \\
\hline Mangos en tajadas & Golden & 425 & 8.50 \\
\hline Duraznos en mitades & A-1 & 820 & 8.99 \\
\hline Duraznos en mitades & Aconcagua & 822 & 8.30 \\
\hline Duraznos en mitades & Arcor & 820 & 10.99 \\
\hline Pera en mitades & Compass & 820 & 8.30 \\
\hline Duraznos en mitades & Compass & 820 & 8.90 \\
\hline Pera en mitades & Del monte & 822 & 14.99 \\
\hline Duraznos en mitades & Dos Caballos & 820 & 8.50 \\
\hline Cocktail de frutas & Fanny & 820 & 8.70 \\
\hline Duraznos en mitades & Wong & 820 & 7.70 \\
\hline Pera en mitades & Wong & 820 & 7.50 \\
\hline Piña en rodajas & Compass & 560 & 5.99 \\
\hline
\end{tabular}

Elaboración Propia

\subsection{Análisis de Disponibilidad de los insumos principales}

\subsubsection{Características principales de la materia prima}

A continuación, se muestra las características principales de la materia prima que en este caso es el mango.

$$
\underline{\text { Mango }}^{15}
$$

(Manguifera Indica): Es una fruta con forma ovalada orbicular de color amarillo anaranjado y presenta una chapa rojiza a la madurez. Tiene un peso que varía entre los 500 a 800 gramos. Presenta poca fibrosidad y alto contenido de azúcares

Además de estas características posee propiedades que se detallan a continuación:

- $\quad$ Por su contenido de potasio tiene un efecto diurético.

- Un mango maduro aporta vitamina $\mathrm{C}$ y vitamina $\mathrm{A}$.

- $\quad$ Los mangos poseen fenoles que son anti-oxidantes poderosos.

- $\quad$ Es rico en hierro, magnesio y selenio.

\footnotetext{
${ }^{15}$ Fuente: Mincetur, Perfil del mercado y competitividad Exportadora de Mango www.mincetur.gob.pe/comercio/otros/penx/pdfs/Mango.pdf [Consulta: 26 de noviembre de 2015 ]
} 
- Ayuda a la buena digestión.

- $\quad$ Por su contenido de vitamina B es recomendable para el buen funcionamiento del sistema nervioso.

\subsubsection{Disponibilidad de la materia prima}

El mango para las conservas se encuentra disponible en los meses de noviembre a abril ya que estos son los meses de cosecha en nuestro país. Las principales provincias que producen mango se muestran en la siguiente tabla:

Tabla 2.11

Producción de mango

\begin{tabular}{|c|c|c|c|c|c|c|c|c|c|c|}
\hline \multicolumn{11}{|c|}{ Producción de mango en toneladas } \\
\hline Años & $\begin{array}{c}\text { TOTAL } \\
\text { NACIONAL }\end{array}$ & AMAZONAS & ANCASH & CAJAMARCA & ICA & LA LIBERTAD & LAMBAYEQUE & LIMA & PIURA & SAN MARTIN \\
\hline 2007 & 294,440 & 1,417 & 6,247 & 8,642 & 4,943 & 6,477 & 13,730 & 9,142 & 233,773 & 3,482 \\
\hline 2008 & 322,721 & 1,300 & 7,702 & 9,318 & 3,739 & 5,693 & 47,033 & 9,103 & 227,810 & 3,587 \\
\hline 2009 & 167,008 & 1,018 & 6,695 & 5,410 & 7,940 & 5,381 & 6,212 & 7,446 & 115,658 & 2,753 \\
\hline 2010 & 454,330 & 1,079 & 10,823 & 6,533 & 9,415 & 5,651 & 42,961 & 7,439 & 359,580 & 2,732 \\
\hline 2011 & 351,937 & 1,308 & 11,801 & 2,892 & 5,056 & 5,719 & 54,416 & 6,809 & 251,048 & 2,987 \\
\hline 2012 & 185,182 & 1,209 & 10,346 & 9,384 & 4,231 & 5,671 & 30,218 & 5,939 & 102,846 & 2,863 \\
\hline 2013 & 458,766 & 1,400 & 9,277 & 9,530 & 5,395 & 5,831 & 52,831 & 9,754 & 349,970 & 2,749 \\
\hline
\end{tabular}

Fuente: Minag, (2015)

Como se puede ver en la tabla 2.12 la mayor productora de mango es Piura que tiene una producción mayor a las 200,000 toneladas anuales de producción. Esta oferta de materia prima es suficiente para cubrir la capacidad de producción con la que cuenta la planta. Sin embargo, al ser una fruta estacional no se podrá utilizar la materia prima en los meses restantes del año y además no se podría importar materia prima de otros países ya que las fechas de cosecha de países cercanos es similar a la de nuestro país y por otra parte la calidad de la materia prima es diferente ya que existen variaciones en el sabor. Es por ello que se plantea la posibilidad de elaborar conservas de otras frutas en los meses en donde no se tenga cosecha de mango.

\subsubsection{Costos de la materia prima}

Para el cálculo del costo de la principal materia prima que es el mango se obtuvo la información histórica de precios en chacra para las principales provincias productoras, la información se muestra en la siguiente tabla: 
Tabla 2.12

Precio de mango en Chacra de las principales provincias productoras

\begin{tabular}{|c|c|c|c|c|c|}
\hline \multicolumn{5}{|c|}{ Precio en chacra(S/./Kg) } \\
\hline Años & Ancash & La Libertad & Lima & Piura & Tumbes \\
\hline 2000 & 0.84 & 0.49 & 0.87 & 0.56 & 0.44 \\
\hline 2001 & 0.84 & 0.45 & 0.52 & 0.38 & 0.41 \\
\hline 2002 & 0.90 & 0.47 & 0.64 & 0.47 & 0.50 \\
\hline 2003 & 0.79 & 0.50 & 0.50 & 0.48 & 0.38 \\
\hline 2004 & 0.82 & 0.47 & 0.55 & 0.63 & 0.39 \\
\hline 2005 & 0.79 & 0.49 & 0.55 & 0.48 & 0.33 \\
\hline 2006 & 0.80 & 0.51 & 0.74 & 0.62 & 0.50 \\
\hline 2007 & 0.81 & 0.62 & 0.83 & 0.52 & 0.69 \\
\hline 2008 & 0.82 & 0.65 & 0.77 & 0.40 & 0.78 \\
\hline 2009 & 0.88 & 0.99 & 0.93 & 0.84 & 0.76 \\
\hline 2010 & 0.84 & 0.74 & 0.76 & 0.37 & 0.80 \\
\hline 2011 & 0.92 & 0.74 & 0.86 & 0.42 & 0.61 \\
\hline 2012 & 0.92 & 0.94 & 0.90 & 1.02 & 0.74 \\
\hline 2013 & 1.00 & 0.55 & 0.71 & 0.23 & 0.85 \\
\hline
\end{tabular}

Fuente: Minag, (2015)

Por otro lado, se conoce que el precio del azúcar Blanca es de $2.2 \mathrm{~S} / . / \mathrm{Kg}$ en promedio, este precio se obtiene al comprar en sacos de $50 \mathrm{Kg}$. También está el ácido cítrico que tiene un costo de $3.6 \mathrm{~S} / . / \mathrm{kg}$ y los envases de polipropileno que tienen un costo unitario de S/.0.10. 


\section{CAPITULO III. LOCALIZACIÓN DE PLANTA}

\subsection{Identificación y análisis detallado de los factores de localización}

\section{a) Proximidad a la materia prima}

Para este proyecto es importante analizar la cercanía a la materia prima para establecer la ubicación de planta para ello se requiere un adecuado medio de transporte para disminuir el tiempo de recorrido entre la fuente de materia prima y la planta de producción, lo que contribuirá a reducir costos y se verá reflejado en el precio al público.

De acuerdo al último informe realizado por el INEI en el 2014, la superficie cultivada de mango en el Perú es de 27,120 hectáreas, de las cuales el 90\% abarca la producción de la principal variedad de mango para exportación debido a sus características naturales que le dan mayor resistencia al proceso hidrotérmico para descartar plagas, además de su buena apariencia y sabor. En consecuencia, el 10\% restante cuya comercialización es local será lo que nuestro proyecto abarcará, cabe resaltar, que este porcentaje sigue siendo suficiente para los niveles de producción del proyecto.

Cabe resaltar que la materia prima es una fruta perecedera, es decir, la vida útil luego de ser cortado no supera los 7 días. Este es un motivo más para ubicar la planta próxima a los sembríos de mango agregando que, de ubicarse en otro lado, se pagaría métodos de preservación lo cual aumentaría los costos. Por ello, para que el proyecto resulte más económico, es recomendable que la planta se encuentre próxima a la materia prima.

Las principales zonas productivas se encuentran en la costa norte por ser un fruto de clima tropical; en menor cantidad se encuentra en Ica. Los departamentos donde se concentra la mayor producción de mango son Piura, Lambayeque y Ancash.

\section{b) Cercanía al mercado}

Los mercados de consumo son lo más importante para cualquier empresa pues sin ellos, sería inútil cualquier esfuerzo que estas realicen; es por ello que es importante que una empresa sepa donde se localizan estos mercados de consumo para determinar no solamente la ubicación geográfica sino todo su sistema logístico empresarial. El mercado objetivo es la 
ciudad de Lima debido al centralismo que presenta el país hacia la capital; además, posee una prospectiva interesante debido a la coyuntura actual.

Aunque no es un factor que favorezca al proyecto debido a la larga distancia de la planta hacia el mercado, se resalta que se busca minimizar este efecto, por ello es que se intenta lograr una ubicación cerca a la panamericana cuyo tránsito es descongestionado y de fácil acceso.

\section{c) Disponibilidad de Mano de Obra}

La planta contará con personal especializado en sus funciones gracias a las capacitaciones que se darán al ingreso de cada empleado y a un rígido proceso de selección. Cabe resaltar que cada trabajador contará con sus beneficios regidos por ley y las que otorgan la empresa.

La mano de obra necesaria para la producción de este producto deberá ser con experiencia en el sector agroindustrial y en especial en el procesamiento de la fruta para tener un mejor control de los procesos.

El Perú es uno de los países que cuenta con mano de obra barata y uno de los que presenta más PEA desocupada ya sea porque está en busca de trabajo a pesar de tener experiencia y conocimientos o porque sea su primer trabajo, a estos se enfocará más el proyecto, aumentando así el porcentaje de PEA en el Perú.

\section{d) Disponibilidad y costos de terrenos}

Factores importantes para la localización de la planta debido a que los costos están incluidos en la inversión del proyecto; además, son necesarios para iniciar la construcción de la planta $\mathrm{y}$ oficinas administrativas por lo que, sin un terreno industrial adecuado en tamaño y ubicación, el proyecto no se podrá llevar a cabo. Se considera para el proyecto que cualquier zona del país a excepción de Lima tiene disponibilidad de terreno para el estudio ya que no está saturado de edificios y plantas industriales a diferencia de la capital. Es importante resaltar que los terrenos más caros están en la capital de cada ciudad a diferencia de sus provincias. En el caso del norte del país, los precios promedio de los terrenos industriales no superan a los de la capital del país, sin embargo, es importante considerar que supera al precio de sus provincias. 


\section{e) Abastecimiento de agua potable y energía eléctrica}

Se debe analizar igualmente la disponibilidad de servicios para poder localizar adecuadamente la planta, para este efecto se verificará la disponibilidad de energía eléctrica, agua potable y alcantarillado en cada una de las localidades. Es fundamental el agua potable ya que es parte del proceso productivo para el producto final y asimismo la energía eléctrica para el funcionamiento de la maquinaria en la planta. Todas las regiones cuentan con agua potable y energía eléctrica, por ello no hay ninguna restricción para la localización.

\section{f) Servicio de transporte y fletes}

La calidad del transporte es variable debido al estado de los camiones disponibles para el transporte del mango. Si bien las vías de acceso son importantes para cualquier empresa ya que se depende del traslado tanto del producto terminado como de la materia prima en forma segura, los servicios de transporte serán tercerizados con una empresa de transporte quien se encargará de hacer todo los trámites para el transporte y descarga; además los costos serán menores porque no se tendrá que invertir ni en mantenimiento ni en flota de camiones ni en personal de transporte; solo en personal de distribución, que es parte del equipo de la empresa, quienes se encargarán de cargar la mercadería en el camión (además de sus otras funciones).

\subsection{Identificación y descripción de las alternativas de localización}

De acuerdo a los factores evaluados en el subcapítulo anterior y considerando que, para la conservación del mango, este no debe durar más de 3 semanas desde su transporte hacia la planta, se concluye que el factor limitante es la cercanía a la materia prima; por ello, los departamentos a analizar en el proyecto serán: Piura, Lambayeque y Áncash.

\subsubsection{Proximidad a la materia prima}

Se requiere que la planta se encuentre cerca las mayores zonas productoras para que los insumos lleguen en perfectas condiciones a la planta y se tenga una buena disponibilidad de ellos. Como ya se indicó los departamentos donde se concentra la mayor producción de 
mango son Piura (75\%), Lambayeque (15\%) y Ancash $(10 \%)^{16}$ tal como se observa la Figura 3.1 .

Cabe resaltar que, las zonas donde más se refina caña de azúcar son también en la zona norte tales como La Libertad, Lambayeque y Áncash que en conjunto aportan 84.8\% de la producción nacional ${ }^{17}$ (ver Figura 3.2).

\section{Figura 3.1}

Principales zonas de cultivo de mangos en el Perú

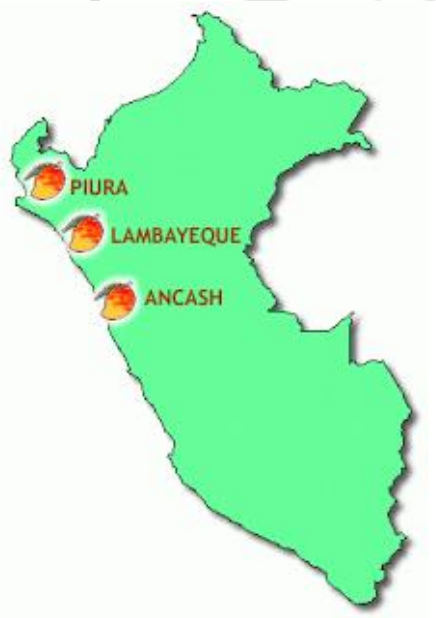

Fuente Google Images, (2015)

\section{Figura 3.2}

Principales zonas de refinería de azúcar en el Perú

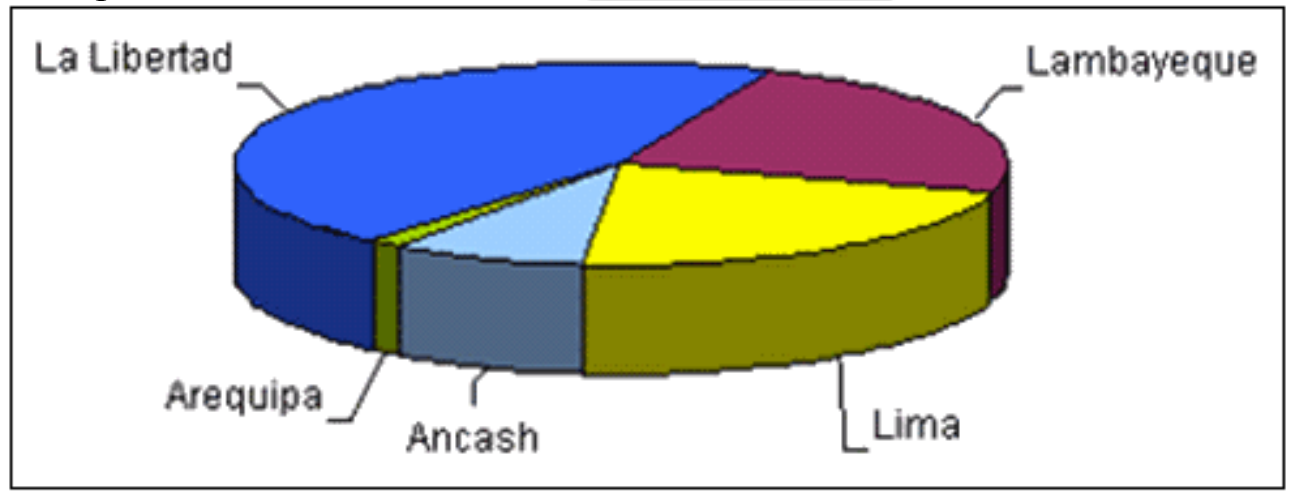

Fuente: Google Images, 2015

\footnotetext{
${ }^{16}$ Fuente: Artículo de RPP Noticias 20/02/2014 - 9:46 < http://www.rpp.com.pe/2014-02-20-produccionperuana-de-mangos-superara-las-140-000-toneladas-noticia_671272.html>

${ }^{17}$ Fuente: Informe técnica $\mathrm{N}^{\circ} 2$ - Febrero 2014 INEI < http://www.inei.gob.pe/media/MenuRecursivo/boletines/01-produccion-nacional-dic-2013.pdf>
} 
Dado que lo más importante es la materia prima, se puede concluir que Piura sería el departamento más adecuado ya que cuenta con el $75 \%$ de la producción de mango, le sigue Lambayeque y finalmente Ancash.

\subsubsection{Cercanía al Mercado}

Como ya se indicó Lima es el mercado al que se dirige este proyecto porque cuenta con mayor mercado potencial y poder adquisitivo. A continuación, se coloca la distancia aproximada en kilómetros entre el lugar más cercano donde se produce la materia prima en cantidades suficientes para el proyecto y el Mercado Objetivo: Lima.

Tabla 3.1

Distancia hacia las localidades en estudio

\begin{tabular}{|c|c|c|c|}
\cline { 2 - 4 } \multicolumn{1}{c|}{} & \multicolumn{3}{c|}{ Distancia (KM) } \\
\hline Lima & 982 & Lambayeque & Ancash \\
\hline
\end{tabular}

Fuente MTC, (2015)

La tabla 3.1 muestra que Ancash y Lambayeque tienen mayor proximidad al mercado en comparación con Piura. Asimismo, para llegar a Piura vía terrestre la duración es de aproximadamente 13 horas, a Lambayeque de 11 horas y a Ancash de 6 horas por lo que se concluye que Áncash es la mejor zona para el proyecto, seguido por Lambayeque y finalmente Piura.

\subsubsection{Disponibilidad de Mano de Obra}

La mano de obra adecuada con el tipo de características descritas se puede conseguir en departamentos en los cuales existe producción agroindustrial, ya que tienen empresas que emplean este tipo de personal. De acuerdo a las tablas 3.2 y 3.3, Piura cuenta con mayor población y su tasa de crecimiento poblacional se mantiene en $1.5 \%$ anualmente y con un $70 \%$ de la PEA de todo el departamento, esto indica un alto índice de mano de obra, así como Lambayeque que cuenta con el 70\% de la PEA y una tasa de crecimiento de $1.3 \%$ anual, finalmente quien tiene más PEA, pero no lleva mucha delantera es Áncash que a pesar del $75 \%$ de PEA tiene baja población y menor tasa de crecimiento. 
Tabla 3.2

Población de las localidades en estudio

\begin{tabular}{|l|c|}
\cline { 2 - 2 } \multicolumn{1}{l|}{} & Población \\
\hline Ancash & $1,063,459$ \\
\hline Piura & $1,676,315$ \\
\hline Lambayeque & $1,112,868$ \\
\hline
\end{tabular}

Fuente: INEI, (2015)

Tabla 3.3

PEA de las localidades en estudio

\begin{tabular}{|c|c|c|c|}
\cline { 2 - 4 } \multicolumn{1}{c|}{} & Piura & Áncash & Lambayeque \\
\hline PEA & 898.3 & 607.7 & 636.2 \\
\hline PEA ocupada & 867.9 & 584.4 & 616.3 \\
\hline PEA desocupada & 30.4 & 23.3 & 19.9 \\
\hline
\end{tabular}

Fuente: INEI, (2015)

Tabla 3.4

PEA según grupo ocupacional de las localidades en estudio

\begin{tabular}{|c|c|c|c|}
\cline { 2 - 4 } \multicolumn{2}{c|}{} & \multicolumn{2}{c|}{ PEA según grupo ocupacional (\%) } \\
\hline $\begin{array}{c}\text { Profesional, técnico, gerente, } \\
\text { administrador }\end{array}$ & 9.8 & 11.6 & 11 \\
\hline $\begin{array}{c}\text { Empleado de oficina } \\
\text { Vendedor }\end{array}$ & 4.8 & 4.7 & 5.4 \\
\hline Agricultor, ganadero, & 18.9 & 19.9 & 15.9 \\
\hline Artesano y operario & 29.3 & 24 & 34 \\
\hline Obrero jornalero & 8.4 & 9.7 & 10.1 \\
\hline Conductor & 5.8 & 4.5 & 4.9 \\
\hline Trabajador de servicios & 6.9 & 9 & 5.8 \\
\hline Trabajador del hogar & 13.7 & 14.4 & 11.3 \\
\hline & 2.3 & 2.4 & 1.4 \\
\hline
\end{tabular}

Fuente: MTPE, (2015)

Tabla 3.5

Tasa de Empleo de las localidades en estudio

\begin{tabular}{|c|c|c|c|}
\cline { 2 - 4 } \multicolumn{1}{c|}{} & \multicolumn{3}{c|}{ Tasa de Empleo (\%) } \\
\cline { 2 - 4 } \multicolumn{1}{c|}{ Desempleo } & Subempleo & $\begin{array}{c}\text { Empleo } \\
\text { Adecuado }\end{array}$ \\
\hline Piura & 3.4 & 54.1 & 42.5 \\
\hline Lambayeque & 3.1 & 55.6 & 41.3 \\
\hline Ancash & 3.8 & 36.8 & 40.6 \\
\hline
\end{tabular}

Fuente: INEI, (2015) 
De acuerdo a la tabla 3.4, Piura tiene casi el $6 \%$ de obreros jornaleros mientras que Lambayeque y Ancash no superan el 5\% en este sector; sin embargo, Lambayeque tiene el mayor porcentaje entre ejecutivos y gerentes (11.6\%) y Ancash el mayor porcentaje de empleados de oficina (5.4\%). Por otro lado, de acuerdo a la tabla 3.5, Ancash y Piura cuentan con las más altas tasas de desempleo de acuerdo a la información del INEI, lo que es una ventaja para aumentar los puestos de trabajo. Cabe resaltar que Piura es el departamento que tiene mayor demanda de mano de obra en el sector agroindustrial, por lo que en épocas de siembra y cosecha, esta escasea y se contrata personal de la sierra y selva frente a la ausencia de mano de obra costeña ${ }^{18}$. Sin embargo, dada la falta de mano de obra, se podrá contratar a personal con cualidades o experiencia similar en pelado y corte ya que el proyecto lo demanda así. Dada esta razón, este factor podría desfavorecer al proyecto, sin embargo, para estas plazas se tratará de atraer personal gracias a los buenos beneficios que la empresa ofrece.

Tabla 3.6

Nivel de Educación de las localidades en estudio

\begin{tabular}{|c|c|c|c|c|}
\cline { 2 - 5 } \multicolumn{1}{c|}{} & \multicolumn{4}{c|}{ Nivel de Educación de la PEA (\%) } \\
\cline { 2 - 5 } & $\begin{array}{c}\text { A lo más } \\
\text { primaria }\end{array}$ & $\begin{array}{c}\text { Educación } \\
\text { Secundaria }\end{array}$ & $\begin{array}{c}\text { Superior No } \\
\text { Universitaria }\end{array}$ & $\begin{array}{c}\text { Superior } \\
\text { Universitaria }\end{array}$ \\
\hline Piura & 34 & 40.2 & 14.9 & 10.9 \\
\hline Lambayeque & 31.4 & 42.7 & 13 & 13 \\
\hline Ancash & 31.8 & 40.3 & 12.7 & 15.2 \\
\hline
\end{tabular}

Fuente: INEI, (2015)

El nivel educativo de la población es un factor importante ya que la empresa requerirá de personal calificado que tenga buena capacidad de análisis e innovación. Aunque el personal que se necesita para las oficinas administrativas (27\%) es menor que el personal para planta $(73 \%)$, es una fuente importante contar con estudios superiores para la toma de decisiones (Ver acápite 6.2 para más detalle). Se analizó el nivel educativo por departamento y los resultados fueron que Ancash posee mejor nivel de educación universitaria con el $15.2 \%$ de su población para las áreas administrativas, pero Piura cuenta con el porcentaje mayor del sector técnico, cuyas personas se necesitarán para el proceso productivo.

${ }^{18}$ http://gestion.pe/impresa/ica-libertad-y-piura-mayor-demanda-mano-obra-agro-2085834 
En conclusión, Ancash es el mejor departamento que se ajusta a las condiciones sociales para el proyecto, seguido de Piura y finalmente, Lambayeque.

\subsubsection{Disponibilidad y costos de terrenos}

En cuanto al espacio de terrenos no urbanos, Ancash tiene mayor ventaja ya que cuenta con superficie disponible, aunque con bajas zonas industriales, seguidamente de Piura que también cuenta con terrenos disponibles y zonas industriales. Lambayeque no cuenta con variedad de terrenos a elección.

Tabla 3.7

Disponibilidad de terrenos de las localidades en estudio

\begin{tabular}{|c|c|c|}
\cline { 2 - 3 } \multicolumn{1}{c|}{} & $\begin{array}{c}\text { Densidad Poblacional } \\
\text { (hab/km2) }\end{array}$ & $\begin{array}{c}\text { Superficie total } \\
\text { (km2) }\end{array}$ \\
\hline Piura & 46.7 & 35,892 \\
\hline Lambayeque & 78.2 & 14,231 \\
\hline Ancash & 29.6 & 35,915 \\
\hline
\end{tabular}

Fuente: INEI, (2015)

En cuanto a los costos de los terrenos, el costo promedio de zonas industriales por metro cuadrado en Piura es de 100 US\$, el de Lambayeque es de 160 US\$ por metro cuadrado y finalmente el de Ancash es de 300 US\$ por metro cuadrado. ${ }^{19}$

Por lo que se concluye que Piura es la mejor opción para este factor debido a su precio y la superficie disponible, le sigue Lambayeque por su bajo costo de terreno en zona industrial y finalmente Áncash.

\subsubsection{Abastecimiento de agua potable y energía eléctrica}

\subsubsection{Abastecimiento de agua}

La cobertura de agua potable por región es variable. Para el proyecto en estudio se requerirá como insumo importante. Algunas empresas productoras y distribuidoras para cada localidad se mencionan en la tabla 3.8 .

\footnotetext{
${ }^{19}$ Los costos son un promedio de costos de distintas páginas web buscadoras de terrenos (mitula, adondevivir, olx, doomos) y periódicos.
} 
Tabla 3.8

Empresas productoras y distribuidoras de agua potable por localidad

\begin{tabular}{|c|c|}
\hline Empresa & Departamento \\
\hline Piura & EPS Grau S.A. \\
\hline Áncash & Seda Chimbote S.A. \\
\hline Lambayeque & Epsel S.A. \\
\hline
\end{tabular}

Fuente: INEI, (2015)

Tabla 3.9

Tarifa de la Categoría Industrial para agua potable y alcantarillado por empresa

\begin{tabular}{|l|c|c|}
\cline { 2 - 3 } \multicolumn{1}{c|}{} & $\begin{array}{c}\text { Tarifa para agua potable } \\
\mathbf{( S / . / m 3 )}\end{array}$ & $\begin{array}{c}\text { Tarifa para alcantarillado } \\
\mathbf{( S / . / m 3 )}\end{array}$ \\
\hline EPSEL S.A. & 7.052 & 3.116 \\
\hline EPS SEDACHIMBOTE S.A. & 3.120 & 1.996 \\
\hline EPS GRAU S.A. & 5.186 & 1.922 \\
\hline
\end{tabular}

Fuente: SUNASS, (2015)

También se ha investigado la calidad del agua y a continuación se muestran los datos en la Tabla 3.10. Comparando con los límites máximos permisibles del agua potable, todos cumplen (pH: 6.5-8.5, Dureza: máximo $500 \mathrm{mg} / \mathrm{lt}$ ); sin embargo, es importante tener en cuenta que la temperatura debe estar a condiciones atmosféricas $25^{\circ} \mathrm{C}$, en este sentido, Piura cumple con esta característica.

Tabla 3.10

Parámetros de calidad del agua por departamento

\begin{tabular}{|c|c|c|c|c|c|}
\hline \multirow{2}{*}{ Empresa } & \multirow{2}{*}{$\mathbf{p H}$} & \multicolumn{2}{|c|}{ Temperatura $\left({ }^{\circ} \mathbf{C}\right)$} & \multicolumn{2}{c|}{ Dureza $(\mathbf{m g} / \mathbf{l t})$} \\
\cline { 3 - 6 } & & Mínimo & Máximo & Mínimo & Máximo \\
\hline Piura & $7-8.5$ & 15 & 27 & 50 & 100 \\
\hline Áncash & $7.22-7.93$ & 16.9 & 22.9 & 100 & 500 \\
\hline Lambayeque & $8.36-8.43$ & 15 & 24 & 69.59 & 76.77 \\
\hline
\end{tabular}

Fuente: Ministerio de Vivienda, Construcción y Saneamiento, (2015)

De acuerdo a las tarifas por localidad, EPS GRAU S.A. de Piura es la que tiene costo promedio de las 3 empresas para el cálculo de agua potable y bajo costo de alcantarillado por m3, le siguen EPS SEDACHIMBOTE S.A. de Áncash quien tiene bajo costo de agua potable y finalmente EPSEL S.A. de Lambayeque. 


\subsubsection{Energía eléctrica}

De los 3 departamentos que se están analizando, Piura y Áncash son las que tienen mayor abastecimiento continuo de electricidad.

Tabla 3.11

Energía Eléctrica en las localidades de estudio

\begin{tabular}{|c|c|c|c|c|c|c|}
\hline & \multicolumn{2}{|c|}{ Producción GW.h } & \multirow{2}{*}{$\begin{array}{l}\mathbf{N}^{\circ} \text { Clientes } \\
\text { Industriales }\end{array}$} & \multirow{2}{*}{$\begin{array}{c}\text { Potencia } \\
\text { Efectiva } \\
\text { MW }\end{array}$} & \multirow{2}{*}{$\begin{array}{c}\text { Facturación } \\
\text { Industrial } \\
\text { (miles US \$) }\end{array}$} & \multirow{2}{*}{$\begin{array}{c}\text { Tarifa } \\
\text { (ctm US\$/ } \\
\text { KW.h) }\end{array}$} \\
\hline & Hidráulica & Térmica & & & & \\
\hline Piura & 193.18 & 711.47 & 2,564 & 238 & 25,682 & 6.65 \\
\hline Lambayeque & & 23.72 & 1,474 & 18 & 8,963 & 7.53 \\
\hline ncash & $1,589.40$ & 10.33 & 1,988 & 337 & 58,844 & 5.31 \\
\hline
\end{tabular}

Fuente: OSINERGMIN, (2015)

Figura 3.3

Tarifario Eléctrico del departamento de Piura

\begin{tabular}{|c|c|c|c|}
\hline & MEDIA TENSIÓN & UNIDAD & $\begin{array}{l}\text { TARIFA } \\
\text { Sin IGV }\end{array}$ \\
\hline \multirow[t]{8}{*}{ TARIFA MT2: } & $\begin{array}{l}\text { TARIFA CON DOBLE MEDICIÓN DE ENERGÍA ACTIVA Y } \\
\text { CONTRATACIÓN O MEDICIÓN DE DOS POTENCIAS 2E2P }\end{array}$ & & \\
\hline & Cargo Fijo Mensual & S/./mes & 6.25 \\
\hline & Cargo por Energía Activa en Punta & $\mathrm{ctm} . \mathrm{S} / . / \mathrm{kW} \cdot \mathrm{h}$ & 18.40 \\
\hline & Cargo por Energía Activa Fuera de Punta & $\mathrm{ctm} . \mathrm{S} / . / \mathrm{kW} \cdot \mathrm{h}$ & 15.28 \\
\hline & Cargo por Potencia Activa de Generación en HP & $\mathrm{S} / . / \mathrm{kW}$-mes & 32.58 \\
\hline & Cargo por Potencia Activa de Distribución en HP & $\mathrm{S} / . / \mathrm{kW}-\mathrm{mes}$ & 10.77 \\
\hline & Cargo por Exceso de Potencia Activa de Distribución en HFP & $\mathrm{S} / . / \mathrm{kW}-\mathrm{mes}$ & 14.43 \\
\hline & Cargo por Energía Reactiva que exceda el $30 \%$ del total de la Energía Activa & $\mathrm{ctm} . \mathrm{S} / . / \mathrm{kVar} . \mathrm{h}$ & 3.59 \\
\hline
\end{tabular}

Fuente: OSINERGMIN, (2015)

Figura 3.4

Tarifario Eléctrico del departamento de Lambayeque

\begin{tabular}{|c|c|c|c|}
\hline & MEDIA TENSIÓN & UNIDAD & $\begin{array}{l}\text { TARIFA } \\
\text { Sin IGV }\end{array}$ \\
\hline \multirow[t]{8}{*}{ TARIFA MT2: } & $\begin{array}{l}\text { TARIFA CON DOBLE MEDICIÓN DE ENERGÍA ACTIVA Y } \\
\text { CONTRATACIÓN O MEDICIÓN DE DOS POTENCIAS 2E2P }\end{array}$ & & \\
\hline & Cargo Fijo Mensual & $\mathrm{S} / . / \mathrm{mes}$ & 6.25 \\
\hline & Cargo por Energía Activa en Punta & ctm. S/./kW.h & 18.64 \\
\hline & Cargo por Energía Activa Fuera de Punta & $\mathrm{ctm} . \mathrm{S} / . / \mathrm{kW} . \mathrm{h}$ & 15.62 \\
\hline & Cargo por Potencia Activa de Generación en HP & $\mathrm{S} / . / \mathrm{kW}-\mathrm{mes}$ & 32.80 \\
\hline & Cargo por Potencia Activa de Distribución en HP & $\mathrm{S} / . / \mathrm{kW}-\mathrm{mes}$ & 12.13 \\
\hline & Cargo por Exceso de Potencia Activa de Distribución en HFP & $\mathrm{S} / . / \mathrm{kW}-\mathrm{mes}$ & 12.36 \\
\hline & Cargo por Energía Reactiva que exceda el 30\% del total de la Energía Activa & $\mathrm{ctm} . \mathrm{S} / . / \mathrm{kVar} \cdot \mathrm{h}$ & 3.59 \\
\hline
\end{tabular}

Fuente: OSINERGMIN, (2015) 
Figura 3.5

Tarifario Eléctrico del departamento de Áncash

\begin{tabular}{|c|c|c|c|}
\hline & MEDIA TENSIÓN & UNIDAD & $\begin{array}{l}\text { TARIFA } \\
\text { Sin IGV }\end{array}$ \\
\hline \multirow[t]{8}{*}{ TARIFA MT2: } & $\begin{array}{l}\text { TARIFA CON DOBLE MEDICIÓN DE ENERGÍA ACTIVA Y } \\
\text { CONTRATACIÓN O MEDICIÓN DE DOS POTENCIAS 2E2P }\end{array}$ & & \\
\hline & Cargo Fijo Mensual & S/./mes & 6.25 \\
\hline & Cargo por Energía Activa en Punta & $\mathrm{ctm} . \mathrm{S} / . / \mathrm{kW} . \mathrm{h}$ & 17.55 \\
\hline & Cargo por Energía Activa Fuera de Punta & $\mathrm{ctm} . \mathrm{S} / . / \mathrm{kW} . \mathrm{h}$ & 14.62 \\
\hline & Cargo por Potencia Activa de Generación en HP & $\mathrm{S} / . / \mathrm{kW}-\mathrm{mes}$ & 32.52 \\
\hline & Cargo por Potencia Activa de Distribución en HP & $\mathrm{S} / . / \mathrm{kW}-\mathrm{mes}$ & 11.07 \\
\hline & Cargo por Exceso de Potencia Activa de Distribución en HFP & $\mathrm{S} / . / \mathrm{kW}-\mathrm{mes}$ & 12.37 \\
\hline & Cargo por Energía Reactiva que exceda el $30 \%$ del total de la Energía Activa & $\mathrm{ctm} . \mathrm{S} / . / \mathrm{kVar} \cdot \mathrm{h}$ & 3.59 \\
\hline
\end{tabular}

Fuente: OSINERGMIN, (2015)

La utilización de la energía eléctrica es vital para el funcionamiento de las máquinas principalmente, por ello es necesario saber que tan disponible se encuentra y los costos que implica. La tabla 3.11 muestra a Áncash como el departamento con mayor cantidad de energía eléctrica, la potencia efectiva es mayor y la tarifa es más baja: además de acuerdo al tarifario eléctrico el cargo total es menor (S/. 62.57) que las demás localidades, le sigue Piura (cargo total $=\mathrm{S} /$ : 64.40) que, aunque no produce la misma energía eléctrica mediante centrales hidroeléctricas como los demás departamentos, tiene más clientes industriales y un costo promedio de tarifa, finalmente Lambayeque (cargo total=S/. 63.92).

\subsubsection{Servicio de transporte y fletes}

A continuación, en la tabla 3.12 se muestran las distancias a recorrer entre los departamentos escogidos. Esto para saber la distancia que recorrerá la materia prima en caso la planta se ubicara en cada uno de estos 3 departamentos; es decir, si, por ejemplo, el mango se obtuviera de Lambayeque y la planta se ubicara en Áncash, entonces la distancia a recorrer sería 517 $\mathrm{km}$ lo que significaría un viaje de aproximadamente 12 horas a una velocidad promedio.

Tabla 3.12

Distancia a recorrer entre departamentos

\begin{tabular}{|c|c|c|c|}
\hline Distancia (KM) & Piura & Lambayeque & Áncash \\
\hline Piura & - & 208 & 720 \\
\hline Lambayeque & 208 & - & 517 \\
\hline Áncash & 720 & 517 & - \\
\hline
\end{tabular}

Fuente: MTC, (2015)

Si bien los viajes no sobrepasan las 24 horas, se deberá tener en cuenta el costo de transporte y los fletes al momento de tomar la decisión, ya que incurrirá en lo que se pague al transportista. 
El transporte en la ciudad de Ancash es limitado; mientras que en Piura y Lambayeque se puede aprovechar la cantidad de empresas registradas para transportar carga, entre sus clases: Camiones, Remolcadores, Remolques y Semi-remolques. Además, se puede observar en la siguiente tabla que para llegar a Piura vía terrestre hay más peajes concesionados que Ancash, en la que su tarifa varía entre 4 y 8 soles para vehículos pesados diferenciados. ${ }^{20}$ Tanto el acceso a Piura, a Lambayeque como a Ancash se realiza vía terrestre por la Panamericana norte.

Tabla 3.13

Servicio de transportes de las localidades en estudio

\begin{tabular}{|c|c|c|c|c|c|}
\cline { 2 - 6 } \multicolumn{1}{c|}{} & $\begin{array}{c}\mathbf{N}^{\circ} \text { Empresas de } \\
\text { transporte de } \\
\text { Carga }\end{array}$ & $\begin{array}{c}\text { Longitud de } \\
\text { la red vial } \\
(\mathbf{k m})\end{array}$ & $\begin{array}{c}\mathbf{N}^{\circ} \\
\text { Estaciones } \\
\text { de Peaje }\end{array}$ & $\begin{array}{c}\mathbf{N}^{\circ} \text { Estaciones } \\
\text { de Pesaje }\end{array}$ & $\begin{array}{c}\text { Longitud } \\
\text { Pavimentada } \\
\text { Nacional }\end{array}$ \\
\hline Piura & 7,365 & $8,459.9$ & 10 & 7 & 977.8 \\
\hline Lambayeque & 7,894 & $3,190.0$ & 9 & 5 & 445.4 \\
\hline Ancash & 917 & $10,837.0$ & 5 & 2 & 932.4 \\
\hline
\end{tabular}

Fuente: MTC, (2015)

Por ello, luego de analizar la tabla 3.13, se llega a la conclusión que Piura es la mejor opción para este factor debido a que tiene más carreteras pavimentadas lo que sirve fácilmente para la circulación de los camiones, le siguen Áncash por su mayor longitud vial y menos peajes; y finalmente, Lambayeque

\subsection{Evaluación y selección de localización}

\subsubsection{Evaluación y selección de la macro localización}

Ahora se analizará la zona de influencia del proyecto y a partir de esta selección se procederá a realizar una macro localización. Por lo tanto, luego de desarrollado el análisis de los factores, se evaluará qué departamento será el más adecuado para ubicar la planta de producción.

Para ello se empleará el Ranking de factores, que es una herramienta que permitirá determinar la localidad más apropiada para el proyecto. Cada factor fue codificado de acuerdo al siguiente esquema:

\footnotetext{
${ }^{20}$ Fuente: OSITRAN
} 

A. Proximidad de la materia prima
B. Cercanía al mercado
C. Disponibilidad de la mano de obra
D. Disponibilidad de energía eléctrica
E. Disponibilidad de agua potable
F. Disponibilidad y costos de terrenos
G. Servicio de transporte y fletes

\section{$\underline{\text { Matriz de enfrentamiento }}$}

Se ha considerado primordial el factor Proximidad a la materia prima, segundo Disponibilidad de agua potable, tercero Disponibilidad de energía eléctrica, cuarto Disponibilidad y costos de terrenos, quinto Disponibilidad de mano de obra y finalmente, con igual puntaje, Cercanía al mercado y Servicio de transporte y fletes.

Tabla 3.14

Matriz de enfrentamiento

\begin{tabular}{|c|c|c|c|c|c|c|c|c|c|}
\cline { 2 - 11 } & A & B & C & D & E & F & G & Puntaje & Ponderación \\
\hline A & & 1 & 1 & 1 & 1 & 1 & 1 & 6 & $27 \%$ \\
\hline B & 0 & & 0 & 0 & 0 & 0 & 1 & 1 & $5 \%$ \\
\hline C & 0 & 1 & & 0 & 0 & 0 & 1 & 2 & $9 \%$ \\
\hline D & 0 & 1 & 1 & & 0 & 1 & 1 & 4 & $18 \%$ \\
\hline E & 0 & 1 & 1 & 1 & & 1 & 1 & 5 & $23 \%$ \\
\hline F & 0 & 1 & 1 & 0 & 0 & & 1 & 3 & $14 \%$ \\
\hline G & 0 & 1 & 0 & 0 & 0 & 0 & & 1 & $5 \%$ \\
\hline
\end{tabular}

Elaboración propia

La escala a tomar en cuenta para la calificación de las localidades es la siguiente.

Tabla 3.15

Escala de Calificación

\begin{tabular}{|c|c|}
\hline \multicolumn{2}{|c|}{ ESCALA DE CALIFICACIÓN } \\
\hline $\mathbf{2}$ & DEFICIENTE \\
\hline $\mathbf{4}$ & REGULAR \\
\hline $\mathbf{6}$ & BUENO \\
\hline
\end{tabular}

Elaboración propia 
A continuación, se presenta la tabla de evaluación de Macro localización.

Tabla 3.16

Evaluación de Macro localización

\begin{tabular}{|c|c|c|c|c|c|c|}
\hline \multirow[b]{2}{*}{ Ponderación } & \multicolumn{2}{|c|}{ PIURA } & \multicolumn{2}{|c|}{ LAMBAYEQUE } & \multicolumn{2}{|c|}{ ANCASH } \\
\hline & Calificación & Puntaje & Calificación & Puntaje & Calificación & Puntaje \\
\hline $27 \%$ & 6 & 1.64 & 4 & 1.09 & 2 & 0.55 \\
\hline $5 \%$ & 2 & 0.09 & 4 & 0.18 & 6 & 0.27 \\
\hline $9 \%$ & 4 & 0.36 & 2 & 0.18 & 6 & 0.55 \\
\hline $18 \%$ & 4 & 0.73 & 2 & 0.36 & 6 & 1.09 \\
\hline $23 \%$ & 6 & 1.36 & 2 & 0.45 & 4 & 0.91 \\
\hline $14 \%$ & 6 & 0.82 & 2 & 0.27 & 4 & 0.55 \\
\hline $5 \%$ & 6 & 0.27 & 4 & 0.18 & 2 & 0.09 \\
\hline & & 5.27 & & 2.73 & & 4.00 \\
\hline
\end{tabular}

Elaboración propia

En conclusión, de acuerdo a la calificación final de cada alternativa, se escoge Piura ya que cumple con las condiciones adecuadas para la ubicación de la planta.

Figura 3.6

Mapa de Piura

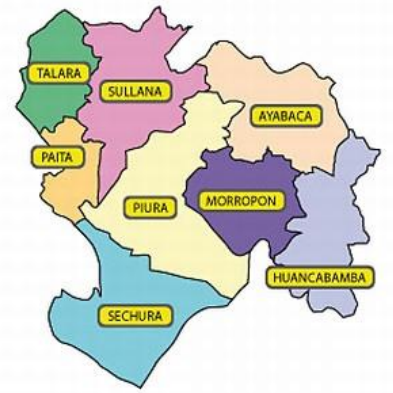

Fuente: Google Images, (2015)

\subsubsection{Evaluación y selección de la micro localización}

Una vez definido el departamento, se realizará un análisis más exhaustivo dentro de esta locación para determinar el lugar preciso de la planta considerando a Piura y Sullana las provincias más adecuadas de esta región, esto debido a que Talara y Paita se dedica más a actividades pesqueras y petroleras y, en la sierra de Piura (Morropón, Ayabaca y Huancabamba) hay menor desarrollo de actividad industrial, donde se dedican más a la 
ganadería y minería y donde la agricultura es para consumo local, no hay comercio ni servicios. A continuación, la siguiente Figura explica detalladamente lo que se pretendió.

Figura 3.7

Dinámica de las provincias de Piura

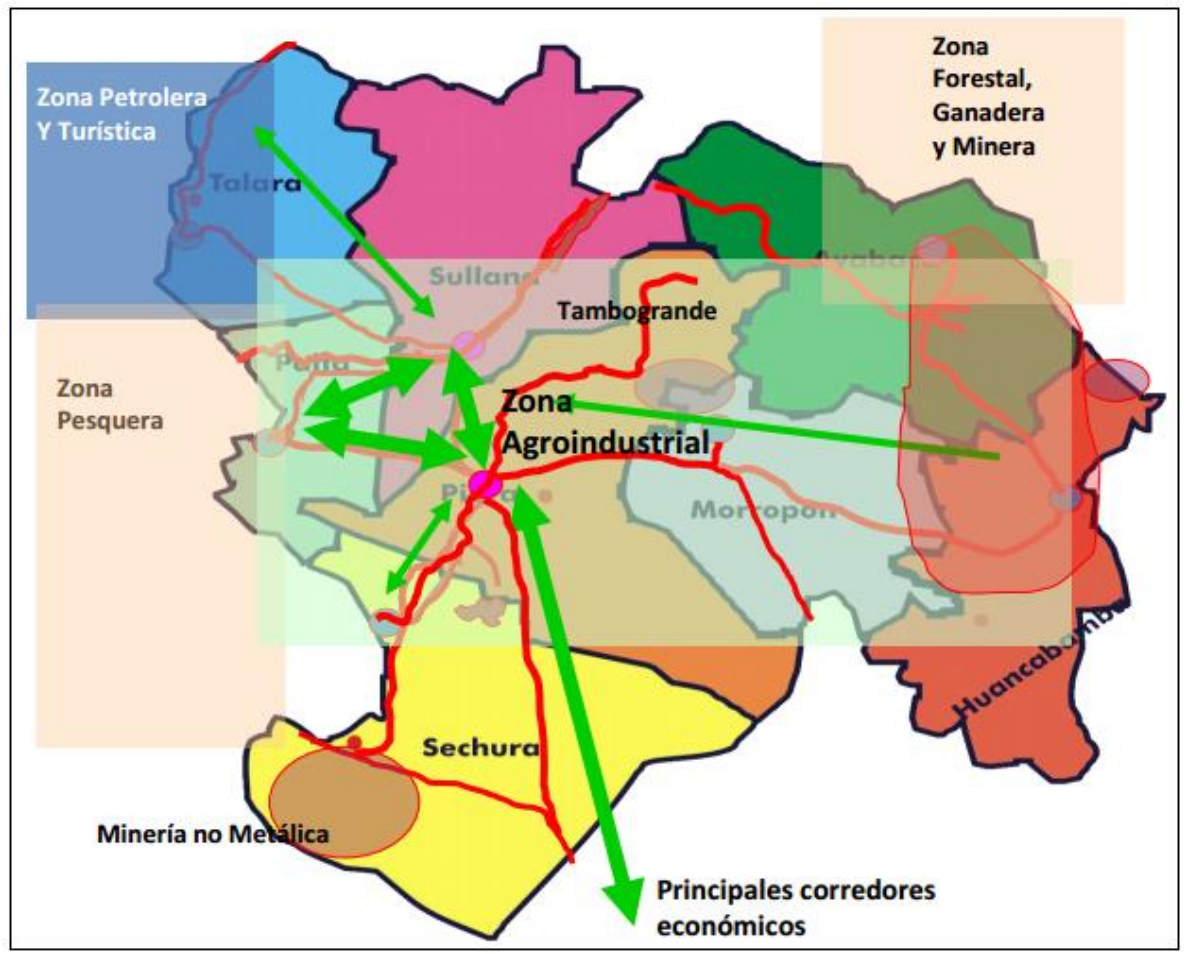

Fuente: MEF, (2015)

En consecuencia, Piura y Sullana serán evaluadas mediante los siguientes factores:

A continuación se presentan los siguientes datos:

$\checkmark$ En cuanto a los costos de los terrenos, el costo promedio de zonas industriales por metro cuadrado en Piura es de 153 US\$ y el de Sullana cuesta 207 US\$ por metro cuadrado ${ }^{21}$.

$\checkmark$ Los precios para el agua potable y alcantarillado de ambas provincias se presentan en la siguiente Tabla.

${ }^{21}$ Los costos son un promedio de costos de distintas páginas web buscadoras de terrenos (mitula, adondevivir, olx, doomos) y periódicos. 
Tabla 3.17

Tarifas de agua potable y alcantarillado por provincia

\begin{tabular}{|c|c|c|}
\cline { 2 - 3 } \multicolumn{1}{c|}{} & $\begin{array}{c}\text { Tarifa para agua } \\
\text { potable (S/./m3) }\end{array}$ & $\begin{array}{c}\text { Tarifa para } \\
\text { alcantarillado } \\
\text { (S///m3) }\end{array}$ \\
\hline Piura & 5.680 & 1.823 \\
\hline Sullana & 5.249 & 2.365 \\
\hline
\end{tabular}

Fuente: SUNASS, (2015)

$\checkmark$ El tarifario eléctrico tanto de Piura como de Sullana es el que se presenta a continuación:

Figura 3.8

Tarifario Eléctrico de las provincias de Piura y Sullana

\begin{tabular}{|c|c|c|c|}
\hline & MEDIA TENSIÓN & UNIDAD & $\begin{array}{l}\text { TARIFA } \\
\text { Sin IGV }\end{array}$ \\
\hline \multirow[t]{8}{*}{ TARIFA MT2: } & $\begin{array}{l}\text { TARIFA CON DOBLE MEDICIÓN DE ENERGÍA ACTIVA Y } \\
\text { CONTRATACIÓN O MEDICIÓN DE DOS POTENCIAS 2E2P }\end{array}$ & & \\
\hline & Cargo Fijo Mensual & S/./mes & 6.25 \\
\hline & Cargo por Energía Activa en Punta & $\mathrm{ctm}, \mathrm{S} / . / \mathrm{kW} \cdot \mathrm{h}$ & 18.40 \\
\hline & Cargo por Energía Activa Fuera de Punta & $\mathrm{ctm} . \mathrm{S} / \mathrm{.} / \mathrm{kW} \cdot \mathrm{h}$ & 15.28 \\
\hline & Cargo por Potencia Activa de Generación en HP & $\mathrm{S} / . / \mathrm{kW}$-mes & 33.19 \\
\hline & Cargo por Potencia Activa de Distribución en HP & $\mathrm{S} / . / \mathrm{kW}-\mathrm{mes}$ & 10.77 \\
\hline & Cargo por Exceso de Potencia Activa de Distribución en HFP & $\mathrm{S} / . / \mathrm{kW}-\mathrm{mes}$ & 14.43 \\
\hline & Cargo por Energía Reactiva que exceda el $30 \%$ del total de la Energía Activa & $\mathrm{ctm} . \mathrm{S} / / \mathrm{kV}$ ar.h & 3.59 \\
\hline
\end{tabular}

Fuente: OSINERGMIN, (2015)

Los datos de mano de obra se obtienen a partir de la planilla (Capítulo 7) y materia prima (Capítulo 7).

En cuanto al costo del servicio logístico integral, ya que este se terceriza se considera que en Piura este costo es 3,200 PEN y en Sullana 3,800 PEN.

Una vez que la región Piura prevalece como la opción más adecuada e interesante para instalar la planta procesadora de conserva de mango en almíbar, se procederá a analizar la Micro localización del proyecto con el método Brown \& Gibson.

Los factores objetivos a evaluar serán:
A. Costo de mano de obra
B. Costo de materia prima
C. Costo de servicios (energía eléctrica, agua potable y terreno)
D. Costo de Servicio Logístico Integral (SLI) 
Los factores subjetivos a evaluar serán:
E. Vías de acceso
F. Impacto ambiental
G. Competencia

Tabla 3.18

Costos anuales de los factores objetivos

\begin{tabular}{|c|c|c|c|c|c|c|}
\cline { 2 - 8 } \multicolumn{1}{c|}{} & $\begin{array}{c}\text { Mano de } \\
\text { Obra }\end{array}$ & $\begin{array}{c}\text { Materia } \\
\text { Prima }\end{array}$ & SLI & Servicios & Total & Recíproco \\
\hline Piura & 113,447 & 262,721 & 195,000 & 254,672 & 825,840 & 0.0000012109 \\
\hline Sullana & 113,447 & 262,721 & 231,000 & 286,752 & 893,920 & 0.0000011187 \\
\hline
\end{tabular}

\begin{tabular}{|c|c|}
\hline FO_Piura & 0.5198 \\
\hline FO_Sullana & 0.4802 \\
\hline
\end{tabular}

Elaboración propia

Tabla 3.19

Matriz de evaluación de factores subjetivos

\begin{tabular}{|c|c|c|c|c|c|}
\hline Factor & Vías de acceso & $\begin{array}{c}\text { Impacto } \\
\text { ambiental }\end{array}$ & Competencia & Total & Índice \\
\hline Vías de acceso & & 1 & 1 & 2 & 0.50 \\
\hline Impacto ambiental & 0 & 1 & 1 & 1 & 0.25 \\
\hline Competencia & 0 & 1 & 1 & 0.25 \\
\cline { 2 - 6 }
\end{tabular}

Elaboración propia

La escala a tomar en cuenta para la calificación de los factores subjetivos es la siguiente.

Tabla 3.20

Escala de Calificación

\begin{tabular}{|c|c|}
\hline \multicolumn{2}{|c|}{$\begin{array}{l}\text { ESCALA DE } \\
\text { CALIFICACIÓN }\end{array}$} \\
\hline 4 & REGULAR \\
\hline 6 & BUENO \\
\hline
\end{tabular}

Elaboración propia 
Tabla 3.21

Puntuación de los factores subjetivos

\begin{tabular}{|c|c|c|}
\multicolumn{1}{c|}{} & \multicolumn{2}{c|}{ Vías de Acceso } \\
\hline Calificación & R \\
\hline Sullana & 6 & 0.6000 \\
\hline
\end{tabular}

\begin{tabular}{|c|c|c|}
\multicolumn{1}{c|}{} & \multicolumn{2}{c|}{ Impacto Ambiental } \\
\hline Calificación & R \\
\hline Piura & 4 & 0.5000 \\
\hline Sullana & 4 & 0.5000 \\
\hline
\end{tabular}

\begin{tabular}{|c|c|c|}
\multicolumn{1}{c|}{} & \multicolumn{2}{c|}{ Competencia } \\
\hline Piura & Calificación & R \\
\hline Sullana & 4 & 0.4000 \\
\hline
\end{tabular}

\begin{tabular}{|c|c|c|c|}
\hline Factor & Piura & Sullana & Índice \\
\hline Vías de acceso & 0.6000 & 0.4000 & 0.5000 \\
\hline Impacto ambiental & 0.5000 & 0.5000 & 0.2500 \\
\hline Competencia & 0.4000 & 0.6000 & 0.2500 \\
\hline
\end{tabular}

\begin{tabular}{c|c|}
\hline FS_Piura & 0.5250 \\
\hline FS_Sullana & 0.4750 \\
\hline
\end{tabular}

Elaboración propia

La importancia relativa que existe entre los factores objetivos y subjetivos de localización, hace necesario asignarle una ponderación $\mathrm{K}$ a uno de los factores y 1-K al otro, de tal manera que se exprese también entre ellos la importancia relativa. Se considera que los factores objetivos son tres veces más importantes que los subjetivos, por ello se tiene que $\mathrm{K}=3$ (1$\mathrm{K})$, es decir $\mathrm{K}=0.75$.

Tabla 3.22

Medida de preferencia de localización

\begin{tabular}{|l|l|}
\hline MPL1 & 0.5211 \\
\hline MPL2 & 0.4789 \\
\hline
\end{tabular}

Elaboración propia 
De acuerdo con el método de Brown y Gibson, la alternativa elegida es Piura, puesto que recibe el mayor valor de medida de ubicación.

Figura 3.9

Mapa de la provincia de Piura

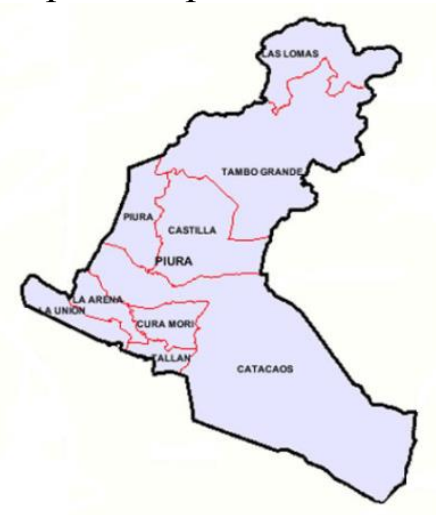

Fuente: Google Images, (2015)
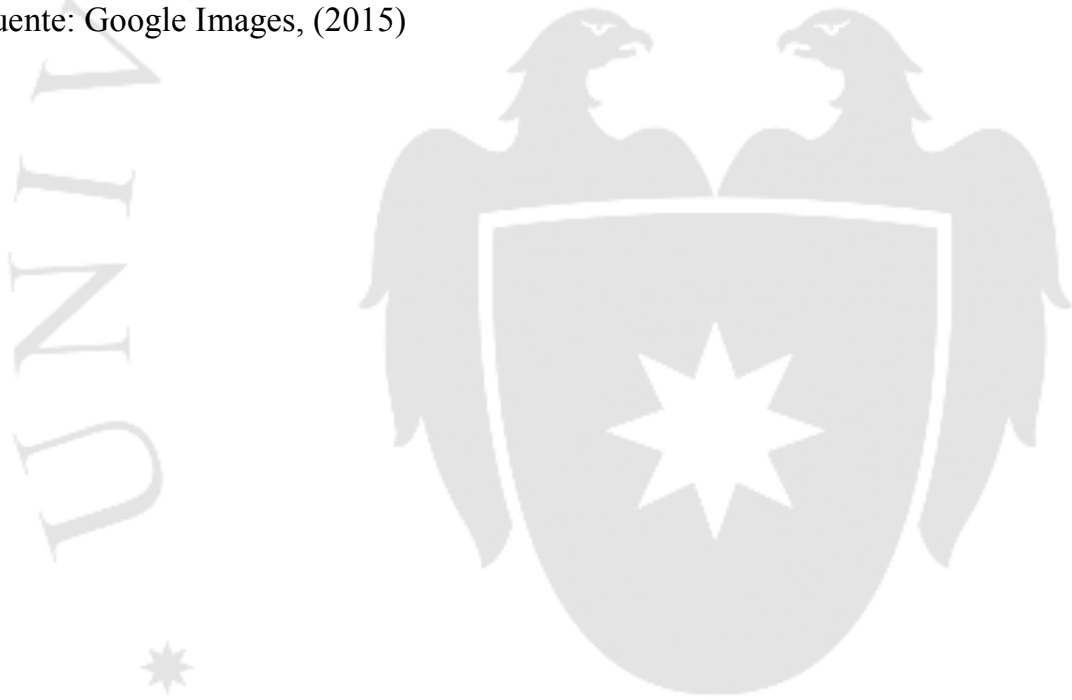


\section{CAPITULO IV. TAMAÑO DE PLANTA}

\subsection{Relación tamaño-mercado}

El factor tamaño mercado está referido a la capacidad que debe tener la planta para poder abastecer la demanda esperada del mercado. Para poder realizar este análisis se debe verificar que la demanda no sea inferior al tamaño mínimo.

Se tomó como referencia la demanda del último año proyectado ya que es en este en donde se presentará la mayor demanda. Con esto se asegura que la demanda de años anteriores se pueda cubrir.

La demanda proyectada para el año 2021 (año 6 del proyecto) será de 370.6 toneladas

\subsection{Relación tamaño-recursos productivos}

Los principales recursos productivos del proyecto son los mangos, azúcar y agua para el almíbar.

La producción de mango se muestra en la siguiente tabla:

Tabla 4.1

Producción nacional de mango

\begin{tabular}{|c|c|c|c|c|c|c|}
\hline \multicolumn{7}{|c|}{ Producción de mango en toneladas } \\
\hline Años & $\begin{array}{c}\text { Total } \\
\text { Nacional }\end{array}$ & Amazonas & Ancash & La Libertad & Lambayeque & Piura \\
\hline 2007 & 294,440 & 1,417 & 6,247 & 6,477 & 13,730 & 233,773 \\
\hline 2008 & 322,721 & 1,300 & 7,702 & 5,693 & 47,033 & 227,810 \\
\hline 2009 & 167,008 & 1,018 & 6,695 & 5,381 & 6,212 & 115,658 \\
\hline 2010 & 454,330 & 1,079 & 10,823 & 5,651 & 42,961 & 359,580 \\
\hline 2011 & 351,937 & 1,308 & 11,801 & 5,719 & 54,416 & 251,048 \\
\hline 2012 & 185,182 & 1,209 & 10,346 & 5,671 & 30,218 & 102,846 \\
\hline 2013 & 458,766 & 1,400 & 9,277 & 5,831 & 52,831 & 349,970 \\
\hline
\end{tabular}

Fuente: Minag, (2015)

Como se puede ver en la tabla 4.1 la producción de mango a nivel nacional es superior a las 100,000 toneladas en todos los años desde el 2007, además se puede notar que Piura es el departamento que produce más. Por estos niveles de producción tan altos se puede concluir 
que la disponibilidad de mangos no serán un limitante para la producción ya que supera en gran número lo requerido por la planta para la producción, el requerimiento de materia prima en relación con la producción total nacional es aproximadamente de $0.08 \%$ anual.

Otro recurso productivo necesario es el azúcar que se utilizara para la elaboración del almíbar. La producción de azúcar solo es en los departamentos de Ancash, Arequipa, La libertad, Lambayeque y Lima

La producción de azúcar se muestra en la siguiente tabla:

Tabla 4.2

Producción nacional de azúcar

\begin{tabular}{|c|c|c|c|c|c|c|}
\hline \multicolumn{7}{|c|}{ Producción (t) } \\
\hline Años & $\begin{array}{c}\text { Total } \\
\text { Nacional }\end{array}$ & Ancash & Arequipa & La Libertad & Lambayeque & Lima \\
\hline 2005 & $6,304,065$ & 512,587 & 82,979 & $2,888,892$ & $1,274,400$ & $1,545,207$ \\
\hline 2006 & $7,245,833$ & 585,778 & 95,354 & $3,284,025$ & $1,689,427$ & $1,591,248$ \\
\hline 2007 & $8,228,623$ & 613,892 & 116,090 & $3,760,283$ & $2,056,475$ & $1,681,884$ \\
\hline 2008 & $9,395,959$ & 628,015 & 90,685 & $4,345,865$ & $2,689,532$ & $1,641,862$ \\
\hline 2009 & $9,936,945$ & 519,197 & 67,069 & $4,807,415$ & $2,982,819$ & $1,560,444$ \\
\hline 2010 & $9,660,895$ & 578,284 & 52,947 & $4,911,755$ & $2,824,848$ & $1,293,061$ \\
\hline 2011 & $9,884,936$ & 663,722 & 50,091 & $4,977,202$ & $2,748,163$ & $1,445,758$ \\
\hline 2012 & $10,368,866$ & 722,001 & 62,380 & $5,234,476$ & $2,767,051$ & $1,582,958$ \\
\hline
\end{tabular}

Fuente: Minag, (2015)

Como se puede ver en la tabla 4.2 la producción de azúcar es muy grande y no representa un limitante ya que supera en gran cantidad lo requerido para la producción y además se puede apreciar una tendencia creciente en la producción.

Por lo tanto, se concluye que para el proyecto la disponibilidad de materias primas no es limitante.

\subsection{Relación tamaño-tecnología}

La relación tamaño tecnología está determinada por la máquina que genera el cuello de botella en base a su capacidad de producción. A continuación, se presenta la tabla 4.3 con las maquinas necesarias para el proceso productivo y sus capacidades. 
Tabla 4.3

Capacidad de las maquinas

\begin{tabular}{|l|c|c|c|}
\hline \multicolumn{1}{|c|}{ Máquinas } & $\begin{array}{c}\text { Número } \\
\text { requerido }\end{array}$ & Capacidad & Unidades \\
\hline Marmita & 1 & 350 & $\mathrm{~kg} / \mathrm{h}$ \\
\hline Lavadora & 3 & 900 & $\mathrm{~kg} / \mathrm{h}$ \\
\hline Envasadora, llenadora y selladora & 1 & 904 & $\mathrm{~kg} / \mathrm{h}$ \\
\hline Etiquetadora & 1 & 1898 & $\mathrm{~kg} / \mathrm{h}$ \\
\hline Secadora de envases & 1 & 1130 & $\mathrm{~kg} / \mathrm{h}$ \\
\hline Encajadora & 1 & 1220 & $\mathrm{~kg} / \mathrm{h}$ \\
\hline Autoclave & 1 & 300 & $\mathrm{~kg} / \mathrm{h}$ \\
\hline
\end{tabular}

Fuente: Somca, (2015)

De esta tabla se puede concluir que el cuello de botella es el recipiente de enclave que sirve para la pasteurización de los productos luego del envasado, este recipiente trabaja por lote de producción. Tiene una capacidad de $100 \mathrm{~kg}$ por lote y cada lote se procesa en 20 minutos aproximadamente por lo que en una hora se puede procesar 3 lotes que representan $300 \mathrm{~kg}$ para un enclave.

Considerando que se trabaja 6 días por semana, un turno de 8 horas por día y 26 semanas al año. Se tiene:

1769 Envases/1h x 8h/1día x 6 días / 1sem x 26sem/año = 2, 207,712 Envases/año o 498.94 Toneladas/año, con esto concluimos que la tecnología no representa un limitante ya que la producción satisface el requerimiento del mercado.

\subsection{Relación tamaño - inversión}

La inversión del proyecto está estimada en S/.4, 259,066, en este monto se incluye los activos fijos y el capital de trabajo. Este monto puede ser financiado con ayuda de programas como COFIDE. En la siguiente tabla se muestran algunas alternativas de financiamiento para el proyecto. 
Tabla 4.4

Servicios financieros - COFIDE

\begin{tabular}{|c|c|c|c|c|c|}
\hline \multirow{2}{*}{$\begin{array}{l}\text { Servicio } \\
\text { Financiero }\end{array}$} & \multirow{2}{*}{ Destino } & \multicolumn{2}{|c|}{ Plazo } & \multirow{2}{*}{ Monto } & \multirow{2}{*}{$\begin{array}{l}\text { Estructura de } \\
\text { financiamiento }\end{array}$} \\
\hline & & Pago & Gracia & & \\
\hline PROBID & $\begin{array}{l}\text { Activo fijo } \\
\text { Capital de trabajo } \\
\text { estructural } \\
\text { Servicios técnicos- } \\
\text { gerenciales }\end{array}$ & Hasta 15 años & $\begin{array}{c}\text { De acuerdo al } \\
\text { proyecto }\end{array}$ & $\begin{array}{c}\text { Hasta } \$ 20,000,000 \\
\text { por proyecto }\end{array}$ & $\begin{array}{c}\text { Hasta el } 100 \% \\
\text { del requerimiento }\end{array}$ \\
\hline \multirow{2}{*}{ PROPEM } & Activo fijo & Hasta 10 años & $\begin{array}{c}\text { De acuerdo al } \\
\text { proyecto }\end{array}$ & $\begin{array}{l}\text { Hasta } \$ 300,000 \\
\text { por subprestatario }\end{array}$ & \multirow{2}{*}{$\begin{array}{c}\text { Hasta el } 100 \% \\
\text { del requerimiento }\end{array}$} \\
\hline & Capital de trabajo & Hasta 3 años & Hasta 1 año & $\begin{array}{l}\text { Hasta } \$ 70,000 \text { por } \\
\text { subprestatario }\end{array}$ & \\
\hline $\begin{array}{l}\text { Multisectorial } \\
\text { Nuevos Soles }\end{array}$ & $\begin{array}{l}\text { Pre-inversión } \\
\text { Activo fijo } \\
\text { Capital de trabajo } \\
\text { Servicios técnicos } \\
\text { gerenciales } \\
\text { Reestructuración } \\
\text { de pasivos }\end{array}$ & Hasta 10 años & Hasta 2 años & $\begin{array}{l}\text { De acuerdo al } \\
\text { proyecto }\end{array}$ & $\begin{array}{c}\text { Hasta el } 100 \% \\
\text { del requerimiento }\end{array}$ \\
\hline
\end{tabular}

Fuente: COFIDE, (2015)

En base a las ofertas de COFIDE la más adecuada para este proyecto es la de PROBID ya que ofrece financiamiento para los Activos fijos, Capital de trabajo estructural y servicios técnicos gerenciales. Esta alternativa de financiamiento ofrece hasta 20, 000,000 USD y no representa una restricción ya que el presupuesto para llevar a cabo el proyecto es inferior a esta cifra. También existe la posibilidad de financiar el proyecto a través de entidades bancarias.

\subsection{Relación tamaño-punto de equilibrio}

El punto de equilibrio es el tamaño mínimo a producir para no tener pérdidas ni ganancias, por debajo de esta cantidad el proyecto dejara de ser rentable y no se generarían ganancias. El presente análisis está centrado en la relación que existe entre los costos fijos, el precio unitario y el costo variable unitario. El número de unidades mínimo a producir corresponderá a la siguiente ecuación:

Tamaño mínimo de planta:

$$
Q \min =\frac{\text { Costo Fijo Total }}{(\text { Precio de venta unitario }- \text { Costo variable unitario })}
$$


Costo fijo total $=$ costos fijos totales de la planta (gastos administrativos, sueldos, mantenimiento de local y su depreciación)

Precio de venta unitario= es el precio al que se venderán los productos terminados.

Costo variable $=$ es el costo en el que se incurre al producir cada conserva de mango.

A continuación, se presentan cálculos aproximados de los costos fijos y variables

Tabla 4.5

Costos directos e indirectos al producto

\begin{tabular}{|c|c|c|c|}
\hline \multicolumn{4}{|c|}{ Costos de producción } \\
\hline Materiales & Cantidad & unidades & Costo unitario (S/.) \\
\hline Mango & 0.1356 & $\mathrm{~kg}$ & 0.12 \\
\hline almíbar & 0.0904 & $\mathrm{~kg}$ & 0.041 \\
\hline $\begin{array}{c}\text { Envases } \\
\text { polipropileno }\end{array}$ & 1 & unidad & 0.10 \\
\hline Film sellador & 1 & unidad & 0.01 \\
\hline Etiqueta & 3 & unidad & 0.03 \\
\hline Ácido cítrico & 0.011 & $\mathrm{~kg}$ & 0.003 \\
\hline Tenedor & 1 & unidad & 0.04 \\
\hline Tapa & 1 & unidad & 0.03 \\
\hline Caja & 1 & unidad & 0.013 \\
\hline \multicolumn{3}{|c|}{ Costo variable unitario (S/.) } & 0.39 \\
\hline \multicolumn{3}{|c|}{ Costo Fijo } & \\
\hline \multicolumn{3}{|l|}{ Maquinaria } & 337,039 \\
\hline \multicolumn{3}{|l|}{ Terreno } & $1,200,000$ \\
\hline \multicolumn{3}{|l|}{ Edificio } & 513,411 \\
\hline \multicolumn{3}{|c|}{ Salarios (anual) } & 347,070 \\
\hline \multicolumn{3}{|c|}{ Costo fijo total (S/.) } & $2,397,520$ \\
\hline
\end{tabular}

Elaboración propia

Reemplazando los valores obtenemos:

$\mathrm{Q} \min =2,397,520 /(3.5-0.39)=771,031$ unidades o 174.25 toneladas

Al ser el tamaño inferior a la demanda del mercado se da a recalcar que este no será un limitante para el presente estudio. 


\subsection{Selección del tamaño de planta}

En base a la información detallada en los puntos anteriores se puede definir el tamaño de planta que se requiere de acuerdo a la demanda del mercado y a la vez indicando que no se tiene ningún tipo de restricción ni limitante de los otros factores estudiados.

El tamaño de planta se definirá por la relación tamaño- mercado. Es decir, se utilizará una planta de mínimo 354.69 t por ser la capacidad necesaria para abastecer la demanda proyectada aparente del proyecto para el primer año.

Adicionalmente se cuenta con la tecnología necesaria para poner en marcha el proceso de producción de conservas de mango además de contarse con una capacidad de producción superior a la necesaria lo que permitiría cubrir una demanda que exceda las proyecciones.

A continuación, se presenta la tabla 4.6 con los factores analizados:

Tabla 4.6

Factores

\begin{tabular}{|c|c|c|}
\hline Factor & $\begin{array}{c}\text { Cantidad anual } \\
\text { en toneladas }\end{array}$ & $\begin{array}{c}\text { Cantidad anual en } \\
\text { unidades de producto }\end{array}$ \\
\hline Demanda & 372.6 & $1,648,982$ \\
\hline Producción & 458,766 & No limitante \\
\hline Tecnología & 498.9 & $2,207,712$ \\
\hline $\begin{array}{c}\text { Punto de } \\
\text { equilibrio }\end{array}$ & 174.3 & 771,018 \\
\hline
\end{tabular}

Elaboración propia

Como se puede apreciar en la tabla de resumen la demanda es el factor que limita el nivel de producción requerido para el proyecto. Por lo tanto, se le considerara para seleccionar el tamaño de planta adecuado. 


\section{CAPITULO V. INGENIERÍA DEL PROYECTO}

\subsection{Definición técnica del producto}

\subsubsection{Especificaciones técnicas del producto}

De acuerdo a la Norma CODEX para las conservas de mango: CODEX STAN 159-1987, se presenta en la Tabla 5.1 un resumen del producto en proyecto.

Tabla 5.1

Términos de las conservas de mango de acuerdo a la Norma Técnica

\begin{tabular}{|c|c|}
\hline Descripción & $\begin{array}{l}\text { Preparado de mango sin pedúnculos, pelado, fresco, limpio y maduro, de las } \\
\text { variedades comerciales que respondan a las características del fruto } \\
\text { Manguifera indica L.; que está envasado y con un medio de cobertura } \\
\text { líquido adecuado, edulcorantes nutritivos, y aderezos y aromatizantes } \\
\text { apropiados para el producto; y tratado térmicamente, en forma adecuada, } \\
\text { antes o después de ser encerrado herméticamente en un recipiente con el } \\
\text { fin de mantener la composición esencial y los factores de calidad del } \\
\text { producto. }\end{array}$ \\
\hline Variedad & Cualquiera adecuado para la preparación de conservas de mango \\
\hline $\begin{array}{l}\text { Forma de } \\
\text { presentación }\end{array}$ & $\begin{array}{l}\text { En cubos (cortada en partes con un tamaño de } 12 \text { mm como mínimo en el } \\
\text { lado más largo) }\end{array}$ \\
\hline Tipo de envasado & corriente (con medio de cobertura líquido) \\
\hline Medio de cobertura & Agua con agregado de zumo natural pequeño propio del producto \\
\hline $\begin{array}{l}\text { Aditivos } \\
\text { alimentarios }\end{array}$ & ○ \\
\hline
\end{tabular}

Fuente: CODEX STAN 159-1987, (2016)

De acuerdo a los criterios de calidad que el producto deberá cumplir, se mencionan los siguientes ${ }^{22}$ :

\footnotetext{
${ }^{22}$ Digesa-Norma Codex 159-1987
} 


\section{$\underline{\text { Color }}$}

El color del producto deberá ser característico del tipo o de la variedad de mango. Los mangos en conserva que contengan ingredientes especiales deberán considerarse de color característico cuando no presenten ninguna decoloración anormal respecto al ingrediente de que se trate.

\section{$\underline{\text { Sabor }}$}

Los mangos en conserva deberán tener un sabor y olor característicos de la variedad o tipo enlatado y deberán estar exentos de olores y sabores extraños al producto. Los mangos enlatados con ingredientes especiales deberán tener el sabor característico que presentan los mangos y las otras sustancias empleadas.

\section{$\underline{\text { Textura }}$}

Los mangos deberán ser razonablemente carnosos y tener poca fibra. Podrán ser más o menos tiernos, pero no deberán ser ni excesivamente pulposos ni excesivamente duros cuando están envasados en medios de cobertura líquidos.

\section{Definición de defectos}

Los defectos permitidos son manchas o decoloración a causa de insectos, unidades aplastadas, cáscaras y materias extrañas inocuas. Se podrá observar en la norma técnica las tolerancias para cada defecto.

Finalmente, de acuerdo al envase y rotulado:

El envase para el mango en almíbar, deberá ser de un material suficientemente inerte a la acción del contenido y de cierre hermético. Su forma y capacidad deberá ajustarse a las normas ITINTEC 350.007. El fondo no deberá presentar ninguna deformación permanente.

El rotulado deberá ajustarse a la Norma “ITINTEC 209.038”, norma general para el rotulado de alimentos envasados, la misma que deberá contener los siguientes puntos:

- $\quad$ Nombre, razón social y marca del fabricante

- $\quad$ Nombre y tipo de producto

- $\quad$ Peso neto aproximado, expresado en gramos.

- $\quad$ Lote y fecha de envase 
- Información nutricional

- $\quad$ Fecha de caducidad

- $\quad$ Todos los envases deberán ser marcados en forma clara e indeleble

La vida útil del producto será de 18 meses desde su envasado, bajo las siguientes condiciones:

- $\quad$ Se debe mantener en lugares frescos y no bajo el sol.

- El envase debe estar en buenas condiciones porque perjudicará las condiciones del producto.

- Consumir todo el producto cuando el envase sea total o parcialmente abierto, en caso contrario, se debe refrigerar.

En resumen, a continuación, se presenta en la tabla 5.2, los criterios de calidad a usar para la conserva de mango en almíbar.

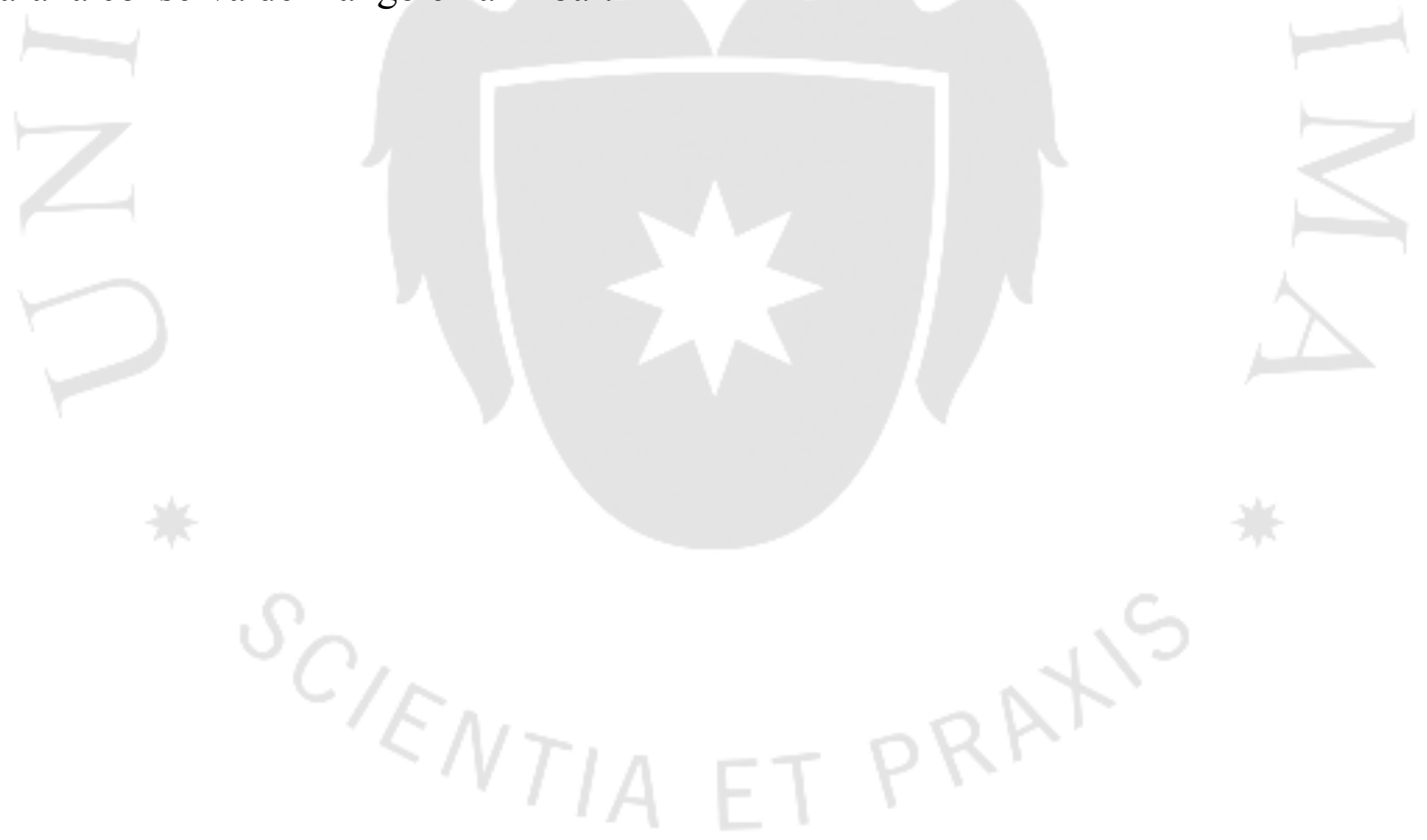


Tabla 5.2

Ficha técnica del producto final

CARACTERÍSTICAS DE CONSERVA DE MANGO EN ALMÍBAR

\begin{tabular}{|c|c|}
\hline Descripción física & $\begin{array}{l}\text { Producto listo para el consumo en presentación de } \\
\text { envase de polipropileno de } 226 \mathrm{~g} \text {. Este producto es elaborado } \\
\text { bajo las mejores condiciones de buenas prácticas de manufactura } \\
\text { y con el seguimiento estricto de las normas y reglamentos } \\
\text { técnicos sanitarios vigente. }\end{array}$ \\
\hline Ingredientes & $\begin{array}{l}\text { * Pulpa de mango } \\
\text { * Agua } \\
\text { * Azúcar blanca } \\
\text { * Aditivo alimentario (ácido cítrico) }\end{array}$ \\
\hline $\begin{array}{l}\text { Características } \\
\text { organolépticas }\end{array}$ & $\begin{array}{l}\text { * Color: Naranja con tonalidad amarilla. } \\
\text { * Olor: Característico a mango. } \\
\text { * Sabor: Característico a mango. Dulce, ligeramente ácido. } \\
\text { * Aspecto: Líquido uniforme transparente con trozos de mango. }\end{array}$ \\
\hline $\begin{array}{l}\text { Características } \\
\text { fisicoquímicas }\end{array}$ & $\begin{array}{l}\text { * Sólidos solubles: } 58-62 \% \\
\text { * } \mathrm{pH}: 2,5-4,0 \\
\text { * Densidad: } 161 \mathrm{~g} / \mathrm{l}^{23} \\
\text { * Almíbar muy edulcorado: no menos de } 15^{\circ} \text { Brix }\end{array}$ \\
\hline Empaque de Presentación & Envases de Polipropileno \\
\hline Información Nutricional & * Ver tabla nutricional en la tabla 5.3. \\
\hline $\begin{array}{l}\text { Información } \\
\text { Complementaria }\end{array}$ & $\begin{array}{l}\text { * Origen del producto: Producto peruano } \\
\text { * Tratamiento tecnológico: pasteurización (autoclave) } \\
\text { * Producto sin alérgenos, no contiene OGM } \\
\text { * A temperatura ambiente } \\
\text { * Certificación HACCP }\end{array}$ \\
\hline
\end{tabular}

Elaboración propia

${ }^{23}$ Tomado de: HOLDSWRTH, S. 1988. Conservación de frutas y hortalizas. Edit. Acribia. Zaragoza-España. 


\subsubsection{Composición del producto}

A continuación, se muestra la composición del producto en la tabla nutricional.

Tabla 5.3

Tabla nutricional de conserva de mango

\begin{tabular}{|c|c|}
\hline \multicolumn{2}{|c|}{ INFORMACIÓN NUTRICIONAL } \\
\hline Tamaño de porción & $1 / 2$ Cucharada ( $226 \mathrm{~g})$ \\
\hline Porciones por envase & 2 \\
\hline \multicolumn{2}{|c|}{ Amount per serving/Cantidades por porción } \\
\hline \multicolumn{2}{|l|}{ Calorías : $30 \mathrm{kcal}$} \\
\hline \multicolumn{2}{|l|}{ Calorias de la grasa: 0} \\
\hline \multicolumn{2}{|c|}{ Valor nutricional por porción de $50 \mathrm{~g}$} \\
\hline Grasa total & $0 \mathrm{~g}$ \\
\hline Grasa saturada & $0 \mathrm{~g}$ \\
\hline Grasas trans & $0 \mathrm{mg}$ \\
\hline Colesterol & $0 \mathrm{~g}$ \\
\hline Sodio & $0 \mathrm{~g}$ \\
\hline Carbohid. Totales & $8.5 \mathrm{~g}$ \\
\hline Fibra dietaria & $0.3 \mathrm{mg}$ \\
\hline Azúcares & $7.7 \mathrm{~g}$ \\
\hline Proteinas & $0.1 \mathrm{~g}$ \\
\hline Peso Neto $(\mathrm{g})$ & 226 \\
\hline Peso Drenado (g) & 130 \\
\hline
\end{tabular}

Fuente: Valle Fértil, (2015)

Además, los ingredientes en sus porcentajes por porción, donde se podrá observar que es lo que contiene en su mayoría el producto.

Tabla 5.4

Porcentaje de ingredientes por porción

\begin{tabular}{|c|c|}
\hline INGREDIENTES & $\%$ \\
\hline Pulpa de mango & $60.0 \%$ \\
\hline Agua & $22.5 \%$ \\
\hline Azúcar & $17.0 \%$ \\
\hline Ácido cítrico & $0.5 \%$ \\
\hline
\end{tabular}

Elaboración propia 


\subsubsection{Diseño gráfico del producto}

A continuación, se muestran imágenes que muestran cada parte del producto.

Figura 5.1

Toma de la base del producto
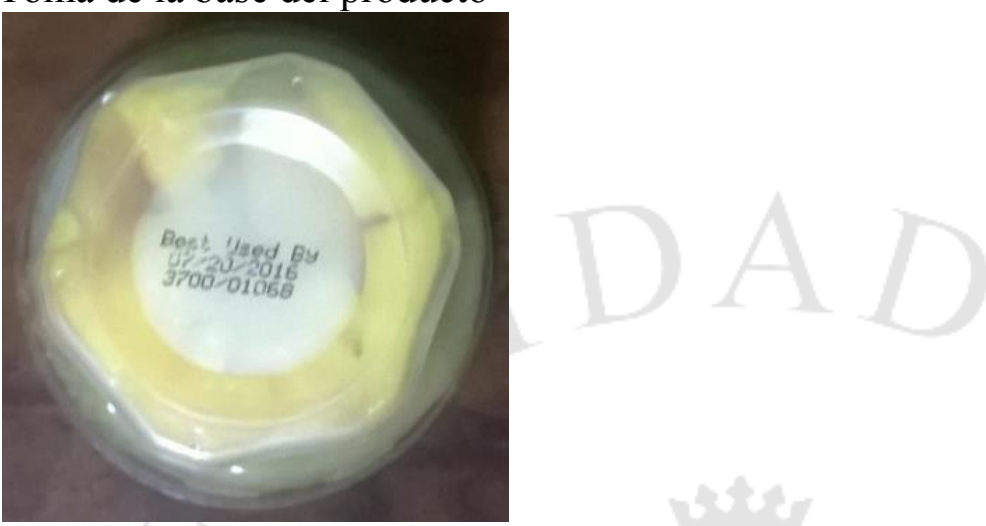

Elaboración propia

Figura 5.2

Toma frontal del producto

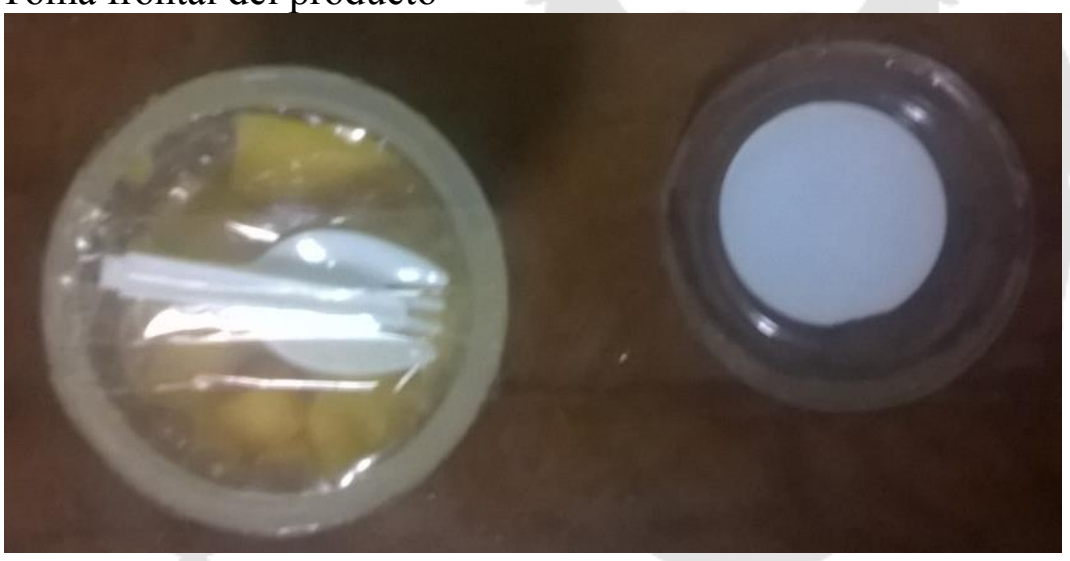

Elaboración propia 
Figura 5.3

Toma de la parte lateral del producto

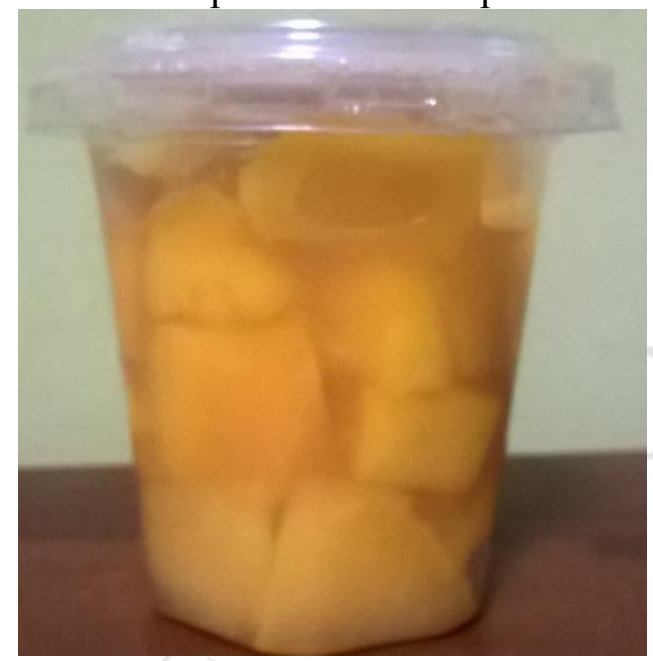

Elaboración propia

\subsubsection{Regulaciones técnicas del producto}

De acuerdo al acápite 5.1.1. Se elaborará este producto en base a la Norma técnica del CODEX para las conservas de mango: CODEX STAN 159-1987. Asimismo, se trabajará de acuerdo a la normativa de la DIGESA cuyo sub-organismo "Dirección de Higiene Alimentaria" inspeccionará y evaluará el ambiente en que se trabaja este proyecto para evitar tener problemas con la entidad.

\subsection{Tecnologías existentes y procesos de producción}

\subsubsection{Naturaleza de la tecnología requerida}

Para el proceso de fabricación de conservas de mango en almíbar, existen diversas tecnologías disponibles; por un lado, se tiene la tecnología artesanal (manual) que es todo lo que se fabrica a mano, y en donde no se utilizan máquinas para la fabricación de los elementos que se necesita para el producto final. Se trata de tecnologías fundadas en un conocimiento empírico. El producto de esta tecnología responde directamente, en cantidad y calidad a las necesidades de los usuarios.

Por otro lado, se tiene la tecnología automatizada y especializada que permite un proceso de producción continuo, sin demoras o tiempos ociosos, muy interesante cuando se requiere elevados estándares de calidad y altos volúmenes de producción. Finalmente, la 
tecnología semiautomática consiste en el uso de maquinarias con el apoyo de operarios para su correcto funcionamiento.

\subsubsection{Descripción de las tecnologías existentes}

A continuación, se hará una breve descripción de las tecnologías que se podrían utilizar para el proceso de producción.

El proceso de selección de la fruta se puede realizar manualmente en una mesa de selección mediante la selección visual de las frutas por el personal o con la ayuda de una máquina que tiene sensores de medición de tamaño y peso.

Los procesos de lavado se pueden realizar manualmente o con una máquina lavadora mediante el método húmedo y seco; es decir, el primero mediante agua a presión o sumergiendo en agua y el segundo por separación de aire.

El proceso de pelado se puede realizar manualmente utilizando cuchillos en una mesa de trabajo para pelar los frutos uno por uno, con apoyo de una peladora o también automáticamente mediante pelado químico, donde se pasan los mangos por un serpentín en donde la cascara del mango es elimina por acción una solución de soda cáustica.

El proceso de cortado se puede realizar manualmente utilizando cuchillos y una prensa para desechar la parte central del fruto, en donde los operarios trabajarán un mango a la vez en una mesa de trabajo.

El proceso de prensado en cubos puede ser manual con la ayuda de una prensa que servirá para obtener los cubos de mango o con una prensa industrial automatizada.

El proceso de llenado de los trozos de mango podrá ser manual lo que es limitado e ineficiente o con una máquina llenadora que ayuda a reducir tiempo y costos.

El proceso de llenado del medio de cobertura podrá ser automático con una máquina inyectora o manualmente con el apoyo de los operarios.

El proceso de sellado tiene que ser automático ya que se usará un adhesivo especial; es decir, la cubierta no será una rosca.

El proceso de secado después del pasterurizado podrá ser automático con una máquina secadora o mediante aire con el apoyo de un operario. 
Los procesos de etiquetado y encajado pueden ser automáticos con una o varias máquinas que realicen estas acciones o puede realizarse manualmente, lo cual es ineficiente ya que incurre en desperdicios y errores.

\subsubsection{Selección de la tecnología}

Para este proyecto se adoptará una posición intermedia (tecnología semiautomática) debido a que no se requiere de maquinaria sofisticada, pero si con cierto grado de automatización y control. Asimismo, el uso de este tipo de tecnología implica una menor inversión a largo plazo ya que permitirá evitar el pago de mano de obra; es decir incurrir en costos por mano de obra constante es mayor que comprar maquinarias que a largo plazo son más baratas que pagar salarios. A continuación, se detallarán las tecnologías para cada operación.

El proceso de selección de la fruta se realizará manualmente en una mesa de selección mediante inspección visual (visualizar tamaño y apariencia) de las frutas por el personal.

El proceso de lavado se realizará con una máquina lavadora industrial, se sumergen los mangos en la máquina con agua y luego son retirados por el personal que opera la máquina.

El proceso de pelado se realizará manualmente utilizando cuchillos, los mangos avanzaran sobre una faja transportadora y serán tomados por los operarios que están ubicados a los costados de la faja, cuando terminen el pelado serán colocados sobre la faja para que avancen a la siguiente operación. Las operaciones de pelado, cortado y prensado se trabajan bajo el mismo sistema en donde la fruta se mueve sobre fajas.

El proceso de cortado se realizará manualmente utilizando cuchillos, en donde los operarios trabajarán un mango a la vez.

El proceso de prensado en cubos será semiautomático con la ayuda de una prensa que servirá para obtener los cubos de mango.

Para el proceso de pasteurización se usará una máquina Exhauster donde se pasteuriza el mango envasado con almíbar.

El proceso de llenado del líquido de gobierno será automático (inyectora) ya que es bajo en costos y logra obtener volúmenes producción medianos que reducirá el tiempo de 
producción y mejora la precisión del llenado en comparación con un proceso manual. Este proceso junto con el sellado y envasado se realizará en una sola máquina (multitareas).

El proceso de secado será automático con una secadora industrial donde habrá un operario que verificará cada cierto tiempo el desempeño de la máquina.

Finalmente, los procesos de etiquetado y encajado serán totalmente automáticos.

Cabe resaltar, que el medio de transporte entre una operación y otra será una cama o banda transportadora de alimentos. Esta actuará también en las áreas manuales en vez de mesas de trabajo lo que implica que estas áreas necesitarán personal rápido de realizar sus actividades.

Se escogió la tecnología semiautomática debido a que la calidad del producto final es mejor ya que hay menos manipuleo de los materiales, el nivel de desechos se reduce y el proceso de producción es continua.

\subsubsection{Proceso de producción}

\subsubsection{Descripción del proceso}

A continuación, se procede a describir el proceso para la elaboración de conservas de mango en almíbar.

- Selección: En este control se separa las frutas que presentan algún deterioro físico, magulladuras, manchas o inmadurez. También se cuantifica la fruta que entrará al proceso. Este proceso se desarrolla de forma manual y se inspecciona visualmente, se realizará en una mesa de rodillos.

- $\quad$ Lavado: El proceso de lavado se realiza en una lavadora industrial que estará cargada con agua. Las frutas serán sumergidas en el agua y luego retiradas por el operario de esa estación.

Pelado: En esta operación se procede a retirar la cáscara de los mangos con cuchillos de acero inoxidable. Cada operario tomará un mango a la vez y pelará la fruta hasta retirar toda la cascará que será depositada en cubos que estarán ubicados debajo de las fajas transportadoras. 
- Cortado: Esta operación se realizará de forma manual sobre una faja transportadora que estará ubicada de manera contigua a la faja de pelado. Aquí se cortarán los mangos en rodajas y se separará la parte central de la fruta.

- $\quad$ Prensado en cubos: Esta operación consiste en colocar los trozos de mango cortados y pelados previamente en una prensa de funcionamiento manual, el operario colocará la fruta y procederá a jalar con las 2 manos las asas de la prensa para obtener cubos de mango.

- $\quad$ Escaldado con almíbar: Los cubos de mango obtenidos luego del prensado serán sometidos a un baño en almíbar.

- $\quad$ Llenado de la fruta: Los trozos de mango serán llenados por una máquina encargada de distribuirlos uniformemente en los envases de polipropileno e inmediatamente se cubrirán con almíbar, esto también es realizado por la máquina de llenado.

- $\quad$ Sellado: En este proceso se coloca el film que sella la parte superior del envase, será realizado por una máquina selladora.

- Pasteurizado: En este proceso las conservas selladas serán pasteurizadas en un autoclave a $90^{\circ} \mathrm{C}$ por 15 minutos.

- Lavado: Esta operación sirve para limpiar el almíbar que se pueda derramar al momento de ser vertido sobre el envase con la fruta.

- Secado: Luego de la operación de lavado las conservas serán secadas en una máquina secadora para que luego sean tapadas y se les pueda pegar una etiqueta con información sobre el producto.

- $\quad$ Tapado: En esta operación a cada conserva se le colocará un tenedor sobre el film y una tapa, esta operación se realiza de forma manual.

- Etiquetado: Los envases serán etiquetados por una máquina etiquetadora, se mostrará el peso, los ingredientes, la fecha de caducidad y el tratamiento que deberá recibir luego de ser abierto.

- Encajado: Las conservas se colocarán en cajas de cartón con capacidad para 30 unidades. 


\subsubsection{Diagrama de proceso: DOP}

A continuación, se presenta el diagrama de operaciones del proceso para la elaboración de conservas de mango en almíbar.

Figura 5.4

Diagrama de Operaciones del Proceso para la elaboración de conservas de mango en almíbar

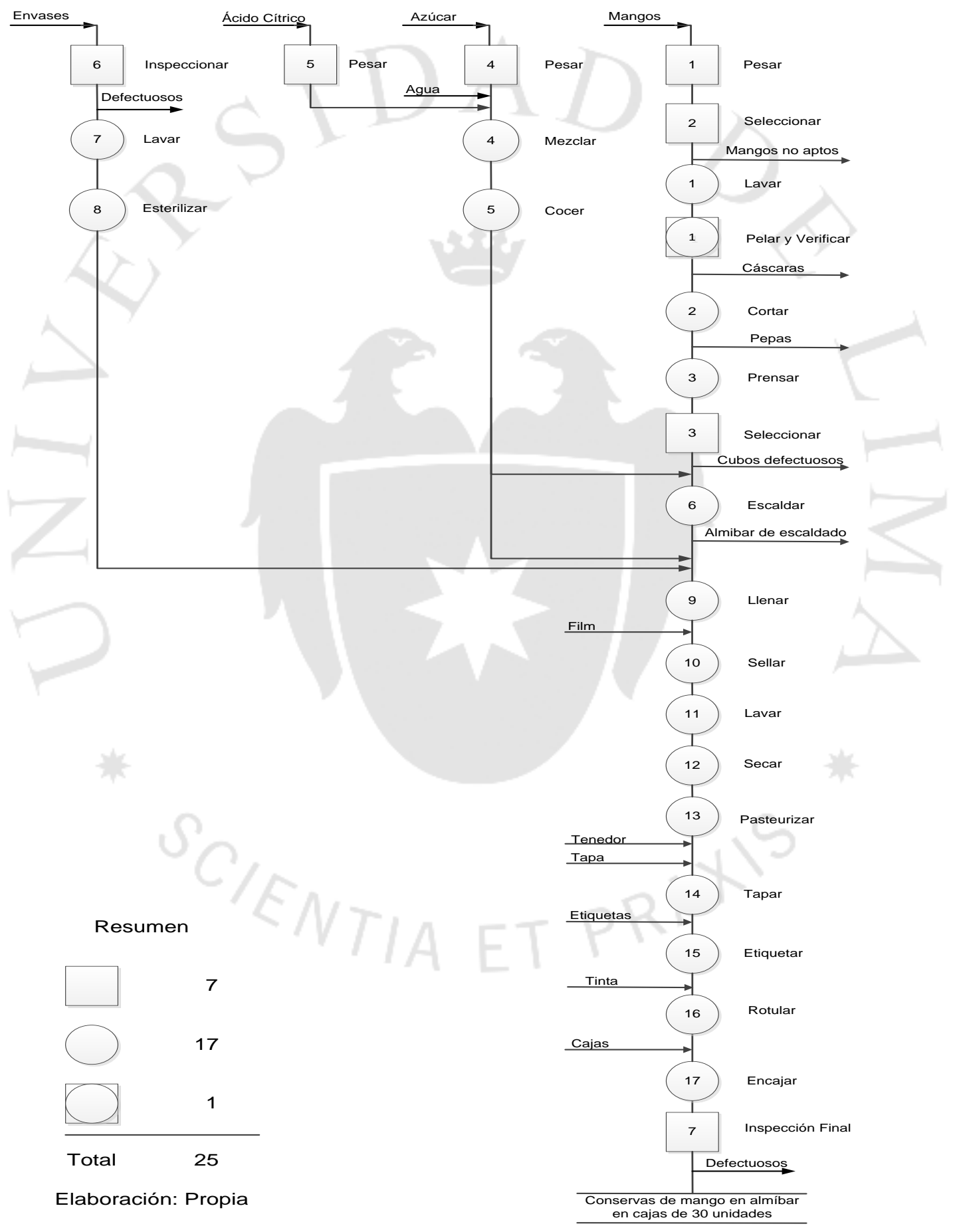




\subsubsection{Balance de materia y energía}

A continuación, se presenta una figura con los porcentajes por cada ingrediente necesitado y la merma que se rechaza.

Figura 5.5.

Balance de materia

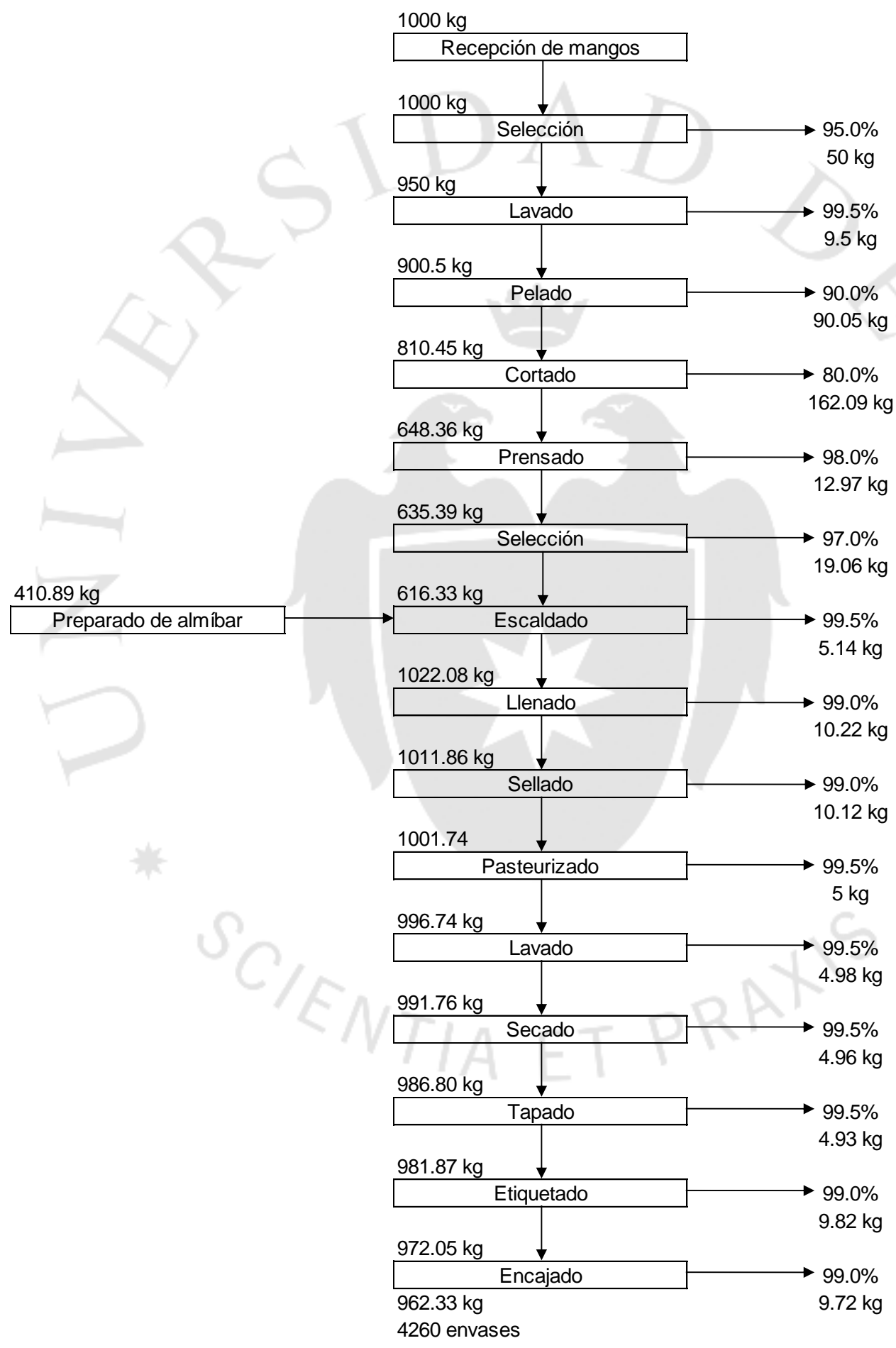

Elaboración propia 


\subsection{Características de las instalaciones y equipos}

\subsubsection{Selección de la maquinaria y equipos}

Las maquinas necesarias para producir las conservas de mango son las siguientes:

- $\quad$ Máquina de lavado

- $\quad$ Máquina de envasado, llenado y sellado

- $\quad$ Autoclave

- $\quad$ Etiquetadora

- $\quad$ Bandas de transporte

- $\quad$ Encajadora

- $\quad$ Equipos de acarreo

- Prensa manual

- Lavadora

\subsubsection{Especificaciones de la maquinaria}

\section{a) Banda de transporte}

La banda transportadora se utiliza para la selección, eliminación manual de frutas de mala calidad, también será utilizada para transportar las frutas hacia la lavadora, está montada sobre ruedas giratorias, posee regulación de altura de las patas y regulación de velocidad de frecuencia en la caja de comando central. 
Figura 5.6

Banda de selección

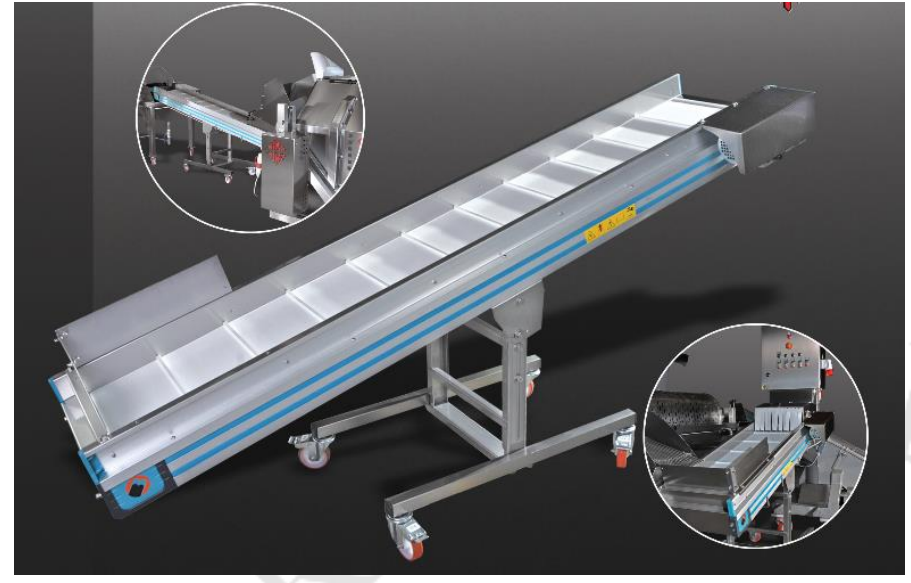

Fuente: Niko, (2015)

Marca: Niko JT1500

Capacidad: $1500 \mathrm{~kg} / \mathrm{hora}$

Ancho: $0.62 \mathrm{~m}$

Largo: $1.52 \mathrm{~m}$

Alto: $0.97 \mathrm{~m}$

Potencia: $0.25 \mathrm{~kW}$

\section{b) Lavado}

Para el lavado se utilizará la máquina lavadora por inmersión de marca Jersa modelo 42. El mango será cargado en la cuba por medio de la cesta y se lavarán en la máquina. 
Figura 5.7

Lavadora por inmersión

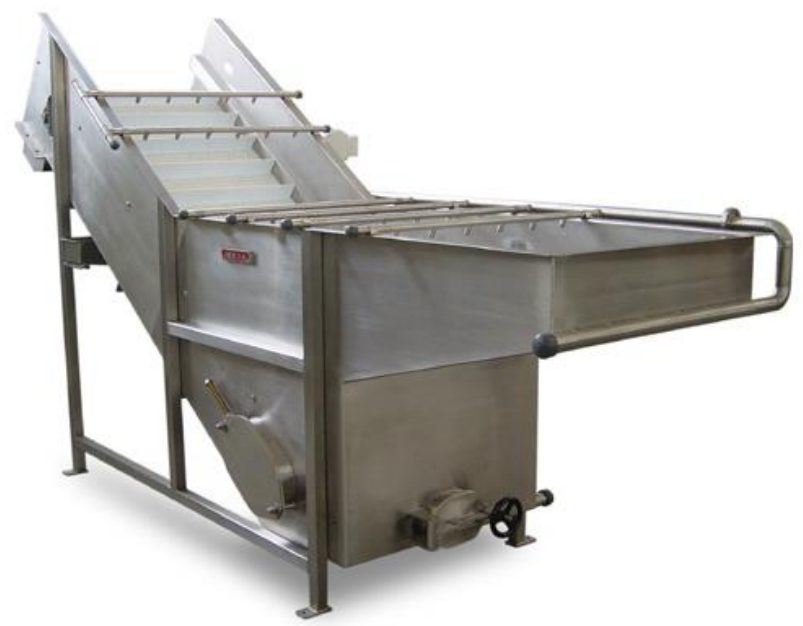

Fuente: Jersa, (2015)

Marca: Jersa

Capacidad: $900 \mathrm{~kg} / \mathrm{hora}$

Ancho $70 \mathrm{~cm}$

Largo: $100 \mathrm{~cm}$

Alto: $120 \mathrm{~cm}$

Potencia 5Kw

\section{c) Envasado, llenado y sellado de envases}

Para los procesos de envasado de fruta, llenado de almíbar en el envase y sellado con calor de los envases al vacío se utilizará la máquina Orics S-50 que trabaja con un movimiento rectilíneo.

Los envases o bandejas son situados automáticamente. El contenido de cada una de las bandejas es llenado, sellado y descargado automáticamente.

Esta máquina puede trabajar con envases desde $1 \mathrm{~g}$ hasta $2000 \mathrm{~g}$, requiere de una alimentación de corriente eléctrica trifásica de $220 \mathrm{~V}-380 \mathrm{~V}$ 
Figura 5.8

Máquina de envasado, llenado y sellado

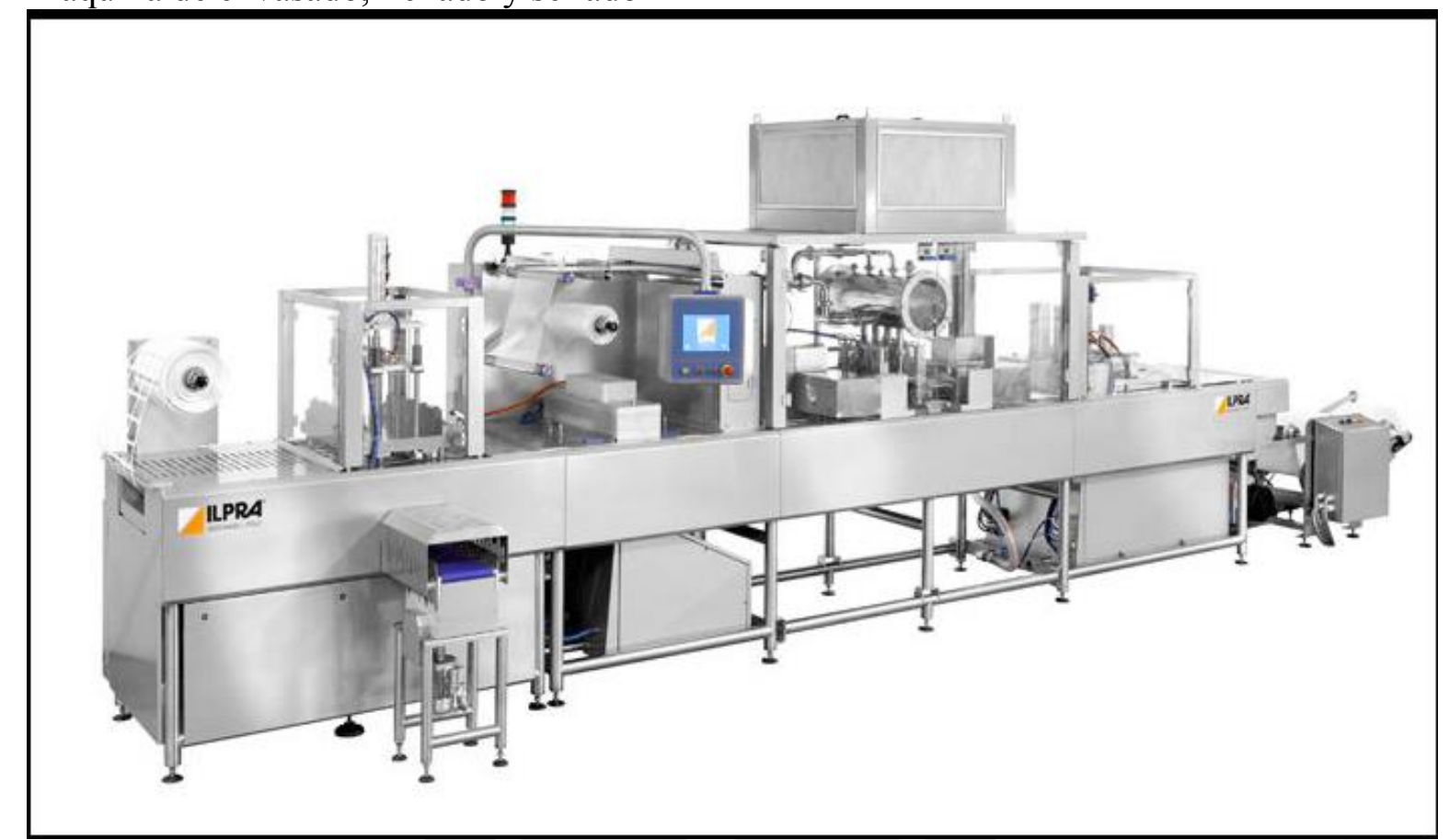

Fuente: Ilpra, (2015)

Marca: ILPRA

Largo: 3.66 metros

Ancho: 0.76 metros

Alto: 1.70 metros

Capacidad: 4000 envases/hora

Potencia: $5 \mathrm{~kW}$

\section{d) Etiquetado}

Para el etiquetado se utilizará una máquina etiquetadora automática que realiza el proceso por ambos lados del envase. Cuenta con una estación de autoadhesivo para la etiqueta del cuerpo más una contra etiqueta con una bobina a cada lado del producto. 
Figura 5.9

Etiquetadora

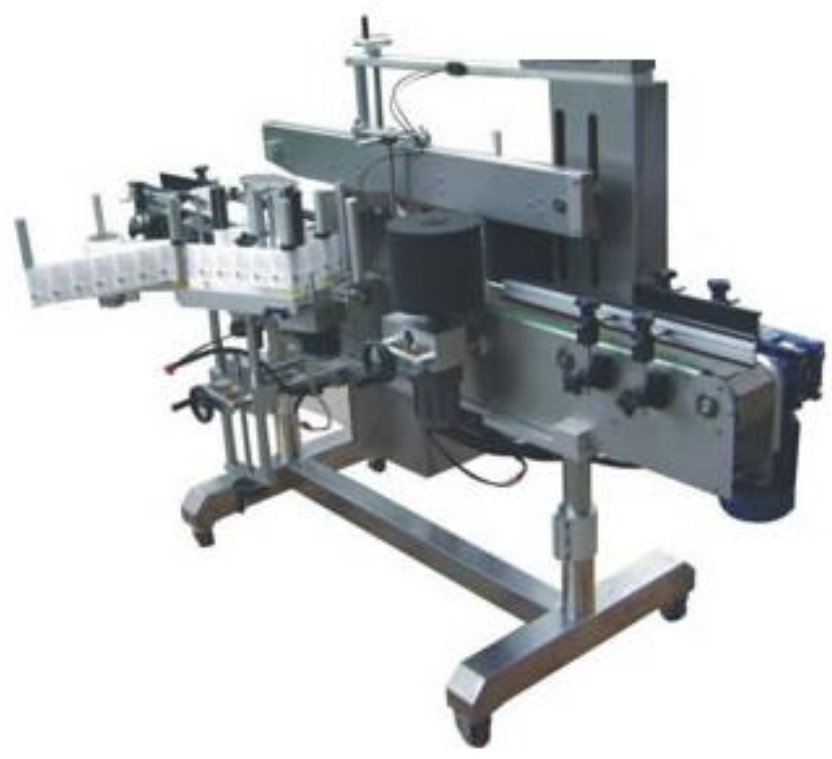

Fuente: Duerfo, (2015)

Marca: Duerfo

Capacidad: 8400 unidades/hora

Largo: 3.05 metros

Ancho: 1.65 metros

Alto: 1.36 metros

Potencia: $4 \mathrm{Kw}$

\section{e) Marmita basculante}

Para la elaboración del almíbar se utilizará una marmita en la cual se realizará el mezclado del agua con azúcar y ácido cítrico para la posterior cocción. 
Figura 5.10

Marmita Basculante
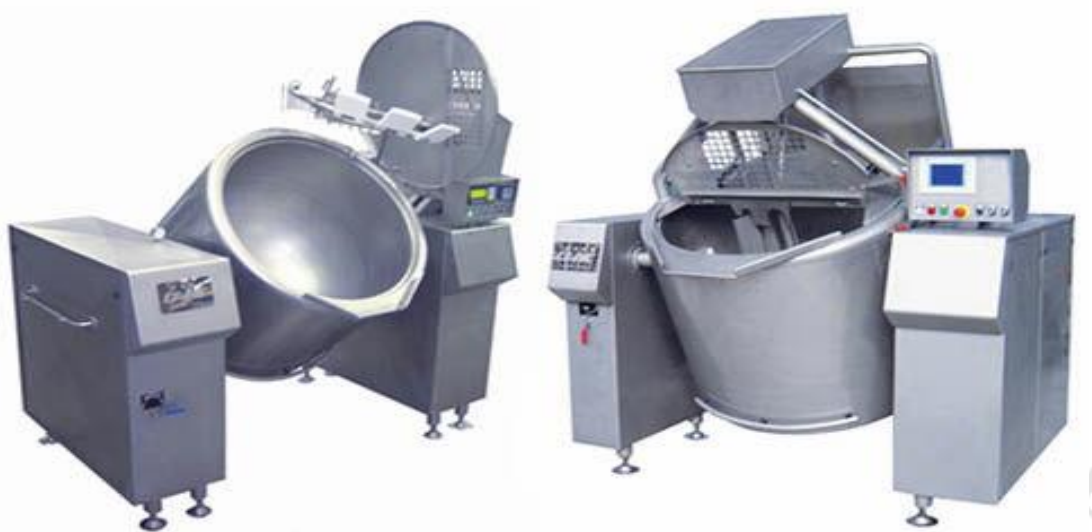

Fuente: Capic, (2015)

Marca: Auriol

Capacidad: 350 litros

Largo: 1.75 metros

Ancho 1.27 metros

Alto: 1.63

Potencia: $12 \mathrm{~kW}$

Capacidad: 150 litros

\section{f) Secadora de envases}

Para el secado de envases se utilizará una secadora industrial de envases que opera de forma lineal, los envases mojados pasarán por la cabina de secado mediante una faja transportadora que forma parte del equipo. 
Figura 5.11

Secadora de envases

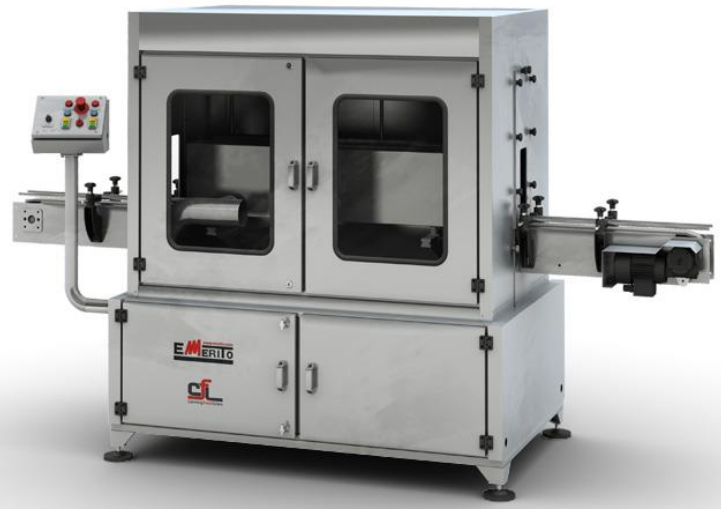

Fuente: INGESIR, (2015)

Marca: Emerito

Capacidad: 5000 envases/h

Largo: 2 metros

Ancho: 1 metro

Alto: 1.8 metros

Potencia: $3 \mathrm{~kW}$

\section{g) Maquina encajadora}

Para colocar en cajas el producto terminado se utilizará una máquina encajadora automática que se encargará de agrupar los envases que entren en su cabina de empaque y las pondrá en cajas según la presentación que se desee. 
Figura 5.12

Máquina encajadora

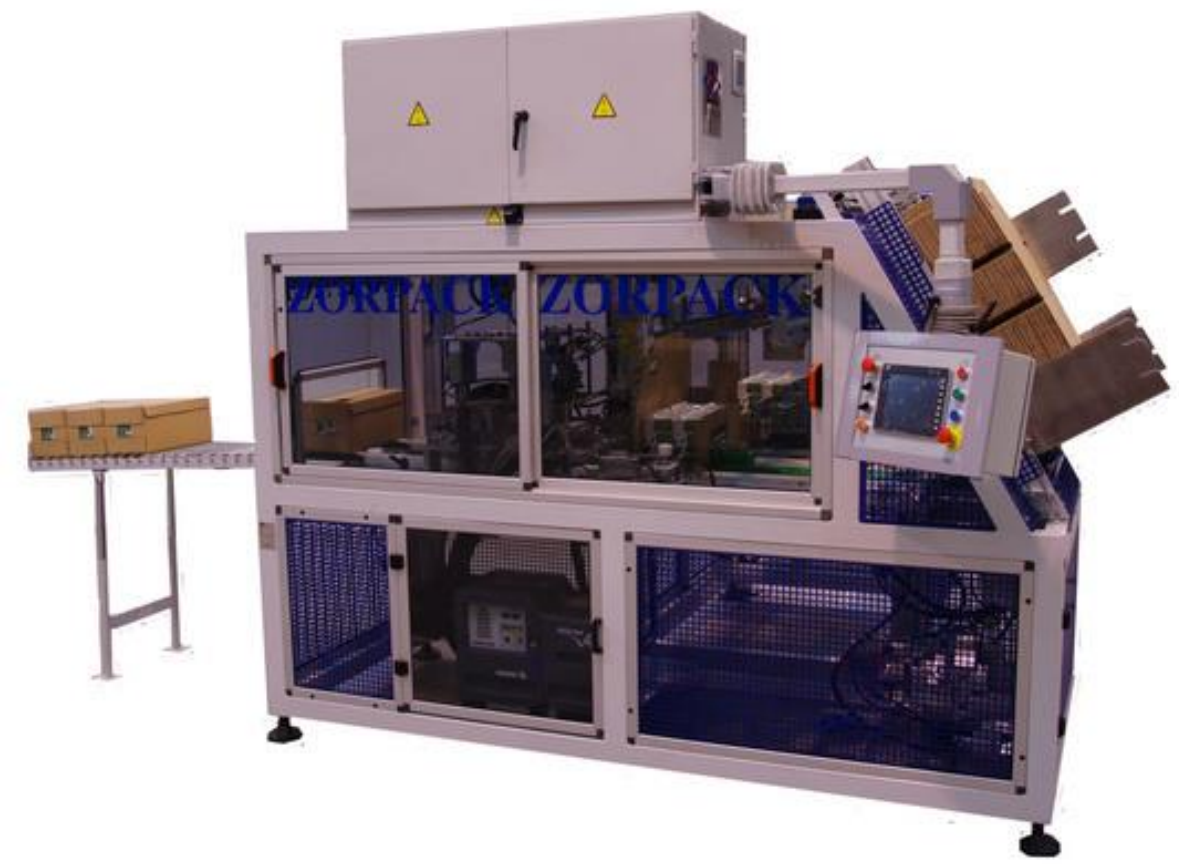

Fuente: Zorpack, (2015)

Marca: Zorpack

Capacidad: 180 cajas de 30 envases por hora

Largo 2.6 metros

Ancho: 3.3 metros

Alto: 2.5 metros

Potencia: $5 \mathrm{~kW}$

\section{h) Pasteurizador (enclave)}

Para la pasteurización final de las conservas se utilizará un enclave horizontal, este equipo someterá a los productos a altas temperaturas con vapor de agua para aumentar su tiempo de vida. 
Figura 5.13

Pasteurizador enclave

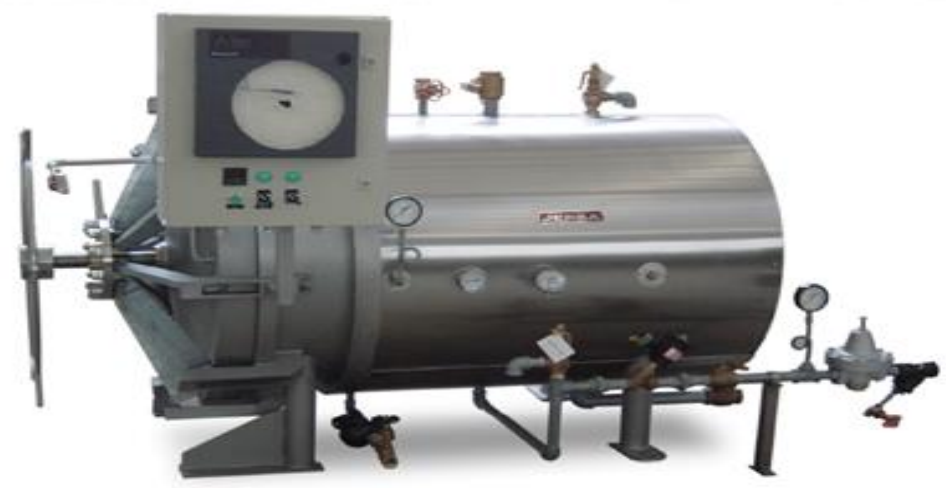

Fuente: Jersa, (2015)

Marca: Jersa

Capacidad: $300 \mathrm{~kg} / \mathrm{hora}$

Altura: 1.8 metros

Diámetro: 0.965

Potencia: $5 \mathrm{~kW}$

\section{i) Prensador de mango}

Para obtener el mango en cubos se utilizarán prensas manuales que trabajan a presión, este equipo es de fácil uso ya que el operario tendrá que colocar las rodajas de mango dentro de la prensa y luego con las dos manos ejercer presión sobre las palancas de la prensa.

Figura 5.14

Prensa manual de fruta

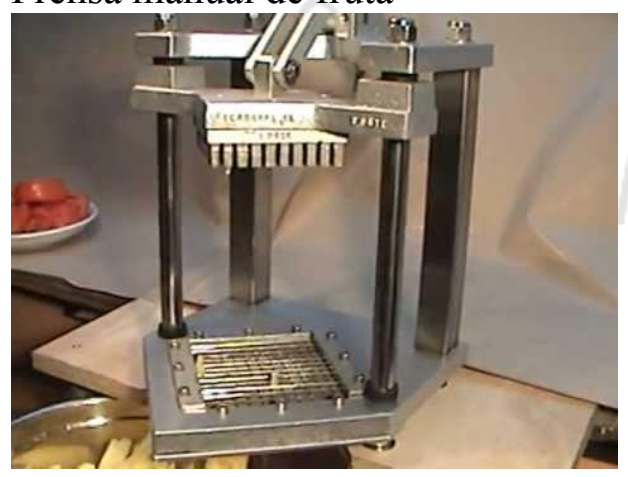

Fuente: Mecalux, (2015) 


\section{j) Equipos de acarreo}

Como equipos de acarreo tenemos las transpaletas manuales y los montacargas que ayudarán a transportar las jabas de fruta en la recepción y el producto terminado para su posterior almacenamiento y carga en los camiones de reparto.

\section{Figura 5.15}

Transpaleta manual

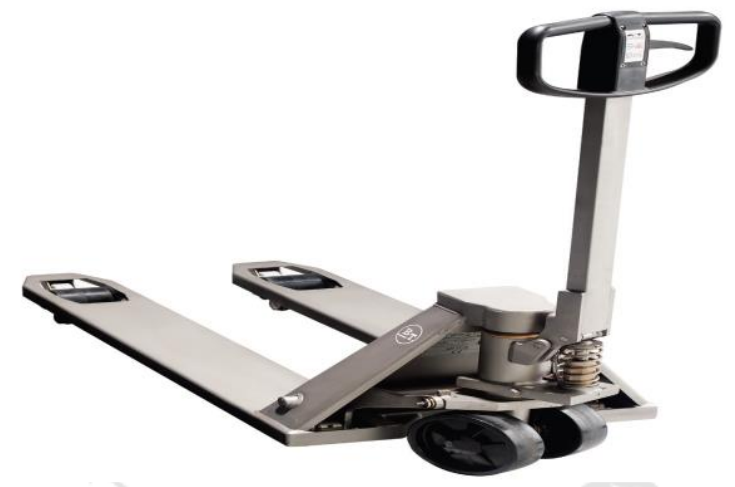

Fuente: Toyota, (2015)

Marca: Toyota

Capacidad de carga: 2 toneladas

El segundo equipo es un montacargas 8FBN15 que será operado por un trabajador para retirar las cajas con fruta de los camiones de descarga y para movilizar el producto terminado en cajas. 
Figura 5.16

Montacargas

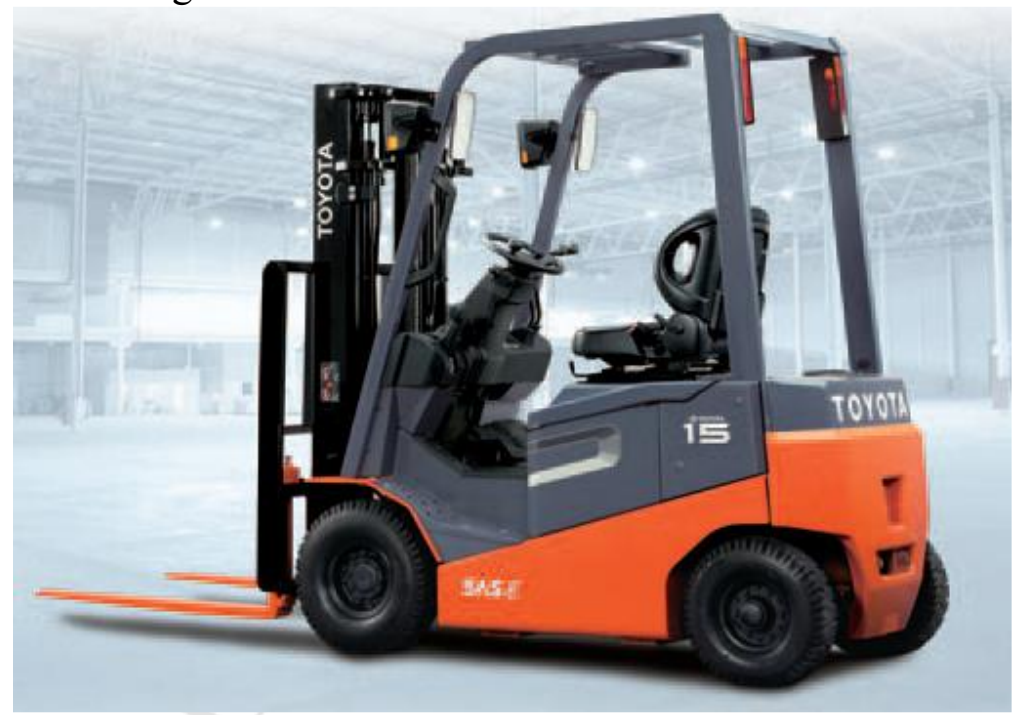

Fuente: Toyota, (2015)

Marca: Toyota

Capacidad: $1500 \mathrm{~kg}$ Ancho: 0.895 metros

Largo: 3.185 metros

Alto: 4.250 metros

Potencia: $9.5 \mathrm{~kW}$

\section{k) Estante para bandejas}

Se utilizarán estantes para colocar los envases y poderlos transportar fácilmente. 
Figura 5.17

Estante para bandejas

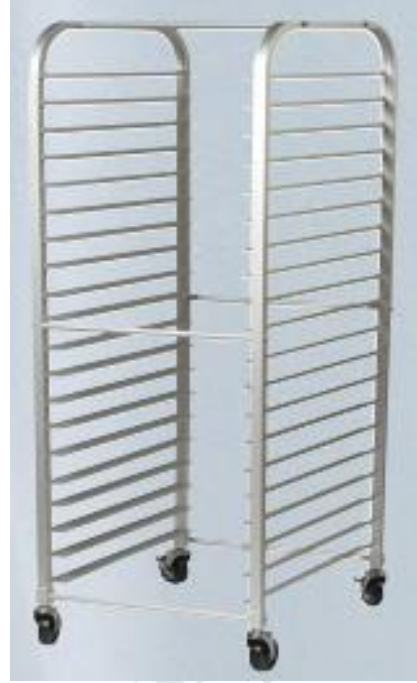

Fuente: Johnson-Rose, (2015)

Marca: Johnson-Rose

Ancho: $0.51 \mathrm{~m}$

Largo: $0.66 \mathrm{~m}$

Alto: $1.7 \mathrm{~m}$

\subsection{Capacidad instalada}

\subsubsection{Cálculo detallado del número de máquinas requeridas}

A continuación, se presenta el número detallado de máquinas para la planta: 
Tabla 5.5

Número de máquinas

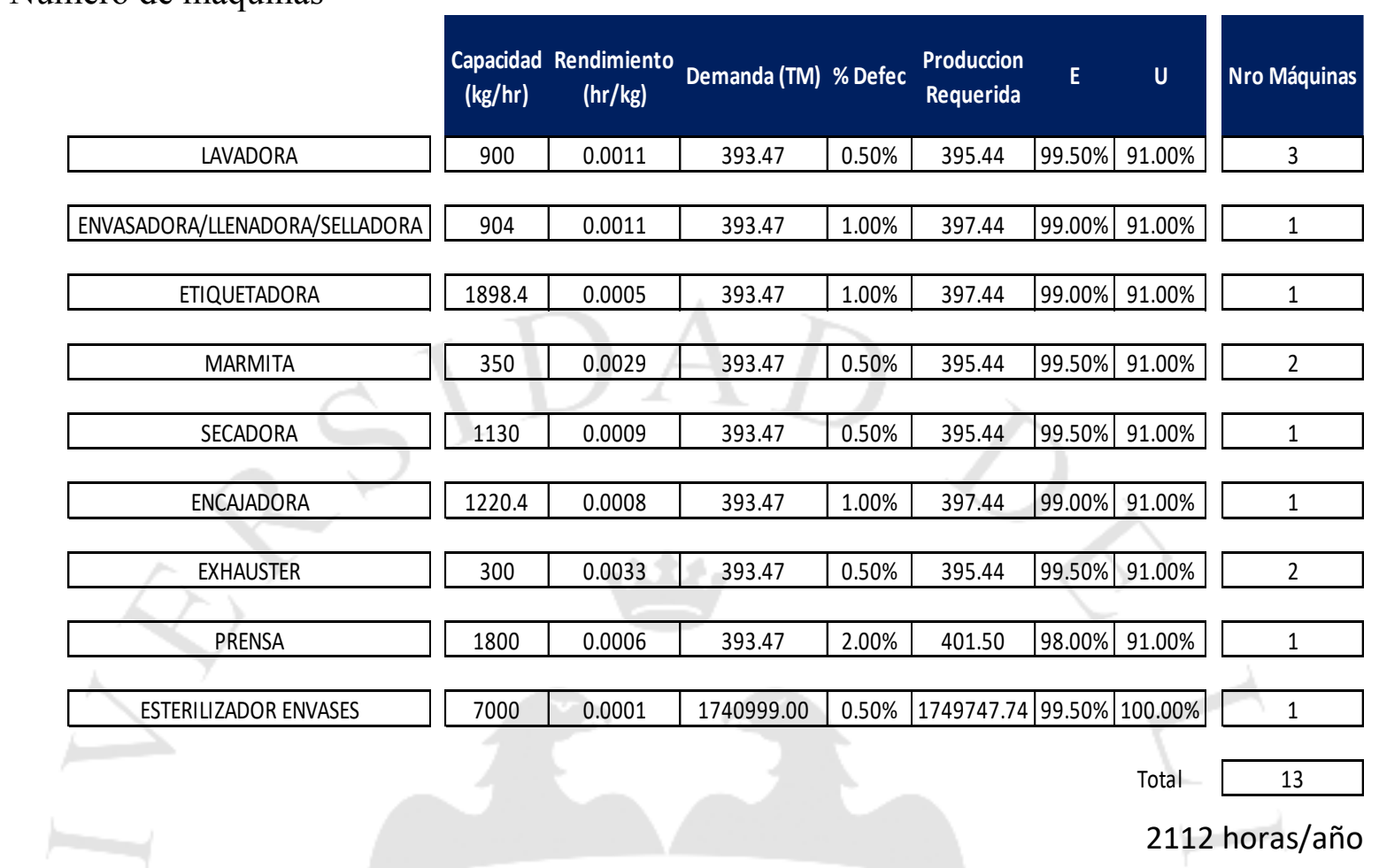

Elaboración propia

También se presenta el número de trabajadores que operarán las máquinas, en el proceso de pasteurizado con Exhauster trabajará 1 operario ya que operar por lotes es necesario cargar y descargar los productos.

Para las operaciones manuales de cortado, pesado y tapado se encargarán 2 operarios por operación ya que demanda tiempo. La operación de pelado requerirá 3 operarios debido a la carga de trabajo.

La prensa será operada por un operario ya que deberá colocar las tajadas de mango en la prensa y proceder a ejercer presión para obtener los cubos.

Para el llenado y sellado se requiere 1 operario, el operario deberá cargar con los envases y los films la máquina para que esta pueda operar de forma correcta y asimismo debe estar controlando que el almíbar se encuentre en la temperatura adecuada y este cargado en la máquina. 
La marmita será operada por 1 operario que se ocupará de cargarla con los ingredientes necesarios para la elaboración del almíbar mediante la mezcla y cocción.

La secadora será operada por un trabajador que se encargará de controlar el nivel de temperatura al cual operará la máquina.

En la encajadora trabajará 1 operario, este se encargará de cargar la máquina con cajas y verificará el correcto funcionamiento del equipo y asimismo se encargará de llevar las cajas que sal en selladas al almacén de productos terminados. Este también supervisará la operación de etiquetado, es decir también será alimentador de etiquetas.

La máquina que pasteurizará los envases será operada por un trabajador que se encargará de controlar los parámetros correctos con los que operará la máquina.

Para determinar el número de operarios requeridos se utilizó la siguiente formula:

$$
\text { Porcentaje de Saturación }=\frac{\text { Tiempo estándar } \times \text { Demanda }}{\text { Eficiencia } \times \text { Horas disponibles }}
$$


Tabla 5.6

Número de operarios

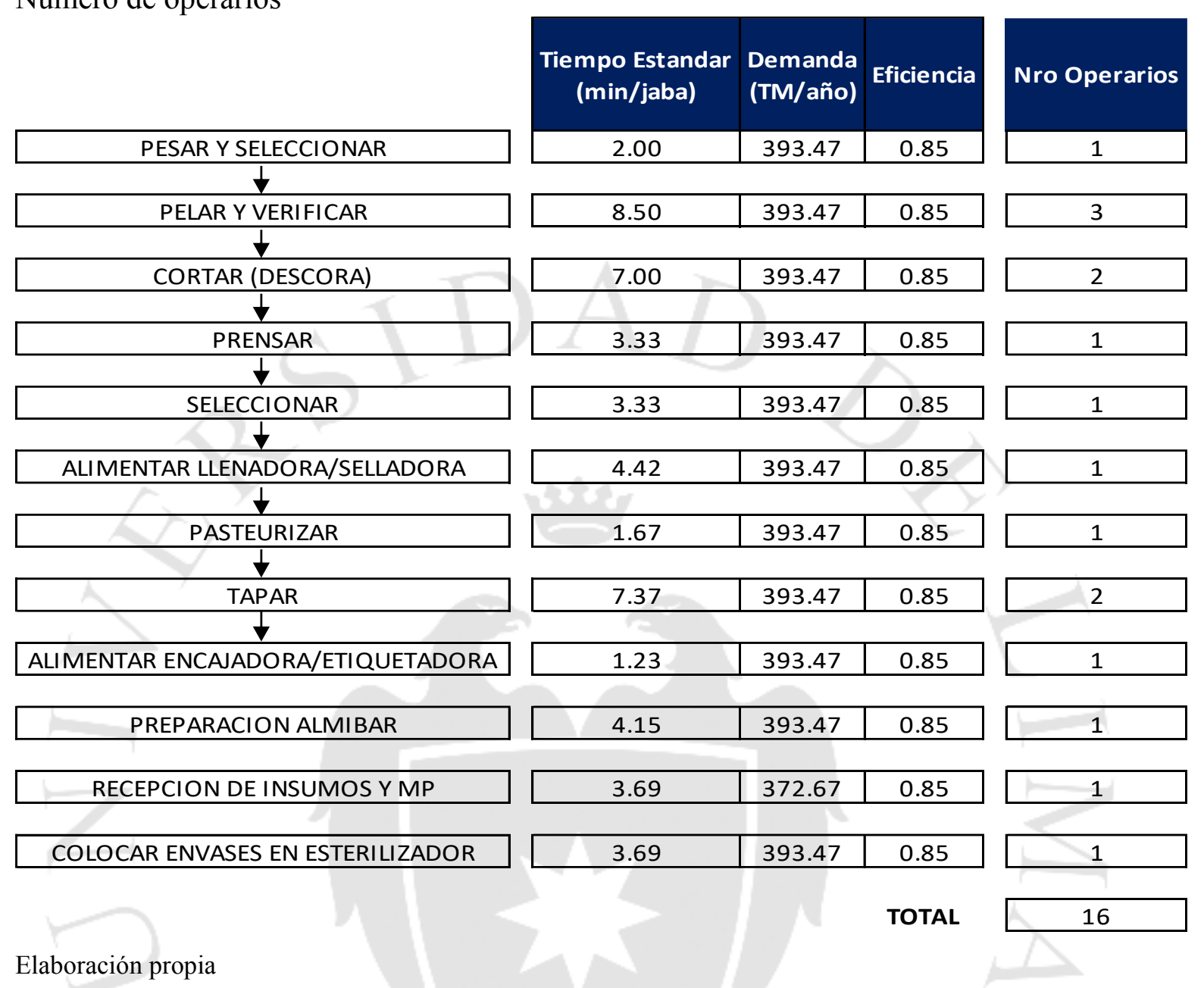

\subsubsection{Cálculo de la capacidad instalada}

La capacidad instalada está determinada por la operación en donde se genera el cuello de botella. Como se mencionó en el punto 4.3 Relación Tamaño - Tecnología el cuello de botella se origina en el Exhauster que tiene una capacidad de $300 \mathrm{~kg}$ por hora o 1328 unidades por hora.

En la planta se trabajará con 2 autoclaves para poder cubrir la demanda proyectada.

Para el cálculo de la capacidad instalada se requieren los siguientes valores:

- Factor de utilización= Número de horas programado/ Número de horas reales

El número de horas programado es de 8 horas por turno, pero dentro de este se considera 45 minutos de refrigerio con estos valores el factor de utilización es de 0.91 
- $\quad$ Factor de eficiencia= depende de la máquina

Con los datos, a continuación, el cálculo de la capacidad instalada es:

\section{Tabla 5.7}

Capacidad instalada

\begin{tabular}{|c|c|c|c|c|c|c|c|c|c|c|}
\hline Operación & $\begin{array}{c}\text { Cantidad } \\
\text { entrada } \\
(\mathrm{kg})\end{array}$ & & $\begin{array}{l}\text { Producción } \\
(\mathrm{kg} / \mathrm{h})\end{array}$ & $\begin{array}{c}\text { \# Máquinas/ } \\
\text { Hombres }\end{array}$ & $\begin{array}{c}\text { Horas reales } \\
(\mathrm{h} / \mathrm{sem})\end{array}$ & E & u & $\begin{array}{c}\text { Capacidad disponible } \\
(\mathrm{kg} / \mathrm{sem})\end{array}$ & FC (un $/ \mathrm{kg}$ ) & $\begin{array}{l}\text { Capacidad instalada } \\
\text { (und/sem) }\end{array}$ \\
\hline Pesado & 1,000 & $\mathrm{~kg}$ & 750 & 2 hombres & 48 & $95.0 \%$ & $100.0 \%$ & 68,400 & 63.42 & $4,338,065$ \\
\hline Lavado & 950 & $\mathrm{~kg}$ & 900 & \begin{tabular}{|l|l|}
3 & maquinas \\
\end{tabular} & 48 & $99.5 \%$ & $91.0 \%$ & 117,346 & 66.76 & $7,834,040$ \\
\hline Pelado & 901 & $\mathrm{~kg}$ & 176 & 3 hombres & 48 & $90.0 \%$ & $100.0 \%$ & 22,871 & 70.43 & $1,610,770$ \\
\hline \begin{tabular}{|l|} 
Cortado \\
\end{tabular} & 810 & $\mathrm{~kg}$ & 214 & \begin{tabular}{|l|l|}
2 & hombres \\
\end{tabular} & 48 & $80.0 \%$ & $100.0 \%$ & 16,457 & 78.26 & $1,287,858$ \\
\hline Prensado & 648 & $\mathrm{~kg}$ & 1,800 & 1 hombre & 48 & $98.0 \%$ & $100.0 \%$ & 84,672 & 97.82 & $8,282,540$ \\
\hline \begin{tabular}{|l|} 
Selección \\
\end{tabular} & 635 & $\mathrm{~kg}$ & 450 & 1 hombre & 48 & $97.0 \%$ & $100.0 \%$ & 20,952 & 99.82 & $2,091,342$ \\
\hline Escaldado & 616 & $\mathrm{~kg}$ & 350 & \begin{tabular}{|l|l}
1 & maquina \\
\end{tabular} & 48 & $99.5 \%$ & $91.0 \%$ & 15,212 & 102.90 & $1,565,310$ \\
\hline Llenado/Selladora & 1,022 & $\mathrm{~kg}$ & 904 & 1 maquina & 48 & $99.0 \%$ & $91.0 \%$ & 39,092 & 62.05 & $2,425,724$ \\
\hline Pasteurizado & 1,002 & $\mathrm{~kg}$ & 300 & 2 maquinas & 48 & $99.5 \%$ & $91.0 \%$ & 26,077 & 63.31 & $1,650,980$ \\
\hline Secadora & 997 & $\mathrm{~kg}$ & 1,130 & 1 maquina & 48 & $99.5 \%$ & $91.0 \%$ & 49,112 & 63.63 & $3,124,944$ \\
\hline Tapado & 992 & $\mathrm{~kg}$ & 271 & 2 hombres & 48 & $99.5 \%$ & $100.0 \%$ & 25,905 & 63.95 & $1,656,599$ \\
\hline Etiquetado & 987 & $\mathrm{~kg}$ & 1,898 & \begin{tabular}{|l|l|}
1 & maquina \\
\end{tabular} & 48 & $99.0 \%$ & $91.0 \%$ & 82,093 & 64.27 & $5,276,140$ \\
\hline Encajado & 977 & $\mathrm{~kg}$ & 1,220 & \begin{tabular}{|l|l|}
1 & maquina \\
\end{tabular} & 48 & $99.0 \%$ & $91.0 \%$ & 52,774 & 64.92 & $3,426,072$ \\
\hline Preparado de almibar & 411 & $\mathrm{~kg}$ & 350 & 1 maquina & 48 & $100.0 \%$ & $91.0 \%$ & 15,288 & 154.35 & $2,359,745$ \\
\hline Esterilizado de envases & 1,582 & $\mathrm{Kg}$ & 1,582 & 1 maquina & 48 & $100.0 \%$ & $100.0 \%$ & 75,936 & 40.09 & $3,044,256$ \\
\hline
\end{tabular}

\section{\begin{tabular}{l|r} 
Cantidad PT $\quad 1,740,999$ envases/año \\
\cline { 2 - 2 } & 63,422 envases/sem
\end{tabular}}

Elaboración propia

\subsubsection{Calidad de la materia prima, de los insumos, del proceso y del producto}

\subsubsection{Materia prima e insumos}

Para poder contar con una excelente calidad total en el proceso de producción de las conservas de mango en cubo es necesario realizar inspecciones continuas al momento de recibir la materia prima a fin de poder detectar los daños que se puedan presentar en la fruta. Estos daños pueden ser obtenidos en la pre-cosecha, en la cosecha y manejo post cosecha. A continuación, se presentan los principales defectos que puede presentar el mango según origen. 
Tabla 5.8

Principales defectos del mango según origen

A. Defectos de Origen Pre cosecha:

\begin{tabular}{|c|c|}
\hline Antracnosis & Golpes \\
\hline Daño de insecto & Pudriciones \\
\hline $\begin{array}{l}\text { Semilla gelatinosa, maduración } \\
\text { prematura }\end{array}$ & Daño por alta concentración de dióxido de carbono \\
\hline Daño de lenticelas & $\begin{array}{l}\text { Decoloración (cáscara) externa (daño por } \\
\text { tratamiento de calor o daño por frío) }\end{array}$ \\
\hline Deformidades & Inmadurez (pobre calidad durante maduración) \\
\hline Cicatrices & $\begin{array}{l}\text { Decoloración (pulpa) interna (debido a daño térmico } \\
\text { o daño por frío) }\end{array}$ \\
\hline Manchas & $\begin{array}{l}\text { Corte inapropiado (pedúnculo es más largo de } 0.5 \\
\text { pulgadas }=12.7 \mathrm{~mm} \text { ) }\end{array}$ \\
\hline Abrasiones de cáscara y rajaduras & Sobre maduro (muy suave) \\
\hline Punta blanda & Quemadura por látex \\
\hline $\begin{array}{l}\text { Ahuecamiento de la zona próxima a la } \\
\text { cicatriz del pedúnculo }\end{array}$ & Daño por deshidratación \\
\hline \multirow[t]{4}{*}{ Daño y manchas de sol } & $\begin{array}{l}\text { Áreas decoloradas y deprimidas (debido al daño por } \\
\text { frío) }\end{array}$ \\
\hline & $\begin{array}{l}\text { Área de los hombros con depresiones (debido a } \\
\text { daño en la pulpa }\end{array}$ \\
\hline & producido por el tratamiento térmico) \\
\hline & $\begin{array}{l}\text { Maduración des uniforme (daño por tratamiento } \\
\text { térmico o daño por frío) }\end{array}$ \\
\hline
\end{tabular}

Fuente: Kader, A, (2008). Parámetros de calidad y estándares de clasificación en mango

En cuanto al azúcar que será utilizada para elaborar el almíbar será necesario tener controles de calidad pero que serán realizados por el proveedor ya que se requiere tener un control de color, contenido de sacarosa, turbidez, partículas insolubles, partículas metálicas, granulometría y sulfitos. Todo esto para garantizar que el azúcar sea adecuado para elaborar el almíbar.

\subsubsection{Procesos}

Para tener una alta calidad en los procesos se requiere educar e informar a los trabajadores sobre el producto que se está elaborando. Al ser este un producto comestible se debe implantar rigurosos controles de calidad mientras se realizan los procesos, por ejemplo, deberá utilizar de manera obligatoria mascarillas, guantes largos y sujetadores de cabello en 
todos los procesos antes del sellado del producto con el propósito de evitar que ingresen contaminantes extraños al producto. También es importante que los operarios pasen por exámenes médicos que aseguren que se encuentran en óptimas condiciones de salud para trabajar, los trabajadores deberán contar con carnet de sanidad vigente. Además, se realizarán continuas labores de limpieza a las máquinas e instalaciones de la planta a fin de evitar que se mezclen los residuos de un lote terminado de procesar con uno que recién empieza su proceso. Otro aspecto es el uso de vestimenta adecuada para evitar posibles contaminantes, se prohibirá el uso de aretes, anillos, etc. Debido a que podrían ingresar al producto antes de que sea sellado.

\subsubsection{Producto}

Para determinar la calidad en el producto final será necesaria la inspección visual sobre el producto, los mangos contenidos en el recipiente por ningún motivo deberán sobresalir del medio acuoso en el que se encuentran, de lo contrario se malograrían rápidamente. Es por ello que la preparación del almíbar debe seguir los más altos estándares de calidad y seguimiento pues su buena elaboración garantizara la calidad final del mango.

También es necesario inspeccionar el correcto sellado de los envases y el llenado de almíbar ya que se debe asegurar que el almíbar cubra toda la fruta.

Se debe verificar que el almíbar sea de color claro transparente y que no aparezcan otros contaminantes dentro del envase sellado.

El tamaño de los cubos de mango será uniforme ya que se obtienen mediante una prensa; sin embargo, quedan trozos pequeños luego del prensado que son retirados por un operario que se encarga de seleccionar los que cumplen con las características de tamaño.

Cuando se reciben los mangos frescos estos son seleccionados. Se separan aquellos mangos que estén muy verdes y no aptos para ser procesados, también los que presenten algún daño, golpe o corte profundo en la superficie ya que esto generará que los cubos no sean uniformes.

Como medida de control se llevarán registros de los lotes producidos con el fin tener una trazabilidad en la producción y si se detectase un producto en malas condiciones se 
inspeccione el lote en el cual fue producido identificando las causas que generaron los defectos en el producto y poder corregirlas.

Como plan de inspección se realizarán muestreos aleatorios en los lotes de productos, pruebas destructivas para poder analizar los parámetros de acidez, grados brix, tamaño de la fruta etc. Esto con la finalidad de detectar que los productos se encuentren en las condiciones adecuadas y cumplan con la calidad ofrecida.

A continuación, se presenta el análisis de los puntos críticos y la matriz de riesgos con los medios preventivos que se aplicar

Figura 5.18

Análisis de puntos críticos

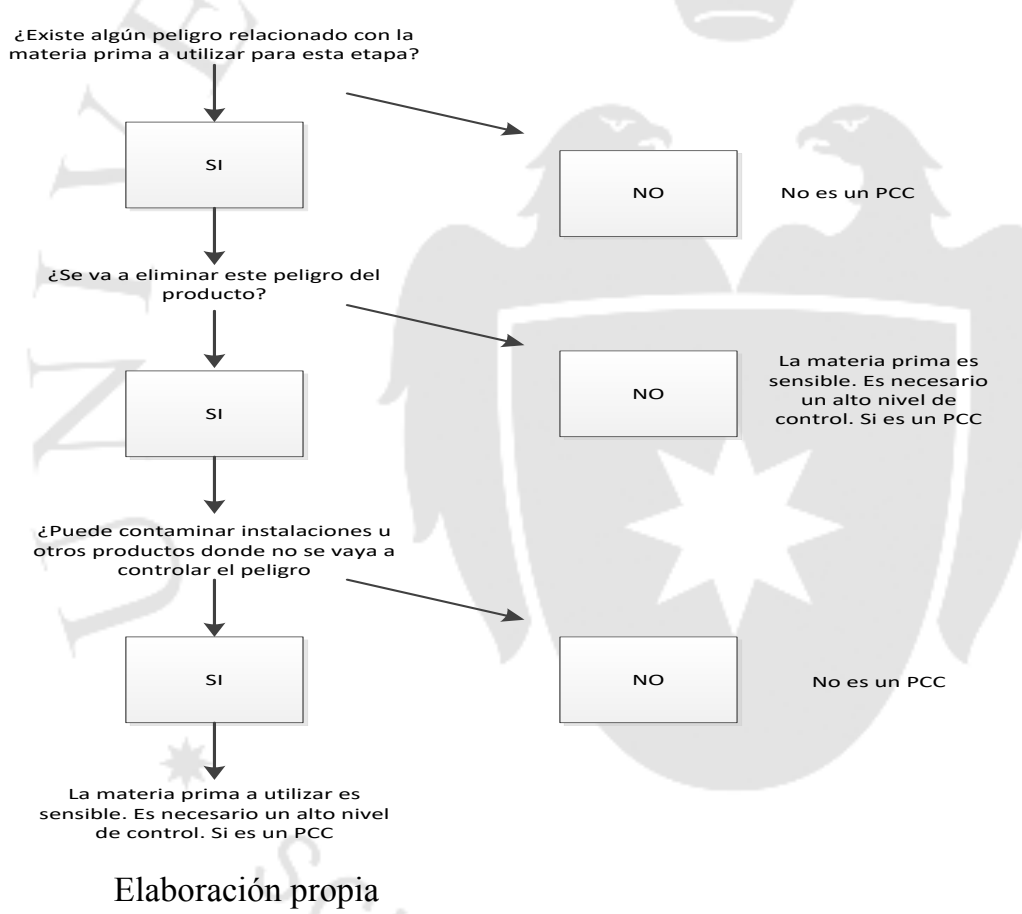


Tabla 5.9

\section{Matriz de riesgo}

\begin{tabular}{|c|c|c|c|c|c|}
\hline Etapa del Proceso & Peligros & $\begin{array}{l}\text { Algún peligro } \\
\text { significativo } \\
\text { para la } \\
\text { seguridad del } \\
\text { alimento }\end{array}$ & $\begin{array}{l}\text { Justifique su decisión de } \\
\text { la columna }\end{array}$ & $\begin{array}{l}\text { Que medios preventivos } \\
\text { pueden ser aplicados }\end{array}$ & $\begin{array}{c}\text { Es esa etapa un } \\
\text { PCC? }\end{array}$ \\
\hline $\begin{array}{l}\text { Recepción de la } \\
\text { materia prima }\end{array}$ & $\begin{array}{l}\text { Biológico: } \\
\text { Crecimiento } \\
\text { Bacteriológico. } \\
\text { Descomposición. } \\
\text { Físico: } \\
\text { Contaminación por } \\
\text { ambiente de descarga. }\end{array}$ & $\begin{array}{l}\text { SI } \\
\text { SI }\end{array}$ & $\begin{array}{c}\text { La fruta puede ser } \\
\text { contaminada por residuos } \\
\text { en el suelo o del ambiente } \\
\text { los camiones están } \\
\text { contaminados por el viaje y } \\
\text { todo lo relacionado con el } \\
\text { transporte y la descarga }\end{array}$ & $\begin{array}{l}\text { Lavar y desinfectar antes de } \\
\text { utilizar las herramientas de } \\
\text { descarga }\end{array}$ & SI \\
\hline Selección & $\begin{array}{l}\text { Biológico: } \\
\text { Crecimiento } \\
\text { Bacteriológico. } \\
\text { Descomposición. } \\
\text { Físico: } \\
\text { Contaminación de las } \\
\text { mesas de selección y } \\
\text { equipos de transporte }\end{array}$ & $\begin{array}{l}\text { SI } \\
\text { NO }\end{array}$ & $\begin{array}{l}\text { La fruta puede ser } \\
\text { contaminada por residuos } \\
\text { en el suelo o del ambiente } \\
\text { Las mesas son } \\
\text { desinfectadas al inicio del } \\
\text { turno de trabajo al igual } \\
\text { que las carretillas de } \\
\text { transporte }\end{array}$ & $\begin{array}{l}\text { Tener un personal de limpieza } \\
\text { encargado de limpiar las } \\
\text { instalaciones diariamente para } \\
\text { mantener la fábrica libre de } \\
\text { polvo u otros contaminantes }\end{array}$ & SI \\
\hline Lavado & $\begin{array}{l}\text { Biológico: } \\
\text { Contaminación } \\
\text { Microbiológica u } \\
\text { organismos patógenos. } \\
\text { Descomposición. }\end{array}$ & NO & $\begin{array}{c}\text { Las tinas de lavado son } \\
\text { desinfectadas al inicio del } \\
\text { turno de trabajo al igual } \\
\text { que las carretillas de } \\
\text { transporte } \\
\text { El agua de lavado tiene } \\
\text { una calidad sanitaria } \\
\text { adecuada } \\
\end{array}$ & $\begin{array}{l}\text { Tener un personal de limpieza } \\
\text { encargado de limpiar las } \\
\text { instalaciones diariamente para } \\
\text { mantener la fábrica libre de } \\
\text { polvo u otros contaminantes }\end{array}$ & NO \\
\hline Pelado & $\begin{array}{l}\text { Biológico: } \\
\text { Contaminación } \\
\text { Microbiológica. } \\
\text { Descomposición. } \\
\text { Físico: } \\
\text { Contaminación por } \\
\text { residuos en cuchillos, } \\
\text { máquinas y manos del } \\
\text { operario contaminadas }\end{array}$ & NO & $\begin{array}{l}\text { La fruta puede ser } \\
\text { contaminada por residuos } \\
\text { en el suelo o del ambiente } \\
\text { Las máquinas son } \\
\text { desinfectadas al inicio del } \\
\text { turno de trabajo al igual } \\
\text { que las carretillas de } \\
\text { transporte y manos del } \\
\text { operario con gel } \\
\text { desinfectante }\end{array}$ & $\begin{array}{l}\text { Tener un personal de limpieza } \\
\text { encargado de limpiar las } \\
\text { instalaciones diariamente para } \\
\text { mantener la fábrica libre de } \\
\text { polvo u otros contaminantes }\end{array}$ & NO \\
\hline Cortado & $\begin{array}{l}\text { Biológico: } \\
\text { Contaminación } \\
\text { Microbiológica } \\
\text { Descomposición } \\
\text { Físico: } \\
\text { Contaminación por } \\
\text { residuos en cuchillos, } \\
\text { máquinas y manos del } \\
\text { operario contaminadas }\end{array}$ & 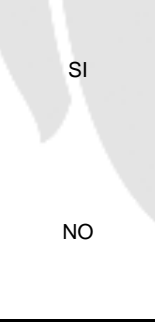 & $\begin{array}{l}\text { La fruta puede ser } \\
\text { contaminada por residuos } \\
\text { en el suelo o del ambiente } \\
\text { Las máquinas son } \\
\text { desinfectadas al inicio del } \\
\text { turno de trabajo al igual } \\
\text { que las carretillas de } \\
\text { transporte y manos del } \\
\text { operario con gel } \\
\text { desinfectante }\end{array}$ & $\begin{array}{l}\text { Tener un personal de limpieza } \\
\text { encargado de limpiar las } \\
\text { instalaciones diariamente para } \\
\text { mantener la fábrica libre de } \\
\text { polvo u otros contaminantes }\end{array}$ & NO \\
\hline Llenado & $\begin{array}{l}\text { Biológico: } \\
\text { Contaminación } \\
\text { Microbiológica u } \\
\text { organismos patógenos } \\
\text { Físico: } \\
\text { Contaminación por } \\
\text { residuos }\end{array}$ & $\begin{array}{l}\text { SI } \\
\text { NO }\end{array}$ & $\begin{array}{l}\text { La fruta cortada puede ser } \\
\text { contaminada por residuos } \\
\text { en el suelo o del ambiente } \\
\text { Las máquinas son } \\
\text { desinfectadas al inicio del } \\
\text { turno de trabajo al igual } \\
\text { que las carretillas de } \\
\text { transporte }\end{array}$ & $\begin{array}{l}\text { Tener un personal de limpieza } \\
\text { encargado de limpiar las } \\
\text { instalaciones diariamente para } \\
\text { mantener la fábrica libre de } \\
\text { polvo u otros contaminantes }\end{array}$ & NO \\
\hline Pasteurizado & $\begin{array}{l}\text { Biológico: } \\
\text { Supervivencia de } \\
\text { microorganismos } \\
\text { patógenos }\end{array}$ & SI & $\begin{array}{l}\text { No se llega a una } \\
\text { adecuada temperatura en } \\
\text { toda la autoclave }\end{array}$ & $\begin{array}{l}\text { Mantener un control adecuado } \\
\text { de la homogeneidad de la } \\
\text { temperatura de pasteurizado } \\
\text { así como un mantenimiento } \\
\text { periódico de los instrumentos } \\
\text { de medición }\end{array}$ & SI \\
\hline
\end{tabular}

Elaboración propia 
Tabla 5.10

Matriz HACCP

\begin{tabular}{|c|c|c|c|c|c|c|c|c|c|}
\hline \multicolumn{10}{|c|}{ Plan de HACCP } \\
\hline \multirow{2}{*}{$\begin{array}{c}\text { Puntos de } \\
\text { Control } \\
\text { Críticos }\end{array}$} & \multirow{2}{*}{$\begin{array}{c}\text { Peligros } \\
\text { Significativos }\end{array}$} & \multirow{2}{*}{$\begin{array}{l}\text { Límites para } \\
\text { cada medida } \\
\text { preventiva }\end{array}$} & \multicolumn{4}{|c|}{ Monitoreo } & \multirow{2}{*}{$\begin{array}{l}\text { Acciones } \\
\text { correctivas }\end{array}$} & \multirow{2}{*}{ Registro } & \multirow{2}{*}{$\begin{array}{l}\text { Verific } \\
\text { ación }\end{array}$} \\
\hline & & & Que & Como & Frecuencia & Quien & & & \\
\hline $\begin{array}{c}\text { Recepción } \\
\text { de la } \\
\text { materia } \\
\text { prima }\end{array}$ & $\begin{array}{l}\text { Biológico: } \\
\text { Crecimiento } \\
\text { Bacteriológico } \\
\text { Descomposición } \\
\text { Físico: } \\
\text { Contaminación por } \\
\text { ambiente de } \\
\text { descarga }\end{array}$ & $\begin{array}{c}\text { Presencia de } \\
\text { polvo, fruta en } \\
\text { descomposició } \\
\text { n, grasa u otros } \\
\text { objetos líquidos } \\
\text { contaminantes }\end{array}$ & $\begin{array}{c}\text { Presencia } \\
\text { excesiva } \\
\text { de material } \\
\text { contamina } \\
\text { nte sobre } \\
\text { la fruta }\end{array}$ & Visual & $\begin{array}{l}\text { Cada lote } \\
\text { recibido }\end{array}$ & $\begin{array}{l}\text { Personal } \\
\text { encargado } \\
\text { de la } \\
\text { recepción } \\
\text { de la } \\
\text { materia } \\
\text { prima }\end{array}$ & $\begin{array}{c}\text { Cambiar } \\
\text { proveedores } \\
\text { de transporte }\end{array}$ & $\begin{array}{l}\text { Registro del } \\
\text { número de } \\
\text { guía del } \\
\text { proveedor }\end{array}$ & Diaria \\
\hline Selección & $\begin{array}{l}\text { Biológico: } \\
\text { Crecimiento } \\
\text { Bacteriológico } \\
\text { Descomposición }\end{array}$ & $\begin{array}{l}\text { Presencia de } \\
\text { polvo, fruta en } \\
\text { descomposició } \\
\text { n, maltratada u } \\
\text { otros objetos o } \\
\text { líquidos } \\
\text { contaminantes }\end{array}$ & $\begin{array}{c}\text { Presencia } \\
\text { excesiva } \\
\text { de material } \\
\text { contamina } \\
\text { nte sobre } \\
\text { la fruta }\end{array}$ & Visual & $\begin{array}{c}\text { Cada } \\
\text { carretilla de } \\
\text { transporte }\end{array}$ & $\begin{array}{l}\text { Personal } \\
\text { encargado } \\
\text { de la } \\
\text { selección } \\
\text { de la } \\
\text { materia } \\
\text { prima }\end{array}$ & $\begin{array}{l}\text { En primer } \\
\text { lugar, } \\
\text { capacitar al } \\
\text { personal, } \\
\text { pero si es } \\
\text { reincidente } \\
\text { aplicar } \\
\text { medidas más } \\
\text { drásticas }\end{array}$ & $\begin{array}{l}\text { Registro de } \\
\text { cada turno } \\
\text { de trabajo }\end{array}$ & Diaria \\
\hline Pasteurizar & $\begin{array}{l}\text { Biológico: } \\
\text { Supervivencia de } \\
\text { microorganismos } \\
\text { patógenos }\end{array}$ & $\begin{array}{l}\text { Ph de } 3.34+- \\
0.312 \\
\text { Grados Brix } \\
\text { entre } 10 \text { y } 14 \\
\text { Temperatura } \\
\text { de } 100 \text { grados } \\
\text { centígrados }\end{array}$ & $\begin{array}{l}\text { Parámetro } \\
\text { s físico - } \\
\text { químicos }\end{array}$ & $\begin{array}{l}\text { Pruebas } \\
\text { de } \\
\text { acidez }\end{array}$ & $\begin{array}{l}\text { Cada lote } \\
\text { pasteurizado }\end{array}$ & $\begin{array}{c}\text { Personal } \\
\text { encargado } \\
\text { del control } \\
\text { del equipo } \\
\text { de } \\
\text { pasteuriza } \\
\text { do }\end{array}$ & $\begin{array}{l}\text { Recalibrar } \\
\text { los } \\
\text { parámetros } \\
\text { del } \\
\text { pasteurizador }\end{array}$ & $\begin{array}{l}\text { Registro de } \\
\text { las } \\
\text { modificacion } \\
\text { es hechas a } \\
\text { la máquina } \\
\text { de } \\
\text { pasteurizado }\end{array}$ & Diaria \\
\hline
\end{tabular}

Elaboración propia

\subsubsection{Estrategia de mejora}

Se pretende implementar método de prevención de defectos para la administración de procesos, el cual disminuye el índice de productos terminados defectuosos e impide errores en futuras producciones. Este método implica herramientas que facilitan el análisis de los procesos tales como las gráficas de control para organizar y presentar datos para detectar las áreas donde la calidad y el rendimiento se deben mejorar. 


\subsection{Impacto ambiental}

La generación de efluentes es inevitable en todo proceso productivo, el presente proyecto genera efluentes en el lavado de la materia prima, para eliminar polvo y posibles restos de insecticida que puedan contener los mangos. Además de esto las máquinas que utilizaremos deberán ser lavadas antes y después de cada turno de trabajo.

Durante el proceso de pelado y descorazonado se produce una gran cantidad de merma por las cáscaras y los huesos o semillas, pero estas pueden tener otros usos debido a sus propiedades, por ejemplo, se puede extraer aceite de las semillas y de la cascara se pueden obtener pectinas y fibra que se pueden vender.

El proyecto presentado no genera un gran impacto ambiental debido a que se trata de procesamiento de alimentos. La mayor cantidad de desperdicios será de tipo orgánico representado por las mermas que se tengan en la producción y los cambios o transformaciones serán realizados sobre la materia prima.

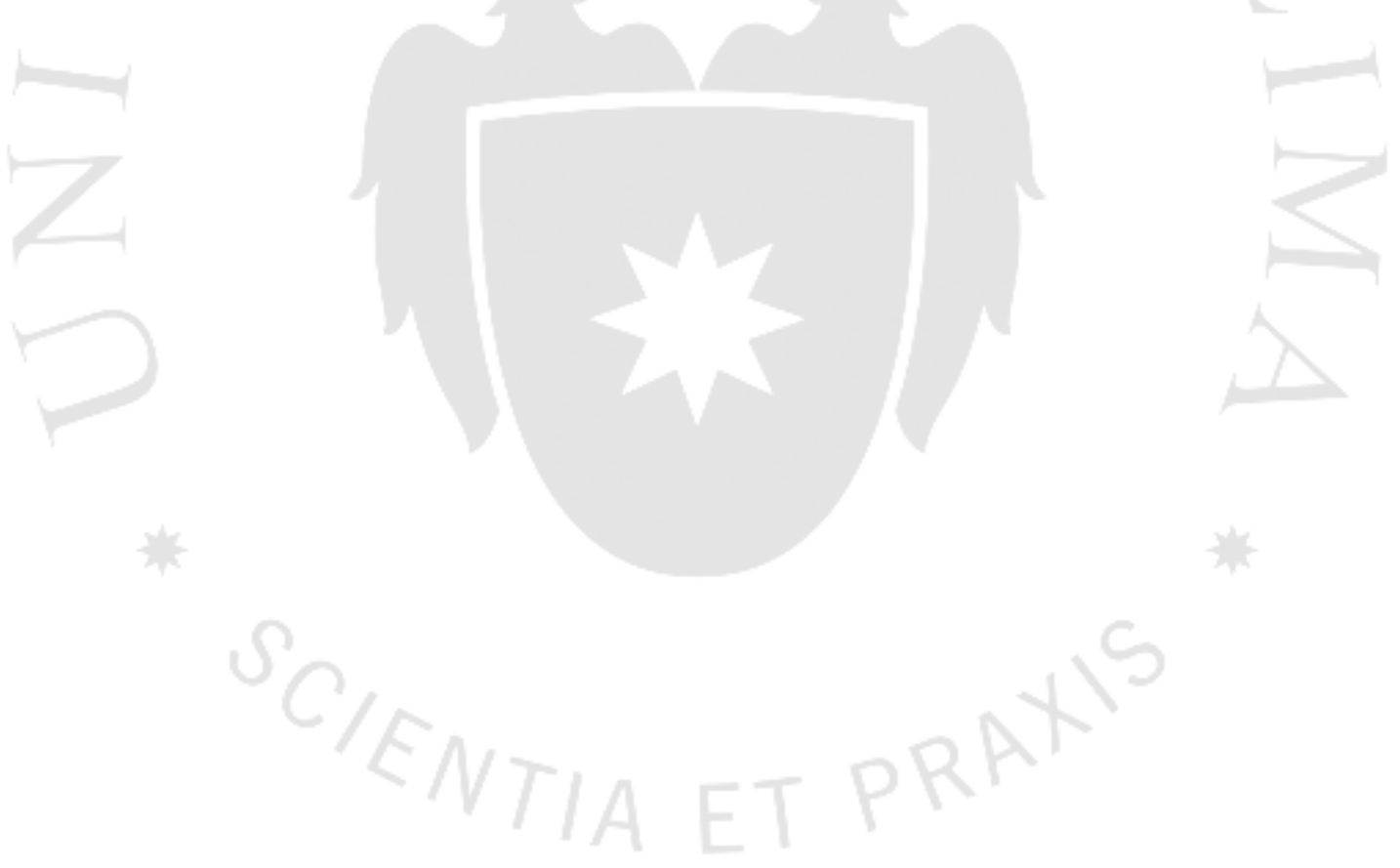


Tabla 5.11

Matriz de evaluación de Impactos ambientales

\begin{tabular}{|c|c|c|c|c|}
\hline Sub-proceso & Aspecto ambiental & Impacto ambiental & $\begin{array}{l}\text { Recurso } \\
\text { afectado }\end{array}$ & Control operacional \\
\hline $\begin{array}{l}\text { Recepción de } \\
\text { mango }\end{array}$ & Eliminación de jabas & $\begin{array}{l}\text { Contaminación del } \\
\text { suelo }\end{array}$ & Suelo & Programa de gestión de jabas \\
\hline $\begin{array}{l}\text { Selección de } \\
\text { mango }\end{array}$ & $\begin{array}{l}\text { Eliminación de mangos } \\
\text { en mal estado } \\
\text { (podridos) y/o no } \\
\text { maduros } \\
\end{array}$ & $\begin{array}{l}\text { Contaminación del } \\
\text { suelo }\end{array}$ & Suelo & Programa de gestión de frutos desechados \\
\hline \multirow[b]{2}{*}{ Lavado } & Consumo de agua & $\begin{array}{l}\text { Agotamiento de los } \\
\text { recursos naturales }\end{array}$ & Agua & Programa de uso eficiente del agua \\
\hline & $\begin{array}{l}\text { Uso de detergentes y } \\
\text { lejía }\end{array}$ & $\begin{array}{l}\text { Contaminación del } \\
\text { mar y ríos }\end{array}$ & $\begin{array}{l}\text { Mar, } \\
\text { Ríos }\end{array}$ & $\begin{array}{l}\text { Evaluación de consumo, programa de gestión } \\
\text { de residuos y envases, procedimiento de } \\
\text { emergencia para derrames. }\end{array}$ \\
\hline Pelado & Eliminación de cáscaras & $\begin{array}{l}\text { Contaminación del } \\
\text { suelo }\end{array}$ & Suelo & Programa de gestión de residuos sólidos \\
\hline Cortado & $\begin{array}{l}\text { Eliminación de pepas } \\
\text { de mango }\end{array}$ & \begin{tabular}{|l} 
Contaminación del \\
suelo
\end{tabular} & Suelo & Programa de gestión de residuos sólidos \\
\hline Prensado & $\begin{array}{l}\text { Eliminación de residuos } \\
\text { de mango }\end{array}$ & $\begin{array}{l}\text { Contaminación del } \\
\text { suelo }\end{array}$ & Suelo & Programa de gestión de residuos sólidos \\
\hline $\begin{array}{l}\text { Selección de } \\
\text { cubos de mango } \\
\text { prensados }\end{array}$ & $\begin{array}{l}\text { Eliminación de residuos } \\
\text { de mango mal prensado }\end{array}$ & $\begin{array}{l}\text { Contaminación del } \\
\text { suelo }\end{array}$ & Suelo & Programa de gestión de residuos sólidos \\
\hline \multirow{2}{*}{ Escaldado } & $\begin{array}{l}\text { Eliminación de almíbar } \\
\text { residual }\end{array}$ & $\begin{array}{l}\text { Contaminación del } \\
\text { mar y ríos }\end{array}$ & $\begin{array}{l}\text { Mar, } \\
\text { Ríos }\end{array}$ & $\begin{array}{l}\text { Evaluación de consumo, programa de gestión } \\
\text { de residuos }\end{array}$ \\
\hline & Consumo de agua & $\begin{array}{l}\text { Agotamiento de los } \\
\text { recursos naturales }\end{array}$ & Agua & Programa de uso eficiente del agua \\
\hline \multirow{2}{*}{ Llenado } & $\begin{array}{l}\text { Consumo de energía } \\
\text { eléctrica }\end{array}$ & $\begin{array}{l}\text { Agotamiento de los } \\
\text { recursos naturales }\end{array}$ & \begin{tabular}{|l|}
$\begin{array}{c}\text { Energía } \\
\text { eléctrica }\end{array}$ \\
\end{tabular} & $\begin{array}{l}\text { Programa de uso eficiente de la energía } \\
\text { eléctrica }\end{array}$ \\
\hline & Eliminación de residuos & $\begin{array}{l}\text { Contaminación del } \\
\text { suelo }\end{array}$ & Suelo & Programa de gestión de residuos sólidos \\
\hline \multirow{2}{*}{ Sellado } & \begin{tabular}{|l}
$\begin{array}{l}\text { Consumo de energía } \\
\text { eléctrica }\end{array}$ \\
\end{tabular} & \begin{tabular}{|l|}
$\begin{array}{l}\text { Agotamiento de los } \\
\text { recursos naturales }\end{array}$ \\
\end{tabular} & \begin{tabular}{|l}
$\begin{array}{l}\text { Energía } \\
\text { eléctrica }\end{array}$ \\
\end{tabular} & $\begin{array}{l}\begin{array}{l}\text { Programa de uso eficiente de la energía } \\
\text { eléctrica }\end{array} \\
\end{array}$ \\
\hline & Eliminación de residuos & \begin{tabular}{|l}
$\begin{array}{l}\text { Contaminación del } \\
\text { suelo }\end{array}$ \\
\end{tabular} & Suelo & Programa de gestión de residuos sólidos \\
\hline \multirow{3}{*}{ Pasteurizado } & $\begin{array}{l}\text { Consumo de energía } \\
\text { eléctrica }\end{array}$ & \begin{tabular}{|l|}
$\begin{array}{l}\text { Agotamiento de los } \\
\text { recursos naturales }\end{array}$ \\
\end{tabular} & \begin{tabular}{|l|}
$\begin{array}{c}\text { Energía } \\
\text { eléctrica }\end{array}$ \\
\end{tabular} & $\begin{array}{l}\text { Programa de uso eficiente de la energía } \\
\text { eléctrica }\end{array}$ \\
\hline & Consumo de agua & \begin{tabular}{|l|} 
Agotamiento de los \\
recursos naturales
\end{tabular} & Agua & Programa de uso eficiente del agua \\
\hline & Uso de vapor & $\begin{array}{l}\text { Contaminación del } \\
\text { aíre }\end{array}$ & Aire & Programa de gestión de vapor \\
\hline \multirow{2}{*}{ Lavado } & $\begin{array}{l}\text { Consumo de energía } \\
\text { eléctrica }\end{array}$ & \begin{tabular}{|l|}
$\begin{array}{l}\text { Agotamiento de los } \\
\text { recursos naturales }\end{array}$ \\
\end{tabular} & \begin{tabular}{|l|}
$\begin{array}{c}\text { Energía } \\
\text { eléctrica }\end{array}$ \\
\end{tabular} & $\begin{array}{l}\text { Programa de uso eficiente de la energía } \\
\text { eléctrica }\end{array}$ \\
\hline & Consumo de agua & $\begin{array}{l}\text { Agotamiento de los } \\
\text { recursos naturales }\end{array}$ & Agua & Programa de uso eficiente del agua \\
\hline Secado & $\begin{array}{l}\text { Consumo de energía } \\
\text { eléctrica }\end{array}$ & $\begin{array}{l}\text { Agotamiento de los } \\
\text { recursos naturales }\end{array}$ & \begin{tabular}{|l|} 
Energía \\
eléctrica
\end{tabular} & $\begin{array}{l}\text { Programa de uso eficiente de la energía } \\
\text { eléctrica }\end{array}$ \\
\hline \multirow{2}{*}{ Tapado } & Eliminación de residuos & $\begin{array}{l}\text { Contaminación del } \\
\text { suelo }\end{array}$ & Suelo & Programa de gestión de residuos sólidos \\
\hline & Uso de tapas de plástico & $\begin{array}{l}\text { Contaminación del } \\
\text { suelo }\end{array}$ & Suelo & $\begin{array}{l}\text { Programa de gestión de envases y productos } \\
\text { defectuosos }\end{array}$ \\
\hline \multirow{2}{*}{ Etiquetado } & $\begin{array}{l}\text { Consumo de energía } \\
\text { eléctrica }\end{array}$ & $\begin{array}{l}\text { Agotamiento de los } \\
\text { recursos naturales }\end{array}$ & \begin{tabular}{|c|}
$\begin{array}{c}\text { Energía } \\
\text { eléctrica }\end{array}$ \\
\end{tabular} & $\begin{array}{l}\text { Programa de uso eficiente de la energía } \\
\text { eléctrica }\end{array}$ \\
\hline & Uso de etiquetas & $\begin{array}{l}\text { Contaminación del } \\
\text { suelo }\end{array}$ & Suelo & $\begin{array}{l}\text { Programa de gestión de envases y productos } \\
\text { defectuosos }\end{array}$ \\
\hline \multirow{2}{*}{ Encajado } & $\begin{array}{l}\text { Consumo de energía } \\
\text { eléctrica }\end{array}$ & $\begin{array}{l}\text { Agotamiento de los } \\
\text { recursos naturales }\end{array}$ & \begin{tabular}{|c|} 
Energía \\
eléctrica
\end{tabular} & $\begin{array}{l}\text { Programa de uso eficiente de la energía } \\
\text { eléctrica }\end{array}$ \\
\hline & Uso de cajas & \begin{tabular}{|l|}
$\begin{array}{l}\text { Contaminación del } \\
\text { suelo }\end{array}$ \\
\end{tabular} & Suelo & $\begin{array}{l}\text { Programa de gestión de envases y productos } \\
\text { defectuosos }\end{array}$ \\
\hline \multirow{2}{*}{$\begin{array}{l}\text { Elaboración de } \\
\text { almíbar }\end{array}$} & $\begin{array}{l}\text { Consumo de energía } \\
\text { eléctrica }\end{array}$ & $\begin{array}{l}\text { Agotamiento de los } \\
\text { recursos naturales }\end{array}$ & $\begin{array}{l}\text { Energía } \\
\text { eléctrica } \\
\end{array}$ & $\begin{array}{l}\text { Programa de uso eficiente de la energía } \\
\text { eléctrica }\end{array}$ \\
\hline & Consumo de agua & $\begin{array}{l}\text { Agotamiento de los } \\
\text { recursos naturales }\end{array}$ & Agua & Programa de uso eficiente del agua \\
\hline
\end{tabular}

Elaboración propia 
Tabla 5.12

Tabla de valoración de factores

\begin{tabular}{|c|c|c|}
\hline \multicolumn{3}{|r|}{ Tabla de valoración de los factores } \\
\hline Factores & Puntaje & Descripción \\
\hline \multirow{2}{*}{ Legal } & 1 & La organización cumple con los requisitos legales \\
\hline & 2 & La organización no cumple con los requisitos legales \\
\hline \multirow{2}{*}{$\begin{array}{l}\text { Grado de } \\
\text { influencia }\end{array}$} & 1 & La organización no tiene influencia en el aspecto ambiental \\
\hline & 2 & La organización tiene influencia \\
\hline \multirow{3}{*}{ Frecuencia } & 1 & El aspecto ambiental solo aflora en circunstancias especiales \\
\hline & 2 & Una vez a la semana \\
\hline & 3 & Diario \\
\hline \multirow{3}{*}{$\begin{array}{l}\text { Severidad en } \\
\text { situación } \\
\text { normal }\end{array}$} & 1 & El efecto no es severo \\
\hline & 2 & El efecto no es dañino a las personas pero deteriora el ambiente \\
\hline & 3 & El efecto es considerable \\
\hline \multirow{3}{*}{ Escala } & 1 & Limitada \\
\hline & 2 & Promedio \\
\hline & 3 & Grande \\
\hline \multirow{3}{*}{$\begin{array}{l}\text { Severidad en } \\
\text { caso de } \\
\text { accidente }\end{array}$} & 1 & Baja \\
\hline & 2 & Normal \\
\hline & 3 & Alta \\
\hline
\end{tabular}

Elaboración propia 
Tabla 5.13

Registro de la evaluación de aspectos ambientales

\begin{tabular}{|c|c|c|c|c|c|c|c|c|c|c|c|c|c|}
\hline 胥 & 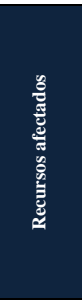 & 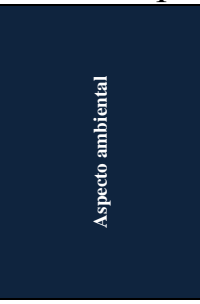 & 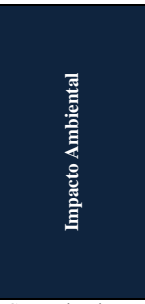 & 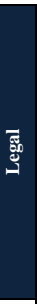 & 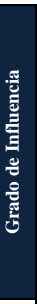 & 遌 & 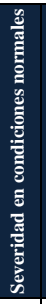 & 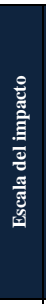 & 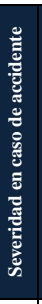 & 苞 & 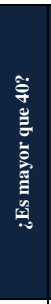 & 윰 & 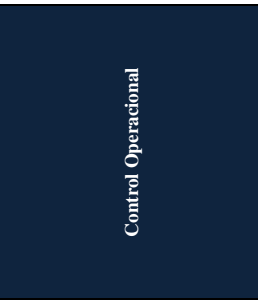 \\
\hline $\begin{array}{l}\text { Recepción de } \\
\text { mango }\end{array}$ & Suelo & Eliminación de jabas & $\begin{array}{l}\text { Contaminación } \\
\text { del suelo }\end{array}$ & 1 & 1 & 2 & 1 & 2 & 1 & 4 & NO & $\begin{array}{c}\text { No } \\
\text { Significativo } \\
\end{array}$ & Programa de gestión de jabas \\
\hline $\begin{array}{l}\text { Selección de } \\
\text { mango }\end{array}$ & Suelo & $\begin{array}{l}\text { Eliminación de mangos } \\
\text { en mal estado } \\
\text { (podridos) y/o no } \\
\text { maduros } \\
\end{array}$ & $\begin{array}{l}\text { Contaminación } \\
\text { del suelo }\end{array}$ & 1 & 2 & 2 & 2 & 2 & 2 & 32 & NO & $\begin{array}{c}\text { No } \\
\text { Significativo }\end{array}$ & $\begin{array}{l}\text { Programa de gestión de frutos } \\
\text { desechados }\end{array}$ \\
\hline \multirow[b]{2}{*}{$\begin{array}{l}\text { Lavado de } \\
\text { fruta }\end{array}$} & Agua & Consumo de agua & $\begin{array}{l}\text { Agotamiento de } \\
\text { los recursos } \\
\text { naturales }\end{array}$ & 1 & 2 & 3 & 2 & 2 & 2 & 48 & SI & $\begin{array}{l}\text { Aspecto } \\
\text { Significativo }\end{array}$ & $\begin{array}{l}\text { Programa de uso eficiente del } \\
\text { agua }\end{array}$ \\
\hline & $\begin{array}{l}\text { Mar, } \\
\text { Ríos }\end{array}$ & $\begin{array}{l}\text { Uso de detergentes y } \\
\text { lejía }\end{array}$ & $\begin{array}{l}\text { Contaminación } \\
\text { del mar y ríos }\end{array}$ & 1 & 2 & 3 & 2 & 2 & 3 & 72 & SI & $\begin{array}{c}\text { Aspecto } \\
\text { Significativo }\end{array}$ & $\begin{array}{l}\text { Evaluación de consumo, } \\
\text { programa de gestión de residuos } \\
\text { y envases, procedimiento de } \\
\text { emergencia para derrames. }\end{array}$ \\
\hline Pelado & Suelo & Eliminación de cáscaras & $\begin{array}{l}\text { Contaminación } \\
\text { del suelo }\end{array}$ & 1 & 2 & 3 & 2 & 2 & 2 & 48 & SI & $\begin{array}{c}\text { Aspecto } \\
\text { Significativo }\end{array}$ & $\begin{array}{l}\text { Programa de gestión de residuos } \\
\text { sólidos }\end{array}$ \\
\hline Cortado & Suelo & $\begin{array}{l}\text { Eliminación de pepas de } \\
\text { mango }\end{array}$ & $\begin{array}{l}\text { Contaminación } \\
\text { del suelo }\end{array}$ & 1 & 2 & 3 & 2 & 2 & 1 & 24 & NO & $\begin{array}{c}\text { No } \\
\text { Significativo } \\
\end{array}$ & $\begin{array}{l}\text { Programa de gestión de residuos } \\
\text { sólidos }\end{array}$ \\
\hline Prensado & Suelo & $\begin{array}{l}\text { Eliminación de residuos } \\
\text { de mango }\end{array}$ & $\begin{array}{l}\text { Contaminación } \\
\text { del suelo }\end{array}$ & 1 & 2 & 3 & 2 & 1 & 2 & 24 & NO & $\begin{array}{c}\text { No } \\
\text { Significativo }\end{array}$ & $\begin{array}{l}\text { Programa de gestión de residuos } \\
\text { sólidos }\end{array}$ \\
\hline $\begin{array}{l}\text { Selección de } \\
\text { cubos de } \\
\text { mango } \\
\text { prensados } \\
\end{array}$ & Suelo & $\begin{array}{l}\text { Eliminación de residuos } \\
\text { de mango mal prensado }\end{array}$ & $\begin{array}{l}\text { Contaminación } \\
\text { del suelo }\end{array}$ & 1 & 2 & 3 & 2 & 1 & 1 & 12 & NO & $\begin{array}{c}\text { No } \\
\text { Significativo }\end{array}$ & $\begin{array}{l}\text { Programa de gestión de residuos } \\
\text { sólidos }\end{array}$ \\
\hline \multirow[t]{2}{*}{ Llenado } & $\begin{array}{l}\text { Energía } \\
\text { eléctrica }\end{array}$ & $\begin{array}{l}\text { Consumo de energía } \\
\text { eléctrica }\end{array}$ & $\begin{array}{l}\text { Agotamiento de } \\
\text { los recursos } \\
\text { naturales } \\
\end{array}$ & 1 & 1 & 3 & 2 & 1 & 1 & 6 & NO & $\begin{array}{c}\text { No } \\
\text { Significativo }\end{array}$ & $\begin{array}{l}\text { Programa de uso eficiente de la } \\
\text { energía eléctrica }\end{array}$ \\
\hline & Suelo & Eliminación de residuos & $\begin{array}{l}\text { Contaminación } \\
\text { del suelo }\end{array}$ & 1 & 1 & 3 & 2 & 1 & 1 & 6 & NO & $\begin{array}{c}\text { No } \\
\text { Significativo } \\
\end{array}$ & $\begin{array}{l}\text { Programa de gestión de residuos } \\
\text { sólidos }\end{array}$ \\
\hline \multirow[t]{2}{*}{ Sellado } & $\begin{array}{l}\text { Energía } \\
\text { eléctrica }\end{array}$ & $\begin{array}{l}\text { Consumo de energía } \\
\text { eléctrica }\end{array}$ & $\begin{array}{l}\text { Agotamiento de } \\
\text { los recursos } \\
\text { naturales } \\
\end{array}$ & 1 & 1 & 3 & 2 & 1 & 1 & 6 & NO & $\begin{array}{c}\text { No } \\
\text { Significativo }\end{array}$ & $\begin{array}{l}\text { Programa de uso eficiente de la } \\
\text { energía eléctrica }\end{array}$ \\
\hline & Suelo & Eliminación de residuos & $\begin{array}{l}\text { Contaminación } \\
\text { del suelo }\end{array}$ & 1 & 1 & 3 & 2 & 1 & 1 & 6 & NO & $\begin{array}{c}\text { No } \\
\text { Significativo } \\
\end{array}$ & $\begin{array}{l}\text { Programa de gestión de residuos } \\
\text { sólidos }\end{array}$ \\
\hline \multirow{3}{*}{ Pasteurizado } & $\begin{array}{l}\text { Energía } \\
\text { eléctrica }\end{array}$ & $\begin{array}{l}\text { Consumo de energía } \\
\text { eléctrica }\end{array}$ & $\begin{array}{l}\text { Agotamiento de } \\
\text { los recursos } \\
\text { naturales }\end{array}$ & 1 & 1 & 3 & 2 & 1 & 1 & 6 & NO & $\begin{array}{c}\text { No } \\
\text { Significativo }\end{array}$ & $\begin{array}{l}\text { Programa de uso eficiente de la } \\
\text { energía eléctrica }\end{array}$ \\
\hline & Agua & Consumo de agua & $\begin{array}{l}\text { Agotamiento de } \\
\text { los recursos } \\
\text { naturales } \\
\end{array}$ & 1 & 1 & 3 & 2 & 1 & 1 & 6 & NO & $\begin{array}{c}\text { No } \\
\text { Significativo }\end{array}$ & $\begin{array}{l}\text { Programa de uso eficiente del } \\
\text { agua }\end{array}$ \\
\hline & Aire & Uso de vapor & $\begin{array}{l}\text { Contaminación } \\
\text { del aíre }\end{array}$ & 1 & 1 & 3 & 1 & 1 & 1 & 3 & NO & $\begin{array}{c}\text { No } \\
\text { Significativo } \\
\end{array}$ & Programa de gestión de vapor \\
\hline \multirow{2}{*}{$\begin{array}{l}\text { Lavado y } \\
\text { secado }\end{array}$} & $\begin{array}{l}\text { Energía } \\
\text { eléctrica }\end{array}$ & $\begin{array}{l}\text { Consumo de energía } \\
\text { eléctrica }\end{array}$ & $\begin{array}{l}\text { Agotamiento de } \\
\text { los recursos } \\
\text { naturales } \\
\end{array}$ & 1 & 1 & 3 & 2 & 1 & 1 & 6 & NO & $\begin{array}{c}\text { No } \\
\text { Significativo }\end{array}$ & $\begin{array}{l}\text { Programa de uso eficiente de la } \\
\text { energía eléctrica }\end{array}$ \\
\hline & Agua & Consumo de agua & $\begin{array}{l}\text { Agotamiento de } \\
\text { los recursos } \\
\text { naturales }\end{array}$ & 1 & 1 & 3 & 2 & 1 & 1 & 6 & NO & $\begin{array}{c}\text { No } \\
\text { Significativo }\end{array}$ & $\begin{array}{l}\text { Programa de uso eficiente del } \\
\text { agua }\end{array}$ \\
\hline \multirow[b]{2}{*}{ Tapado } & Suelo & Eliminación de residuos & $\begin{array}{l}\text { Contaminación } \\
\text { del suelo }\end{array}$ & 1 & 1 & 3 & 2 & 1 & 1 & 6 & NO & $\begin{array}{c}\text { No } \\
\text { Significativo }\end{array}$ & $\begin{array}{l}\text { Programa de gestión de residuos } \\
\text { sólidos }\end{array}$ \\
\hline & Suelo & Uso de tapas de plástico & $\begin{array}{l}\text { Contaminación } \\
\text { del suelo }\end{array}$ & 1 & 1 & 3 & 2 & 1 & 1 & 6 & NO & $\begin{array}{c}\text { No } \\
\text { Significativo }\end{array}$ & $\begin{array}{l}\text { Programa de gestión de envases } \\
\text { y productos defectuosos }\end{array}$ \\
\hline \multirow[t]{2}{*}{ Etiquetado } & $\begin{array}{l}\text { Energía } \\
\text { eléctrica }\end{array}$ & $\begin{array}{l}\text { Consumo de energía } \\
\text { eléctrica }\end{array}$ & $\begin{array}{l}\text { Agotamiento de } \\
\text { los recursos } \\
\text { naturales } \\
\end{array}$ & 1 & 1 & 3 & 2 & 1 & 1 & 6 & NO & $\begin{array}{c}\text { No } \\
\text { Significativo } \\
\end{array}$ & $\begin{array}{l}\text { Programa de uso eficiente de la } \\
\text { energía eléctrica }\end{array}$ \\
\hline & Suelo & Uso de etiquetas & $\begin{array}{l}\text { Contaminación } \\
\text { del suelo }\end{array}$ & 1 & 1 & 3 & 2 & 2 & 1 & 12 & NO & $\begin{array}{c}\text { No } \\
\text { Significativo } \\
\end{array}$ & $\begin{array}{l}\text { Programa de gestión de envases } \\
\text { y productos defectuosos }\end{array}$ \\
\hline \multirow[t]{2}{*}{ Encajado } & $\begin{array}{l}\text { Energía } \\
\text { eléctrica }\end{array}$ & $\begin{array}{l}\text { Consumo de energía } \\
\text { eléctrica }\end{array}$ & $\begin{array}{l}\text { Agotamiento de } \\
\text { los recursos } \\
\text { naturales } \\
\end{array}$ & 1 & 1 & 2 & 2 & 1 & 1 & 4 & NO & $\begin{array}{c}\text { No } \\
\text { Significativo }\end{array}$ & $\begin{array}{l}\text { Programa de uso eficiente de la } \\
\text { energía eléctrica }\end{array}$ \\
\hline & Suelo & Uso de cajas & $\begin{array}{l}\text { Contaminación } \\
\text { del suelo }\end{array}$ & 1 & 1 & 2 & 2 & 1 & 1 & 4 & NO & $\begin{array}{c}\text { No } \\
\text { Significativo } \\
\end{array}$ & $\begin{array}{l}\text { Programa de gestión de envases } \\
\text { y productos defectuosos }\end{array}$ \\
\hline \multirow{2}{*}{$\begin{array}{l}\text { Elaboración } \\
\text { de almíbar }\end{array}$} & $\begin{array}{l}\text { Energía } \\
\text { eléctrica }\end{array}$ & $\begin{array}{l}\text { Consumo de energía } \\
\text { eléctrica }\end{array}$ & $\begin{array}{l}\text { Agotamiento de } \\
\text { los recursos } \\
\text { naturales }\end{array}$ & 1 & 1 & 3 & 2 & 1 & 1 & 6 & NO & $\begin{array}{c}\text { No } \\
\text { Significativo }\end{array}$ & $\begin{array}{l}\text { Programa de uso eficiente de la } \\
\text { energía eléctrica }\end{array}$ \\
\hline & Agua & Consumo de agua & $\begin{array}{l}\text { Agotamiento de } \\
\text { los recursos } \\
\text { naturales }\end{array}$ & 1 & 1 & 3 & 2 & 1 & 1 & 6 & NO & $\begin{array}{c}\text { No } \\
\text { Significativo }\end{array}$ & $\begin{array}{l}\text { Programa de uso eficiente del } \\
\text { agua }\end{array}$ \\
\hline $\begin{array}{l}\text { Acceso a } \\
\text { rutas y } \\
\text { reparación del } \\
\text { suelo }\end{array}$ & Suelo & Destrucción del suelo & $\begin{array}{l}\text { Contaminación } \\
\text { del suelo }\end{array}$ & 1 & 2 & 1 & 2 & 2 & 2 & 16 & NO & $\begin{array}{c}\text { No } \\
\text { Significativo }\end{array}$ & $\begin{array}{l}\text { Programa de gestión de residuos } \\
\text { sólidos }\end{array}$ \\
\hline $\begin{array}{l}\text { Construcción } \\
\text { de la planta }\end{array}$ & Suelo & Destrucción del suelo & $\begin{array}{l}\text { Contaminación } \\
\text { del suelo }\end{array}$ & 1 & 2 & 1 & 2 & 2 & 2 & 16 & NO & $\begin{array}{c}\text { No } \\
\text { Significativo }\end{array}$ & $\begin{array}{l}\text { Programa de gestión de residuos } \\
\text { sólidos }\end{array}$ \\
\hline $\begin{array}{l}\text { Desmantelado } \\
\text { de equipos } \\
\text { fijos al suelo }\end{array}$ & Suelo & Destrucción del suelo & $\begin{array}{l}\text { Contaminación } \\
\text { del suelo }\end{array}$ & 1 & 2 & 1 & 2 & 2 & 2 & 16 & NO & $\begin{array}{c}\text { No } \\
\text { Significativo }\end{array}$ & $\begin{array}{l}\text { Programa de gestión de residuos } \\
\text { sólidos }\end{array}$ \\
\hline
\end{tabular}

Elaboración propia 


\subsection{Seguridad y salud ocupacional}

A continuación, se analizarán los tipos de riesgo que podría tener el personal y las medidas de seguridad que se necesitan para el cuidado del personal dentro del edificio.

\subsubsection{Riesgos de seguridad}

Se implementará un sistema de seguridad que elimine o minimice los riesgos que pudiesen existir en la empresa, para ello se trabajará con indicadores de riesgos de seguridad como: número de heridos por accidente, perdidas de días laborales, daños en propiedades, daños en producción, números de accidentes anual; con estos indicadores se podrá medir y dar una amplia visión para disminuir la probabilidad de ocurrencia de algún problema de seguridad.

Los principales riesgos que ocurrirían en la planta se detallan en la tabla 5.14, a conocer, los procesos de Pelado, Cortado, Pasteurizado, Cocción, Operaciones en el patio de maniobras y operaciones con las distintas máquinas.

Para evitar estos riesgos se dispondrán las medidas de seguridad adecuadas de los ambientes, tantas medidas contra incendios, señalización del local en caso de emergencia, extinguidores, vías de evacuación en caso de incendio, terremoto o algún otro problema en contra de la vida humana.

\subsubsection{Riesgos de salud}

Se tomará medidas necesarias para el resguardo de los trabajadores, para ello se deben conocer los procesos de la fábrica; en relación al proyecto en estudio se trabajará con un equipo que operará a alta temperatura (esterilizador) por lo que se proveerá a los trabajadores los implementos necesarios para el resguardo de su salud. Para tener un control, se trabajará con indicadores de riesgos para la salud como: casos de cáncer en la empresa, peligros respiratorios, problemas neurológicos y reproductivos.

En materia de salud y seguridad ocupacional, todas las industrias con más de 20 trabajadores deben cumplir con requerimientos legales, según el DS N009-2005-TR ${ }^{24}$. Entre ellas, las atribuciones, funciones y obligaciones tanto de empleador como del trabajador, políticas de seguridad y salud, registros y documentación del sistema de

\footnotetext{
${ }^{24}$ Reglamento de Seguridad y Salud en el trabajo D.S. N009-2005-TR
} 
gestión de seguridad y salud en el trabajo, prevención y protección contra riesgos, eliminación de desperdicios, señales de seguridad, primeros auxilios, entre otros.

El cumplimiento de estos requerimientos disminuye el riesgo de accidentes al interior de la industria; sin embargo, siempre existe la posibilidad de producirse involuntariamente accidentes. Los problemas más comunes asociados a la salud ocupacional que presenta el sector de conservas de fruta son:

- Dermatitis a consecuencia del manejo de azúcar.

- La exposición a residuos de insecticidas, fungicidas y parásitos de la tierra que pueda tener la fruta producto de la cosecha puede producir alergias.

- Problemas de espalda por levantamiento de cargas pesadas.

- Deterioro de audición por exposición prolongada a excesivos ruidos de las maquinarias como la lavadora, encajadora y envasadora.

- Problemas ergonómicos por la postura frente al ordenador en las oficinas administrativas.

Las principales medidas recomendadas para prevenir los problemas de salud ocupacional son:

- Cursos de entrenamiento para los trabajadores en las técnicas y principios de un trabajo seguro.

- Pisos ásperos para evitar resbalones.

Optimización de las condiciones de trabajo; otorgando al trabajador un asiento que mantenga la posición de la espalda erguida (ergonómico) y una mesa adecuados en altura, conseguir un grado de humedad adecuado para las oficinas administrativas, situar el puesto acorde a una buena iluminación, estudio de acoplamientos hombre/máquina, realizar pausas activas para hacer ejercicios de relajación y cambio de tareas tanto al personal administrativo como al personal de planta (en grupos)

- Evitar el contacto con insecticidas, fungicidas y parásitos usando las herramientas necesarias para su cuidado como guantes, lentes de seguridad, mascarillas, entre otros.

- Chequeo preventivo anual (EPS)

- Uso de Equipos de Protección Personal (EPP)

- Acondicionamiento adecuado de la planta en relación a seguridad industrial mediante ductos de ventilación (Figura 5.20) 


\subsubsection{Medidas de seguridad}

Una de las medidas de seguridad más importantes es que tanto el edificio de planta como el de oficinas estén debidamente señalizados por avisos para que el personal tenga en cuenta el cuidado que debe tener en todo momento. Entre las principales señalizaciones tenemos las de auditivas y las visuales. A continuación, en la siguiente tabla se observa las actividades más riesgosas en la planta y las medidas que se optan para aminorar el riesgo.

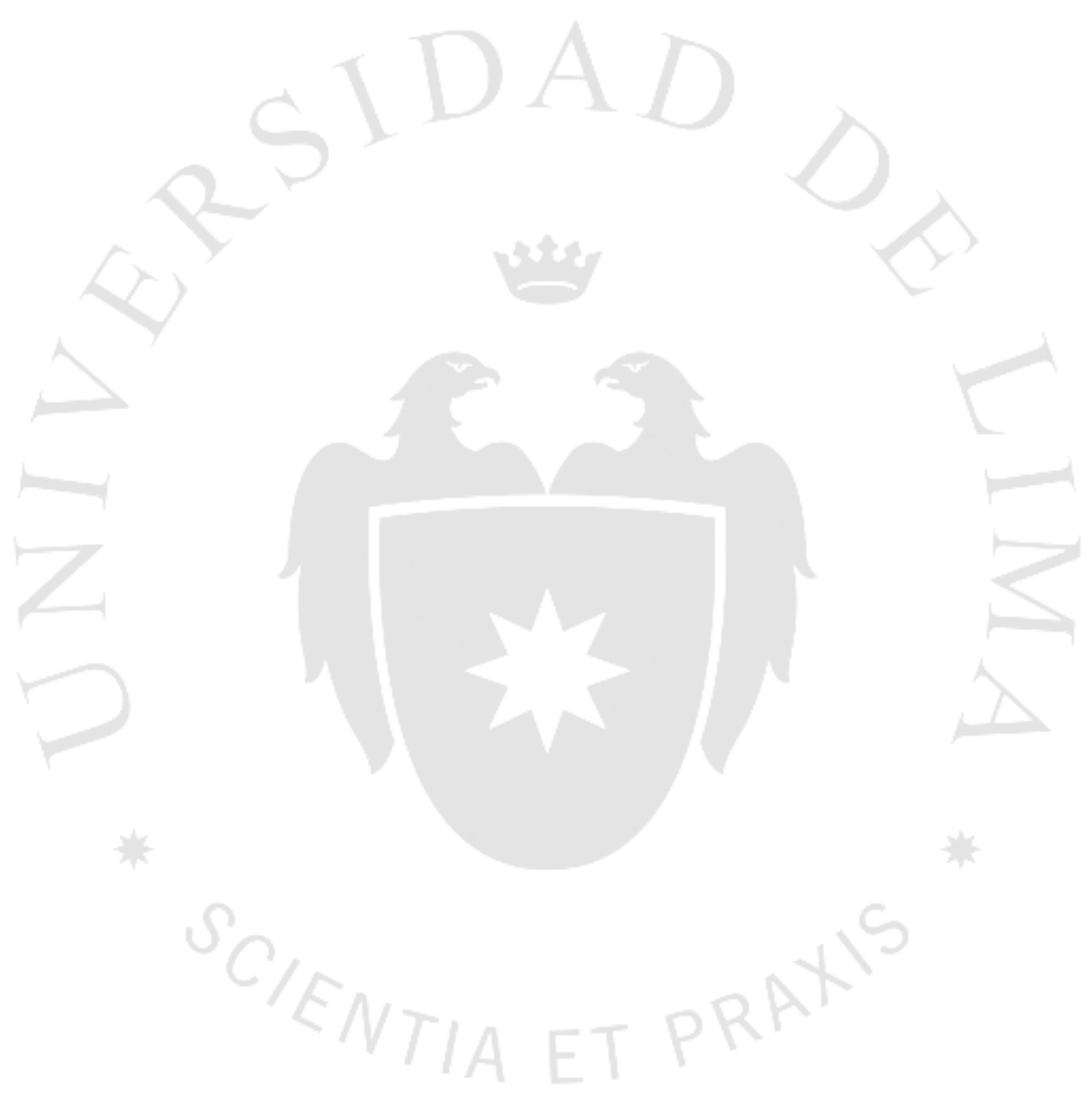


Tabla 5.14

Matriz IPER ${ }^{25}$

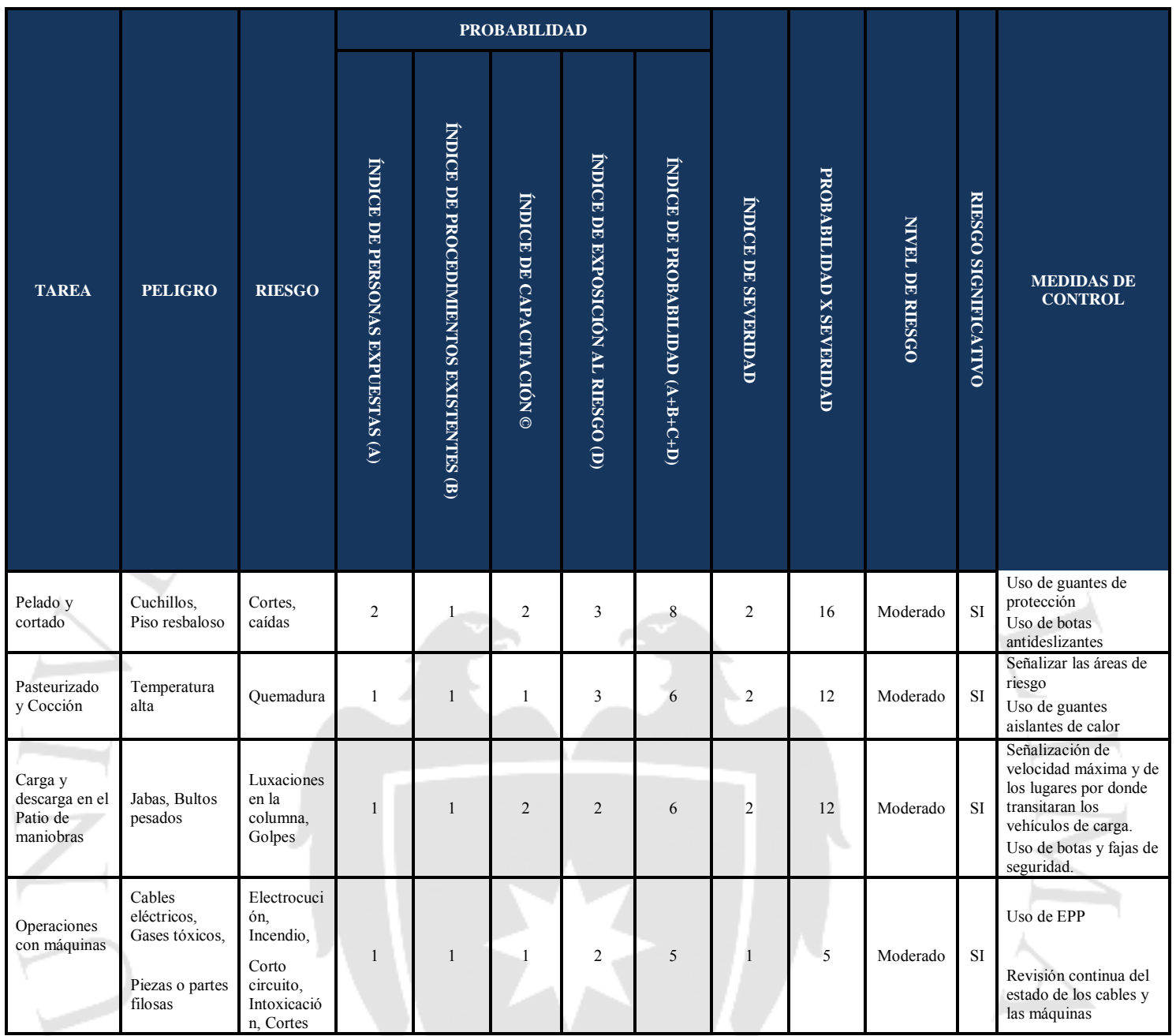

Elaboración propia

\subsection{Sistema de mantenimiento}

El mantenimiento al igual que la seguridad es de importancia, ya que permitirá asegurar el logro de los objetivos, competitividad y rentabilidad. De un buen mantenimiento podemos hacer una mejor programación de la producción evitando contratiempo en los plazos de entrega, además se podrá dar a los clientes una mejor calidad y se podrá cumplir con los tiempos de entrega pactados.

En la siguiente tabla se muestran los equipos con los mantenimientos que se aplicaran, así como la frecuencia.

25 Las probabilidades se obtuvieron del capítulo "Identificación de peligros y evaluación de riesgos laborales" pág. 169 de RM-050-2013-TR. 
Tabla 5.15

Tipos de mantenimiento según máquina

\begin{tabular}{|c|c|c|c|}
\hline Equipo & $\begin{array}{c}\text { Tipo de } \\
\text { mantenimiento }\end{array}$ & Descripción & Frecuencia \\
\hline Banda de selección & preventivo & Lubricación y limpieza & Mensual y limpieza diaria \\
\hline Lavadora & preventivo & Lubricación y limpieza & Al final del día \\
\hline Marmita basculante & preventivo & Limpieza e inspección & Al final del día \\
\hline $\begin{array}{l}\text { Envasadora, llenadora y } \\
\text { selladora }\end{array}$ & reactivo/proactivo & $\begin{array}{c}\text { Se medirán los niveles de } \\
\text { velocidad }\end{array}$ & $\begin{array}{c}\text { Cuando varíen los niveles de } \\
\text { velocidad }\end{array}$ \\
\hline Exhauster & proactivo & $\begin{array}{l}\text { Se medirán las condiciones de la } \\
\text { máquina por monitoreo }\end{array}$ & Al final del día \\
\hline Secadora de envases & reactivo/proactivo & $\begin{array}{c}\text { Se medirán los niveles de } \\
\text { velocidad }\end{array}$ & $\begin{array}{c}\text { Cuando varíen los niveles de } \\
\text { velocidad }\end{array}$ \\
\hline Autoclave horizontal & preventivo & Limpieza e inspección & Al final del día \\
\hline Etiquetadora & reactivo/proactivo & $\begin{array}{l}\text { Se medirán los niveles de } \\
\text { velocidad }\end{array}$ & $\begin{array}{c}\text { Cuando varíen los niveles de } \\
\text { velocidad }\end{array}$ \\
\hline Encajonadora & reactivo/proactivo & $\begin{array}{l}\text { Se medirán los niveles de } \\
\text { velocidad }\end{array}$ & $\begin{array}{c}\text { Cuando varíen los niveles de } \\
\text { velocidad }\end{array}$ \\
\hline
\end{tabular}

Elaboración propia

\subsection{Programa de producción}

\subsubsection{Factores para la programación de la producción}

Los principales factores para la programación de la producción están dados por el nivel de servicio que se quiere brindar. Para este proyecto se pretende tener un nivel de servicio de $95 \%$

Para determinar el programa de producción en unidades de producto terminado para el primer año se procedió a calcular el stock de seguridad.

Tabla 5.16

Datos para el cálculo del stock de seguridad

\begin{tabular}{|c|c|}
\hline \multicolumn{2}{|c|}{ S.S. $=\mathbf{Z}(\boldsymbol{\alpha}){ }^{*} \boldsymbol{\sigma}$} \\
\hline Nivel de servicio & $95 \%$ \\
\hline $\mathbf{Z}(\boldsymbol{\alpha})$ & 1.65 \\
\hline Desviación estándar $(\sigma)$ & $2 \%$ \\
\hline
\end{tabular}

Elaboración propia 
Tabla 5.17

Cálculo del stock de seguridad

\begin{tabular}{|l|c|c|c|c|c|c|}
\hline Año & $\begin{array}{c}\text { Demanda } \\
\text { (Ton) }\end{array}$ & $\begin{array}{c}\text { Demanda } \\
\text { (unidades de } \\
\text { producto } \\
\text { terminado 226 g) }\end{array}$ & $\begin{array}{c}\text { Desviación } \\
\text { estándar } \\
(\mathbf{2 \%})\end{array}$ & $\mathbf{Z = 9 5 \%}$ & $\begin{array}{c}\text { Stock de } \\
\text { seguridad } \\
\text { (Ton) }\end{array}$ & $\begin{array}{c}\text { Stock de seguridad } \\
\text { (unidades de } \\
\text { producto } \\
\text { terminado 226 g) }\end{array}$ \\
\hline 2016 & 372.67 & $1,648,998$ & 0.02 & 1.96 & 14.61 & 64,641 \\
\hline 2017 & 376.77 & $1,667,137$ & 0.02 & 1.96 & 14.77 & 65,352 \\
\hline 2018 & 380.92 & $1,685,476$ & 0.02 & 1.96 & 14.93 & 66,071 \\
\hline 2019 & 385.11 & $1,704,016$ & 0.02 & 1.96 & 15.10 & 66,797 \\
\hline 2020 & 389.34 & $1,722,760$ & 0.02 & 1.96 & 15.26 & 67,532 \\
\hline 2021 & 393.47 & $1,740,998$ & 0.02 & 1.96 & 15.42 & 68,247 \\
\hline
\end{tabular}

Elaboración propia

Mantener el stock de seguridad calculado en almacenes no representa un gasto significativo al no ocupar mucho volumen, además de ser una cantidad pequeña en comparación con la demanda anual que se tiene y también al tener una vida útil de 18 meses no se pone en riesgo el producto.

\subsubsection{Programa de producción para la vida útil del proyecto}

Con los datos obtenidos del stock de seguridad para todos los años del proyecto, se calculó el programa de producción para cada año del proyecto.

Tabla 5.18

Programa de producción

\begin{tabular}{|c|c|c|c|c|}
\hline Año & $\begin{array}{c}\text { Demanda } \\
\text { (Ton) }\end{array}$ & $\begin{array}{c}\text { Stock de } \\
\text { seguridad } \\
\text { (Ton) }\end{array}$ & $\begin{array}{c}\text { Programa de } \\
\text { producción } \\
\text { (Ton) }\end{array}$ & $\begin{array}{c}\text { Programa de producción (unidades } \\
\text { de producto terminado 226 g) }\end{array}$ \\
\hline 2016 & 372.67 & 14.61 & 387.28 & $1,713,639$ \\
\hline 2017 & 376.77 & 14.77 & 391.54 & $1,732,489$ \\
\hline 2018 & 380.92 & 14.93 & 395.85 & $1,751,546$ \\
\hline 2019 & 385.11 & 15.10 & 400.20 & $1,770,813$ \\
\hline 2020 & 389.34 & 15.26 & 404.61 & $1,790,292$ \\
\hline 2021 & 393.47 & 15.42 & 408.89 & $1,809,245$ \\
\hline
\end{tabular}

Elaboración propia

\subsection{Requerimiento de insumos, personal y servicios}

\subsubsection{Materia prima, insumos y otros materiales}

A continuación, se presentan los requerimientos de materia prima, insumos y otros materiales necesarios para la producción de las conservas. Estas cantidades fueron calculadas en base a la demanda del proyecto. 
Es importante mencionar que el mango compone el $60 \%$ del peso neto de la conserva mientras que el almíbar el 40\% restante. El almíbar está compuesto por agua $(22,5 \%)$, azúcar $(17 \%)$ y ácido cítrico $(0.5 \%)$ en peso.

Tabla 5.19

Requerimientos de materia prima e insumos

\begin{tabular}{|l|c|c|c|c|c|c|}
\multicolumn{1}{|c}{ Año } & $\mathbf{2 0 1 6}$ & $\mathbf{2 0 1 7}$ & $\mathbf{2 0 1 8}$ & $\mathbf{2 0 1 9}$ & $\mathbf{2 0 2 0}$ & $\mathbf{2 0 2 1}$ \\
\hline Producción (Ton) & 387.28 & 391.54 & 395.85 & 400.20 & 404.61 & 408.89 \\
\hline Mango (Ton) & 232.37 & 234.93 & 237.51 & 240.12 & 242.76 & 245.33 \\
\hline Agua (L) & 87,139 & 88,097 & 89,066 & 90,046 & 1,036 & 92,000 \\
\hline Azúcar (Ton) & 65.84 & 66.56 & 67.29 & 68.03 & 68.78 & 69.51 \\
\hline Ácido Cítrico (Ton) & 1.936 & 1.958 & 1.979 & 2.001 & 2.023 & 2.044 \\
\hline Envases (unid) & $1,713,639$ & $1,732,489$ & $1,751,546$ & $1,770,813$ & $1,790,292$ & $1,809,245$ \\
\hline Films (unid) & $1,713,639$ & $1,732,489$ & $1,751,546$ & $1,770,813$ & $1,790,292$ & $1,809,245$ \\
\hline Tapas (unid) & $1,713,639$ & $1,732,489$ & $1,751,546$ & $1,770,813$ & $1,790,292$ & $1,809,245$ \\
\hline Tenedores (unid) & $1,713,639$ & $1,732,489$ & $1,751,546$ & $1,770,813$ & $1,790,292$ & $1,809,245$ \\
\hline
\end{tabular}

Elaboración propia

\subsubsection{Servicios: energía eléctrica, agua, combustible, vapor, etc.}

Los servicios más importantes que requiere la empresa para que funcionen las instalaciones son: servicios de electricidad, telefonía y agua potable.

La energía eléctrica será consumida por las máquinas principales del proceso, excepto por algunas que operen de forma manual, y por el alumbrado para las oficinas administrativas, así como uso de los ordenadores y aire acondicionado. Para calcular el consumo de $\mathrm{kW}$-h estimado por operaciones de producción, se ha utilizado el dato de potencia de consumo de electricidad de cada máquina obtenido del acápite 5.3.2.

Tabla 5.20

Consumo de $\mathrm{kW}$ por máquina

\begin{tabular}{|l|c|c|c|}
\hline \multicolumn{1}{|c|}{ Máquina } & Potencia $(\mathbf{K w})$ & \# máquinas & kW total \\
\hline Banda de transporte & 0.25 & 5 & 1.25 \\
\hline Exhauster & 5 & 1 & 5 \\
\hline Lavadora & 5 & 3 & 15 \\
\hline Envasadora múltiple & 5 & 1 & 5 \\
\hline Esterilizador envases & 5 & 1 & 5 \\
\hline Etiquetadora & 4 & 1 & 4 \\
\hline Marmita & 12 & 1 & 12 \\
\hline Secadora & 3 & 1 & 3 \\
\hline Encajadora & 5 & 1 & 5 \\
\hline Pasteurizador & 5 & 1 & 5 \\
\hline \multicolumn{2}{|c|}{ Total } & $\mathbf{6 0 . 2 5}$ \\
\hline
\end{tabular}

Elaboración propia 
Para conocer el consumo anual de kW-hora se necesita saber la relación que indica las horas de funcionamiento de las máquinas que se necesita por año. Para esto se tiene lo siguiente:

Horas de producción al año:

$$
8 \frac{h}{t} \times 1 \frac{t}{d} \times 22 \frac{d}{m} \times 6 \frac{m}{a}=2112 \frac{h}{a}
$$

En base a este dato, se puede decir que anualmente se consume 101,376 kW-h en maquinaria. En la siguiente tabla se resume el consumo de energía total anual. Se resalta que en consumo de otros se incluye la ventilación y montacargas.

Tabla 5.21

Consumo de $\mathrm{kW}$ total anual

\begin{tabular}{|c|c|c|c|c|}
\hline Año & $\begin{array}{c}\text { Consumo } \\
\text { maquinaria }\end{array}$ & $\begin{array}{c}\text { Consumo } \\
\text { administrativo }\end{array}$ & $\begin{array}{c}\text { Consumo } \\
\text { otros }\end{array}$ & Total (kW-h) \\
\hline 2016 & 101,376 & 5,000 & 10,000 & 116,376 \\
\hline 2017 & 101,376 & 5,000 & 10,000 & 116,376 \\
\hline 2018 & 101,376 & 5,000 & 10,000 & 116,376 \\
\hline 2019 & 101,376 & 5,000 & 10,000 & 116,376 \\
\hline 2020 & 101,376 & 5,000 & 10,000 & 116,376 \\
\hline 2021 & 101,376 & 5,000 & 10,000 & 116,376 \\
\hline
\end{tabular}

Elaboración propia

El consumo de agua será abundante en los procesos de lavado y enjuagado, sobre todo, en mayor medida, se utilizará agua en el proceso de formulación del almíbar, considerando que se tratará de reducir el consumo de agua utilizando filtros para reutilizar agua para el proceso de lavado y enjuagado, asimismo, se usará agua también en las oficinas administrativas y para el servicio de limpieza. Para el cálculo del consumo de agua de administración se basa en el dato de que cada habitante en Piura consume un promedio de $170 \mathrm{~m} 3 / \mathrm{h} /$ día y se considera 67 empleados en total. 
Tabla 5.22

Consumo de agua (m3) anual

\begin{tabular}{|c|c|c|c|}
\hline Año & $\begin{array}{c}\text { Consumo de agua } \\
\text { insumo }\end{array}$ & $\begin{array}{c}\text { Consumo de agua } \\
\text { administrativa }\end{array}$ & Total (m3) \\
\hline 2016 & 87 & 1,378 & 1,465 \\
\hline 2017 & 88 & 1,378 & 1,466 \\
\hline 2018 & 89 & 1,378 & 1,467 \\
\hline 2019 & 90 & 1,378 & 1,468 \\
\hline 2020 & 91 & 1,378 & 1,469 \\
\hline 2021 & 92 & 1,378 & 1,470 \\
\hline
\end{tabular}

Elaboración propia

El servicio de telefonía fija, celulares y línea móvil también está incluido aquí ya que es importante la comunicación tanto interna como externa. Solo los jefes y gerentes y ejecutivos de ventas, inicialmente, tendrán celulares con acceso a datos para revisar sus correos y llamadas telefónicas que forman un total de 10 celulares, asimismo, solo habrá inicialmente 2 anexos por departamento.

Tabla 5.23

Costo anual por consumo de telefonía

\begin{tabular}{|c|c|c|c|}
\hline Año & $\begin{array}{c}\text { Costo de telefonía } \\
\text { fija e internet }\end{array}$ & $\begin{array}{c}\text { Costo celulares } \\
\text { y líneas }\end{array}$ & Costo total (S/.) \\
\hline 2016 & 3,800 & 1,900 & 5,700 \\
\hline 2017 & 3,800 & 1,900 & 5,700 \\
\hline 2018 & 3,800 & 1,900 & 5,700 \\
\hline 2019 & 3,800 & 1,900 & 5,700 \\
\hline 2020 & 3,800 & 1,900 & 5,700 \\
\hline 2021 & 3,800 & 1,900 & 5,700 \\
\hline
\end{tabular}

Elaboración propia

\subsubsection{Determinación del número de operarios y trabajadores indirectos}

Los trabajadores de la empresa se dividen en los que se encuentran en el proceso de fabricación del producto, es decir los que conforman la mano de obra directa y el personal administrativo que conforman la mano de obra indirecta.

El número de operarios se detalla a continuación. Cabe mencionar que los operarios encargados de los procesos con máquinas también serán encargados de su funcionamiento adecuado y limpieza. 
A continuación, se presenta la tabla 5.24 con el número de operarios para el proceso productivo.

Tabla 5.24

Número de operarios

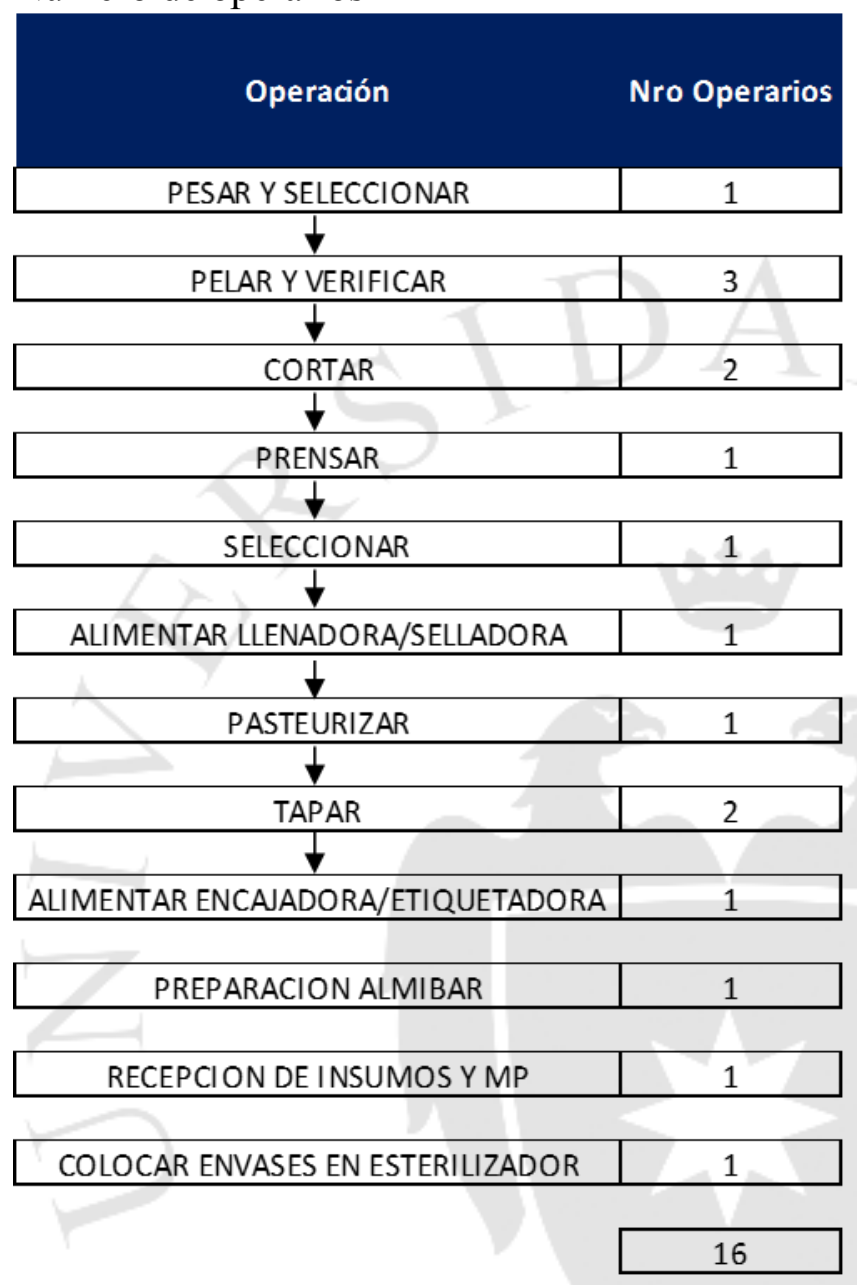

Elaboración propia 
A continuación, se presenta la tabla 5.25 con el personal administrativo necesario.

Tabla 5.25

Personal administrativo

\begin{tabular}{|l|c|}
\hline Puesto & $\begin{array}{l}\text { Número de } \\
\text { vacantes }\end{array}$ \\
\hline Gerencia general & 1 \\
\hline Gerente de finanzas & 1 \\
\hline Asistente financiero & 1 \\
\hline Jefe de producción & 1 \\
\hline Supervisor de producción & 1 \\
\hline Gerente de ventas & 2 \\
\hline Ejecutivo de ventas (KAM) & 1 \\
\hline Asistente de ventas & 1 \\
\hline Técnico de Calidad & 1 \\
\hline Gerente de operaciones & 1 \\
\hline Asistente de operaciones & 1 \\
\hline Jefe de almacén & 1 \\
\hline Responsable de almacén & 1 \\
\hline Jefe de mantenimiento & 1 \\
\hline Técnico de mantenimiento & 1 \\
\hline Responsable de Sistemas & 1 \\
\hline Responsable de R.R.H.H & 1 \\
\hline Recepcionista & $\mathbf{1 9}$ \\
\hline \multicolumn{1}{|c|}{ Total } & \\
\hline
\end{tabular}

Elaboración propia

\subsubsection{Servicios de terceros}

Para la planta propuesta es necesario contar con los servicios de terceros entre los cuales se encuentran los de seguridad, personal de cafetería, servicio de limpieza y el de transporte. Estos servicios serán realizados por terceros ya que no parte fundamental del negocio y no agregan algún tipo de valor por lo que pueden ser realizados por otras personas. 


\subsection{Disposición de planta}

\subsubsection{Características físicas del proyecto}

\section{Factor edificio}

En el capítulo de localización, se obtuvo que la ubicación de la planta del presente proyecto es la ciudad de Piura, será de un solo nivel debido a que el valor de los terrenos es más barato que un local ya establecido, se facilitarán las operaciones entre áreas, mejor manejo de material y maquinaria; además, la planta puede ampliarse horizontalmente de acuerdo a la estructura inicial que se le haya dado.

Otros motivos por los cuales el edificio es un de un solo piso es por el peso de los equipos y porque en un futuro se puede prever de cambios en la distribución.

\section{- Suelos:}

Los pisos deberán ser de un material altamente resistente, que no permitan que los trabajadores puedan resbalarse (antideslizante) y que se puedan limpiar fácilmente, debido a esto se utilizaran pisos epóxicos $100 \%$ sólidos hecho a base de polímero con agregados de sílice y acero para soportar el trabajo realizado día a día. Para el edificio administrativo, los suelos estarán alfombrados.

\section{- Cubiertas y techos:}

Las cubiertas y techos afectan a la distribución sobre todo por lo que respecta a su altura por encima del suelo. Las cubiertas y techos vienen afectados, también, en muchos casos, por el tipo de construcción. Estos serán altos para facilitar el trabajo y estarán equipados de buenos sistemas de iluminación. Se hará una construcción tipo nave industrial que servirán de sustento para calaminas que darán protección extra para caso de lluvias y serán de material no inflamable. Los techos serán de Eternit debido a su rápida instalación, bajo costo y posibilidad de rápido arreglo.

\section{- Paredes y columnas:}

La planta tendrá un cerco perimétrico compuesto de ladrillo y concreto con estructura de fierro. Dentro, será una edificación convencional de ladrillo y concreto para el área de producción; mientras que en la zona administrativa las separaciones entre las distintas áreas que forman cubículos se harán con paredes de materiales pre fabricado o drywall para que en un futuro se pueda modificar la disposición de planta si fuera necesario. 
Figura 5.19

Cubículos de drywall en una oficina

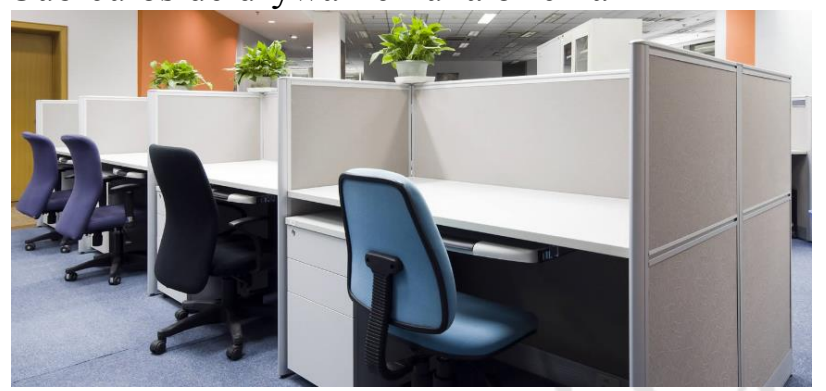

Fuente: Google Images, (2015)

Las paredes serán lisas, protegidas y pintadas en tonos claros, susceptibles de ser lavadas o blanqueadas y serán mantenidas en buen estado de conservación, reparándose tan pronto como se produzca grietas, agujeros o cualquier clase de desperfectos.

\section{Factor servicio}

\section{$\underline{\text { Servicios relativos al personal }}$}

\section{- Iluminación:}

La iluminación es importante y sobre todo en el área de producción debe contar con una buena iluminación, pisos oscuros y paredes claras a fin de que el operario se encuentre cómodo para realizar sus tareas, sin sentir incomodidad ni exponerse a futuros problemas debido al reflejo de la luz o a la fatiga visual.

\section{- Instalaciones sanitarias:}

Es dada por el número de empleados. Son permanentes y difíciles de ampliar por lo que se debe planificar anticipadamente considerando un mayor número de usuarios. Estos deben estar limpios, iluminados y bien ventilados. En la siguiente tabla se observa el número de artefactos que se necesitará por baño. 
Tabla 5.26

Servicios higiénicos

\begin{tabular}{|ccccc|}
\hline $\begin{array}{c}\text { Número de } \\
\text { empleados }\end{array}$ & $\begin{array}{c}\text { Inodoros y } \\
\text { Urinarios }\end{array}$ & Lavamanos & Duchas & Vestuarios \\
\hline $\mathbf{1}$ a 9 & 1 & 1 & 2 & 2 \\
\hline $\mathbf{1 0}$ a $\mathbf{2 4}$ & 2 & 2 & 4 & 4 \\
\hline $\mathbf{2 5}$ a 49 & 3 & 3 & 6 & 6 \\
\hline $\mathbf{5 0}$ a 74 & 4 & 4 & 8 & 8 \\
\hline $\mathbf{7 5}$ a $\mathbf{1 0 0}$ & 5 & 5 & 10 & 10 \\
\hline
\end{tabular}

Fuente: Ingesite, (2015)

Todos los establecimientos de trabajo, deben tener o instalar un inodoro, un lavamanos, un urinario y una ducha, separados por sexos, y dotados de todos los elementos indispensables para su servicio, consistentes en papel higiénico, tachos de basura, toallas de papel, espejos, jabón, desinfectantes y desodorantes.

Los artefactos sanitarios, deben ser construidos de un material impermeable, inoxidable, y con acabado liso que facilite la limpieza.

\section{- Comedor}

Operarios, ingenieros, técnicos y ejecutivos podrán almorzar según el horario establecido, entre 11:30am y 2:00pm. El comedor estará a cargo de un concesionario externo que estará ubicado dentro del recinto del centro de trabajo en una zona que no permita riesgos de contaminación ambiental ni interfiera con las operaciones de planta ni con las actividades administrativas.

\section{- Ventilación}

Una buena ventilación es crítica dentro de un área de trabajo cerrada debido a que esta debe encargarse de la distribución y esparcimiento de aire fresco. Generalmente, en las industrias la mayoría de máquinas generan calor y esto afecta directamente a los operarios lo cual genera incomodidad y en consecuencia, disminución de la productividad. Dentro del área de producción se usará el aire de los ductos de ventilación, mientras que en oficinas se utilizará además el aire del ambiente de las ventanas grandes para el mejor ingreso del aire al interior. Se debe considerar proporcionar suficiente aire fresco para diluir los contaminantes que se generen dentro del edificio: las emanaciones 
de gases por altas temperaturas en la marmita, secadora y exhauster, deben controlarse mediante la captación en el punto de generación.

Figura 5.20

Ductos de ventilación

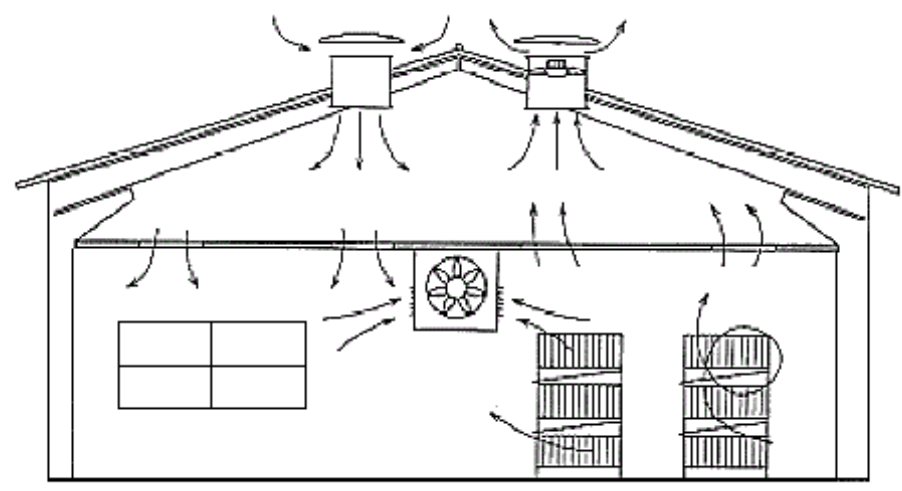

Fuente: Google Images, (2015)

\section{- Estacionamiento}

La planta contará con un amplio estacionamiento de vehículos ya que es necesario para los empleados y para la llegada de clientes.

\section{$\underline{\text { Relativo a la maquinaria }}$}

La planta contará con un área de mantenimiento para que se puedan prevenir posibles problemas de funcionamiento en las máquinas, accidentes o un aumento en el porcentaje de fallas existentes.

\section{$\underline{\text { Relativo al material }}$}

Para mantener una producción adecuada se asignarán estaciones de trabajo específicas y áreas de inspección para el control de producción. Los residuos tendrán un tratamiento especial antes de ser desechados para evitar la contaminación del medio ambiente y lograr así un control integral de la contaminación. Se implementará basureros de colores para que aumenten la conciencia de reciclaje de los residuos y sus posibles reutilizaciones.

\subsubsection{Determinación de las zonas físicas requeridas}

Las zonas físicas requeridas tanto para la planta como para oficinas son las siguientes. 
Tabla 5.27

Áreas de Planta

\begin{tabular}{|c|}
\hline Áreas de Planta \\
\hline Patio de carga y descarga \\
\hline Jefatura de Producción \\
\hline Jefatura de Almacén \\
\hline Laboratorio de Control de Calidad \\
\hline SS.HH, Vestuarios de Planta para Damas y Caballeros \\
\hline Área de Mantenimiento \\
\hline Almacén de Desperdicios \\
\hline Almacén de Materias Primas \\
\hline Almacén de Insumos \\
\hline Almacén de Productos Terminados \\
\hline Estacionamiento \\
\hline Comedor \\
\hline
\end{tabular}

Elaboración propia

Tabla 5.28

Áreas Administrativas

\begin{tabular}{|c|}
\hline Áreas Administrativas \\
\hline Gerencia General \\
\hline Área de Finanzas \\
\hline Área de Marketing \\
\hline Área de Ventas \\
\hline SS.HH \\
\hline Damas y Caballeros \\
\hline Área de Operaciones \\
\hline Área de RRHH \\
\hline Área de sistemas \\
\hline Recepción \\
\hline Sala de reuniones \\
\hline
\end{tabular}

Elaboración propia

\subsubsection{Cálculo de áreas para cada zona}

Se elaborará una adecuada disposición de la planta de tal manera que se optimiza el espacio disponible, para ello se realizará un cálculo aproximado de las superficies siguiendo el método Guerchet, el que permitirá determinar las áreas requeridas por los diferentes factores de la disposición de planta. 
Tabla 5.29

Análisis de Guerchet $\left(\mathrm{en} \mathrm{m}^{2}\right)$

\begin{tabular}{|l|c|c|c|c|c|c|c|c|c|}
\hline Elementos Fjjos & $\mathbf{L}$ & $\mathbf{A}$ & $\mathbf{h}$ & $\mathbf{N}$ & $\mathbf{n}$ & $\mathbf{S s}$ & $\mathbf{S g}$ & $\mathbf{S e}$ & St \\
\hline Balanzas & 0.90 & 0.50 & 0.10 & 3 & 3 & 0.45 & 1.35 & 1.04 & 8.52 \\
\hline Máquina Lavadora & 1.00 & 0.70 & 1.20 & 2 & 3 & 0.70 & 1.40 & 1.21 & 9.94 \\
\hline Escaldador & 1.75 & 1.27 & 1.63 & 1 & 1 & 2.22 & 2.22 & 2.57 & 7.01 \\
\hline Máquina Envasadora & 3.66 & 0.76 & 1.70 & 2 & 1 & 2.79 & 5.57 & 4.83 & 13.19 \\
\hline $\begin{array}{l}\text { Esterilizador de } \\
\text { envases }\end{array}$ & 3.00 & 0.83 & 1.30 & 2 & 1 & 2.49 & 4.98 & 4.31 & 11.78 \\
\hline $\begin{array}{l}\text { Máquina } \\
\text { Etiquetadora }\end{array}$ & 3.05 & 1.65 & 0.36 & 2 & 1 & 5.02 & 10.03 & 8.69 & 23.74 \\
\hline $\begin{array}{l}\text { Bandas de } \\
\text { transporte }\end{array}$ & 1.52 & 0.62 & 0.97 & 4 & 5 & 0.94 & 3.77 & 2.72 & 37.17 \\
\hline Máquina Encajadora & 2.60 & 3.30 & 2.50 & 2 & 1 & 8.58 & 17.16 & 14.86 & 40.60 \\
\hline Máquina Secadora & 3.00 & 1.00 & 1.80 & 2 & 1 & 3.00 & 6.00 & 5.20 & 14.20 \\
\hline Marmita & 1.75 & 1.27 & 1.63 & 1 & 2 & 2.22 & 2.22 & 2.57 & 14.02 \\
\hline $\begin{array}{l}\text { Punto de espera } \\
\text { (luego del exhauster) }\end{array}$ & 0.66 & 0.51 & 1.77 & 0 & 1 & 0.34 & 0.00 & 0.20 & 0.54 \\
\hline Máquina Exhauster & 0.00 & 0.00 & 1.80 & 2 & 2 & 0.73 & 1.46 & 1.27 & 6.92 \\
\hline $\begin{array}{l}\text { Total } \\
\text { Matal }\end{array}$ & & & & & & & 179.11 \\
\hline
\end{tabular}

Ssxn Ssxnxh

\begin{tabular}{|c|c|}
\hline 1.35 & 0.14 \\
\hline 2.10 & 2.52 \\
\hline 2.22 & 3.62 \\
\hline 2.79 & 4.74 \\
\hline 2.49 & 3.24 \\
\hline 5.02 & 1.78 \\
\hline 4.71 & 4.57 \\
\hline 8.58 & 21.45 \\
\hline 3.00 & 5.40 \\
\hline 4.45 & 7.25 \\
\hline 0.34 & 0.60 \\
\hline 1.46 & 2.63 \\
\hline 38.51 & 57.94 \\
\hline
\end{tabular}

\begin{tabular}{|l|c|c|c|c|c|c|c|c|c|}
\hline Elementos Móviles & $\mathbf{L}$ & $\mathbf{A}$ & $\mathbf{h}$ & $\mathbf{N}$ & $\mathbf{n}$ & $\mathbf{S s}$ & $\mathbf{S g}$ & $\mathbf{S e}$ & $\mathbf{S t}$ \\
\hline Montacarga & 3.56 & 1.24 & 2.26 & 0 & 1 & 4.39 & 0.00 & 0.00 & 0.00 \\
\hline Operarios & 0.00 & 0.00 & 1.65 & 0 & 38 & 0.50 & 0.00 & 0.00 & 0.00 \\
\hline $\begin{array}{l}\text { Estante de } \\
\text { pasteurización }\end{array}$ & 0.66 & 0.51 & 1.70 & 0 & 5 & 0.34 & 0.00 & 0.00 & 0.00 \\
\hline Carretilla hidráulica & 1.52 & 0.69 & 1.22 & 0 & 1 & 1.04 & 0.00 & 0.00 & 0.00 \\
\hline
\end{tabular}

Total

\section{hem hee $\mathrm{K}$}

\begin{tabular}{l|l|l|l|l}
\hline 1.74 & 1.50 & 0.58 \\
\hline
\end{tabular}

Elaboración propia

De acuerdo al análisis de Guerchet, la planta deberá tener un área mínima aproximada de $179.11 \mathrm{~m}^{2}$ dividiéndose en $17 \mathrm{~m}$ de largo x $10.54 \mathrm{~m}$ de ancho a convenir por la empresa; el resto de las áreas administrativas tendrán las siguientes áreas aproximadas: 
Tabla 5.30

Áreas adicionales de la empresa

\begin{tabular}{|c|c|}
\hline Nombre del área & Área Total $\left(\mathbf{m}^{\mathbf{2}}\right)$ \\
\hline Patio de carga y descarga & 104.5 \\
\hline Jefatura de Producción & 17.5 \\
\hline Jefatura de Almacén & 17.5 \\
\hline Oficinas administrativas & 212.5 \\
\hline Laboratorio de Control de Calidad & 17.5 \\
\hline Estacionamiento & 68 \\
\hline Comedor & 51 \\
\hline SS.HH, Vestuarios de Planta & 51 \\
\hline Damas y Caballeros & 15 \\
\hline SS.HH de Oficinas Damas y & 17.5 \\
\hline Caballeros & 15 \\
\hline Área de Mantenimiento & 16 \\
\hline Almacén de Desperdicios & 16 \\
\hline Almacén de Materias Primas & 20 \\
\hline Almacén de Insumos & \\
\hline Almacén de Productos Terminados & \\
\hline
\end{tabular}

Elaboración propia

- Cálculo de áreas de Almacenes:

Producto terminado:

- 1 caja de 30 envases mide $46 \mathrm{~cm}$ de ancho x $55 \mathrm{~cm}$ de largo x $9 \mathrm{~cm}$ de alto.

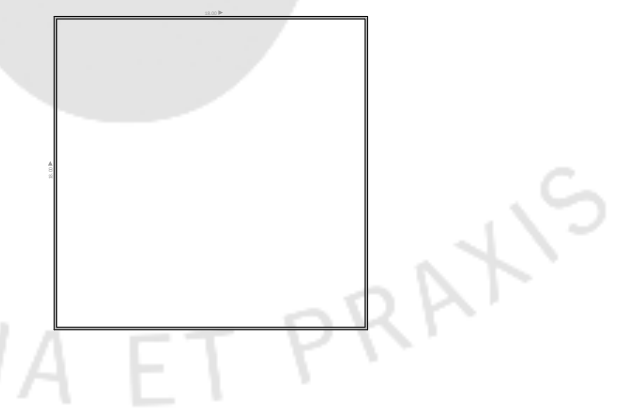

- $\quad$ En una cama de la paleta entran 4 cajas que hace un peso total de 27.12 kilos.

- $\quad$ En 12 niveles de carga, hacen un total de 325.44 kilos y una altura de $1.08 \mathrm{~cm}$; es decir, esto es lo que entrará en una paleta completa (48 cajas x 30 envases)

- $\quad$ De acuerdo a los estantes mostrados en el anexo 3 (Mecalux), el larguero será de 3.3m; es decir, 3 paletas por nivel y en total son 3 niveles. Sí se podrá aprovechar 
el techo del 2 do piso ya que las uñas del montacargas pueden elevarse hasta $3 \mathrm{~m}$ y la altura hasta el segundo rack es de $2.84 \mathrm{~m}$.

- $\quad$ En total, habría 9 paletas en 1 rack y son 2 racks. Total: 18 paletas $=5.8$ toneladas.

- $\quad$ En conclusión, se tendrá que desplazar la máxima cantidad de paletas durante la semana para semanalmente reponer el almacén ya que este permite almacenar solo para 1 semana útil.

\section{Materia Prima:}

Como ya se mencionó el capítulo 5, se usarán jabas para trasladar la materia prima del punto de venta hacia la planta, estas jabas tienen medidas de $113.67 \mathrm{~cm}$ de largo $\mathrm{x}$ $93.35 \mathrm{~cm}$ de ancho x $26.88 \mathrm{~cm}$ de alto, lo que quiere decir que solo una jaba entra en una paleta y se acumularán solo en 1 nivel debido a que la capacidad de la jaba es de 3.31 toneladas y el montacargas puede cargar hasta 3ton. Las jabas se almacenarán a granel en el almacén hasta una altura de 11 niveles (altura donde las uñas del montacargas pueden llegar como máximo), asimismo a lo largo de todo el almacén se podrán colocar camas de 12 jabas lo que suman un máximo de 435 ton, cantidad llega a cubrir el requerimiento anual. En el anexo 3, se pueden ver las medidas de la jaba.

Finalmente, a continuación, se presenta el plano de la planta en base a los criterios mencionados en las tablas 5.27 y 5.28 lo que proporciona un área total de $187 \mathrm{~m}^{2}$ aproximadamente.

\subsubsection{Dispositivos de seguridad industrial y señalización}

El local contará con lo siguiente:

- Señalización: se colocarán adhesivos con señales de advertencia, salvamento y socorro, lucha contra incendios, prohibiciones, obligaciones al personal y de riesgo permanente.

- Vías de circulación: Por razones de seguridad se deberán separar siempre que sea posible las vías reservadas a los peatones de las reservadas a vehículos y medios de transporte.

- Extintores: se colocarán extintores de tipo PQS (Polvo químico seco) para combatir los 3 tipos de fuego A (pallets, envases PP, documentos), B (líquidos inflamables como el combustible (para el uso de grupo electrógeno en caso de emergencia 
que la planta no cuente con energía y se tenga que activar), disolventes como los usados para la limpieza de las máquinas o de las oficinas, insumos como el ácido cítrico) y C (máquinas) asegurando la máxima protección de toda la planta y aislando químicamente al fuego evitando la reacción en cadena. No conduce electricidad hacia el usuario. Asimismo, se colocarán extintores $\mathrm{CO} 2$ que lo hacen perfecto para la extinción de incendios en oficinas. El $\mathrm{CO} 2$ es un gas que no es combustible y que no reacciona químicamente con otras sustancias por lo que puede ser utilizado para apagar una gran cantidad de tipos de fuego.

- Guardas para las máquinas: La función de una guarda evidentemente es mantener al trabajador fuera del área de peligro. A continuación, se ofrece algunas guardas y dispositivos que se usaran en las máquinas.

\section{Guardas}

a) Barreras fijas: para las lavadoras con una rejilla metálica para las transmisiones, etiquetadora, encajadora y llenadora/selladora.

b) Cribas: para cubrir las correas y poleas de la banda de transporte y evitar el atrapamiento.

\section{Dispositivos}

a) Dispositivos detectores de presencia: como un cable de parada de emergencia en la faja transportadora para evitar que en un accidente siga funcionando la banda.

b) Botones de parada de emergencia: para el escaldador, marmita, autoclave y pasteurizador comercial.

- $\quad$ EPP: Uso de equipos de protección para el personal.

- Luces de emergencia: la planta contará con estas luces para casos en que haya baja energía.

- Zona de evacuación: el patio de maniobras será señalizado como una zona de evacuación para la planta. Para las oficinas, se hará un espacio fuera de la empresa.

\subsubsection{Disposición general}

La misión de diseñar es encontrar la mejor ordenación de las áreas de trabajo y del equipo en aras a conseguir la máxima economía en el trabajo al mismo tiempo que la mayor seguridad y satisfacción de los trabajadores. 
Cabe resaltar que el tipo de distribución que se usará es por proceso (función) ya que se adapta a los cambios en la secuencia de operaciones; además, así cada zona está especializada.

A continuación, se presenta el análisis relacional que permitirá comprender la correspondencia que existe entre cada área, asimismo se presenta una tabla de códigos de proximidad a usar.

Figura 5.21

Identificación de actividades

\begin{tabular}{|c|c|c|}
\hline Simbolo & Color & Actividad \\
\hline & Rojo & Operación (montaje) \\
\hline & Verde & $\begin{array}{c}\text { Operación, } \\
\text { proceso o fabricación }\end{array}$ \\
\hline & Amarillo & Transporte \\
\hline & Naranja & Almacenaje \\
\hline
\end{tabular}

Fuente: Díaz B; Jarufe B y Noriega M.T, (2007).

Tabla 5.31

Códigos de proximidad entre áreas

\begin{tabular}{|cccc|}
\hline Código & Proximidad & Color & $\mathbf{N}^{\circ}$ de líneas \\
\hline $\mathrm{A}$ & Absolutamente necesario & Rojo & 4 rectas \\
$\mathrm{E}$ & Especialmente necesario & Amarillo & 3 rectas \\
I & Importante & Verde & 2 rectas \\
O & Normal & Azul & 1 recta \\
U & Sin importancia & & \\
X & No deseable & Plomo & 1 zigzag \\
XX & Altamente no deseable & Negro & 2 zigzag \\
\hline
\end{tabular}

Fuente: Díaz B; Jarufe B y Noriega M.T, (2007).

Además de estos códigos, se debe indica los motivos de dicha relación entre las actividades y áreas que existen dentro de la planta de producción de conservas de mango en almíbar. 
Tabla 5.32

Lista de motivos

\begin{tabular}{|c|c|}
\hline Código & Motivos \\
\hline 1 & Secuencia de Proceso \\
\hline 2 & Recepción y despacho \\
\hline 3 & Excesivo ruido \\
\hline 4 & Flujo de materiales \\
\hline 5 & Higiene \\
\hline 6 & Comodidad del Personal \\
\hline 7 & Inspección o Control \\
\hline 8 & Peligro \\
\hline
\end{tabular}

Elaboración propia

Considerando las actividades y áreas, las relaciones del proyecto se muestran; tanto la cercanía como lejanía en la siguiente tabla relacional: 
Figura 5.22

Tabla relacional de actividades

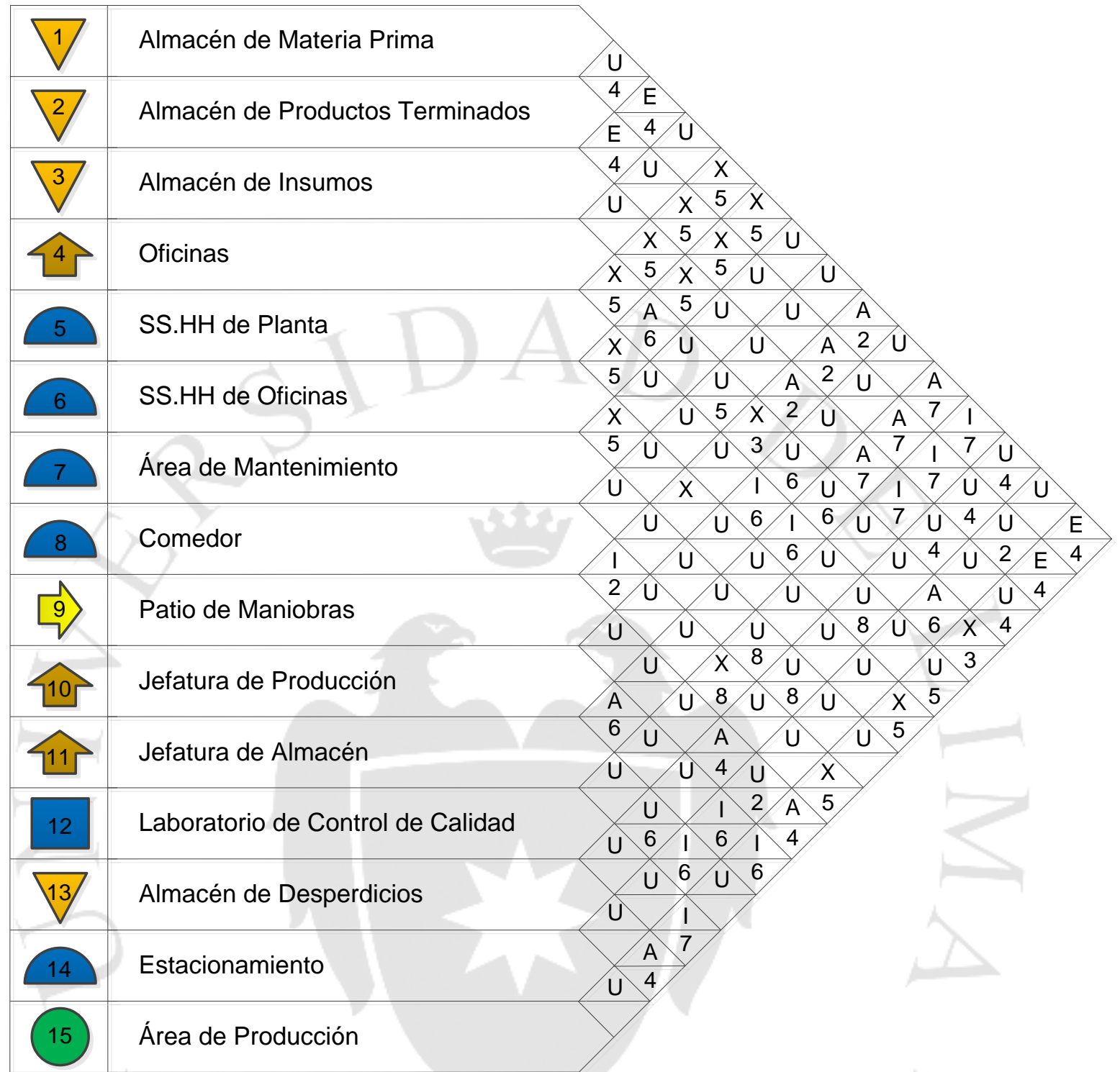

Elaboración propia 
Tomando como base la tabla relacional, se obtienen los siguientes valores de proximidad.

Tabla 5.33

Valores de proximidad

\begin{tabular}{|c|c|c|c|c|c|c|c|c|}
\hline $\mathbf{A}$ & $\mathbf{E}$ & $\mathbf{I}$ & \multicolumn{5}{|c|}{$\mathbf{U}$} & $\mathbf{X}$ \\
\hline $4-6$ & $1-3$ & $8-9$ & $1-7$ & $11-12$ & $4-11$ & $5-8$ & $4-8$ & $1-5$ \\
\hline $1-9$ & $2-3$ & $5-10$ & $2-7$ & $1-13$ & $2-14$ & $6-8$ & $8-10$ & $2-5$ \\
\hline $2-9$ & $1-15$ & $5-11$ & $3-7$ & $2-13$ & $4-7$ & $7-8$ & $8-11$ & $3-5$ \\
\hline $3-9$ & $2-15$ & $1-12$ & $5-7$ & $3-13$ & $5-12$ & $8-13$ & $3-15$ & $4-5$ \\
\hline $10-11$ & & $2-12$ & $5-9$ & $10-13$ & $7-12$ & $13-14$ & & $1-6$ \\
\hline $9-13$ & & $3-12$ & $7-9$ & $11-13$ & $5-13$ & $14-15$ & & $2-6$ \\
\hline $4-14$ & & $10-14$ & $1-10$ & $5-14$ & $7-13$ & $1-4$ & & $3-6$ \\
\hline $13-15$ & & $11-14$ & $2-10$ & $6-14$ & $1-14$ & $2-4$ & & $6-7$ \\
\hline $9-15$ & & $10-15$ & $3-10$ & $8-14$ & $3-14$ & $3-4$ & & $6-9$ \\
\hline $1-11$ & & $12-15$ & $7-10$ & $12-14$ & $7-14$ & $12-13$ & & $8-12$ \\
\hline $2-11$ & & & $9-10$ & $7-15$ & $9-14$ & $4-12$ & & $4-15$ \\
\hline $3-11$ & & & $7-11$ & $11-15$ & $5-15$ & $6-10$ & & $6-15$ \\
\hline & & & $9-11$ & $1-2$ & $1-8$ & $6-11$ & & $8-15$ \\
\hline & & & $9-12$ & $6-13$ & $2-8$ & $6-12$ & & $5-6$ \\
\hline
\end{tabular}

Elaboración propia

Una vez realizados estos pasos, se procede a mostrar el diagrama relacional a continuación. 
Figura 5.23

Diagrama Relacional

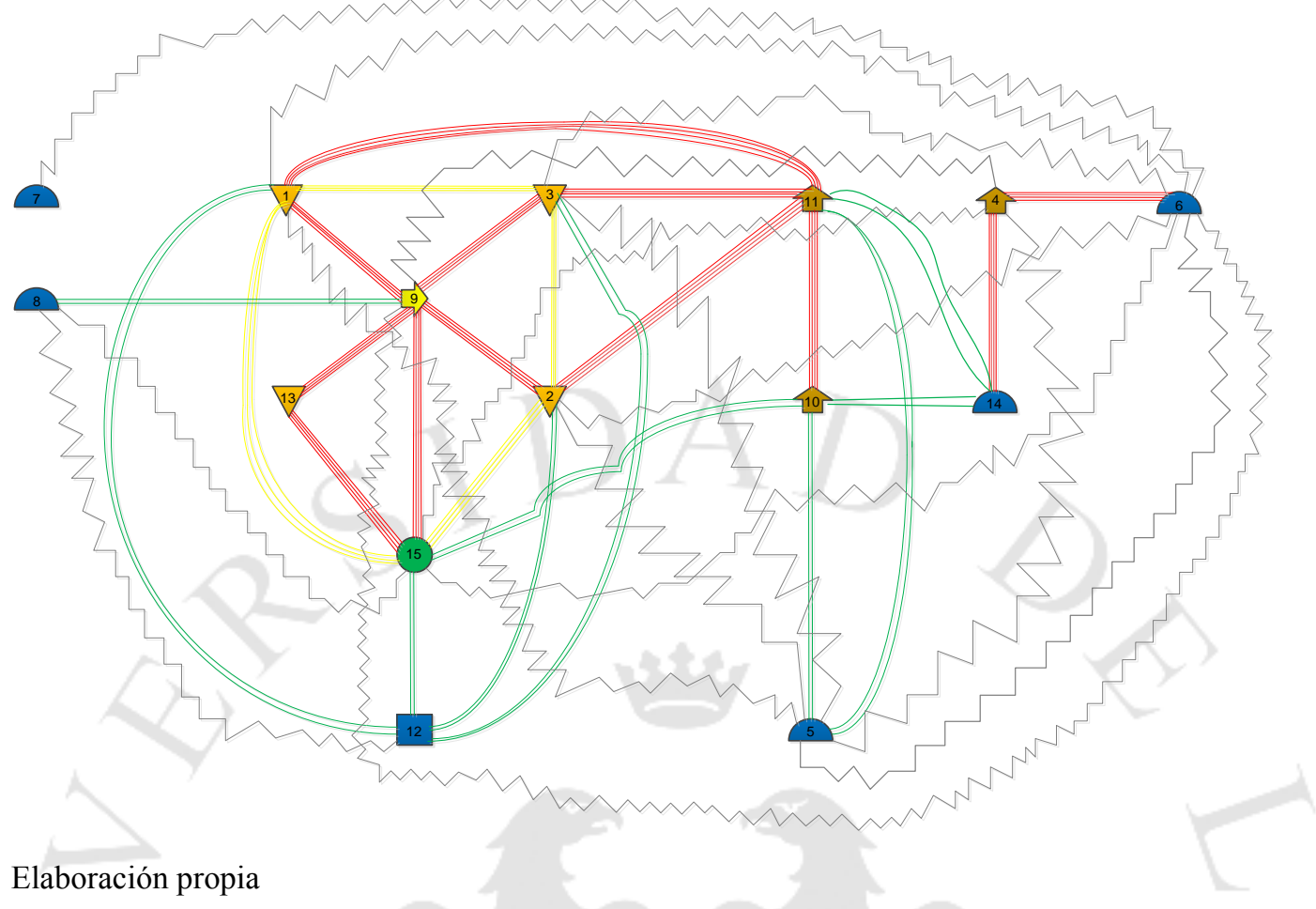

5.10.6. Disposición de detalle

A continuación, se presenta la disposición a detalle en un plano tentativo de las distintas áreas. 
Figura 5.24. Plano de distribución de la planta

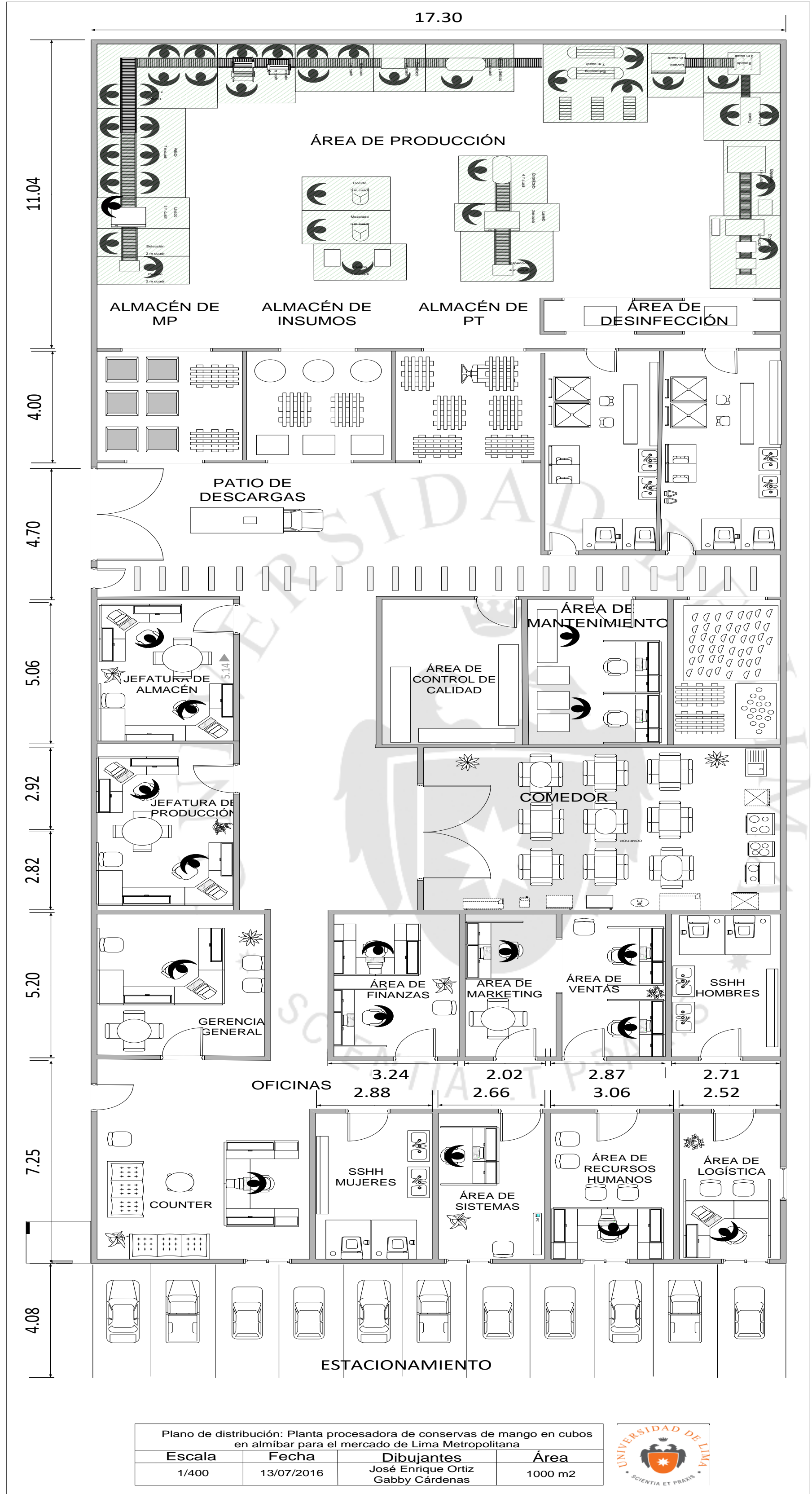

Elaboración propia 


\subsection{Cronograma de implementación del proyecto}

Se hará uso de un Diagrama de Gantt para programar la secuencia y duración de las tareas con el objetivo de presentar un cronograma de tiempo contabilizado en días. A continuación, se presenta una tabla de actividades.

Tabla 5.34

Lista de tareas a realizar en el proyecto

\begin{tabular}{|c|l|c|}
\hline$\#$ & \multicolumn{1}{|c|}{ Actividades } & $\begin{array}{c}\text { Duración } \\
\text { (días) }\end{array}$ \\
\hline 1 & Estudio de factibilidad del proyecto & 60 \\
\hline 2 & Ingeniería básica y detalle & 90 \\
\hline 3 & Financiamiento & 30 \\
\hline 4 & Licitación & 30 \\
\hline 5 & Preparación del terreno antes de las obras civiles & 8 \\
\hline 6 & Obras civiles & 90 \\
\hline 7 & Compra de la maquinaria (Procura) & 45 \\
\hline 8 & Instalación de los servicios & 7 \\
\hline 9 & Instalación y montaje de la maquinaria y equipos & 5 \\
\hline 10 & Instalación de mobiliario & 15 \\
\hline 11 & Reclutamiento y Capacitación del personal & 45 \\
\hline 12 & Pruebas finales & 5 \\
\hline 13 & Puesta en marcha & \\
\hline
\end{tabular}

Elaboración propia

El proyecto tendrá una duración aproximada de 24 meses asumiendo que inicia a comienzos del siguiente año, tal como se muestra en la siguiente imagen. 
Figura 5.25

Diagrama de Gantt

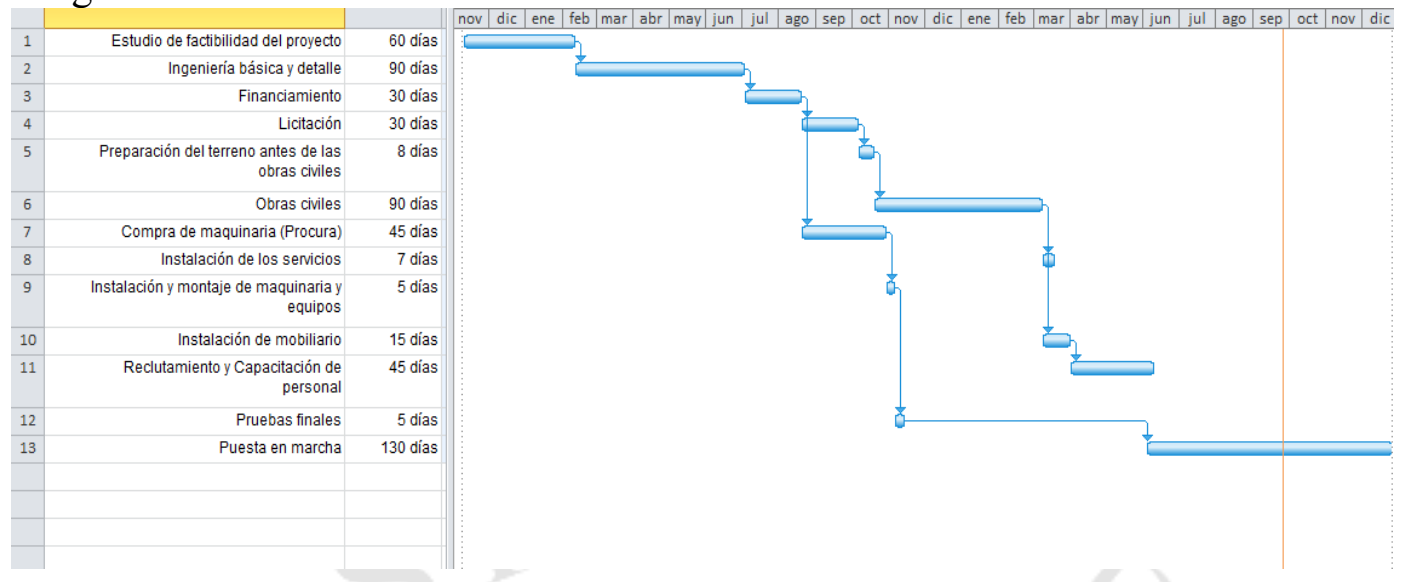

Elaboración propia 


\section{CAPÍTULO VI. ORGANIZACIÓN ADMINISTRATIVA}

\subsection{Formación de la Organización empresarial}

A continuación, se muestran los principales aspectos de la organización y su formación.

\section{$\underline{\text { Misión }}$}

Satisfacer al cliente brindándole productos naturales procesados de calidad asegurada y valor añadido, elaboradas con los más altos estándares del mercado en una nueva presentación de consumo.

\section{$\underline{\text { Visión }}$}

Ser la empresa líder en el rubro de conservas de fruta en el país, reconocida por nuestro trabajo de alta calidad, innovación constante, responsabilidad social y por el talento de nuestra gente confiando en su capacidad para alcanzar un crecimiento sostenido y así multiplicar el valor de la compañía.

\section{$\underline{\text { Política de calidad }}$}

Somos un equipo de trabajo cuyas acciones diarias las ejecutamos con una elevada vocación de servicio a los Clientes en nuestra visión de empresa de categoría mundial, basadas en los siguientes principios:

A. INTEGRIDAD PERSONAL como expresión de disciplina, orden, respeto, honestidad y entusiasmo.

B. CREATIVIDAD E INNOVACIÓN como parte de nuestro reto diario para el mejoramiento continuo.

C. PRODUCTIVIDAD en nuestro trabajo y en el empleo de los recursos materiales.

D. CONSCIENCIA en la práctica de un trabajo libre de errores y en el COMPROMISO leal con la institución y con las realizaciones de calidad

E. COMUNICACIÓN INTERNA Y EXTERNA de manera sincera, sencilla, precisa, oportuna y personalizada.

F. CUMPLIMIENTO Y ENTREGA de lo acordado a tiempo, excediendo las expectativas. 
G. CABALIDAD de hacer todo con exactitud y terminar con precisión aquello a lo que nos comprometemos, cuidando los detalles.

\section{Creación de la organización}

Luego de analizar la viabilidad del proyecto continúa la elección de la forma jurídica a adoptar (Empresa Individual, Sociedad Civil, Limitada, Sociedad Anónima...). En este caso, se opta por Sociedad Anónima debido a las características citadas en la tabla 6.1. Uno de los puntos principales, es que el proyecto cuenta con 35 trabajadores por lo que los demás tipos de empresa son una restricción.

El propósito de formar jurídicamente una empresa es limitar la responsabilidad de los socios o personas. Las personas que constituyen la Sociedad convienen en aportar bienes o servicios para el ejercicio en común de actividades económicas. La sociedad es una persona jurídica (reconocida por la ley), distinta a los socios que la forman y es ella la que resulta dueña de los bienes que los socios aportan. Efectuando el aporte, los socios no son dueños de los bienes aportados, sino de una acción o derecho respecto a la sociedad.

\section{$\underline{\text { Valores }}$}

Compromiso: Estar comprometido con la empresa en su servicio para lograr siempre los resultados esperados y generar valor de manera permanente, buscando sobrepasar los estándares de excelencia y tener iniciativas que tengan un impacto dentro y fuera de la organización.

Seguridad: base fundamental de un buen negocio. Todo lo que se hace se basa en la seguridad de los empleados y de las comunidades que rodean la organización.

Innovación: Trabajar permanentemente para crear y mejorar productos, servicios y procesos.

Integridad: Actuar de manera ética y con espíritu de servicio, que genere confianza en los clientes, usuarios, colaboradores, proveedores, accionistas y la comunidad, obrando en el marco de la ley y de las normas establecidas en el país.

Transparencia: Realizar las gestiones de forma objetiva, clara y verificable. 
Respeto: Reconocer, aceptar y comprender a todas las personas que interactúan con la Organización. Interactuar reconociendo los intereses colectivos y la diversidad individual.

Comunicación: valor fundamental, se intenta que las relaciones y conexiones dentro de los miembros de la empresa y con los clientes sea fluida y sincera.

Trabajo en Equipo: se intenta la integración de cada uno de miembros de la empresa al grupo laboral, que sean promovidos mejores resultados gracias a un ambiente positivo. Para ello es elemental la participación de los distintos miembros de la empresa en diversos ámbitos.

Honestidad: orientado tanto para los miembros de la empresa entre sí, como con los clientes. Se promueve la verdad como una herramienta elemental para generar confianza y la credibilidad de la empresa.

Tabla 6.1

Características del tipo de empresa a adoptar

\begin{tabular}{|c|c|c|c|c|c|}
\hline $\begin{array}{l}\text { Tipo de } \\
\text { empresa }\end{array}$ & $\begin{array}{l}\mathbf{N}^{o} \text { de } \\
\text { Socios }\end{array}$ & Capital & Constitución & $\begin{array}{l}\text { Órganos de } \\
\text { la empresa }\end{array}$ & Características \\
\hline $\begin{array}{l}\text { Sociedad } \\
\text { Anónima } \\
\text { S.A. }\end{array}$ & $\begin{array}{c}\text { Mínimo } 2 \text { y } \\
\text { sin límite } \\
\text { máximo }\end{array}$ & $\mid \begin{array}{lr}\text { En la sociedad } \\
\text { anónima } & \text { sólo } \\
\text { pueden } & \text { ser } \\
\text { objeto de aporte } \\
\text { los bienes o } \\
\text { derechos } \\
\text { susceptibles de } \\
\text { valoración } \\
\text { económica. } \\
\text { No se admite el } \\
\text { aporte } \\
\text { servicios en la } \\
\text { sociedad } \\
\text { anónima }\end{array}$ & $\begin{array}{l} \\
\text { Se constituye por } \\
\text { escritura pública, } \\
\text { en la que está } \\
\text { contenido el pacto } \\
\text { social. } \\
\text { Requiere } \\
\text { inscripción en el } \\
\text { registro }\end{array}$ & $\begin{array}{l}\text {-Junta General } \\
\text { de Accionistas } \\
\text {-El Directorio } \\
\text {-Gerente. }\end{array}$ & \begin{tabular}{|l} 
El capital está representado por \\
acciones nominativas y se \\
integra por aportes de los \\
accionistas, quienes no \\
responden personalmente de \\
las deudas sociales. \\
La sociedad puede constituirse \\
de dos formas 1. Constitución \\
por los socios y 2. Por la oferta \\
a terceros (invitación pública a \\
ser accionista), sobre la base \\
del programa suscrito por los \\
fundadores. \\
Forma usada para empresas \\
grandes.
\end{tabular} \\
\hline
\end{tabular}

Fuente: Emprendepyme, (2015)

A continuación, los pasos que se debe seguir para la formación de una empresa.

a) Verificar si el nombre elegido pertenece a otra sociedad.

b) Elaboración de la Minuta de constitución. 
c) Elaboración de Escritura Pública

d) Inscripción en los Registros Públicos

e) Inscripción en SUNAT/ ESALUD/Trabajadores.

f) Inscripción u obtención de permisos especiales para poder iniciar actividades.

g) Licencia funcionamiento otorgada por el Municipio.

h) Autorización de Libro de Planillas.

\subsection{Requerimientos de personal directivo, administrativo y de servicios}

El proyecto es una mediana empresa que trabaja 1 turno en la planta; agregando el personal ya mencionado en el punto anterior sería una cantidad medianamente alta de trabajadores los que conforman la empresa. A continuación, se presentan algunas tablas del personal que se requiere para cada puesto tanto en el área operativa como el área administrativa.

Tabla 6.2

Número de trabajadores operativos

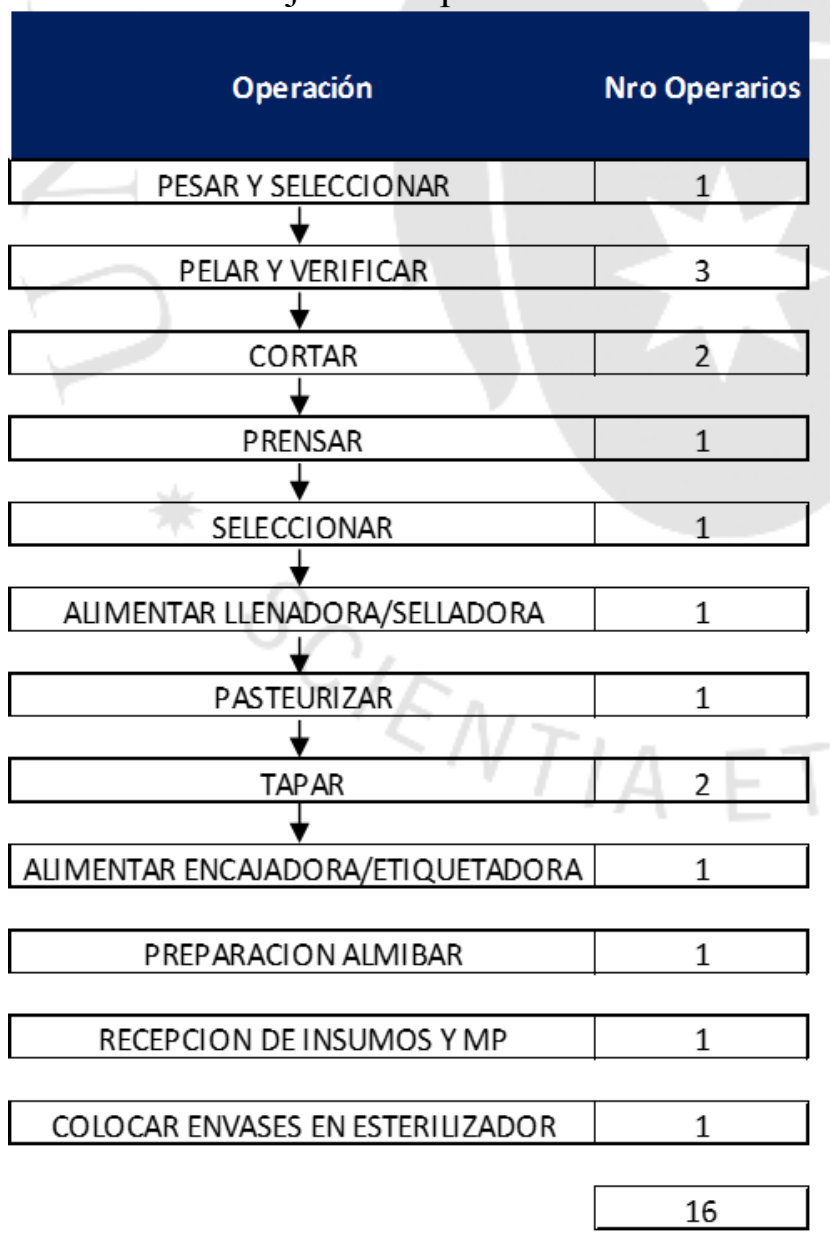

Elaboración propia 
A continuación, se presenta la tabla 6.3 con el personal administrativo necesario.

Tabla 6.3

Personal administrativo

\begin{tabular}{|c|c|}
\hline Puesto & Número de vacantes \\
\hline Gerencia general & 1 \\
\hline Gerente de finanzas & 1 \\
\hline Asistente financiero & 1 \\
\hline Jefe de producción & 1 \\
\hline Supervisor de producción & 1 \\
\hline Gerente de ventas & 1 \\
\hline Ejecutivo de ventas (KAM) & 2 \\
\hline Asistente de ventas & 1 \\
\hline Jefe de Calidad & 1 \\
\hline Gerente de operaciones & 1 \\
\hline Asistente de operaciones & 1 \\
\hline Jefe de almacén & 1 \\
\hline Responsable de almacén & $1 p=$ \\
\hline Jefe de mantenimiento & 1 \\
\hline Técnico de mantenimiento & 1 \\
\hline Analista de sistemas & 1 \\
\hline Responsable de R.R.H.H & 1 \\
\hline Recepcionista & 1 \\
\hline Total & 19 \\
\hline
\end{tabular}

Elaboración propia

Tabla 6.4

Número de trabajadores terceros

\begin{tabular}{|l|c|}
\hline Personal tercero & Cantidad \\
\hline Vigilante & 2 \\
\hline Personal Cafetería & 4 \\
\hline Limpieza & 2 \\
\hline Transporte & 3 \\
\hline Total & $\mathbf{1 1}$ \\
\hline
\end{tabular}

Elaboración propia

Como se puede visualizar, se necesita un total de 35 empleados que trabajan en planilla directamente con la empresa y 11 empleados por Outsourcing.

Asimismo, a continuación se describen algunas de las funciones del personal administrativo. 
Jefe de producción: es el responsable de velar por los buenos procedimientos de producción en la planta y reportar al gerente general. Sus principales funciones son:

- Controla la labor de los supervisores de áreas y del operario en general.

- Es responsable de las existencias de materia prima, material de empaque $\mathrm{y}$ productos en proceso durante el desempeño de sus funciones.

- Vela por la calidad de todos los productos fabricados.

- Ejecuta planes de mejora y de procesos.

- Emite informes, analiza resultados, genera reportes de producción que respalden la toma de decisiones.

- Establece controles de seguridad y determina parámetros de funcionamiento de equipos y procesos que garanticen la producción y mantengan la seguridad del empleado.

- Seguimiento de los trabajos en planta.

- Planifica de manera general cada una de las órdenes que ingresen a la empresa.

Jefe de Calidad: es el responsable de asegurar el cumplimiento de las especificaciones de las materias primas, insumos, procesos y productos de acuerdo a los programas de calidad establecidos. Contribuir a lograr una mejora continua en la calidad de los procesos y por consiguiente de los productos. Ejecutar las actividades relacionadas al Sistema Integrado de Gestión (ISO 9001, ISO 14001, OHSAS 18001 y HACCP) a fin de garantizar su consolidación de acuerdo a los objetivos de la organización. Dentro de sus principales funciones se encuentra:

- Garantizar el cumplimiento de los programas de calidad y programar de manera efectiva seguimientos especiales que permitan lograr la mejora continua de los procesos.

- Garantizar los resultados analíticos del laboratorio, mediante un control de los equipos del laboratorio, capacitación al personal e intercomparación analítica. 
- Apoyar en el seguimiento al desarrollo de nuevos productos mediante pruebas de laboratorio y en línea.

- Participar activamente dentro del Sistema Integrado de Gestión (ISO 9000, ISO 14000, OHSAS 18000 y HACCP) a fin de garantizar su consolidación de acuerdo a los objetivos de la organización.

- Aprobar o rechazar las materias primas, materiales de envasado y empaque y productos terminados.

- Aprobar las especificaciones, las instrucciones de muestreo, los métodos de ensayos y otros procedimientos de calidad.

Jefe de mantenimiento: es el responsable de que las máquinas sean confiables y estén disponibles para la producción de conservas de mango.

Algunas de sus funciones son:

- Planificación de los mantenimientos (General y Parada de Planta).

- Asignación de personal para mantenimientos.

- Elaboración del indicador de fallas por máquina y definición de acciones correctivas.

- Planificar, programar y supervisar los trabajos de mantenimiento en las instalaciones de planta.

- Inspeccionar los equipos críticos de planta y realizar las coordinaciones respectivas para intervención oportuna.

Gerente General: es el principal responsable de liderar la gestión estratégica, dirigiendo y coordinando a las distintas áreas para asegurar la rentabilidad, competitividad, continuidad y sustentabilidad de la empresa, cumpliendo con los lineamientos estratégicos del directorio y las normativas y reglamentos vigentes. Sus principales funciones son:

- Liderar la gestión estratégica

- Liderar la formulación y aplicación del plan de negocios

- Alinear a las distintas Gerencias 
- Presentar al Directorio estados de situación e información de las marcha de la empresa

- Velar por el respecto de las normativas y reglamentos vigentes

Gerente de finanzas: es el encargado de monitorear y controlar los gastos de la empresa. Sus principales funciones son:

- Investigar e identificar fuentes de financiamiento para las empresas.

- Analizar la situación económica-financiera de las empresas.

- Administrar los sistemas contables y los procesos tributarios.

- Administrar los riesgos económicos financieros tributarios.

- Analizar la rentabilidad de la empresa para identificar el cumplimiento y las modificaciones de objetivos establecidos.

- Analizar y evaluar los proyectos de inversión.

- Monitorear y controlar los gastos de la empresa.

- Gestionar el Capital de Trabajo en Cuentas por cobrar, efectivo y cuentas por pagar para asegurar la mejora de los indicadores clave de rendimiento críticos.

Gerente de ventas: Responsable de direccionar la gestión de las ventas y de la rentabilidad de la unidad de negocio a través de la planificación, desarrollo y control de acciones orientadas al cumplimiento de estándares corporativos, el análisis de resultados de las ventas y el impulso de las mismas, así como el análisis de indicadores de la gestión comercial para alinearlos al propósito de la corporación, promoviendo el mantenimiento de los altos niveles de satisfacción del cliente que persigue la marca. Algunas de sus funciones son:

- Representar a la empresa en los aspectos comerciales en los canales de venta.

- Presentar planes de mejora continua para la gestión comercial de la compañía. 
- Proponer mensualmente actividades comerciales y/o de mercadeo que permitan mejorar la rotación del producto.

- Revisar periódicamente la asignación de zonas para cada una de las personas a su cargo.

- Supervisión, monitoreo y definición de las metas del equipo de ventas.

- Establecer los objetivos de venta anuales en función de las perspectivas del mercado.

Ejecutivo de ventas: es el encargado de seguir al proceso de ventas hasta su facturación. Sus principales funciones son:

- Cumplimiento de objetivos

- Cumplimiento de cuota y plan de ventas

- Generar y/o desarrollar cartera de clientes para su administración.

- Generar y concretar las oportunidades de ventas captando para ello nuevos clientes y fidelizando los actuales

- Realizar las cotizaciones en función a los requerimientos de los clientes

- Asegurar con el cliente la atención adecuada del servicio ofrecido

- Gestionar la cartera de clientes realizando visitas comerciales y manteniéndolos informados sobre nuevos productos y servicios para conseguir consolidar y aumentar el volumen de ventas. De igual forma prospectar constantemente nuevos clientes y hacer seguimiento a los mismos.

- Colaborar en el tratamiento eficaz de las reclamaciones de los clientes.

Gerente de operaciones: es el responsable de cumplir los objetivos de las operaciones de planificación, compras, almacenaje y distribución. Otros objetivos incluyen ahorros de productividad, excelencia logística y Reducción de tiempo de ciclo. Sus principales responsabilidades son:

- Controlar los costos y presupuesto de la operación logística.

- Gestionar y controlar la planificación, compras. 
- Realizar el seguimiento de las órdenes, control de tiempo y de calidad logística, principal alerta operativa hacia el área comercial.

- Planificar, ejecutar y gestionar el plan integral de la cadena de suministros (compras, almacenes, distribución, contratos).

Asistente de operaciones: es el responsable de garantizar el abastecimiento oportuno de los materiales de buena calidad y costos razonables cumpliendo con los estándares de la empresa. Le compete la negociación y evaluación de proveedores, la planificación y evaluación del estado y stock de los principales materiales utilizados, implementando estrategias para el seguimiento diario de entrada de material de obra. Sus funciones implican:

- Revisar las solicitudes de compra de materiales y repuestos, asegurando las compras solicitadas para los diferentes proyectos y procesos, negociando costos y atendiendo el cumplimiento de los acuerdos negociados con los proveedores.

- Gestionar y evaluar a diferentes proveedores de acuerdo a los procesos de licitación.

- Negociar con los diferentes proveedores y afianzar acuerdo de largo plazo.

- Elaboración de presupuestos de compras.

- Control y actualización del stock al Área Comercial

Jefe de almacén: es el responsable de la administración y control operativo del almacén de productos y control operativo del transporte para las operaciones de distribución. Sus principales funciones son:

- Verificación, ingreso y acomodo de mercadería

- Picking de pedidos

- Mantiene el control de inventarios

- Administra la información vinculada a la gestión de almacenes 
- Genera informes de necesidades de abastecimiento, remitiendo los pedidos sugeridos correspondientes.

- Administrar el inventario de los almacenes de la empresa, controlar las entradas y salidas normales y especiales de pedidos y guías.

- Revisar y supervisar el inventario de los almacenes.

- Entregar y controlar el ingreso y salida de materiales, insumos y repuestos a utilizar en el área técnica.

Jefe de TI: es el encargado de obtener el mejor rendimiento de los recursos de sistemas a fin de asegurar y optimizar los procesos de las áreas usuarias.

- Adecuar las nuevas tecnologías, de acuerdo a las políticas del grupo.

- Responsable de la administración de los equipos y sistemas dentro de la sala de servidores.

- Administrador de servicios de comunicaciones internet, intranet y otros.

- Administrar la seguridad (base de datos, aplicativos, contraseñas, archivos, programas).

- Mantenimiento de computadoras personales y equipos red.

- Realizar el protocolo de backup de toda la información de la empresa.

- Realizar la actualización periódica del antivirus utilizado en servidores y computadoras personales

- Brindar soporte de primer nivel al usuario final.

- Velar por la disponibilidad de los servicios de TI: Servidores, Redes (LAN, WAN, VPN, WIFI).

Jefe de RRHH: es el responsable de la dirección de las funciones de administración y desarrollo del personal de la empresa, promover el mantenimiento de un buen ambiente de trabajo y clima laboral en toda la empresa. Algunas de sus funciones a continuación:

- Los movimientos y ocurrencias del personal. 
- El programa de capacitaciones anual y mantener los registros que evidencien en el cumplimiento de estas actividades

- Todo lo vinculado al bienestar y asistencia social de los trabajadores.

- La correcta y oportuna elaboración de las planillas.

- Controlar la emisión y registros de contratos de trabajo, el rol de vacaciones, la asistencia del personal, faltas y justificaciones de las mismas.

- Evaluar el desempeño del personal

- Velar por el cumplimiento de la normativa legal laboral vigente y realizar actividades de seguimiento para el control y aplicación de las mismas.

\subsection{Estructura Organizacional}

La siguiente estructura de trabajo muestra la forma en la que se dividirá la empresa.

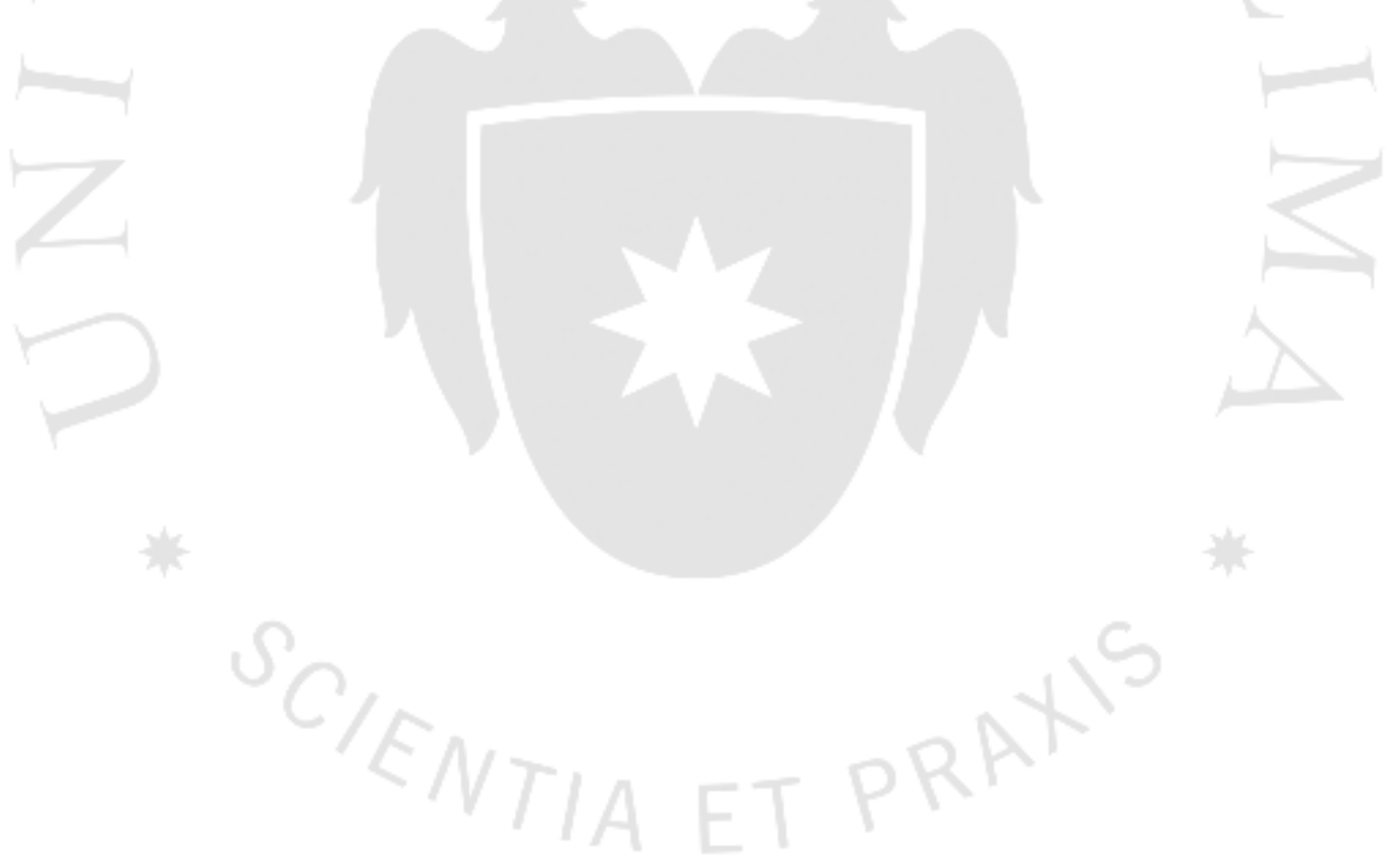




\section{Figura 6.1}

\section{Organigrama de la Empresa}

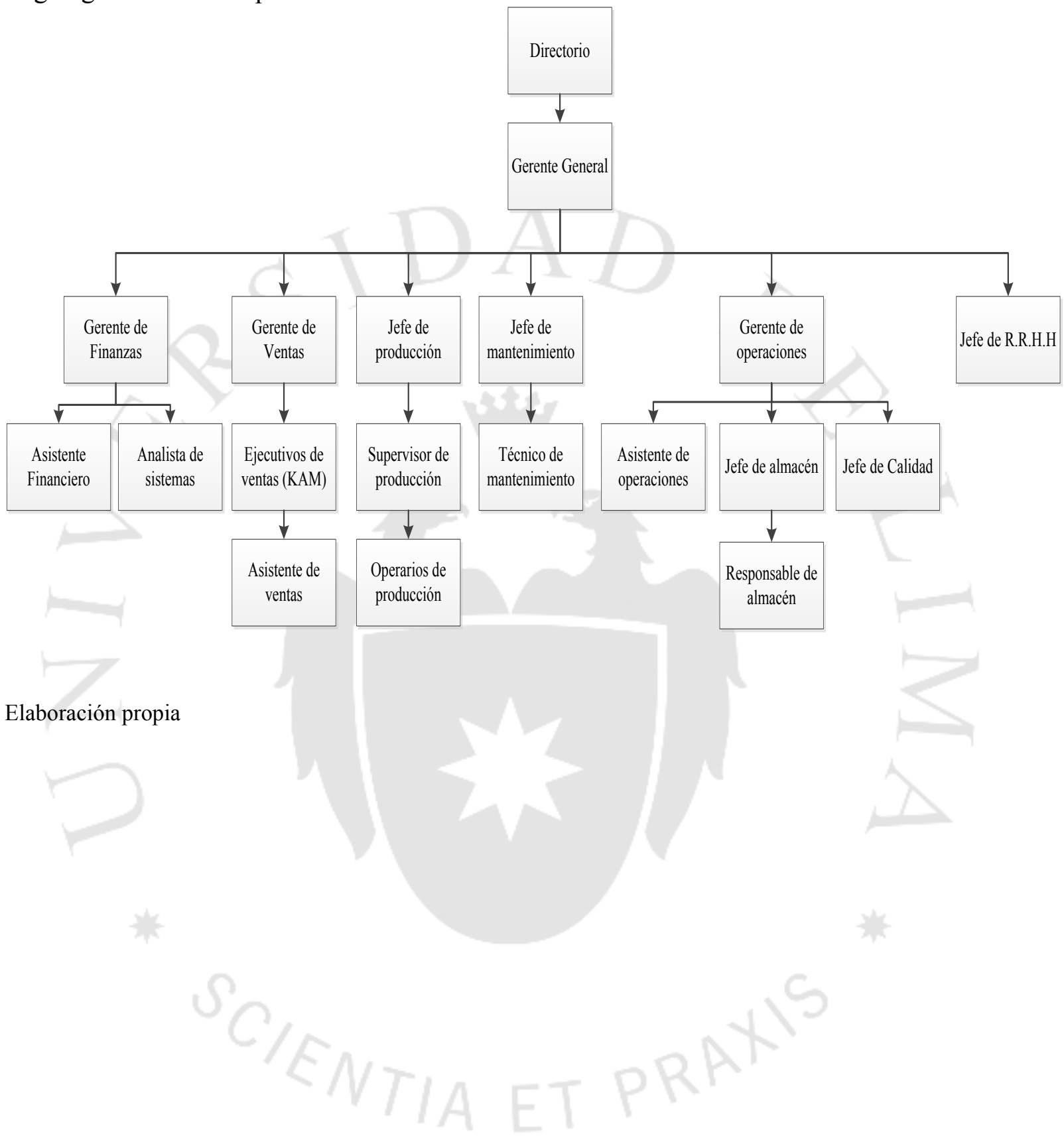




\section{CAPITULO VII. ASPECTOS ECONÓMICOS Y FINANCIEROS}

\subsection{Inversiones}

\subsubsection{Estimación de las inversiones de largo plazo (tangibles e intangibles)}

Para estimar el nivel de inversión que se requiere en el presente estudio se procedió a evaluar los costos que tienen las máquinas para el proceso de producción, la materia prima requerida para la producción, el terreno, herramientas de planta y oficina, muebles y enseres, gastos en energías, los sueldos que se le pagaran al personal y finalmente otros costos necesarios para que la planta pueda operar. A continuación, se presenta una tabla con el valor de la inversión en maquinaria y equipos.

Tabla 7.1

Valor de la maquinaria

\begin{tabular}{|l|c|c|c|}
\multicolumn{1}{|c|}{ Máquinas y equipos } & $\begin{array}{c}\text { Número } \\
\text { requerido }\end{array}$ & Valor (S/.) & $\begin{array}{c}\text { Costo total } \\
(\mathbf{S} / .)\end{array}$ \\
\hline Banda de transporte & 5 & 17,400 & 87,000 \\
\hline Balanza digital & 3 & 300 & 900 \\
\hline Exhauster & 1 & 11,600 & 11,600 \\
\hline Lavadora & 3 & 23,200 & 69,600 \\
\hline Prensa & 1 & 250 & 250 \\
\hline Envasadora multiple (llenadora/selladora) & 1 & 50,000 & 50,000 \\
\hline Escaldador & 1 & 12,000 & 12,000 \\
\hline Etiquetadora & 1 & 10,000 & 10,000 \\
\hline Marmita & 1 & 15,959 & 15,959 \\
\hline Secadora & 1 & 12,000 & 12,000 \\
\hline Encajadora & 1 & 17,000 & 17,000 \\
\hline Esterilizador de envases & 1 & 15,000 & 15,000 \\
\hline Transpaleta manual & 2 & 2,500 & 5,000 \\
\hline Montacargas & 1 & 23,000 & 23,000 \\
\hline Estante de bandejas & 5 & 900 & 4,500 \\
\hline Detector de vacío & 1 & 2,600 & 2,600 \\
\hline Balanza de laboratorio & 1 & 150 & 150 \\
\hline Refractómetro & 2 & 240 & 480 \\
\hline
\end{tabular}

Elaboración propia

El costo del terreno es de 1, 200,000 soles y los edificios ascienden a un costo de 513,411 soles con lo que la inversión fija tangible es de 2, 767,529 soles. A continuación, en las siguientes tablas se muestra la inversión en activos fijos tangibles e intangibles. 
Tabla 7.2

Presupuesto de activos fijos tangibles

\begin{tabular}{|c|c|}
\hline ACTIVO FIJO & $\begin{array}{c}\text { IMPORTE } \\
\text { (S/.) }\end{array}$ \\
\hline Terreno & $1,200,000$ \\
Edificaciones planta & 513,411 \\
Edif. Ofic. Administrativa & 451,179 \\
Maquinaria y equipo & 337,039 \\
Herramientas planta & 3,950 \\
Herramientas oficina & 46,700 \\
Muebles y enseres & 15,250 \\
Imprevistos fabriles & 150,000 \\
Imprev. No fabriles & 50,000 \\
\hline Total & $2,767,529$ \\
\hline
\end{tabular}

Elaboración propia

Tabla 7.3

Presupuesto de activos fijos intangibles

\begin{tabular}{|c|c|}
\hline $\begin{array}{l}\text { ACTIVO FIJO } \\
\text { INTANGIBLE }\end{array}$ & $\begin{array}{l}\text { IMPORTE } \\
\text { (S/.) }\end{array}$ \\
\hline Estudios Pre-factibilidad & 20,000 \\
\hline Estudios Factibilidad & 40,000 \\
\hline Gastos constitución legal & 3,000 \\
\hline Licencia Funcionamiento & 2,000 \\
\hline Supervisión & 40,000 \\
\hline Puesta en Marcha & 50,000 \\
\hline Pruebas Finales & 30,000 \\
\hline Contingencias & 45,360 \\
\hline Total & 230,360 \\
\hline
\end{tabular}

Elaboración propia

\subsubsection{Estimación de las inversiones de corto plazo (Capital de trabajo)}

Para que la empresa pueda operar necesita contar con dinero en efectivo para realizar compras de materia prima e insumos además de poder pagar el sueldo de operarios y personal administrativo hasta que reciba ingresos por las ventas realizadas.

El pago a los proveedores de materia prima e insumos se realizará al contado mientras que se cobrará luego de 3 meses después de realizada la venta a los clientes, esto debido a que el mercado tiene esas políticas de pago. Es por ello que a partir del mes número 5 se obtienen ingresos por las ventas. Cabe mencionar que durante el primer mes la planta solo se dedicará a producir 
En la siguiente tabla se muestran los requerimientos necesarios para los primeros meses:

Tabla 7.4

Requerimientos para los primeros 4 meses de capital de trabajo en soles

\begin{tabular}{|lc|c|c|c|c|c|}
\cline { 2 - 7 } \multicolumn{1}{c|}{} & Mes 1 & Mes 2 & Mes 3 & Mes 4 & Mes 5 & Mes 6 \\
\hline $\begin{array}{l}\text { Pagto de Materia prima e insumos } \\
\text { otros }\end{array}$ & 129,024 & 130,443 & 131,878 & 133,329 & 134,795 & 136,222 \\
\hline Ingresos por venta & 183,840 & 184,125 & 184,126 & 184,411 & 184,696 & 184,698 \\
\hline Resultado del mes & 0 & 0 & 0 & 0 & 499,811 & 499,811 \\
\hline
\end{tabular}

Elaboración propia

Se requiere S/. 1, 261,177 como capital de trabajo para los primeros 4 meses.

La inversión total está compuesta por los activos fijos y el capital de trabajo que hacen un total de 4, 259, 066 soles.

Tabla 7.5

Inversión Total en soles

\begin{tabular}{|l|c|}
\hline Activos Fijos Tangibles & $2,767,529$ \\
\hline Activos Fijos Intangibles & 230,360 \\
\hline Capital de trabajo & $1,261,177$ \\
\hline Inversión Total & $\mathbf{4 , 2 5 9 , 0 6 6}$ \\
\hline
\end{tabular}

Elaboración propia

\subsection{Costos de producción}

\subsubsection{Costos de la materia prima, insumos y otros materiales}

A continuación, se presenta el histórico de precios del mango en Piura. El costo utilizado es de S/. 1.10 por kilo de mango por ser el mayor en todos los años hasta el 2015. 
Tabla 7.6

Precio de mango en chacra en Piura

\begin{tabular}{|c|c|}
\hline \multicolumn{2}{|c|}{ PRECIO EN CHACRA (S/./Kg) } \\
\hline Años & PIURA \\
\hline 2005 & 0.48 \\
\hline 2006 & 0.62 \\
\hline 2007 & 0.52 \\
\hline 2008 & 0.4 \\
\hline 2009 & 0.84 \\
\hline 2010 & 0.37 \\
\hline 2011 & 0.42 \\
\hline 2012 & 1.02 \\
\hline 2013 & 1.08 \\
\hline 2014 & 1.1 \\
\hline 2015 & 1.05 \\
\hline
\end{tabular}

Fuente: MINAG, (2015)

Además, se presenta una tabla resumen del costo de todos los materiales e insumos necesarios para producir una conserva de mango en almíbar.

Tabla 7.7

Costos de producción

\begin{tabular}{|c|c|c|c|}
\hline \multicolumn{4}{|c|}{ Costos de material directo de producción } \\
\hline Materiales & Cantidad & unidades & $\begin{array}{c}\text { Costo unitario } \\
(\mathbf{S} / .)\end{array}$ \\
\hline Mango & 135.6 & $\mathrm{~g}$ & 0.15 \\
\hline almíbar & 90.4 & $\mathrm{~g}$ & 0.09 \\
\hline Envases polipropileno & 1 & unidad & 0.10 \\
\hline Film sellador & 1 & unidad & 0.01 \\
\hline Tapas & 1 & unidad & 0.03 \\
\hline Tenedores & 1 & unidad & 0.04 \\
\hline Etiquetas & 3 & unidad & 0.03 \\
\hline Caja & 1 & unidad & 0.01 \\
\hline
\end{tabular}

Elaboración propia

A continuación, se presentarán los costos de materias primas e insumos a lo largo de la vida del proyecto: 
Tabla 7.8

Costo de mango por año en soles

\begin{tabular}{|c|c|c|c|c|c|c|}
\hline Años & 2016 & 2017 & 2018 & 2019 & 2020 & 2021 \\
\hline Mango (kg) & 232,369 & 234,926 & 237,510 & 240,122 & 242,764 & 245,334 \\
\hline Costo (S/.) & 255,606 & 258,418 & 261,261 & 264,135 & 267,040 & 269,867 \\
\hline
\end{tabular}

Elaboración propia

Tabla 7.9

Costos de azúcar por año en soles

\begin{tabular}{|c|c|c|c|c|c|c|}
\hline Años & 2016 & 2017 & 2018 & 2019 & 2020 & 2021 \\
\hline Azúcar (kg) & 65,838 & 66,562 & 67,294 & 68,035 & 68,783 & 69,511 \\
\hline Costo (S/.) & 144,844 & 146,437 & 148,048 & 149,676 & 151,323 & 152,925 \\
\hline
\end{tabular}

Elaboración propia

Tabla 7.10

Costo de Agua por año en soles

\begin{tabular}{|c|c|c|c|c|c|c|}
\hline Años & 2016 & 2017 & 2018 & 2019 & 2020 & 2021 \\
\hline Agua (litros) & 87,139 & 88,097 & 89,066 & 90,046 & 91,036 & 92,000 \\
\hline Costo (S/.) & 6,145 & 6,213 & 6,281 & 6,350 & 6,420 & 6,488 \\
\hline
\end{tabular}

Elaboración propia

Tabla 7.11

Costo de Ácido Cítrico por año en soles

\begin{tabular}{|c|c|c|c|c|c|c|}
\hline Años & 2016 & 2017 & 2018 & 2019 & 2020 & 2021 \\
\hline Ácido Cítrico (kg) & 1,936 & 1,958 & 1,979 & 2,001 & 2,023 & 2,044 \\
\hline Costo (S/.) & 6,971 & 7,048 & 7,125 & 7,204 & 7,283 & 7,360 \\
\hline
\end{tabular}

Elaboración propia

Tabla 7.12

Costo de films para sellado por año en soles

\begin{tabular}{|c|c|c|c|c|c|c|}
\hline Años & 2016 & 2017 & 2018 & 2019 & 2020 & 2021 \\
\hline $\begin{array}{c}\text { Films } \\
\text { (unidades) }\end{array}$ & $1,713,639$ & $1,732,489$ & $1,751,546$ & $1,770,813$ & $1,790,292$ & $1,809,245$ \\
\hline Costo (S/.) & 17,136 & 17,325 & 17,515 & 17,708 & 17,903 & 18,092 \\
\hline
\end{tabular}

Elaboración propia

Tabla 7.13

Costo de cajas de cartón por año en soles

\begin{tabular}{|c|c|c|c|c|c|c|}
\hline Años & 2016 & 2017 & 2018 & 2019 & 2020 & 2021 \\
\hline $\begin{array}{c}\text { Cajas de cartón } \\
\text { (unidades) }\end{array}$ & 57,121 & 57,750 & 58,385 & 59,027 & 59,676 & 60,308 \\
\hline Costo (S/.) & 714 & 722 & 730 & 738 & 746 & 754 \\
\hline
\end{tabular}

Elaboración propia 
Tabla 7.14

Costo de envases de polipropileno por año en soles

\begin{tabular}{|c|c|c|c|c|c|c|}
\hline Años & 2016 & 2017 & 2018 & 2019 & 2020 & 2021 \\
\hline $\begin{array}{c}\text { Envases } \\
\text { (unidades) }\end{array}$ & $1,713,639$ & $1,732,489$ & $1,751,546$ & $1,770,813$ & $1,790,292$ & $1,809,245$ \\
\hline Costo (S/.) & 171,364 & 173,249 & 175,155 & 177,081 & 179,029 & 180,925 \\
\hline
\end{tabular}

Elaboración propia

Tabla 7.15

Costo de las tapas de plástico en soles

\begin{tabular}{|c|c|c|c|c|c|c|}
\hline Años & 2016 & 2017 & 2018 & 2019 & 2020 & 2021 \\
\hline $\begin{array}{c}\text { Tapas } \\
\text { (unidades) }\end{array}$ & $1,713,639$ & $1,732,489$ & $1,751,546$ & $1,770,813$ & $1,790,292$ & $1,809,245$ \\
\hline Costo (S/.) & 51,409 & 51,975 & 52,546 & 53,124 & 53,709 & 54,277 \\
\hline
\end{tabular}

Elaboración propia

Tabla 7.16

Costo de los tenedores de plástico en soles

\begin{tabular}{|c|c|c|c|c|c|c|}
\hline Años & 2016 & 2017 & 2018 & 2019 & 2020 & 2021 \\
\hline $\begin{array}{c}\text { Tenedores } \\
\text { (unidades) }\end{array}$ & $1,713,639$ & $1,732,489$ & $1,751,546$ & $1,770,813$ & $1,790,292$ & $1,809,245$ \\
\hline Costo (S/.) & 68,546 & 69,300 & 70,062 & 70,833 & 71,612 & 72,370 \\
\hline
\end{tabular}

Elaboración propia

Tabla 7.17

Costo de las etiquetas en soles

\begin{tabular}{|c|c|c|c|c|c|c|}
\hline Años & 2016 & 2017 & 2018 & 2019 & 2020 & 2021 \\
\hline $\begin{array}{c}\text { Stickers } \\
\text { (unidades) }\end{array}$ & $5,140,917$ & $5,197,467$ & $5,254,639$ & $5,312,440$ & $5,370,877$ & $5,427,736$ \\
\hline Costo (S/.) & 51,409 & 51,975 & 52,546 & 53,124 & 53,709 & 54,277 \\
\hline
\end{tabular}

Elaboración propia

Finalmente, para calcular el costo de producción se tomará como base 1 mes.

Tabla 7.18

Costos mensuales de insumos y materia prima en soles

\begin{tabular}{|c|c|c|c|}
\hline Insumo & Cantidad & Precio S/. & Costo S/. \\
\hline Mango (kg) & 38,728 & 1.10 & 42,601 \\
\hline Azúcar (kg) & 10,973 & 2.20 & 24,141 \\
\hline Agua (Litros) & 14,523 & 0.07 & 1,024 \\
\hline Ácido Cítrico (kg) & 323 & 3.60 & 1,162 \\
\hline Films (unidades) & 285,606 & 0.01 & 2,856 \\
\hline Cajas (unidades) & 9,520 & 0.01 & 119 \\
\hline Envases (unidades) & 285,606 & 0.10 & 28,561 \\
\hline Tapas (unidades) & 285,606 & 0.03 & 8,568 \\
\hline Tenedores (unidades) & 285,606 & 0.04 & 11,424 \\
\hline Stickers (unidades) & 856,819 & 0.01 & 8,568 \\
\hline \multicolumn{2}{|c|}{ Total } & 129,024 \\
\hline
\end{tabular}

Elaboración propia 


\subsubsection{Costo de la mano de obra directa}

El costo de la mano de obra directa está representado por el sueldo que perciben los trabajadores que tienen una relación directa con la producción, con esto nos referimos a los operarios de la empresa. En la siguiente tabla se presenta los costos generados por la mano de obra directa. Para obtener estos resultados se considera el pago de 12 sueldos + 2 gratificación + CTS + el pago a ESSALUD equivalente al 9\% del sueldo base al mes del trabajador.

Tabla 7.19

Costos anuales de mano de obra directa en soles

\begin{tabular}{|c|c|c|c|c|c|c|c|}
\hline Número de operarios & & $\begin{array}{c}\text { Salario } \\
\text { Base al } \\
\text { mes }\end{array}$ & $\begin{array}{l}\text { Asignación } \\
\text { Familiar }\end{array}$ & $\begin{array}{l}\text { Gratific } \\
\text { aciones }\end{array}$ & CTS & $\begin{array}{l}\text { Sueldo anual } \\
\text { computable unit }\end{array}$ & Total \\
\hline Selección & 1 & 850 & 85 & 935 & 545 & $7,090.42$ & $7,090.42$ \\
\hline Pesado & 2 & 850 & 85 & 935 & 545 & $7,090.42$ & $14,180.83$ \\
\hline Pelado & 2 & 850 & 85 & 935 & 545 & $7,090.42$ & $14,180.83$ \\
\hline Prensado & 1 & 850 & 85 & 935 & 545 & $7,090.42$ & $7,090.42$ \\
\hline Cortado & 3 & 850 & 85 & 935 & 545 & $7,090.42$ & $21,271.25$ \\
\hline Llenado/Sellado & 1 & 850 & 85 & 935 & 545 & $7,090.42$ & $7,090.42$ \\
\hline Pasteurizado de conserva & 1 & 850 & 85 & 935 & 545 & $7,090.42$ & $7,090.42$ \\
\hline Esterilizado de envases & 1 & 850 & 85 & 935 & 545 & $7,090.42$ & $7,090.42$ \\
\hline Mezcla / Cuece & 1 & 850 & 85 & 935 & 545 & $7,090.42$ & $7,090.42$ \\
\hline Tapado & 2 & 850 & 85 & 935 & 545 & $7,090.42$ & $14,180.83$ \\
\hline Etiquetado/Encajado & 1 & 850 & 85 & 935 & 545 & $7,090.42$ & $7,090.42$ \\
\hline Total Operarios & 16 & & & & & & 113,447 \\
\hline
\end{tabular}

Elaboración propia

A continuación, la tabla de costos directos totales, tanto de mano de obra como de materiales.

Tabla 7.20

Cuadro de costos directos (S/.)

\begin{tabular}{|l|c|}
\hline Mano de obra directa & 113,447 \\
\hline Materiales directos & $774,144.31$ \\
\hline Total Costos Directos & $\mathbf{8 8 7 , 5 9 1}$ \\
\hline
\end{tabular}

Elaboración propia 


\subsubsection{Costo Indirecto de Fabricación (materiales indirectos, mano de obra indirecta y costos generales de planta)}

\section{Mano de obra indirecta}

El costo de la mano de obra indirecta está representado por el sueldo que percibe el personal de las áreas administrativas quienes sirven de apoyo a la producción, distribución y al comercio. En la siguiente tabla se presenta los costos generados por las áreas administrativas. Para obtener estos resultados se hace el pago de 12 sueldos +2 gratificación + CTS + el pago a ESSALUD equivalente al 9\% del sueldo base al mes del trabajador.

Tabla 7.21

Costo anual de mano de obra indirecta en soles

\begin{tabular}{|c|c|c|c|c|c|c|c|c|}
\hline \multicolumn{2}{|c|}{$\begin{array}{c}\text { Personal } \\
\text { Administrativo }\end{array}$} & $\begin{array}{c}\text { Salario } \\
\text { Base al mes }\end{array}$ & $\begin{array}{c}\text { Promedio } \\
\text { Variable } 6 \\
\text { meses }\end{array}$ & $\begin{array}{l}\text { Asignación } \\
\text { Familiar }\end{array}$ & Gratificaciones & CTS & $\begin{array}{c}\text { Sueldo anual } \\
\text { computable unit }\end{array}$ & Total \\
\hline $\begin{array}{l}\text { Gerencia } \\
\text { general }\end{array}$ & 1 & 20,000 & & 85 & 20,085 & 11,716 & $304,622.50$ & $304,622.50$ \\
\hline $\begin{array}{l}\text { Gerente de } \\
\text { finanzas }\end{array}$ & 1 & 14,000 & & 85 & 14,085 & 8,216 & $213,622.50$ & $213,622.50$ \\
\hline $\begin{array}{l}\text { Asistente } \\
\text { financiero }\end{array}$ & 1 & 2,000 & & 85 & 2,085 & 1,216 & $31,622.50$ & $31,622.50$ \\
\hline $\begin{array}{l}\text { Jefe de } \\
\text { producción }\end{array}$ & 1 & 8,000 & & 85 & 8,085 & 4,716 & $122,622.50$ & $122,622.50$ \\
\hline $\begin{array}{l}\text { Supervisor de } \\
\text { producción }\end{array}$ & 1 & 6,000 & & 85 & 6,085 & 3,550 & $92,289.17$ & $92,289.17$ \\
\hline $\begin{array}{l}\text { Gerente de } \\
\text { ventas }\end{array}$ & 1 & 12,000 & 4,000 & 85 & 16,085 & 9,383 & $203,955.83$ & $203,955.83$ \\
\hline $\begin{array}{l}\text { Ejecutivo de } \\
\text { ventas (KAM) }\end{array}$ & 2 & 6,000 & 2,000 & 85 & 8,085 & 4,716 & $102,622.50$ & $205,245.00$ \\
\hline $\begin{array}{l}\text { Asistente de } \\
\text { ventas }\end{array}$ & 1 & 2,000 & 600 & 85 & 2,685 & 1,566 & $34,722.50$ & $34,722.50$ \\
\hline $\begin{array}{l}\text { Técnico de } \\
\text { Calidad }\end{array}$ & 1 & 2,500 & & 85 & 2,585 & 1,508 & $39,205.83$ & $39,205.83$ \\
\hline $\begin{array}{l}\text { Gerente de } \\
\text { operaciones }\end{array}$ & 1 & 14,000 & & 85 & 14,085 & 8,216 & $213,622.50$ & $213,622.50$ \\
\hline $\begin{array}{l}\text { Asistente de } \\
\text { operaciones }\end{array}$ & 1 & 2,000 & & 85 & 2,085 & 1,216 & $31,622.50$ & $31,622.50$ \\
\hline $\begin{array}{l}\text { Jefe de } \\
\text { almacén }\end{array}$ & 1 & 8,000 & & 85 & 8,085 & 4,716 & $122,622.50$ & $122,622.50$ \\
\hline $\begin{array}{l}\text { Responsable de } \\
\text { almacén }\end{array}$ & 1 & 3,000 & & 85 & 3,085 & 1,800 & $46,789.17$ & $46,789.17$ \\
\hline $\begin{array}{l}\text { Jefe de } \\
\text { mantenimiento }\end{array}$ & 1 & 8,000 & 7 & 85 & 8,085 & 4,716 & $122,622.50$ & $122,622.50$ \\
\hline $\begin{array}{l}\text { Técnico de } \\
\text { mantenimiento }\end{array}$ & 1 & 2,000 & & 85 & 2,085 & 1,216 & $31,622.50$ & $31,622.50$ \\
\hline $\begin{array}{l}\text { Responsable de } \\
\text { Sistemas }\end{array}$ & 1 & 3,000 & & 85 & 3,085 & 1,800 & $46,789.17$ & $46,789.17$ \\
\hline $\begin{array}{l}\text { Responsable de } \\
\text { R.R.H.H }\end{array}$ & 1 & 3,000 & & 85 & 3,085 & 1,800 & $46,789.17$ & $46,789.17$ \\
\hline Recepcionista & 1 & 1,500 & & 85 & 1,585 & 925 & $24,039.17$ & $24,039.17$ \\
\hline Total & 19 & & & & & & & $1,934,428$ \\
\hline
\end{tabular}

Elaboración propia 


\section{Materiales indirectos}

Se tienen como costos indirectos a los materiales como repuestos, lubricantes y combustible, los mismos que también se calcularon en base a 1 mes.

Tabla 7.22

Costos anuales de materiales indirectos en soles

\begin{tabular}{|l|c|}
\hline Repuestos & 24,000 \\
\hline Combustible & 22,800 \\
\hline Lubricantes & 6,000 \\
\hline Total & $\mathbf{5 2 , 8 0 0}$ \\
\hline
\end{tabular}

Elaboración propia

Tabla 7.23

Costos anuales indirectos en soles

\begin{tabular}{|l|c|}
\hline Mano de obra indirecta & $1,934,428$ \\
\hline Materiales indirectos & 52,800 \\
\hline Gastos indirectos & 212,398 \\
\hline Total Costos Indirectos & $\mathbf{2 , 1 9 9 , 6 2 5}$ \\
\hline
\end{tabular}

Elaboración propia

\section{Servicios}

Los servicios que se costearon fueron los de electricidad, agua, telefonía, combustible, aire acondicionado y seguridad, en la siguiente tabla se pueden apreciar los costos promedio mensuales y anuales por cada uno de estos conceptos.

Tabla 7.24

Costos mensuales y anuales de los principales servicios requeridos para el área de producción

\begin{tabular}{|c|c|c|}
\hline Servicios & S/./ mes & S/. / año \\
\hline Agua & 8,100 & 97,198 \\
\hline Electricidad & 2,000 & 24,000 \\
\hline Telefonía & 2,850 & 34,200 \\
\hline Combustible & 1,900 & 22,800 \\
\hline Aire acondicionado & 300 & 3,600 \\
\hline Seguridad & 2,550 & 30,600 \\
\hline Total & $\mathbf{1 7 , 7 0 0}$ & $\mathbf{2 1 2 , 3 9 8}$ \\
\hline
\end{tabular}

Elaboración propia 


\section{Costo de producción unitario}

Finalmente, como resultado se tiene los costos de producción indirectos y directos totales y el costo unitario.

Tabla 7.25

Costos de producción en soles

\begin{tabular}{|l|c|}
\hline Costos Directos al año & 887,591 \\
\hline Costos Indirectos al año & $2,199,625$ \\
\hline Total Costos de Producción & $\mathbf{3 , 0 8 7 , 2 1 6}$ \\
\hline
\end{tabular}

Elaboración propia

Tabla 7.26

Costos unitarios de producción en soles

\begin{tabular}{|l|c|}
\hline Total Costos de Producción & $3,087,216$ \\
\hline Unidades a producir al año & $1,713,639$ \\
\hline Total Costos de Producción & $\mathbf{1 . 8 0}$ \\
\hline
\end{tabular}

Elaboración propia

\subsection{Presupuestos operativos}

\subsubsection{Presupuesto de ingreso por ventas}

En la siguiente tabla se muestra el presupuesto de ingresos obtenidos por las ventas de las conservas.

Tabla 7.27

Presupuesto de ingresos en soles

\begin{tabular}{|l|c|c|c|c|c|c|}
\cline { 2 - 7 } \multicolumn{1}{c|}{} & \multicolumn{7}{c|}{ PRESUPUESTO DE VENTAS ANUALES (S/.) } \\
\hline Año & $\mathbf{2 0 1 6}$ & $\mathbf{2 0 1 7}$ & $\mathbf{2 0 1 8}$ & $\mathbf{2 0 1 9}$ & $\mathbf{2 0 2 0}$ & $\mathbf{2 0 2 1}$ \\
\hline Ventas (env) & $1,713,639$ & $1,732,489$ & $1,751,546$ & $1,770,813$ & $1,790,292$ & $1,809,245$ \\
\hline Precio & 3.5 & 3.5 & 3.5 & 3.5 & 3.5 & 3.5 \\
\hline Ventas (S/.) & $5,997,736$ & $6,063,712$ & $6,130,412$ & $6,197,847$ & $6,266,023$ & $6,332,359$ \\
\hline
\end{tabular}

Elaboración propia

\subsubsection{Presupuesto operativo de costos}

\subsubsection{Presupuesto de Depreciaciones}

Para este presupuesto no se tiene valor de mercado al final de la vida útil y el porcentaje de depreciación anual se detalla en las tablas a continuación tanto de activos fijos tangibles como intangibles. 
Tabla 7.28

Presupuesto de depreciaciones de activos tangibles

\begin{tabular}{|c|c|c|c|c|c|c|c|c|c|c|}
\hline \multicolumn{11}{|c|}{ PRESUPUESTO DE DEPRECIACION DE ACTIVOS FINOS TANGIBLES } \\
\hline \multirow{2}{*}{$\begin{array}{l}\text { ACTIVO FIJO } \\
\text { TANGIBLE }\end{array}$} & \multirow{2}{*}{$\begin{array}{c}\text { IMPORTE } \\
(\mathrm{S} / .)\end{array}$} & \multirow{2}{*}{$\begin{array}{c}\% \\
\text { DEP. }\end{array}$} & \multicolumn{6}{|c|}{ AÑO } & \multirow{2}{*}{$\begin{array}{c}\text { DEPRECIACIÓN } \\
\text { TOTAL }\end{array}$} & \multirow{2}{*}{$\begin{array}{l}\text { VALOR } \\
\text { RESIDUAL }\end{array}$} \\
\hline & & & 2016 & 2017 & 2018 & 2019 & 2020 & 2021 & & \\
\hline Terreno & $1,200,000$ & & 0 & 0 & 0 & 0 & 0 & 0 & 0 & $1,200,000$ \\
\hline Edificaciones planta & 513,411 & $5.00 \%$ & 25,671 & 25,671 & 25,671 & 25,671 & 25,671 & 25,671 & 154,023 & 359,388 \\
\hline Edif. Ofic. Adminis & 451,179 & $3.00 \%$ & 13,535 & 13,535 & 13,535 & 13,535 & 13,535 & 13,535 & 81,212 & 369,967 \\
\hline Naquinaria y equipo & 337,039 & $10.00 \%$ & 33,704 & 33,704 & 33,704 & 33,704 & 33,704 & 33,704 & 202,223 & 134,816 \\
\hline Herramientas planta & 3,950 & $10.00 \%$ & 395 & 395 & 395 & 395 & 395 & 395 & 2,370 & 1,580 \\
\hline Herramientas oficina & 46,700 & $10.00 \%$ & 4670 & 4670 & 4670 & 4670 & 4670 & 4670 & 28,020 & 18,680 \\
\hline Muebles y enseres & 15,250 & $10.00 \%$ & 1525 & 1525 & 1525 & 1525 & 1525 & 1525 & 9,150 & 6,100 \\
\hline Imprevistos fabriles & 150,000 & $10.00 \%$ & 15000 & 15000 & 15000 & 15000 & 15000 & 15000 & 90,000 & 60,000 \\
\hline Imprev. No fabriles & 50,000 & $10.00 \%$ & 5000 & 5000 & 5000 & 5000 & 5000 & 5000 & 30,000 & 20,000 \\
\hline Total & $2,767,529$ & & 99,500 & 99,500 & 99,500 & 99,500 & 99,500 & 99,500 & 596,999 & $2,170,530$ \\
\hline Deprec. Fabril & 2 & & 79,439 & 79,439 & 79,439 & 79,439 & 79,439 & 79,439 & 476,637 & \\
\hline Deprec. No Fabril & $y$ & & 20,060 & 20,060 & 20,060 & 20,060 & 20,060 & 20,060 & 120,362 & \\
\hline
\end{tabular}

Elaboración propia

Tabla 7.29

Presupuesto de depreciaciones de activos intangibles

\begin{tabular}{|c|c|c|c|c|c|c|c|c|c|c|}
\hline \multicolumn{11}{|c|}{ PRESUPUESTO DEAMORTIZACION DEACTIVOS INTANGIBLES } \\
\hline \multirow{2}{*}{$\begin{array}{l}\text { ACTIVO FIJO } \\
\text { INTANGIBLE }\end{array}$} & \multirow{2}{*}{$\begin{array}{l}\text { IMPORTE } \\
\text { (S/.) }\end{array}$} & \multirow{2}{*}{$\begin{array}{c}\% \\
\text { DEP. }\end{array}$} & \multicolumn{6}{|c|}{ AÑo } & \multirow{2}{*}{$\begin{array}{c}\text { DEPRECIACIÓN } \\
\text { TOTAL }\end{array}$} & \multirow{2}{*}{$\begin{array}{l}\text { VALOR } \\
\text { RESIDUAL }\end{array}$} \\
\hline & & & 2016 & 2017 & 2018 & 2019 & 2020 & 2021 & & \\
\hline Estudios Pre-factibilidad & 20,000 & $10.00 \%$ & 2,000 & 2,000 & 2,000 & 2,000 & 2,000 & 2,000 & 12,000 & 8,000 \\
\hline Estudios Factibilidad & 40,000 & $10.00 \%$ & 4,000 & 4,000 & 4,000 & 4,000 & 4,000 & 4,000 & 24,000 & 16,000 \\
\hline Gastos constitución legal & 3,000 & $10.00 \%$ & 300 & 300 & 300 & 300 & 300 & 300 & 1,800 & 1,200 \\
\hline Licencia Funcionamiento & 2,000 & $10.00 \%$ & 200 & 200 & 200 & 200 & 200 & 200 & 1,200 & 800 \\
\hline Supervision & 40,000 & $10.00 \%$ & 4,000 & 4,000 & 4,000 & 4,000 & 4,000 & 4,000 & 24,000 & 16,000 \\
\hline Puesta en Marcha & 50,000 & $10.00 \%$ & 5,000 & 5,000 & 5,000 & 5,000 & 5,000 & 5,000 & 30,000 & 20,000 \\
\hline Pruebas Finales & 30,000 & $10.00 \%$ & 3,000 & 3,000 & 3,000 & 3,000 & 3,000 & 3,000 & 18,000 & 12,000 \\
\hline Contingencias & 45,360 & $10.00 \%$ & 4,536 & 4,536 & 4,536 & 4,536 & 4,536 & 4,536 & 27,216 & 18,144 \\
\hline Total & 230,360 & & 23,036 & 23,036 & 23,036 & 23,036 & 23,036 & 23,036 & 138,216 & 92,144 \\
\hline
\end{tabular}

Elaboración propia 


\subsubsection{2. $\quad$ Presupuesto total de costos de producción}

Este presupuesto detalla el costo de producción hallado del costo de producción unitario y las unidades a producir y de la depreciación fabril calculada en la tabla 7.28.

Tabla 7.30

Presupuesto de costos de producción

Presupuesto de costo de producción (S/.) por año

\begin{tabular}{|l|c|c|c|c|c|c|}
\cline { 2 - 7 } \multicolumn{1}{c|}{} & 2016 & 2017 & 2018 & 2019 & 2020 & 2021 \\
\hline Costo Producción & 774,144 & 782,660 & 791,269 & 799,973 & 808,773 & 817,335 \\
\hline Depreciación Fabril & 79,439 & 79,439 & 79,439 & 79,439 & 79,439 & 79,439 \\
\hline Total Costo Producción & 853,584 & 862,099 & 870,709 & 879,413 & 888,212 & 896,774 \\
\hline
\end{tabular}

Elaboración propia

\subsubsection{Presupuesto operativo de gastos}

\subsubsection{Presupuesto de gastos generales}

En este presupuesto se detallan los gastos de administración y ventas como los servicios administrativos, servicio de transporte y seguridad, publicidad, promociones, eventos, comisiones, sueldos administrativos (excluyendo las ya incluidas de producción) e imprevistos. Además se incluye la depreciación no fabril que se detalló en la tabla 7.28 y la amortización de intangibles de la tabla 7.29.

Tabla 7.31

Presupuesto de gastos generales

\begin{tabular}{|l|c|c|c|c|c|c|}
\hline \multicolumn{7}{|c|}{ PRESUPUESTO DE GASTOS GENERALES (S/.) } \\
\hline & 2016 & 2017 & 2018 & 2019 & 2020 & 2021 \\
\hline Gastos Adm. Y Ventas & 559,341 & 562,761 & 562,781 & 566,200 & 569,620 & 569,640 \\
\hline Depreciación No Fabril & 20,060 & 20,060 & 20,060 & 20,060 & 20,060 & 20,060 \\
\hline Amortización Intangibles & 23,036 & 23,036 & 23,036 & 23,036 & 23,036 & 23,036 \\
\hline Total Gastos Generales & $\mathbf{6 0 2 , 4 3 7}$ & $\mathbf{6 0 5 , 8 5 7}$ & $\mathbf{6 0 5 , 8 7 7}$ & $\mathbf{6 0 9 , 2 9 7}$ & $\mathbf{6 1 2 , 7 1 7}$ & $\mathbf{6 1 2 , 7 3 6}$ \\
\hline
\end{tabular}

Elaboración propia

\subsection{Presupuestos Financieros}

\subsubsection{Presupuesto de Servicio de Deuda}

Debido al monto de inversión trabajará con un $40 \%$ de financiamiento a una tasa de $7.5 \%$ anual ofrecida por el banco Santander, esta es la mejor tasa ofrecida por los principales bancos para medianas empresas. En la siguiente tabla se muestran las tasas de los bancos que acreditan proyectos. 
Tabla 7.32

Tasas de Interés Efectiva de Bancos

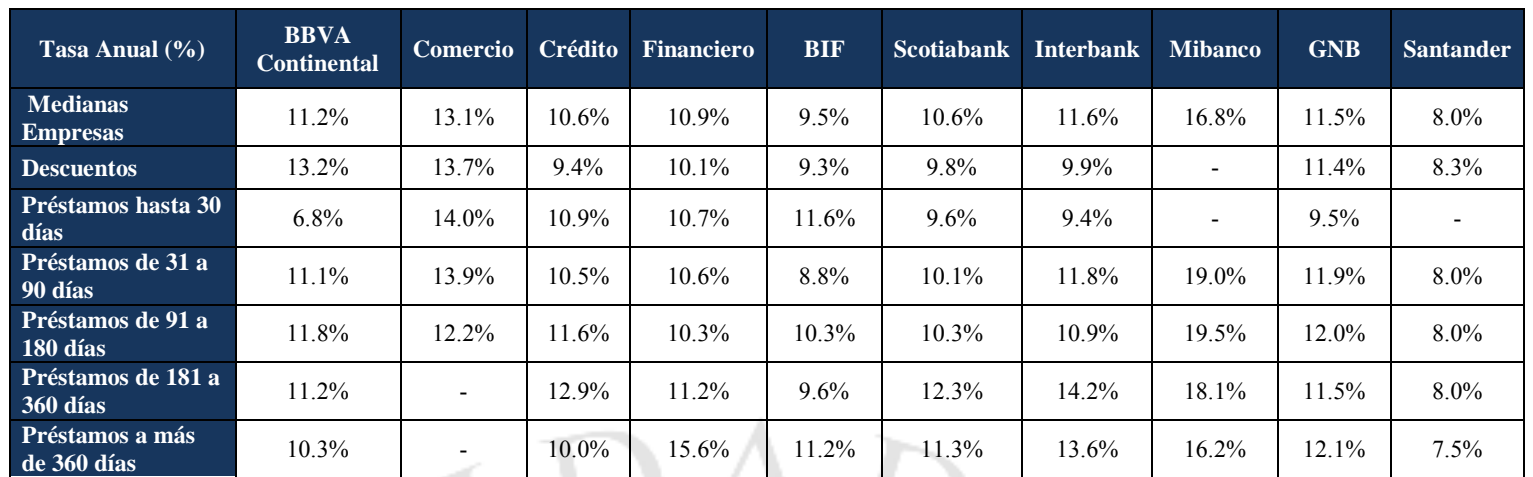

Fuente: SBS, (2016)

A continuación se muestra el cronograma de pagos. Este cronograma se basa en los 6 años de vida útil del proyecto sin periodo de gracia a cuotas constantes a la tasa indicada.

Tabla 7.33

Cronograma de Pagos

\begin{tabular}{|c|c|c|c|c|c|}
\hline \multicolumn{7}{|c|}{ Servicio de la deuda } \\
\hline Año & Deuda & Amortización & Intereses & Saldo & Cuota \\
\hline 2016 & $1,703,626$ & 235,177 & 127,772 & $1,468,449$ & 362,949 \\
2017 & $1,468,449$ & 252,815 & 110,134 & $1,215,634$ & 362,949 \\
2018 & $1,215,634$ & 271,776 & 91,173 & 943,858 & 362,949 \\
2019 & 943,858 & 292,160 & 70,789 & 651,698 & 362,949 \\
2020 & 651,698 & 314,072 & 48,877 & 337,627 & 362,949 \\
2021 & 337,627 & 337,627 & 25,322 & 0 & 362,949 \\
TOTAL & & $\mathbf{1 , 7 0 3 , 6 2 6}$ & $\mathbf{4 7 4 , 0 6 7}$ & & \\
\hline
\end{tabular}

Elaboración propia

\subsubsection{Presupuesto de Estado de Resultados}

A continuación se muestra el Estado de Ganancias y Pérdidas, donde se usa un impuesto a la renta de $28 \%$. 
Tabla 7.34

Estado de Ganancias y Pérdidas

\begin{tabular}{|c|c|c|c|c|c|c|}
\hline \multicolumn{7}{|c|}{ ESTADO DERESULTADOS(S/.) } \\
\hline & 2016 & 2017 & 2018 & 2019 & 2020 & 2021 \\
\hline INGRESO POR VENTAS & $5,997,736$ & $6,063,712$ & $6,130,412$ & $6,197,847$ & $6,266,023$ & $6,332,359$ \\
\hline (-) COSTO DE PRODUCCION & $3,087,216$ & $3,095,732$ & $3,104,341$ & $3,113,045$ & $3,121,845$ & $3,130,407$ \\
\hline$(=)$ UTLLIDAD BRUTA & $2,910,520$ & $2,967,980$ & $3,026,071$ & $3,084,802$ & $3,144,179$ & $3,201,952$ \\
\hline (-) GASTOS GENERALES & 602,437 & 605,857 & 605,877 & 609,297 & 612,717 & 612,736 \\
\hline (-) GASTOS FINANCIEROS & 127,772 & 110,134 & 91,173 & 70,789 & 48,877 & 25,322 \\
\hline (=) UTLIDAD ANTES DE PART. IMP. & $2,180,311$ & $2,251,989$ & $2,329,022$ & $2,404,716$ & $2,482,585$ & $2,563,894$ \\
\hline (-) PARTICPACIONES(10\%) & 218,031 & 225,199 & 232,902 & 240,472 & 248,258 & 256,389 \\
\hline (-) IMPUESTO A LA RENTA (28\%) & 610,487 & 630,557 & 652,126 & 673,320 & 695,124 & 717,890 \\
\hline ( $)$ UTILIDAD ANTES DERESERVA LEGAL & $1,351,793$ & $1,396,233$ & $1,443,994$ & $1,490,924$ & $1,539,202$ & $1,589,614$ \\
\hline (-) RESERVA LEGAL (HASTA 10\%) & 135,179 & 139,623 & 144,399 & 149,092 & 153,920 & 158,961 \\
\hline (=) UTLLIDAD DISPONBLLE & $1,216,613$ & $1,256,610$ & $1,299,594$ & $1,341,831$ & $1,385,282$ & $1,430,653$ \\
\hline
\end{tabular}

Elaboración propia

\subsubsection{Presupuesto de Estado de Situación Financiera}

A continuación, se presenta el detalle del porcentaje de participación que es de $60 \%$ de capital propio y $40 \%$ con financiamiento obtenido por préstamo bancario.

Para el cálculo del costo de capital (COK) se ha utilizado el método CAPM (Capital Asset Pricing Model) con la siguiente formula:

$$
C O K=R f+B(R m-R f)+R p
$$

Donde:

$\mathrm{COK}=$ Costo de capital

$\mathrm{Rf}=$ Tasa libre de riesgo

$\beta=$ Beta

$\mathrm{Rm}=$ Rendimiento del mercado

$\mathrm{Rp}=$ Riesgo país

En el Anexo 2 se muestra el detalle para cada variable. A continuación se presenta el cálculo del COK

$$
\text { COK }=2.59 \%+0.79 *(12.38 \%-2.59 \%)+2.86 \%=13.2 \%
$$

Con estos datos se obtiene que el COK es $13.2 \%$. 
Tabla 7.35

Costo Capital

\begin{tabular}{|l|c|c|c|c|}
\hline \multicolumn{5}{|c|}{ INVERSION TOTAL (S/.) } \\
\hline & IMPORTE (S/.) & \% PARTICIP. & Costo Dinero & TASA DE DCTO \\
\hline & & & & \\
ACCIONISTAS & $2,555,440$ & $60.00 \%$ & $13.27 \%$ & $7.96 \%$ \\
PRESTAMO & $1,703,626$ & $40.00 \%$ & $7.50 \%$ & $2.10 \%$ \\
& & & & $\mathbf{1 0 . 0 6 \%}$ \\
\hline
\end{tabular}

Elaboración propia

\section{5. $\quad$ Flujos de Fondos Netos}

\subsubsection{Flujo de Fondos económicos}

A continuación, el flujo de fondos económico incluyendo los cuadros anteriores de presupuestos y el estado de resultados.

Tabla 7.36

Flujo de fondo económico

\begin{tabular}{|l|c|c|c|c|c|c|c|}
\hline \multicolumn{7}{|c|}{ FLUJO DE CAJA ECONOMICO (S/.) } \\
\hline & & $\mathbf{2 0 1 6}$ & $\mathbf{2 0 1 7}$ & $\mathbf{2 0 1 8}$ & $\mathbf{2 0 1 9}$ & $\mathbf{2 0 2 0}$ & $\mathbf{2 0 2 1}$ \\
\hline INVERSION TOTAL & $-4,259,066$ & & & & & & \\
UTILIDAD ANTES DE RESERVA LEGAL & & $\mathbf{1 , 3 5 1 , 7 9 3}$ & $\mathbf{1 , 3 9 6 , 2 3 3}$ & $\mathbf{1 , 4 4 3 , 9 9 4}$ & $\mathbf{1 , 4 9 0 , 9 2 4}$ & $\mathbf{1 , 5 3 9 , 2 0 2}$ & $\mathbf{1 , 5 8 9 , 6 1 4}$ \\
(+) AMORTIZACION DE INTANGIBLES & & 23,036 & 23,036 & 23,036 & 23,036 & 23,036 & 23,036 \\
(+) DEPRECIACION FABRIL & & 79,439 & 79,439 & 79,439 & 79,439 & 79,439 & 79,439 \\
(+) DEPRECIACION NO FABRIL & & 20,060 & 20,060 & 20,060 & 20,060 & 20,060 & 20,060 \\
(+) PARTICIPACIONES (10\%) & & 218,031 & 225,199 & 232,902 & 240,472 & 248,258 & 256,389 \\
(+) GASTOS FINANCIEROS (1-t) & & 91,996 & 79,296 & 65,644 & 50,968 & 35,192 & 18,232 \\
(+) VALOR RESIDUAL (V. LIBROS) & & & & & & & $\mathbf{3 , 5 2 3 , 8 5 1}$ \\
\hline FLUJO NETO DE FONDOS ECONOMICO & $-4,259,066$ & $\mathbf{1 , 7 8 4 , 3 5 5}$ & $\mathbf{1 , 8 2 3 , 2 6 4}$ & $\mathbf{1 , 8 6 5 , 0 7 6}$ & $\mathbf{1 , 9 0 4 , 9 0 0}$ & $\mathbf{1 , 9 4 5 , 1 8 8}$ & $\mathbf{5 , 5 1 0 , 6 2 2}$ \\
\hline
\end{tabular}

Elaboración propia

\subsubsection{Flujo de fondos financieros}

A continuación, el flujo de fondo financiero incluyendo las tablas anteriores de presupuestos y el estado de resultados. 
Tabla 7.37

Flujo de fondo financiero

\begin{tabular}{|l|c|c|c|c|c|c|c|}
\hline \multicolumn{7}{|c|}{ FLUJO DE CAJA FINANCIERO (S/.) } \\
\hline & & $\mathbf{2 0 1 6}$ & $\mathbf{2 0 1 7}$ & $\mathbf{2 0 1 8}$ & $\mathbf{2 0 1 9}$ & $\mathbf{2 0 2 0}$ & $\mathbf{2 0 2 1}$ \\
\hline INVERSION TOTAL & $-\mathbf{4 , 2 5 9 , 0 6 6}$ & & & & & & \\
PRESTAMO & $\mathbf{1 , 7 0 3 , 6 2 6}$ & & & & & & \\
UTILIDAD ANTES DE RESERVA LEGAL & & $\mathbf{1 , 3 5 1 , 7 9 3}$ & $\mathbf{1 , 3 9 6 , 2 3 3}$ & $\mathbf{1 , 4 4 3 , 9 9 4}$ & $\mathbf{1 , 4 9 0 , 9 2 4}$ & $\mathbf{1 , 5 3 9 , 2 0 2}$ & $\mathbf{1 , 5 8 9 , 6 1 4}$ \\
(+) AMORTIZACION DE INTANGIBLES & & 23,036 & 23,036 & 23,036 & 23,036 & 23,036 & 23,036 \\
(+) DEPRECIACION FABRIL & & 79,439 & 79,439 & 79,439 & 79,439 & 79,439 & 79,439 \\
(+) DEPRECIACION NO FABRIL & & 20,060 & 20,060 & 20,060 & 20,060 & 20,060 & 20,060 \\
(+) PARTICIPACIONES (10\%) & & 218,031 & 225,199 & 232,902 & 240,472 & 248,258 & 256,389 \\
(-) AMORTIZACION DEL PRESTAMO & & $-235,177$ & $-252,815$ & $-271,776$ & $-292,160$ & $-314,072$ & $-337,627$ \\
(+) VALOR RESIDUAL (V. LIBROS) & & & & & & & $3,523,851$ \\
\hline FLUJO NETO DE FONDOS FINANCIERO & $-2,555,440$ & $1,457,183$ & $1,491,153$ & $1,527,655$ & $\mathbf{1 , 5 6 1 , 7 7 2}$ & $1,595,925$ & $5,154,763$ \\
\hline
\end{tabular}

Elaboración propia 


\section{CAPITULO VIII. EVALUACIÓN ECONÓMICA Y FINANCIERA DEL PROYECTO}

\subsection{Evaluación económica}

De acuerdo al flujo de fondos económico se tienen los siguientes resultados.

Tabla 8.1

Análisis del flujo de fondo económico

\begin{tabular}{|l|c|}
\hline VAN ECONOMICO = & $\mathbf{5 , 8 6 8 , 8 4 4}$ \\
RELACION B / C = & $\mathbf{2 . 3 8}$ \\
TASA INTERNA DE RETORNO ECONOM = & $\mathbf{4 2 . 3 \%}$ \\
PERIODO DE RECUPERACION ( AÑOS) & $\mathbf{2 . 7 9}$ \\
\hline
\end{tabular}

Elaboración propia

\subsection{Evaluación financiera}

De acuerdo al flujo de fondo financiero se tienen los siguientes resultados.

Tabla 8.2

Análisis del flujo de fondo financiero

\begin{tabular}{|l|c|}
\hline VAN FINANCIERO = & $\mathbf{4 , 0 9 2 , 7 8 7}$ \\
RELACION B / C ( 5981548/1'200,000) = & $\mathbf{2 . 6 0}$ \\
TASA INTERNA DE RETORNO FINAN. = & $\mathbf{6 0 . 2 0 \%}$ \\
PERIODO DE RECUPERACION ( AÑOS) & $\mathbf{2 . 2 7}$ \\
\hline
\end{tabular}

Elaboración propia

\subsection{Análisis de ratios e indicadores económicos y financieros del proyecto}

Resultados económicos

- El valor del VAN económico del proyecto S/. 5, 868,844 es un valor positivo, esto indica que la inversión generará ganancias.

- $\quad$ El valor de la TIR económico obtenido es $42.3 \%$, este valor es mayor al costo de capital que tiene una tasa de $10.06 \%$ cuyo cálculo se muestra en el capítulo 7.4.3. Dicho valor indica que el retorno del proyecto es suficiente para compensar el costo de oportunidad del dinero y además produce un rendimiento adicional.

- La relación costo beneficio debe ser mayor a 1 y el valor obtenido en la evaluación económica es de 2.38 , lo cual indica que se recupera la inversión y se obtiene adicional. 
- El periodo de recupero obtenido es de 2.38, este valor indica que los montos de la inversión se recuperan en 2 años y 9 meses por lo que se llega a recuperar la inversión durante los 6 años del proyecto.

Los resultados obtenidos permiten concluir que el proyecto es viable.

\section{$\underline{\text { Resultados financieros }}$}

- El valor del VAN financiero del proyecto S/. 4, 092,787 es un valor positivo, esto indica que la inversión produciría ganancias.

- El valor de la TIR financiero obtenido es $60.20 \%$, este valor es mayor al costo de capital que tiene una tasa de $10.06 \%$ cuyo cálculo se muestra en el capítulo 7.4.3. Dicho valor indica que el retorno del proyecto es suficiente para compensar el costo de oportunidad del dinero y además produce un rendimiento adicional.

- La relación costo beneficio debe ser mayor a 1 y el valor obtenido en la evaluación financiera es de 2.6 , lo cual indica que se recupera la inversión y se obtiene adicional.

El periodo de recupero obtenido es de 2.27, este valor indica que los montos de la inversión se recuperan en casi 2 años y 3 meses por lo que se llega a recuperar la inversión durante los 6 años del proyecto.

Los resultados obtenidos permiten concluir que el proyecto es viable y rentable tanto económica como financieramente.

\subsection{Análisis de sensibilidad del proyecto}

El análisis de sensibilidad del proyecto se realizará mediante la evaluación de 2 variables y su efecto sobre el VAN y el TIR. En este caso se realizará un análisis de sensibilidad en el precio ya que la demanda del proyecto anualmente ya es variable. 
a) Variación del precio sin financiación:

Para realizar el análisis se hacen variaciones del precio desde S/. 3.50 hasta 70\% más y menos con variaciones de $10 \%$ cada vez; para cada precio se determina el Valor Actual Neto descontado, la Tasa Interna de Retorno y la relación Beneficio Costo $(B / C)$. En la siguiente tabla se puede verificar que para una variación del $-40 \%$ en el precio, el VAN del proyecto es negativo, o sea que la rentabilidad es baja, lo cual se puede corroborar al calcular la TIR que para este precio es del $0.32 \%$.

Tabla 8.3

Análisis de sensibilidad en el precio sin financiación

\begin{tabular}{|c|c|c|c|c|}
\hline Var & Precio & VANE & B/C & TIRE \\
\hline$-60 \%$ & 1.4 & $-5,673,775$ & -0.33 & $-23.10 \%$ \\
\hline$-50 \%$ & 1.75 & $-3,750,005$ & 0.12 & $-11.54 \%$ \\
\hline$-40 \%$ & 2.1 & $-1,826,235$ & 0.57 & $0.32 \%$ \\
\hline$-30 \%$ & 2.45 & 97,535 & 1.02 & $10.61 \%$ \\
\hline$-20 \%$ & 2.8 & $2,021,305$ & 1.47 & $21.33 \%$ \\
\hline$-10 \%$ & 3.15 & $3,945,074$ & 1.93 & $31.90 \%$ \\
\hline Base & 3.5 & $5,868,844$ & 2.38 & $42.35 \%$ \\
\hline $10 \%$ & 3.85 & $7,792,614$ & 2.83 & $52.71 \%$ \\
\hline $20 \%$ & 4.2 & $9,716,384$ & 3.28 & $63.02 \%$ \\
\hline $30 \%$ & 4.55 & $11,640,153$ & 3.73 & $73.28 \%$ \\
\hline $40 \%$ & 4.9 & $13,563,923$ & 4.18 & $83.50 \%$ \\
\hline $50 \%$ & 5.25 & $15,487,693$ & 4.64 & $93.71 \%$ \\
\hline $60 \%$ & 5.6 & $17,411,463$ & 5.09 & $103.89 \%$ \\
\hline
\end{tabular}

Elaboración propia 
Figura 8.1

Gráfica de sensibilidad sin financiación

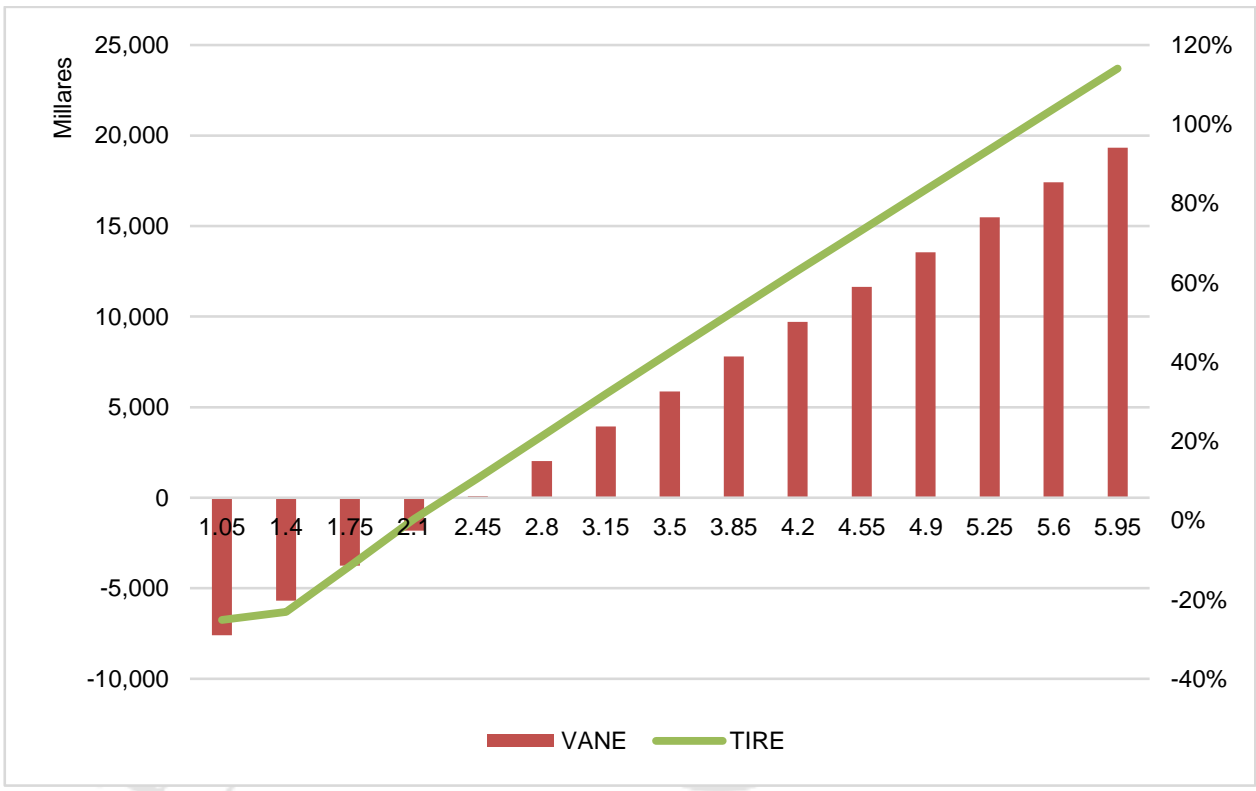

Elaboración propia

b) Variación del precio con financiación:

De la misma forma se hace el cálculo con una financiación, en la siguiente tabla se puede verificar que para una variación del $-30 \%$ en el precio, el VAN del proyecto es negativo, o sea que la rentabilidad es baja, lo cual se puede corroborar al calcular la TIR que para este precio es del $12.64 \%$.

Tabla 8.4

Análisis de sensibilidad en el precio con financiación

\begin{tabular}{|c|c|c|c|c|}
\hline Var & Precio & VANF & B/C & TIRF \\
\hline$-50 \%$ & 1.75 & $-3,629,311$ & -0.42 & $-16.70 \%$ \\
\hline$-40 \%$ & 2.1 & $-2,084,891$ & 0.18 & $-2.32 \%$ \\
\hline$-30 \%$ & 2.45 & $-540,472$ & 0.79 & $12.64 \%$ \\
\hline$-20 \%$ & 2.8 & $1,003,948$ & 1.39 & $28.11 \%$ \\
\hline$-10 \%$ & 3.15 & $2,548,367$ & 2.00 & $44.01 \%$ \\
\hline Base & 3.5 & $4,092,787$ & 2.60 & $60.20 \%$ \\
\hline $10 \%$ & 3.85 & $5,637,206$ & 3.21 & $76.61 \%$ \\
\hline $20 \%$ & 4.2 & $7,181,626$ & 3.81 & $93.17 \%$ \\
\hline $30 \%$ & 4.55 & $8,726,045$ & 4.41 & $109.82 \%$ \\
\hline $40 \%$ & 4.9 & $10,270,465$ & 5.02 & $126.54 \%$ \\
\hline $50 \%$ & 5.25 & $11,814,884$ & 5.62 & $143.31 \%$ \\
\hline
\end{tabular}

Elaboración propia 
Figura 8.2

Gráfica de sensibilidad sin financiación

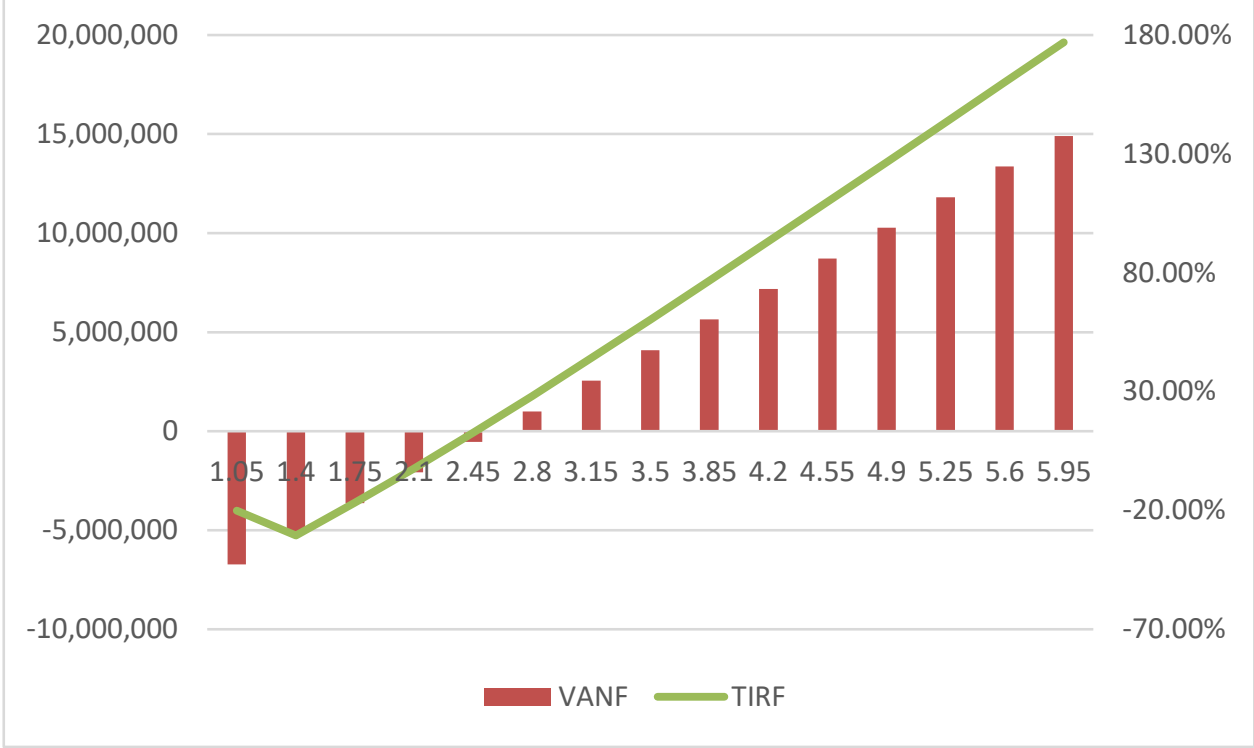

Elaboración propia

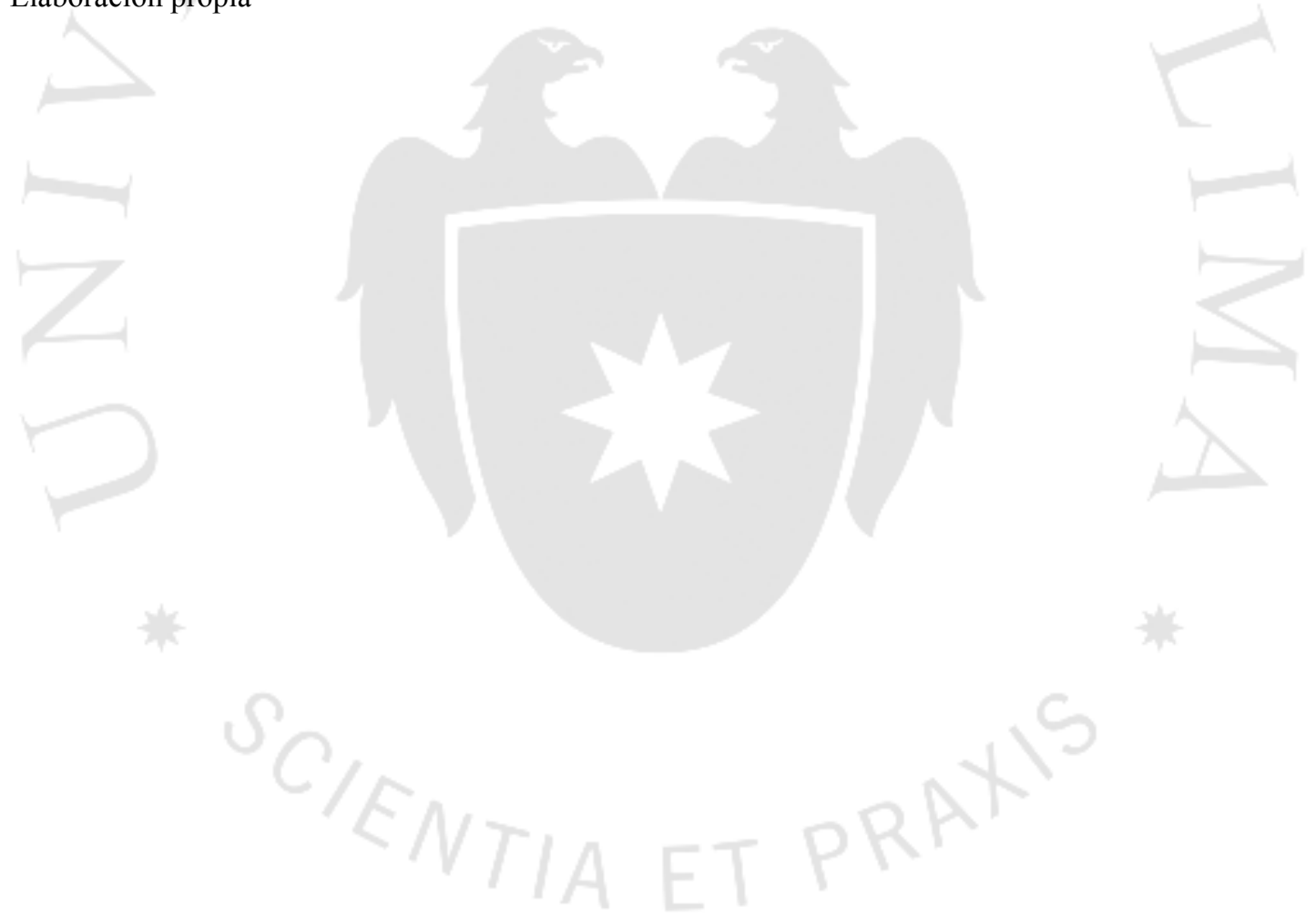




\section{CAPITULO IX. EVALUACIÓN ECONÓMICA Y FINANCIERA DEL PROYECTO}

\subsection{Identificación de las zonas y comunidades de influencia del proyecto}

Las zonas de influencia están definidas en el marco de referencia geográfica en el cual se realizará el análisis y la evaluación ambiental de este proyecto.

Es en estas zonas donde potencialmente se presentarán y percibirán los impactos ambientales que se generarán debido a las actividades de la planta sobre el medio ambiente o sobre los componentes sociales y económicos.

Se considera como zona de influencia directa el distrito de Piura, ya que es donde se ubicará la planta, también las zonas donde se cosechan las frutas utilizadas como materias primas y finalmente Lima metropolitana ya que será el lugar donde se comercializará el producto.

\subsection{Análisis de indicadores sociales}

\subsubsection{Valor agregado}

El valor agregado es el beneficio que recibe la economía al llevarse a cabo el proyecto, es la manera en que se muestra la contribución del proyecto al PBI. Está compuesto por los pagos de salarios, sueldos, intereses y demás egresos generados, estos pasarán a ser una fuente de dinero para otras personas o empresas y así permitirán el desarrollo de la economía.

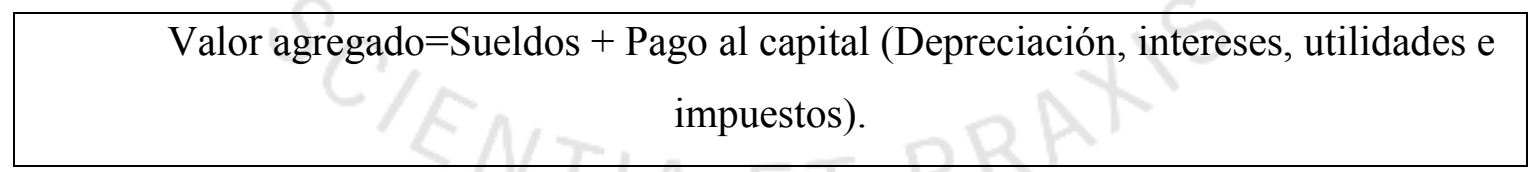


El valor cálculo del valor agregado se presenta en la siguiente tabla:

Tabla 9.1

Valor Agregado considerando sueldos, depreciación y otros

\begin{tabular}{|l|c|c|c|c|c|c|}
\cline { 2 - 7 } \multicolumn{1}{c|}{} & $\mathbf{2 0 1 6}$ & $\mathbf{2 0 1 7}$ & $\mathbf{2 0 1 8}$ & $\mathbf{2 0 1 9}$ & $\mathbf{2 0 2 0}$ & $\mathbf{2 0 2 1}$ \\
\hline Sueldos & $2,047,874$ & $2,047,874$ & $2,047,874$ & $2,047,874$ & $2,047,874$ & $2,047,874$ \\
\hline Depreciación & 99,500 & 99,500 & 99,500 & 99,500 & 99,500 & 99,500 \\
\hline Gastos financieros & 127,772 & 110,134 & 91,173 & 70,789 & 48,877 & 25,322 \\
\hline Utilidad antes de impuestos & $2,180,311$ & $2,251,989$ & $2,329,022$ & $2,404,716$ & $2,482,585$ & $2,563,894$ \\
\hline Valor agregado & $4,455,457$ & $4,509,497$ & $4,567,568$ & $4,622,879$ & $4,678,836$ & $4,736,590$ \\
\hline Valor agregado acumulado & $4,455,457$ & $8,964,953$ & $13,532,522$ & $18,155,401$ & $22,834,237$ & $27,570,826$ \\
\hline Unidades vendidas & $1,713,639$ & $1,732,489$ & $1,751,546$ & $1,770,813$ & $1,790,292$ & $1,809,245$ \\
\hline Valor agregado por unidad & 2.60 & 2.60 & 2.61 & 2.61 & 2.61 & 2.62 \\
\hline
\end{tabular}

Elaboración propia

\subsubsection{Densidad de capital}

\section{Densidad de capital $=$ Inversión total / Número de empleados}

El indicador de densidad de capital mide la cantidad de dinero necesaria para generar un puesto de trabajo en el proyecto. Con este indicador se puede clasificar a la empresa como micro, pequeña, mediana o gran empresas.

$$
\text { Densidad de capital }=\frac{4,259,066}{35}=121,688 \frac{S / .}{\mathrm{Hab}-a \tilde{n} o}
$$

De acuerdo a lo obtenido con el índice, la densidad de capital de trabajo para este proyecto es de $121,688 \frac{S / .}{H a b-a n ̃ o}$

\subsubsection{Intensidad de capital}

\section{Intensidad de capital $=$ Inversión total / Valor agregado acumulado}

El indicador de intensidad de capital nos muestra la relación de la inversión total versus el valor agregado del proyecto, nos permitirá medir cual es el grado de aporte del proyecto a través del nivel de inversión, para generar valor agregado sobre los insumos.

$$
\text { Intensidad de capital }=\frac{4,259,066}{27,570,826}=0.154
$$




\subsubsection{Generación de divisas}

El indicador de generación de divisas nos muestra la relación existente entre el saldo neto de divisas versus la inversión total

Balance neto de divisas $=$ Exportaciones - Importaciones
Generación de divisas $=$ Inversión total $/$ Balance neto de divisas

Nuestro proyecto no considera Exportar ni importar productos terminados por lo que el indicador de generación de divisas no se puede aplicar.

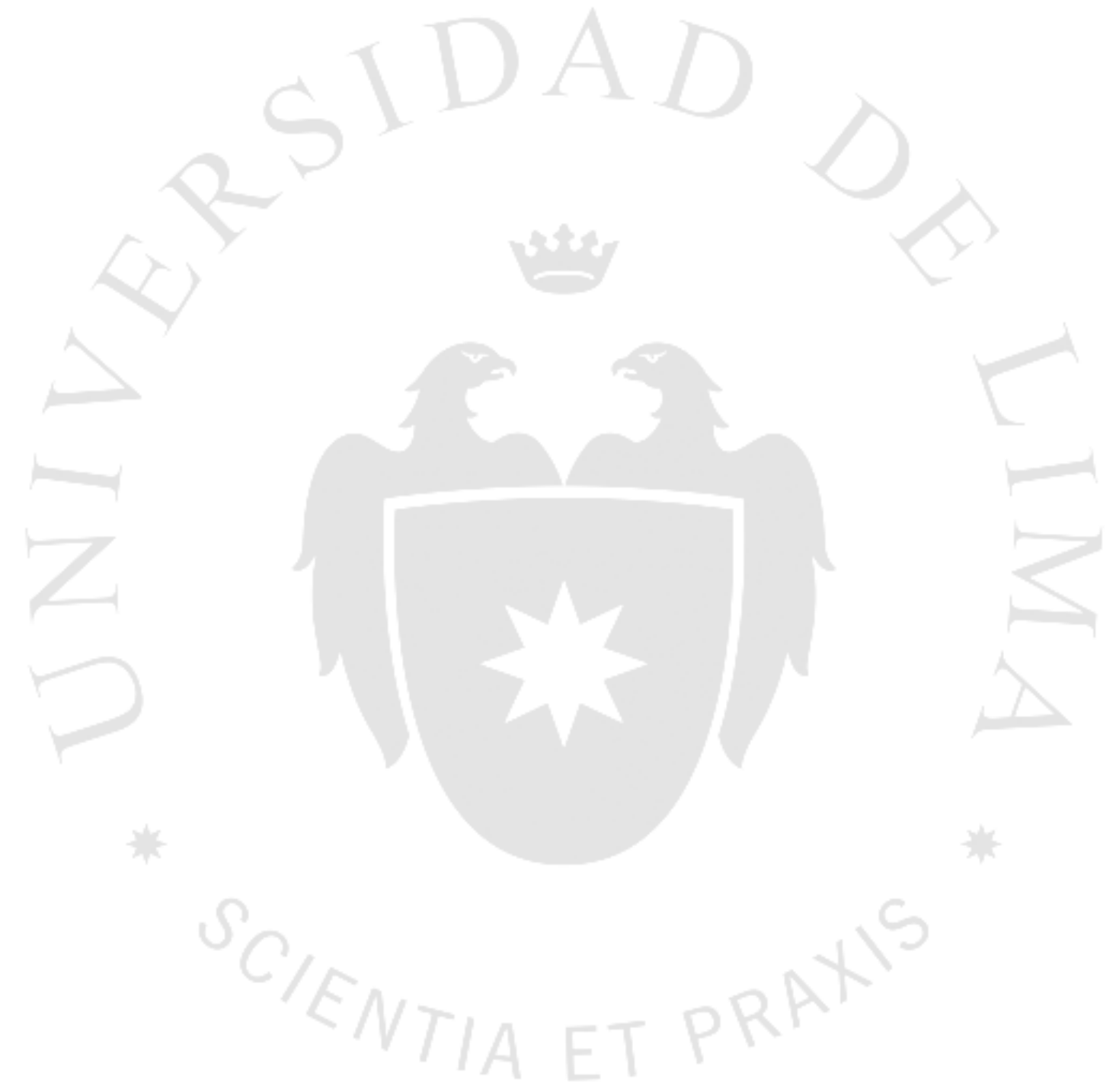




\section{CONCLUSIONES}

- Se concluye que, en base a los métodos de Ranking de factores y Brown \& Gibson, la mejor ubicación para localizar la planta es Piura, esto debido a que el factor más importante es la cercanía a la materia prima.

- Se concluye que el proyecto es tecnológicamente viable debido a que existe maquinaria disponible en el mercado para cumplir con la capacidad de producción.

- Se concluye que existe demanda para las conservas de mango que cuentan con buena aceptación del mercado. Los hábitos de consumo de comida natural y saludable han cobrado importancia en la cultura peruana lo que implica una aceptación a futuro del mercado seleccionado; además, gracias a las encuestas realizadas se logró saber que tanta aceptación tendrá el producto hacia al mercado dirigido.

- La no competencia de una industria como la de este proyecto da la facilidad de desarrollar y hacer crecer la empresa haciéndose sólida cada día sin de barreras de entrada. Si bien es cierto que hay competencia de materia prima sustituta mas no de la que se propone, es una amenaza también ya que el consumidor enfrenta disponibilidad de variedad.

- En conclusión, se tiene una demanda de 387.28 toneladas que irá creciendo anualmente $1.1 \%$ ganando poco más de 4 millones de soles y recuperando la inversión financieramente en 2.5 años.

- Ya que el mango es estacional y la producción solo será por 6 meses, no se importará la materia prima de otros países ya que éste es su principal valor agregado; además, se fomenta el consumo de productos naturales nacionales. En consecuencia, la calidad y características del mango peruano son distintas a la de otros países, por lo que se vería reflejado en el producto final.

- La capacidad de planta está limitada por el cuello de botella cuya operación es el pasteurizado debido a que ésta máquina procesa como máximo $300 \mathrm{~kg} / \mathrm{h}$.

- El costo de material para producir las conservas es de 1.80 nuevos soles, agregándole el margen se obtiene un precio al público de S/. 3.5 que empalma con lo que dijeron las encuestas realizadas. 
- La inversión estimada es de aproximadamente 4 millones de soles siendo $60 \%$ de capital propio y se financiará del banco $40 \%$ ya que es la tasa más baja la que ofrece el banco Santander.

- Debido a que es una empresa que se encuentra en la etapa de iniciación, el número de personal está limitado a las áreas más importantes de toda organización, lo mismo que es necesario y suficiente para capacitar y operar adecuadamente.

- Los canales de ventas preferidos, según las encuestas e Ipsos Apoyo son los supermercados y bodegas, lugares adecuados para vender el producto.

- Como impacto social el proyecto generará nuevos puesto de trabajo, además beneficiará a los consumidores brindándoles un producto de fácil consumo que les permitirá ahorrar tiempo y de alto valor nutricional.

- Como impacto ambiental se concluye que el proyecto no afecta el medio ambiente de forma significativa ya que se está trabajando con frutas y sus residuos como pepas y cascarás que no contaminan al ser orgánicos. 


\section{RECOMENDACIONES}

- Aplicación de mejora continua a lo largo del proceso de producción permitirá mejorar la eficiencia e innovación de las técnicas de producción.

- Se recomienda producir conservas de otras frutas de la región de Piura cuya época de cosecha no sea la misma que la del mango, esto es para tener una producción continua a lo largo de todo el año.

- El abastecimiento de la materia prima resulta un factor limitante, por lo que se recomienda la importación de otra fruta o sustitución de este con otro producto como la piña para no dejar de operar la planta y asegurar la producción y el personal; del mismo modo se podrá ofrecer mejores incentivos para estos. También, se recomienda sobre producir el producto terminado para almacenarlo cuando la planta para y solo comercializar el producto, debido a que el producto terminado puede estar a temperatura ambiente y tiene un tiempo de vida de 18 meses.

- Aprovechar del almacén de desperdicios, las semillas y cáscaras de mango para venderlas o generar un nuevo negocio de aceite natural a partir de estos residuos orgánicos, esto diversificaría la línea del negocio, lanzaría nuevos productos a nuevos segmentos de mercado y generaría un medio ambiente sin contaminación al no desechar estos restos. A la par, se recomienda realizar tratamiento de agua para ahorrar costos en los procesos y evitar desechar agua sucia apoyando al medio ambiente a su mejor desarrollo.

- Buscar certificar el producto por empresas especializadas en calidad para darle mayor confianza al consumidor sobre el alimento y brindar una imagen superior tanto a los consumidores como a los proveedores de la empresa.

- Registrar la marca del producto en Indecopi para evitar el plagio de la misma. 


\section{$R()(5$ ( $1 \&, \$ 6$}

Adrian, J; Fragne, R. (1990). La ciencia de los alimentos de la A a la Z. Zaragoza, España

APEM. (2008). Perspectivas sectoriales del mango. Recuperado de http://comexperu.org.pe/

Asociación peruana de productores de mango. (2012). Estudio prospectivo de mercado del mango. Recuperado de http://Promango.org

Becerra, M.S. (1988). Industrialización del mango de la variedad Haden. (Tesis para optar por el título de ingeniero industrial). Universidad de Lima.

Benassini, M. (2008). Introducción a la investigación de mercados, enfoque para América Latina. (2da edición) Lima: Fondo editorial - Universidad de Lima.

Briceño L, (07 de febrero del 2012). Determinando la tasa de descuento de un proyecto. Recuperado de http://blogs.gestion.pe/deregresoalobasico/2012/02/determinando-latasa-de-descue-2.html

Cáceres, K. (2011). Estudio preliminar para la instalación de una planta procesadora de conservas de mandarina y naranja en almíbar para el mercado nacional. (Seminario de investigación en ingeniería Industrial II 2011-1). Universidad de Lima.

Calderón, G (2010). Estudio preliminar para la instalación de una planta procesadora de conservas de uva red Globe en almíbar. (Seminario de tesis). Universidad de Lima.

Cámara de comercio y producción de Piura. (2014). El caso del mango en Piura. Recuperado de http://www.camcopiura.org.pe

CODEX STAN 159, (1987). Norma del Codex para mangos en conserva. Recuperado de http://www.mango.org/Mangos

Díaz, B; Jarufe, B y Noriega, M.T. (2007) Disposición de planta (2da edición) Lima, Universidad de Lima, Fondo editorial.

Fonseca, C. (2012). Estudio preliminar para la elaboración de cocktail de frutas en almíbar acompañado de yogurt (Seminario de tesis). Universidad de lima.

Fríes, A.M. (2012). Panorama mundial y nacional de mango. Inform@cción agraria. (9), 15-20. Recuperado de http://agroaldia.minag.gob.pe/

Gallo Rivera del mar, C. (2010). Estudio preliminar para la instalación de una planta procesadora de conservas de mandarina en almíbar en envase de termo formado (Seminario de tesis). Universidad de Lima. 
INEI, (2014). Principales zonas de refinería de azúcar en el Perú. Recuperado de http://www.inei.gob.pe/

INEI, (2015). Población en las principales ciudades del Perú. Recuperado de http://www.inei.gob.pe/

INEI. (2015). Densidad poblacional y superficie de las principales ciudades del Perú. Recuperado de http://www.inei.gob.pe/

Instituto Nacional de Estadística e Informática. (2015). Sistema de indicadores demográficos. Recuperado de www.inei.gob.pe/inicio.htm

Ipsos Apoyo, (2014). Marcas de conservas de fruta de mayor consumo [versión PDF]. Recuperado de http://www.ipsos.pe/

Janampa C. (1988). Estudio tecnológico para el desarrollo de una planta procesadora de hojuelas de mango. (Tesis para optar por el título de ingeniero industrial). Universidad de Lima.

Kader, A, (2008). Parámetros de calidad y estándares de clasificación en mango [versión PDF]. Recuperado de http://www.mango.org/Mangos/

Lira, P (10 de enero del 2014). Ica, La Libertad y Piura con la mayor demanda de mano de obra para agro. Recuperado de http://gestion.pe/impresa/

Maximixe consult S.A. (2011). Caser: riesgos de mercado (Lima) Mango, 28-44.

MEF, (2015). Dinámica de las provincias de Piura. Recuperado de https://www.mef.gob.pe/

Minag, (2014). Evolución de producción y rendimiento de mango nacional. Recuperado de http://www.agroaldia.minag.gob.pe/biblioteca/

Minag, (2015). Producción nacional de azúcar. Recuperado de http://www.agroaldia.minag.gob.pe/

Minag, (2015). Producción nacional de mango. Recuperado de http://www.agroaldia.minag.gob.pe/

Minag, (2015).Producción de mango en Perú. Recuperado de http://www.agroaldia.minag.gob.pe/

Mincetur, (2015). Perfil del mercado y competitividad exportadora de mango. Recuperado de http://www.mincetur.gob.pe

MTC, (2015). Distancia entre ciudades del Perú. Recuperado de http://www.mtc.gob.pe/

MTC, (2015). Servicios de transportes en Piura, Lambayeque y Ancash. Recuperado de http://www.mtc.gob.pe/ 
MVCS. (2015). Parámetros de calidad del agua por departamento. Recuperado de www.vivienda.gob.pe/

OSINERGMIN. (2015). Tarifas de energía eléctrica por departamento. Recuperado de www.osinergmin.gob.pe/

Prepolec, T. (1989). Estudio tecnológico del proceso de obtención de conservas de mango. (Tesis para optar el grado bachiller en Ingeniería Industrial). Universidad de Lima.

Romero, O (2013). Estudio de prefactibilidad para la instalación de una productora de conservas de tomates cherry en almíbar. (Tesis para optar por el título de ingeniero industrial). Universidad de Lima

Sbarbaro, A (2002). Estudio de prefactibilidad para la industrialización del longan. (Tesis para optar por el título de ingeniero industrial). Universidad de Lima

SBS, (2016). Tasas de interés efectiva de bancos. Recuperado de http://www.sbs.gob.pe/principal/categoria/tasa-de-interes-promedio/154/c-154

Sociedad Nacional de Industrias. (2014). Conservas de fruta. Recuperado de http://sni.org.pe

SUNASS, (2015). Tarifas de agua potable y alcantarillado por provincia. Recuperado de www.sunass.gob.pe/

SUNASS. (2015). Tarifa de la categoría industrial para agua potable y alcantarillado por empresa. Recuperado de www.sunass.gob.pel

SUNAT, (2015). Exportaciones de mango. Recuperado de http://www.sunat.gob.pe/

SUNAT, (2015). Importaciones de mango. Recuperado de http://www.sunat.gob.pe/

SUNAT. (2016). Importaciones de Mango. Recuperado de http://sunat.gob.pe

Valle fértil, (2015). Información nutricional de mango en almíbar. Recuperado de http://www.vallefertil.com/productos/conservas-dulces/mango.html 


\section{BIBLIOGRAFÍA}

Comex Perú, (2015). Mangos encaminados. Recuperado de http://www.comexperu.org.pe/

Euromonitor Internacional, (2015). Alimentos conservados. Recuperado de http://www.portal.euromonitor.com/portal/analysis/relatedtab/

INEI, (2015). Distribución de personas según NSE 2015 en Lima Metropolitana. Recuperado de https://www.inei.gob.pe/

Mendoza, S (15 de enero del 2012). Perú es el sétimo país con mayor rendimiento en producción de mangos del mundo. Andina. Recuperado de http://www.andina.com.pe/

Valle fértil, (2015). Información nutricional de mango en almíbar. Recuperado de http://www.vallefertil.com/

Villahermosa, L (23 de abril del 2013). Producción peruana de mango crece cerca de $200 \%$ en febrero. América Economía. Recuperado de http://www.americaeconomia.com/ 


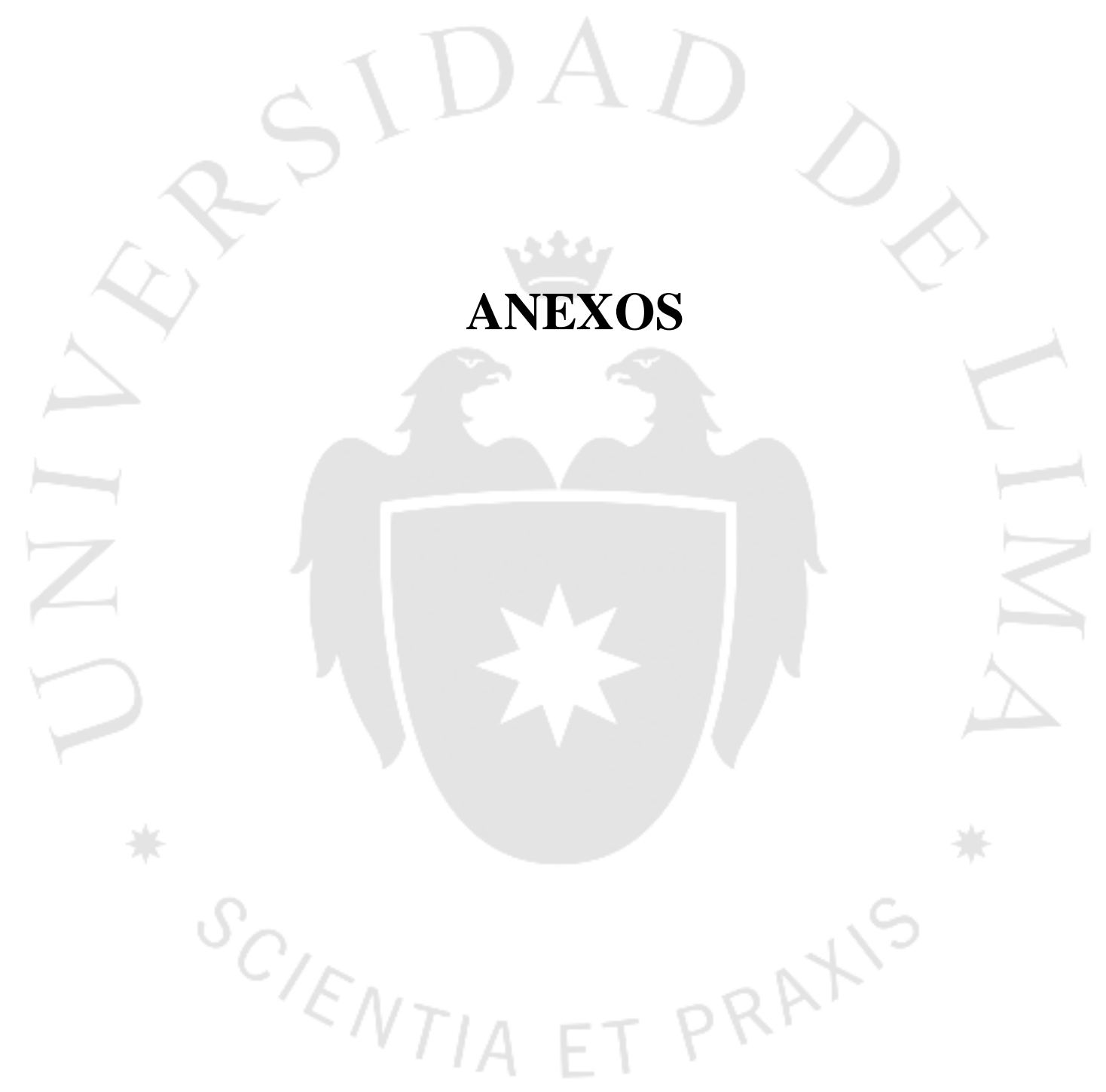




\section{Anexo 1: Encuestas}

Encuesta conservas de mango en almíbar en envases de polipropileno de 226 gramos

1. ¿Consume frutas en conserva?

$\mathrm{Si}$

No

2. ¿Qué tan frecuente consume frutas en conserva?

Todos los días

Quincenal

Mensual

Semestral

Una vez al año

3. ¿Qué es lo que busca al momento de comprar una fruta en conserva?

Precio

Calidad

Marca

Sabor

Valor nutricional

Otro:

4. ¿Estaría dispuesto a consumir mango en almíbar?

$\mathrm{Si}$

No

5. ¿Cuánto estaría dispuesto a pagar por una conserva de mango en almíbar de 226 gramos en un envase de polipropileno con film plástico?

2.5 Soles

3.0 Soles

3.5 Soles

4.0 Soles

4.5 Soles

Otro: 
6. En la siguiente escala del 1 al 10 señale el grado de su probable compra siendo 1 probablemente y 10 definitivamente

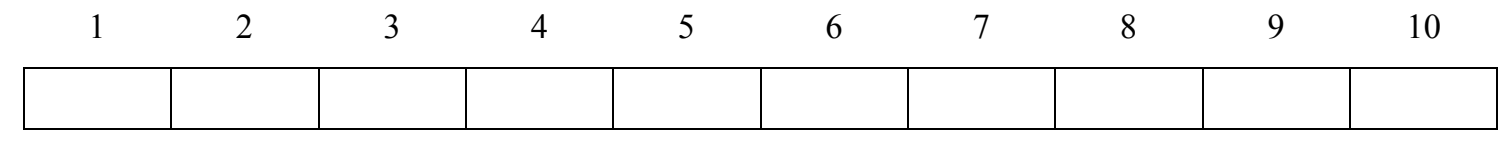

7. ¿En qué establecimiento le gustaría encontrar este producto?

Supermercado

Mercado

Bodega

Máquinas dispensadoras

Otro:

\section{Resultados de la encuesta}

A continuación, se muestran los resultados obtenidas de la encuesta, estos resultados fueron utilizados para hacer los cálculos para poder determinar la demanda

Figura 1.1

Consumo de conservas de fruta

\section{Consume frutas en conserva}

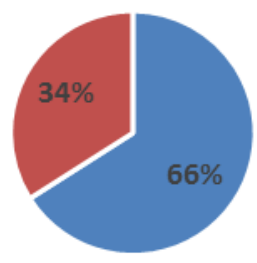

- Si = No

Elaboración propia 
Figura 1.2

Intensidad de compra

\section{Intensidad de compra}

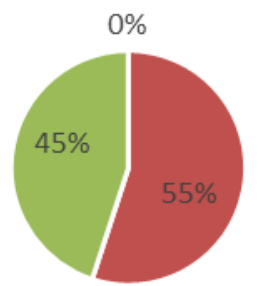

- 1 a 3 - 4 a 7 a 10

Elaboración propia

Figura 1.3

Cuanto pagaría por la conserva

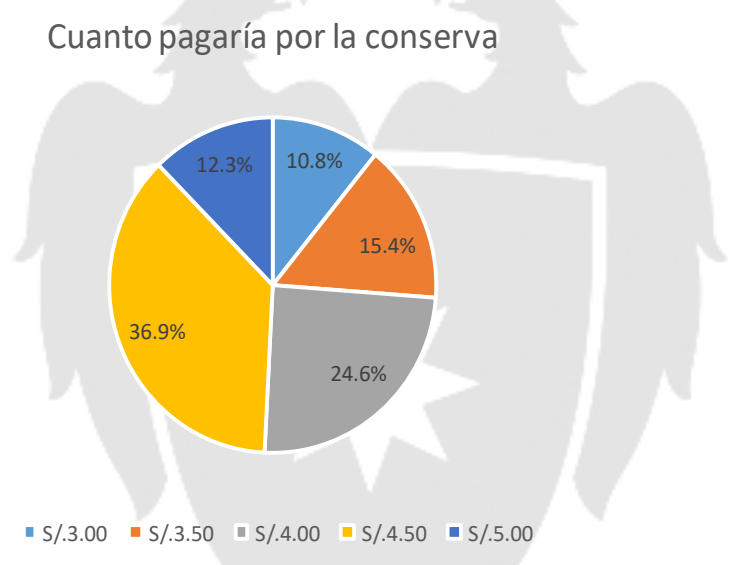

Elaboración propia

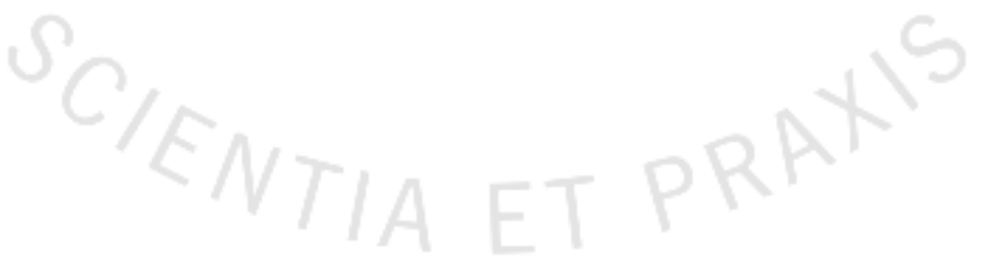




\section{Anexo 2: Cálculo del costo de capital}

\section{Definición del Beta para el sector}

El sector analizado es el de alimentos procesados obteniéndose un $\beta=0.79^{26}$. Los cálculos han sido realizados con base en el promedio de empresas de dicho sector.

\begin{tabular}{|l|c|c|c|c|c|}
\hline Industry Name & Number of Firms & Market D/E Ratio & TaxRate & Unlevered Beta & Cash/Firm Value \\
\hline Food Processing & 89 & $26.16 \%$ & $14.09 \%$ & 0.79 & $2.46 \%$ \\
\hline
\end{tabular}

\section{Cálculo de la tasa libre de riesgo}

La tasa libre de riesgo es el rendimiento que se puede obtener libre de riesgo de incumplimiento. Existe consenso para considerar como tasa libre de riesgo al rendimiento ofrecido por los bonos del tesoro americano, pues en toda su historia esta entidad jamás ha incurrido en falta de pago a los inversionistas, lo que hace suponer a la mayoría de los autores que estos instrumentos están libres de todo riesgo de incumplimiento ${ }^{27}$. En este caso se ha definido una tasa libre de riesgo del $2.59 \%{ }^{28}$

\section{Riesgo País - Perú}

El riesgo país es el riesgo de una inversión económica debido solo a factores específicos y comunes a un cierto país. Puede entenderse como un riesgo promedio de las inversiones realizadas en cierto país. Mide el entorno político, económico, seguridad pública etc.

\section{Retorno del mercado}

Se considera una aproximación al portafolio de Mercado el índice Estándar \& Poor's 500 que contiene el listado de las 500 empresas más grandes que cotizan en la NYE, AMEX y NASDAQ. La ventaja de este índice es que se construye sobre la ponderación de las acciones a partir del valor de mercado de cada empresa.

\footnotetext{
${ }^{26}$ http://pages.stern.nyu.edu/ ADAMODAR/New_Home_Page/datafile/Betas.html

27 “Los Parámetros del Capital Asset Pricing Model”. Sergio Bravo

${ }^{28}$ Customixed Geometric Risk Premium Estimator. http://people.stern.nyu.edu/adamodar/
} 